TOWARDS IMPROVED SEASONAL RAINFALL PREDICTIONS OVER EAST AFRICA

Margaret Wambui Kimani 
Graduation committee

\section{Chairman/Secretary}

Prof. dr. ir. A. Veldkamp

University of Twente

\section{Supervisor}

Prof. dr. Bob Su

University of Twente

\section{Co-supervisor}

Dr J.C.B. Hoedjes

University of Twente

\section{Members}

Prof. dr. Victor Jetten

Dr. Chris Mannaerts

Prof. dr. Kenichi Ueno

University of Twente

University of Twente

University of Tuskuba,Japan

Prof. dr. Soroosh Sorooshian

Prof. dr. Remko Uijlenhoet

University of California,Irvine, USA

Wageningen University

ITC dissertation number ...

ITC, P.O. Box 217, 7500 AE Enschede, The Netherlands

ISBN 978-90-365-

DOI http://dx.doi.org/10.3990/1.97890365

Cover designed by

Printed by ITC Printing Department, Enschede, The Netherlands

Copyright (c) Margaret Wambui Kimani, Enschede, The Netherlands

All rights reserved. No part of this publication may be reproduced without The prior knowledge and permission of the Author. 


\title{
TOWARDS IMPROVED SEASONAL RAINFALL PREDICTIONS OVER EAST AFRICA
}

\author{
DISSERTATION \\ to obtain \\ the degree of doctor at the University of Twente, \\ on the authority of the rector magnificus, \\ prof.dr. T.T.M. Palstra, \\ on account of the decision of the graduation committee, \\ to be publicly defended \\ on Wednesday, May 8,2019 at 14.45 hrs
}

by

\section{Margaret W Kimani}

born on 9th September 1968

in Murang'a, Kenya 
This dissertation has been approved by:

Prof. dr. Bob Su (supervisor)

Dr J.C.B Hoedjes (co-supervisor) 


\section{Summary}

Empirical seasonal rainfall predictions over East Africa can be improved by use of the most consistent and representative rainfall data that characterize its variability to determine atmospheric-sea interactions that govern the seasonal to inter-annual variabilities. Rainfall variability is externally induced by largescale circulations and locally by the heterogeneity of the terrain like topography and inland water bodies that modify its processes. The General Circulation Models (GCM) used for seasonal predictions have challenges characterizing the sub-grid processes because of their coarse resolutions and models initialization challenges. The unpredictable variability has led to the loss of lives and destruction of properties over this region. Out of the two main rainfall season of March-May (MAM) and October-December(OND), MAM is more challenging because of its different mechanisms not well understood. It is the most dependent on for agricultural and water resource management because of its large intensity and longest rain days. This thesis is composed of six chapters and chapter 1 which is introduction details the scientific and societal importance of the research. It empirically uses the satellite rainfall data to explore the processes leading to rainfall variability by identifying the atmospheric-ocean interactions to improve the predictions. This requires consistent and long climatological rainfall data.

Thus, the second chapter following thesis introduction deals with assessments of seven satellite-derived rainfall products; Tropical Applications of Meteorology using Satellite and ground-based observations (TAMSAT), African Rainfall Climatology And Time series (TARCAT), Climate Hazards Group InfraRed Precipitation with Station data (CHIRPS), Tropical Rainfall Measuring Mission (TRMM-3B43), Climate Prediction Centre (CPC) Morphing technique (CMORPH), Precipitation Estimation from Remotely Sensed Information using Artificial Neural Networks Climate Data Record (PERSIANN-CDR), CPC Merged Analysis of Precipitation (CMAP), and Global Precipitation Climatology Project (GPCP) using locally gridded rain gauge data over the region. This was aimed at identifying the most suitable product that can consistently characterize rainfall variability spatially and temporally. A grid-based statistical comparison between the two datasets was employed, based on pixel values located at the rainfall stations. Further, the impact of topography on the performance of the products was assessed in areas of the highest negative bias mainly observed in October-December (OND) rainfall months. All the products could replicate rainfall patterns but exhibited systematic errors, especially on high elevated areas which decreased with an increase in temporal resolution from a monthly to yearly scale. CMORPH, CHIRPS, and TRMM showed consistently high performance during both seasons, attributed to their ability to retrieve rainfall of different rainfall regimes but CHIRPS was chosen based on its long climatology.

In the third chapter, the Bayesian bias correction was applied to CHIRPS $\vee 2$ and the rain gauge data used as a reference. Assessments of the approach's influence on the rainfall estimate spatially and temporally were explored. 
Significant performance of the approach was observed during years of low rainfall from shallow convention but decreased in areas of sparse rain gauge network that insufficiently represented rainfall variabilities. The locally bias corrected CHIRPS was then used to identify atmospheric processes linked with rainfall variability.

In the fourth chapter, moisture distribution influence on rainfall variability during different phases of Indian Ocean Dipole Mode (IOD) over the region was assessed. Since the region is in the equatorial tropics, convective variables were utilized to identify moisture convergence areas in relation to convective processes. Results showed advected moisture as the source of precipitable moisture and contribution from local evaporation is minimal mainly affecting the Lake Victoria region. Moisture is dominantly advected from the Indian Ocean through low-level convergence particularly during Inter tropical Convergence Zone (ITCZ) overpass. During the southwest monsoon (June through September), mid-tropospheric moisture convergence is experienced from the west attributed to Congo Basin. The Kenya highlands act as moisture sinks separating the west and the eastern part of the region and the locally induced convection over Lake Victoria are suppressed by the fluxes. Empirical Orthogonal Functions (EOF 1,2) of moisture were utilized to determine the impact of the Dipole Mode Index (DMI) and Nino 3.4 to moisture distributions during different phases of IOD.DMI has the largest influence during ITCZ overpass explaining $>60 \%$ and less during southwest monsoon months. EOF2 contributes $31 \%$ influence in May attributed to DMI with little impact from Nino3.4. EOF1 is dominantly influenced by DMI but during early onset of southwest monsoon corresponding with El Niño year suppression of moisture influx from the Indian Ocean are experienced.

In the fifth chapter, Real-time Multivariate MJO (Madden-Julian oscillation), or RMM, amplitudes were utilized to link the atmospheric variability to Ocean forcing, related to rainfall variability (especially extremes). The analysis was based on ERA-Interim reanalysis data at different timescales. For the oceanic influence, the Sea Surface Temperature (SST) forcing on 2-m surface temperature related to $\mathrm{MJO}$ convections was used to test the predictability of the MAM rainfall season, covering a period of 33 years (1981-2013). The study observed that MAM MJO modulates low-level moisture influx from the Indian Ocean enhancing Convergence Zone that extends over to the western part of the region bordering the Congo Basin. The SST time series are derived from 3 areas, namely the Maritime Continent, southwestern and central Indian Ocean and utilized as predictors of moisture budget as proxy of rainfall. A Stepwise regression model shows the highest skill at lag 4, with a Brier skill score (BS) of 0.02 and an Anomalies of Correlation Coefficients (ACC) of 0.82 . Whereas the influence of MJO on rainfall during OND (and JJA) rainy seasons is fairly minor, MJO has a major impact on the rainfall dynamics during the MAM rainy season. Consequently, the inclusion of the MAM MJO magnitude (notably for MJO 1 and MJO 8) can help improve seasonal prediction for the MAM rainy season in East Africa. 
Finally, Chapter 6 gives the synthesis detailing the conclusions and recommendation from the study. 


\section{Samenvatting}

Empirische seizoensverwachtingen voor Oost Afrika kunnen worden verbeterd door het gebruik van consistente en representatieve neerslagdata. De variatie in neerslag geeft inzicht in de interacties tussen de atmosfeer en de oceanen, de voornaamste drijvers van de variatie van jaar tot jaar in extreme neerslag. Deze interactie beinvloed de grootschalige circulatie. Op lokaal niveau beinvloeden geografische factoren, zoals bijvoorbeeld relief en de aanwezigheid van meren, deze processen. General Circulation Models (GCM), ofwel Algemene Circulatie Modellen, die gebruikt worden voor het opstellen van een seizoensverwachting, hebben moeite om kleinschalige processen te karakteriseren, deels vanwege de lage resolutie van deze modellen, en deels vanwegen limitaties in het initialiseren van deze modellen. Het gebrek aan goede seizoensverwachtingen heeft in het verleden geleid tot slachtoffers en schade aan bezittingen door onverwachte extreme weersomstandigheiden. Van de twee regenseizoenen in het studiegebied, maart-april-mei (MAM) en oktober-november-december (OND), is het verbeteren van de MAM seizoensverwachting het meest uitdagend. De reden hiervoor is dat de drijvende processen achter deze regentijd het minst goed bekend zijn. Aangezien deze regentijd de langste van de twee is, en voor het meeste neerslag zorgt, is het verbeteren van de MAM seizoensverwachting vooral erg belangrijk voor de agrarische en water management sectoren. Deze dissertatie bestaat uit zes hoofdstukken en een introductie, waarin de wetenschappelijke en sociologische relantie wordt uitgelicht. Neerslagdata op bases van satellietdata worden op empirische wijze gebruikt om de processen die de inter-jaarlijkse variatie veroorzaken te onderzoeken. Dit wordt gedaan door atmosfeer-oceaan interacties te identificeren, met als doel de seizoensverwachting voor maart, april en mei (MAM) voor Oost Afrika te verbeteren. Hiervoor zijn consistente historische neerslag climatologie data nodig.

In hoofdstuk 2 worden verschillende satellite neerslag producten, te weten TARCAT (Tropical Applications of Meteorology using Satellite and ground-based observations (TAMSAT) African Rainfall Climatology and Time series), CHIRPS v2 (Climate Hazards Group InfraRed precipitation with Station data), TRMM3B43 (Tropical Rainfall Measuring Mission), CMORPH v1 (Climate Prediction Centre (CPC) Morphing technique), PERSIANN-CDR (Precipitation Estimation from Remotely Sensed Information using Artificial Neural Networks - Climate Data Record), CMAP (CPC Merged Analysis of Precipitation) en GPCP (Global Precipitation Climatology Project), beoordeeld. Dit gebeurt aan de hand van gerasterde neerslagdata gebaseerd op regenmeter netwerken in Oost Afrika. Het doel van deze analyse is de bepaling van het meest consistente en bruikbare satelliet neerslag product voor het karakteriseren van de ruimtelijke en temporele neerslag variatie in Oost Afrika. De analyse omvat een statistische vergelijking tussen de satelliet neerslag producten en de waarnemingen op de locaties van de waarnemingen. Ook is het effect van orografische factoren op de prestaties van de verschillende satelliet producten geëvalueerd, voor gebieden met de grootste gemiddelde afwijking tussen de satellietdata en de waarnemingen. Deze evaluatie is uitgevoerd voor de regentijd in oktober, november en december. Alle satelliet producten bleken in 
staat om neerslagpatronen te repliceren, maar systematische afwijkingen bleken bij alle producten aanwezig te zijn. Deze afwijkingen manifesteerden zich hoofdzakelijk in hoger gelegen gebieden, en de afwijking nam toe bij een lagere temporele resolutie, van maandelijks naar jaarlijks. CMORPH, CHIRPS en TRMM presteerden consistent beter dan de andere producten, gedurende zowel de maart-april-mei regentijd als de oktober-november-december regentijd, hoofdzakelijk dankzij hun vermogen om verschillende regen types goed te karakteriseren. CHIRPS heeft als bijkomend voordeel de beschikbaarheid van een langdurige historische reeks, en is daarom gekozen als het meest geschikte satelliet neerslag product.

In hoofdstuk 3 wordt de Bayesiaanse afwijkingscorrectie toegepast op CHIRPS versie 2, met de gerasterde neerslagdata als referentie. Hierbij wordt vooral gekeken naar de invloed van de Bayesiaanse afwijkingscorrectie op het verbeteren van de ruimtelijke en temporele representativiteit van de CHIRPS data. Met name tijdens jaren met weinig neerslag uit ondiepe convectieve systemen presteerde de methode goed. De methode heeft tekortkomingen in gebieden met weinig neerslag observaties, aangezien de lokale neerslagvariaties niet voldoende gerepresenteerd worden in de referentie dataset. De gecorrigeerde CHIRPS data zijn vervolgens gebruikt voor de identificatie van atmosferische processen die van invloed zijn op neerslagvariaties.

Vervolgens wordt in hoofdstuk 4 de invloed van atmosferische vocht distributie op regen variabiliteit, tijdens verschillende fases van de IOD, bekeken. Aangezien het studiegebied in de equatoriale tropen ligt zijn convectieve variabelen gebruikt om gebieden van vocht convergentie, in relatie tot convectieve gebieden, te identificeren. De resultaten duiden op vochtadvectie als primaire bron van atmosferische waterdam waaruit neerslag kan vormen. De bijdrage van lokale verdamping is minimaal, en hoofdzakelijk geadvecteerd vanuit het gebied bij het Victoriameer. De dominante bron van vochtadvectie is de Indische Oceaan, op lagere niveaus van de atmosfeer, en vindt plaats tijdens de passage van de ITCZ over het studiegebied. Tijdens de zuidwestelijke moesson vindt mid-troposferische vocht convergentie plaast vanuit het westen, met als brongebied het Congo-bassin. De Keniaanse hooglanden functioneren als put voor atmosferisch vocht, en als scheiding tussen het oosten en het westen van het studiegebied. Lokale convectie in het Victoriameer gebied wordt onderdrukt door de advectieve fluxen. Empirische Ortogonale Functies voor vocht (EOF 1 en 2) zijn gebruikt om de invloed van de Dipole Mode Index (DMI) en Nino 3.4 op vochtverdeling in het studiegebied te bepalen, tijdens verschillende fases van de IOD. DMI blijkt de grootste invloed te hebben tijdens de passage van de ITCZ, en verklaart voor die periode meer dan $60 \%$ van de vochtverdeling. De invloed van de DMI neemt af tijdens de zuidwestelijke moesson. EOF 2 draagt $31 \%$ aan invloed bij, ook door de DMI; de bijdrage van Nino 3.4 is marginaal. EOF 1 wordt hoofdzakelijk beinvloedt door DMI, maar tijdens een vroege start van de zuidwestelijke moesson tijdens een El Niño jaar wordt een onderdrukking van de vocht instroom vanaf de Indische Oceaan waargenomen, die geassocieerd wordt met Nino 3.4. 
In het vijfde hoofdstuk worden Real-time Multivariate Madden-Julian Oscillation (RMM) amplitudes gebruikt om atmosferische variabiliteit aan oceaan forceringen te koppelen. Deze atmosferische variabiliteit heeft met name betrekking op (extreme) neerslagvariabiliteit. Voor deze analyse wordt gebruik gemaakt van ERA-Interim heranalyse data met verschillende tijdschalen. Voor de invloed van de oceaan is de forcering van zee-oppervlakte temperaturen op de $2 \mathrm{~m}$ oppervlakte temperatuur, gerelateerd aan MJO convectie, gebruikt, om de voorspelbaarheid van de maart-april-mei (MAM) regentijd te testen. Dit is uitgevoerd over een periode van 33 jaar (19812013). Tijdens dit onderzoek is geconstateerd dat MAM MJO de laag-niveau vocht instroom vanaf het indische oceaan MJO convergentie versterkende gebied moduleert. Dit gebied strekt zich uit van de westelijke kant van het studiegebied tot in het Congo basin. De zee-oppervlakte temperaturen worden afgeleid van drie gebieden, te weten het maritieme continent, de zuidwestelijke Indische Oceaan, en de centrale Indische Oceaan. Deze worden vervolgens gebruikt als predictoren van het vocht budget, die als proxy voor de neerslaghoeveelheid wordt gebruikt. Een stapsgewijs regressiemodel heeft de beste prestaties voor stap 4 gevonden, met een Brier prestatiescore van 0.02, en een anomalie van correlatiecoëfficiënt van 0.82 . Waar de invloed van MJO op de neerslaghoeveelheid tijdens de OND en de juni, juli, augustus (JJA) regentijden betrekkelijk klein is, heeft $\mathrm{MJO}$ juist een bijzonder grote invloed op de dynamiek van de neerslag tijdens de MAM regentijd. De consequentie hiervan is dat het gebruik van de MAM MJO magnitude, met name die voor MJO 1 en MJO 8, de seizoensverwachting voor de MAM regentijd in Oost Afrika aanzienlijk kan verbeteren.

Tenslotte wordt in hoofdstuk 6 de synthese gegeven, alsmede de conclusies en aanbevelingen van het onderzoek. 


\section{Preface}

All things are possible if one keeps the focus, never looking at the size of the problem but having the will to explore.

Weather affects all of us and as a Meteorologist answering the common man why it never rained when his crops dried up or why it rained too much, and it ruined all his properties were both challenging and motivating to get a solution. With God all things are possible. So I worked and searched to uncover this myth and this far I have reached.

Dedicated to my dear mother, Tabitha Nyambura (Best Mama)

My beloved Husband, Paul Wanyoike and lovely Son James Mwangi

Thank you for your patience and moral support. 


\section{Acknowledgements}

Doing PhD require hard work and determination, but above all glory to God, who is the author of all wisdom and knowledge. Every day we are in pursuit of what he created with his word. Let me take this opportunity to thank and acknowledge all those in one way or another were stepping stones to bring me this far. I acknowledge the contribution of all, and God will reward you.

I owe my sincere gratitude to my Supervisor Pro. Dr Bob. Su for believing in me and giving me a chance to pursue my dream. "Thank you for your insightful research guidance and encouragements". Through many challenges I encountered, I could count on his support. "Only God can reward you. I can only say thank you".

First, I would like to appreciate and acknowledge the Netherlands Fellowship Program (NFP) of the Netherlands organization for international cooperation in higher education (NUFFIC) for making me realize my dreams by their financial support. I am indebted to the generosity of this country, first for sponsoring my Master program and now for my PhD, and I don't have enough words to say thank you and may God bless and prosper this Nation.

I am grateful to Water resource Department through professor Su and the ITC foundation scholarship program (FSP) for facilitating the completion of the study when I was faced by unavoidable financial circumstance leading to a short extension. Your kindness will forever be remembered.

I would like to thank the Government of Kenya, through the Ministry of Environment and Forestry for giving me the opportunity to pursue my study and facilitating the data request to the Intergovernmental Authority on Development (IGAD) Climate Prediction and Application Centre (ICPAC) regional office, Nairobi.

My sincere thanks go to my co-supervisor, Dr Joost Hoedjes for his guidance and patience. His searching questions were always inspiring me into solving difficult problems.

My sincere gratitude is reserved to my family, words cannot express the respect and love I have for them. A heartfelt thanks to my husband, Paul, and our son James for enduring my absence and travelling every December to the Netherlands to enjoy the festival season of Christmas with me. Your love and dedication motivated me to push on through every barrier. Your unconditional love could not be shaken by the distance between us, "Thank you".

Besides my academic work, I had the privilege to serve as student assessor of ITC faculty Board. Thanks, Prof.dr. A. Veldkamp, prof.dr. F.D. van der Meer, prof.dr.ir. A. Stein, B.A.J. Leurink and M. Verburg for allowing me to work with you and learn a lot from you.

Outside the PhD work, I made many friends; I will always remember the time we shared. The ITC International Hotel for been my second home for over four years; I will miss you all. I will not forget International Christian Fellowship (ICF) through Dr Paul van Dijk and Rev.Josine for giving me a chance to serve and learn the word of God (Always home away from home). Theresa, Loes and all for the friendly atmosphere you accorded me. This study would not have been easy without the company of enthusiastic and friendly Water Resource Department members: 
Pro. dr Z.Su, Prof.dr. D.van der Wal, E.L Butt, J.de Koning, Drs R.Becht, ir.A.M van Lie shout, Dr M.W. Lubczynski, Dr B.H.P Maathuis, Dr. ir.C.M.M.Mannerts, Ir.G.N Parodi, Dr.ing.T.H.M Rientjes, Dr.ir.S.Salama,

Dr. ir.W.J.Timmermans, Dr.Ir.C.van der Tol, ing.M. Ucer, Dr Z. verkerdy, Dr. ir.R.van der Velde, L.Wang, Dr Y.Zeng, Dr.D.Zheng, Dr B. Wang and My fellow PhD students: H.F. Benninga, M.L Blatchford, A.S.Z. El-Said, ir.J.G. Hofste, ir.K.K.Kumah, S.M. Njuki, E.Prikaziuk, D.T. Rwasoka, L.Yu, Y. Abbasi,B.Arabi,B.Bayat,C.R.Cisneros,I.L.De Sousa Brandao, J.Du, W.Gumindoga, M.Lekula, M.Li, C.Liu, Mr.S.Lv, N.P. Majozi, M. Manyika, T.L.Masaka, O.A.A. Mohamed, G.Ntakos, C.K. Omondi, V.Rahimpour Golroudbary, N.Rahmawati, L.N.N.Wandera, Q.Wang, P.Yang, X.Yu, X.Yuan, R.Zeng, P. Zhang, H.Zhao; thank you all for the time we shared and occasional departmental gatherings and outings; thank you all for the time we shared and occasional departmental gatherings and outings.

Additionally, outside the Water department, I made many friends, and they all contributed to my success, Theresa, Maria, Loes Rudolf..... and the list is long I will forever remember your kindness. 


\section{Table of Contents}

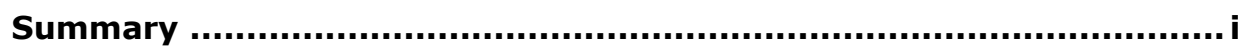

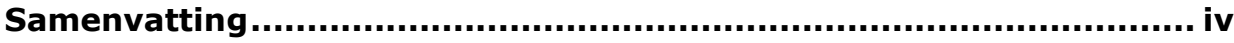

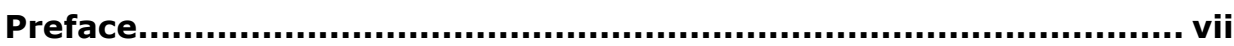

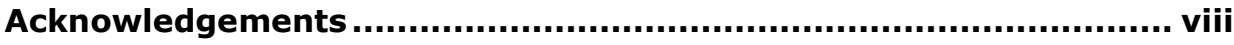

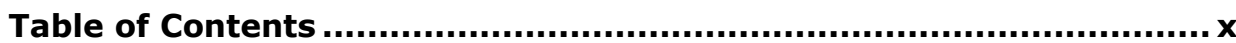

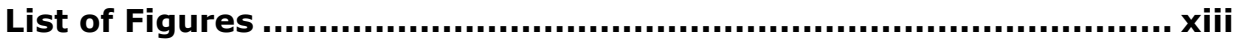

List of Tables............................................................................... xvii

List of Abbreviations and Symbols ............................................ xviii

1. General Introduction .......................................................... 1

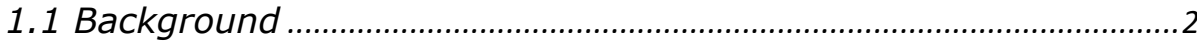

1.1.1 Scientific and societal relevance.............................................

1.1.2 Problem Statement ...................................................................

1.1.3 Main Objective And Research Questions......................................

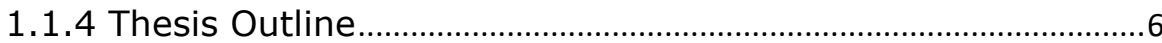

2. An Assessment of Satellite-Derived Rainfall Products Relative to Ground Observations over East Africa....................................... 9

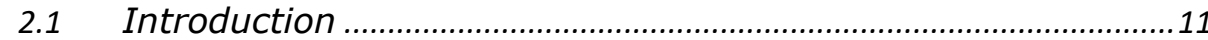

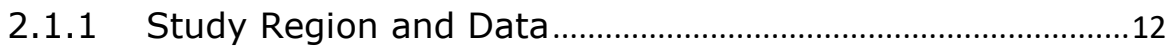

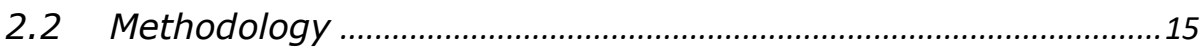

2.2.1 Assessments of Spatial and Temporal Characteristics ..........16

2.2.2 Assessments of Seasonal Influences........................................17

2.2.3. Assessments of Topographic Impacts .......................................18

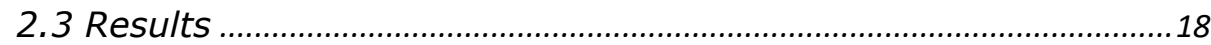

2.3.1 Performance of Monthly Satellite Rainfall Products ................18

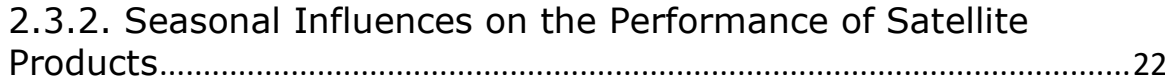

2.3.3. Topographic Influence on the Performance of Satellite

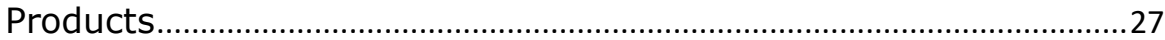

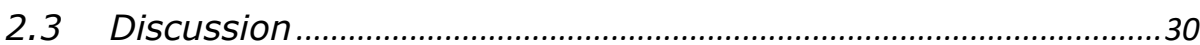

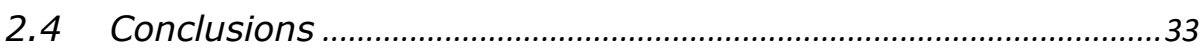


3 Bayesian Bias Correction of Satellite Rainfall Estimates for Climate Studies ........................................................................... 35

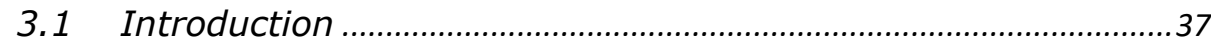

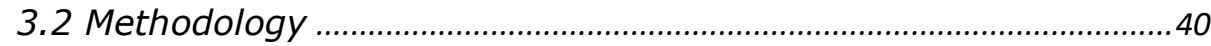

3.2.1 Bayesian Method ................................................................................40

3.2.2 Evaluation of Bias Corrected CHIRPS Rainfall............................44

3.2.3 Assessments of Bayesian Approach Performance ....................45

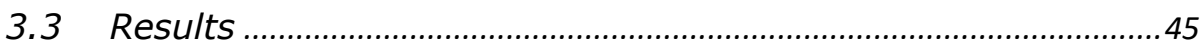

3.3.1 Assessments of Bias-Corrected CHIRPS Estimates..............45

3.3.2 Analysis of Bayesian Performance...............................................53

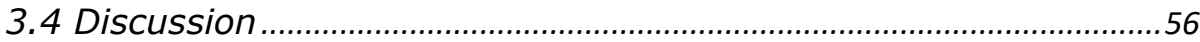

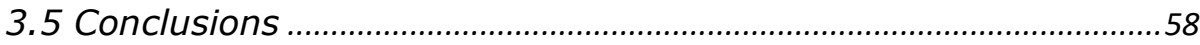

4 An assessments of moisture distribution influence on rainfall variability during different phases of Indian Ocean Dipole over East Africa .............. 61

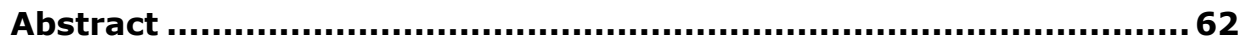

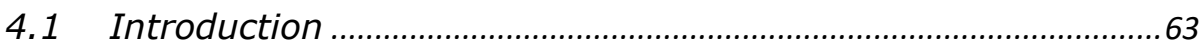

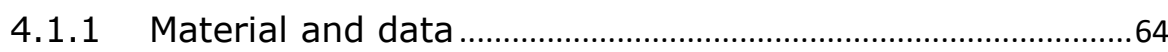

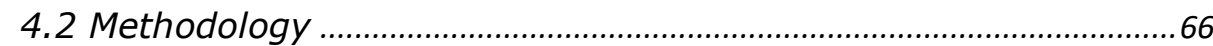

4.2.1 Estimation of moisture budget ......................................................66

4.2.2 Moisture budget comparison with convection variables ...68

4.2.3 Assessments of Indian Ocean Dipole forcing ............................69

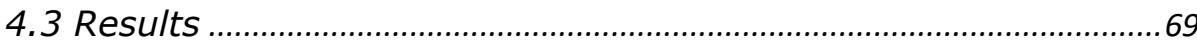

4.3.1 Analysis of moisture budget and rainfall ...............................69

4.3.2 Analysis of adverted Moisture and convection variables.71

4.3.3 Indian Ocean Dipole forcing.......................................................79

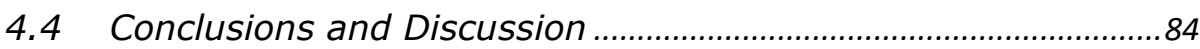

5 An assessment of MJO Circulation Influence on Air-Sea Interactions for Improved Seasonal Rainfall Predictions over East Africa ...........................................................................................8 87

5. 1 Introduction ..................................................................................... 88

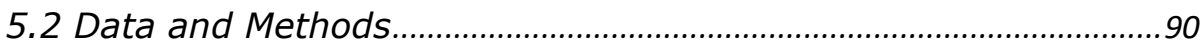

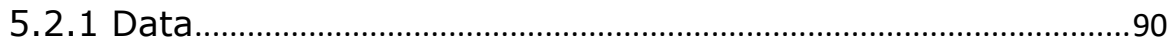

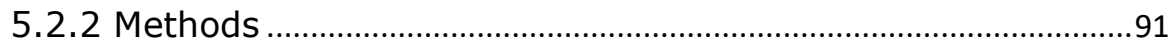

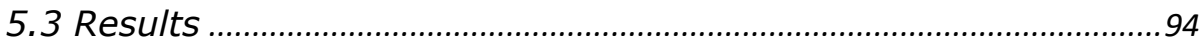

5.3.1 Comparison of $\mathrm{MJO}$ indices and convection variables............94

5.3.2 MJO circulation impacts ...............................................................96 


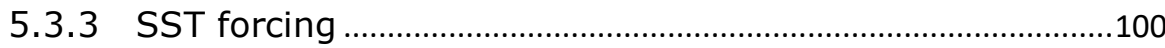

5.3.4 MAM seasonal Forecasting.........................................................102

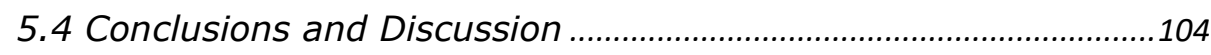

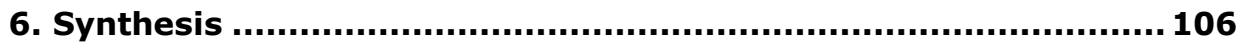

6.1 Overall conclusions.........................................................................107

6.2 Challenges and Recommendations ................................................111

Bibliography.............................................................................. 113

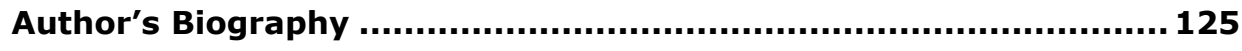

Author's Publications ............................................................... 126 


\section{List of Figures}

Figure 2. 1: Map of East Africa, with Shuttle Radar Topography Mission (SRTM) 90 m digital elevation model and the highlighted pixels (red) were among the pixels used to analyze the elevation variabilities to the eastern direction. Mount Kenya region elevation map is zoomed over the selected pixels within areas of high negative bias. Rain gauge stations are in black....

Figure 2. 2:Taylor diagrams displaying a statistical comparison between gridded rain gauge data and seven satellite-derived rainfall products per month for the wet months from March to May and October to December over a period of 15 years $(1998-2012)$.................... 20

Figure 2. 3: Mean squared error (MSE) contributions by the correlation (f1), variance (f2), and the mean ( $\mathrm{f} 3$ ) components derived from the satellite averages of the rainfall estimates (1998-2012) with respect to the rain gauge data...................................................... 20

Figure 2. 4: Monthly mean bias ( $\mathrm{mm} / \mathrm{month})$ of satellite rainfall products in April (1998-2012).

Figure 2. 5: Monthly mean bias $(\mathrm{mm} / \mathrm{month})$ of satellite rainfall products in November (1998-2012).

Figure 2. 6: Mean low level $(850 \mathrm{mb})$ wind direction flow during the months of April and November (1998-2012) over the region of East Africa. The size of the wind arrow indicates the wind magnitude strength (the larger the arrow head, the higher the wind speed).............. 23

Figure 2. 7: Mean bias derived from averages in April (1998-2012) between satellite rainfall estimates and corresponding gridded rain gauge data for East Africa...... 24

Figure 2. 8: Mean bias derived from averages in November (1998-2012) between satellite rainfall estimates and corresponding gridded rain gauge data for East Africa.

Figure 2. 9: Correlation coefficients derived from rainfall averages in April (1998-2012) between satellite rainfall estimates and corresponding gridded rain gauge data for East Africa.

Figure 2. 10: Correlation coefficients derived from rainfall averages in November (1998-2012) between satellite rainfall estimates and corresponding gridded rain gauge data for East Africa.

Figure 2. 11: Elevation $(m)$ variations of selected pixels from near Mount Kenya eastward, which are among the areas identified with a high negative bias of varying magnitudes by all satellite rainfall products. Different colors represent the elevation variabilities from one satellite pixel to another.

Figure 2. 12: Scatter plots of the mean bias of satellite rainfall estimates in relation to the elevation variations derived from the rainfall averages (1998-2012) with respect to the rain gauge data during the peak rainfall month of April of the MAM season, over the Kenyan highlands where Mount Kenya is located. The five directions from Mount Kenya to the north, south, east, northeast, and southeast are shown for each product. 
Figure 2. 13: Mean bias of satellite rainfall estimates in relation to the elevation variations derived from the rainfall averages (1998-2012) with respect to the rain gauge data during the peak rainfall month of November in the OND season, over the Kenyan highlands where Mount Kenya is located. The five directions from Mount Kenya to the north, south, east, northeast, and southeast are shown for each product.

Figure 3. 1: Map of East Africa with the Shuttle Radar Topography Mission (SRTM) 90 m digital elevation model. Rain gauge station distributions used for gridding are highlighted in black. In red are the selected pixels for assessments.

Figure 3. 2: Monthly Taylor diagrams displaying the statistical comparison between the Climate Hazards Group Infrared Precipitation with Stations (CHIRPS) (red) and bias-corrected CHIRPS (bc) (blue) estimates with corresponding rain gauge data (green) as the reference. Shown are the wet months of the rainfall seasons (MarchMay and October-December) over a period of 11 years (2003-2013). The azimuthal angle represents the correlation coefficient; radial distance is the standard deviation ( $\mathrm{mm} / \mathrm{month}$ ), and green contours represent RMSD ( $\mathrm{mm} / \mathrm{month})$.

Figure 3. 3: Same as for Figure 3.2, but for the relatively drier months of January, February, June-August and September.

Figure 3. 4: Monthly mean bias derived from averages (2003-2013) of rain gauge data and satellite rainfall estimates of CHIRPS $(A)$ and bias corrections (CHIRPS (bc)) (B)

Figure 3. 5: Taylor diagrams displaying the statistical comparison between the CHIRPS (red) and bias-corrected (blue) CHIRPS estimates with corresponding rain gauge data (green) as the reference for years 2003-2008. The azimuthal angle represents the correlation coefficient; the radial distance represents the standard deviation (mm/year), and the green contours represent RMSD (mm/year). .. 50

Figure 3. 6: As per Figure 3.5, but for the years 2009-2013.............. 51

Figure 3. 7: Yearly spatial bias patterns derived from the averages of the anomalous wet years (2003 and 2006), the dry (2005), and standard (2008) of the CHIRPS and bias-corrected CHIRPS (bc) abbreviated as $(A, B)$, respectively, relative to the rain gauge data.

Figure 3. 8: Yearly scatter plots for of pixels in areas of lowest bias correction.

Figure 4. 1: Map of East Africa, with Shuttle Radar Topography Mission (SRTM) $90 \mathrm{~m}$ digital elevation model. The black dots represent rainfall stations gridded and used in locally bias correcting CHIRPS rainfall data for 33 years (1981-2013)

Figure 4. 2: Monthly averages (1981-2013) of total moisture budget flux and its components through the four boundaries; eastern $\left(\mathrm{Q}_{E}\right)$, western $\left(\mathrm{Q}_{\mathrm{w}}\right)$, southern $\left(\mathrm{Q}_{\mathrm{S}}\right)$ and northern $\left(\mathrm{Q}_{\mathrm{N}}\right)$ and the total moisture budget $\left(\mathrm{Q}_{\mathrm{T}}\right)\left(\mathrm{kgm}^{-1} \mathrm{~S}^{-1}\right)$ and corresponding rainfall over East Africa. 
Figure 4. 3: Mean (1981-2013) monthly rainfall (mm), and integrated (surface: $850 \mathrm{mb}$, top: $200 \mathrm{mb}$ pressure levels) column moisture budget $\left(\mathrm{Kg} \mathrm{m}^{-1} \mathrm{~s}^{-1}\right)$ and their correlations over East Africa. Only correlations that are significant at 95\% confidence level are shown.71

Figure 4. 4: Same as figure 4 but for MSLP

Figure 4. 5: Monthly CAPE ( $/ \mathrm{kg})$ spatial distribution and correlation coefficients between with corresponding moisture budget $\left(\mathrm{Kgm}^{-1} \mathrm{~s}^{-1}\right)$ from their averages (1981-2013) over East Africa.................... 73

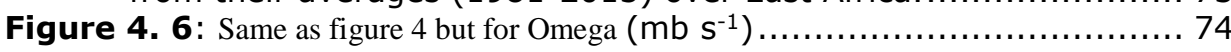

Figure 4. 7: Same as figure 9 but with $2-m$ surface temperature $(K)$ abbreviated as T2m.

Figure 4. 8: Month of April Omega $\left(\mathrm{mb} \mathrm{s}^{-1}\right)$ over East Africa during the dry 1984 (Figure 4.8a) and 2001 (Figure 4.8c), and relatively wet 1997 (Figure 4.8b) and 2006 (Figure 4.8d) ) years from the surface (1000 $\mathrm{mb}$ ) to near tropopause (200 mb) within a rectangular area enclosing East Africa between $29^{\circ} \mathrm{E}$, and $42^{\circ} \mathrm{E}$, and $12^{\circ} \mathrm{S}$, and $5^{\circ} \mathrm{N}$. Average Omega within the land mass was used to determine the moisture convergence levels (Figure 4.8e).

Figure 4. 9: Same as figure 4.8 but for the month of May.................... 77

Figure 4. 10: Same as figure 4.8 but for the month of August.............. 78

Figure 4. 11: Same as figure 4.8 but for the month of November ........... 79

Figure 4. 12: shows composite spatial distribution of EOFs for moisture budget $\left(\mathrm{kgm}^{-1} \mathrm{~s}^{-1}\right)$ distribution derived from monthly means (19812013) during the positive phase of Indian Ocean dipole (+ve IOD). 80

Figure 4. 13: Shows composite spatial distribution of EOFs for moisture budget $\left(\mathrm{kgm}^{-1} \mathrm{~s}^{-1}\right)$ distribution derived from monthly means (19812013) during the negative phase of Indian Ocean dipole(-ve IOD). 80

Figure 4. 14 : Scatter plot of EOF 1 against Dipole mode Index during positive(+ve) negative(-ve), and neutral, Indian Ocean Dipole (IOD) years................................................................. 81

Figure 4. 15: Scatter plot of EOF 2 against Dipole mode Index during positive(+ve) negative(-ve), and neutral Indian Ocean Dipole (IOD) years.................................................................. 82

Figure 4. 16: Scatter plot of EOF 1 against Nino 3.4 during positive (+ve) negative (-ve), and neutral Indian Ocean Dipole (IOD) years. ...... 83

Figure 4. 17: Scatter plot of EOF 2 against Nino 3.4 during positive(+ve) negative(-ve), and neutral Indian Ocean Dipole (IOD) years.

Figure 5. 1: Composite of seasonally significant (monthly amplitude $>1$ ) MAM RMM MJO indices and corresponding MAM (a) and correlation coefficients (b) between MAM MJO indices from (a) 1 to (h) 8 averaged amplitudes and convective variables (b). Significant correlations at the $95 \%$ confidence level are $>0.5$

Figure 5. 2: Composite of seasonally significant (monthly amplitude $>1$ ) MAM RMM MJO indices and JJA (a) and OND (b) rainfall patterns. .. 96

Figure 5. 3: Monthly time series averages of RMM MJO (RMM 1, 2 and magnitude and corresponding rainfall and total moisture budget indices across the four boundaries enclosing East Africa during the anomalous dry $(5.3 a-d)$ years associated with enhanced MJO (60\% days $>1$ ) shown in and similarly, anomalous wet years (5.3e-h) with $\mathrm{e}$ and $\mathrm{f}$ been $\mathrm{MJO}$ enhanced years. 
Figure 5. 4: Seasonal (MAM, JJA and OND) spatial rainfall distributions of the early (March-April) peak MJO active dry years in 1981 (Figure $5.4 a-c$ ) and late (April-May) peak in 2005 (Figure 5.4d-f)........... 98

Figure 5. 5: Seasonal (MAM, JJA and OND) spatial rainfall distributions of the early (March-April) peak of wet year (1997, Figure 5.5a-c) and late (April-May) peak of a wet year (2003)

Figure 5. 6: Seasonal (MAM JJA and OND) Pearson correlation patterns of average RMM MJO (1981-2013) magnitudes and corresponding rainfall across East Africa. Only significant correlations at a $95 \%$ confident level are displayed. Included are the low-level (850-mb) wind patterns for the corresponding seasons.

Figure 5. 7: Composite of sea surface temperature indices during the extremely dry inactive $(1984,2010)$ and active $(1981,2005) \mathrm{MJO}$ years (Figure $5.7 \mathrm{a}$ and $5.7 \mathrm{~b}$, respectively). Wet inactive $(2006,2012)$ and active $(1997,2003)$ MJO years are presented in Figure 5.7c and $5.7 d$.

Figure 5. 8: March-May (MAM) Pearson correlation patterns of surface temperature and MJO 8 for the period 1981-2013 (a) and the correlations between surface temperature and SST. Only significant correlations at a $95 \%$ confidence level are presented. Horizontal wind patterns showing areas of low-level convergence are depicted in the map.

Figure 5. 9: Lagged March-May (MAM) prediction and estimated moisture budget $\left(\mathrm{kg} \mathrm{m}^{-1} \mathrm{~s}^{-1}\right)$ (rainfall proxy) patterns derived using SST indices over the Indian Ocean and Maritime Continent related to MJO circulations for the validation period 2004-2013. .103 


\section{List of Tables}

Table 3.1: Statistics for the monthly spatial evaluation........................ 49

Table 3.2: Statistics for the yearly spatial evaluation............................ 53

Table 3.3: Statistics for the yearly Bayesian performance analysis........... 55

Table 5. 1: Regression prediction model validation output for moisture budget $\left(\mathrm{kg} \mathrm{m}^{-1} \mathrm{~s}^{-1}\right)$ (rainfall proxy) indices as predictand and sea surface temperature $(k)$ indices extracted from three geographical locations (SWIO,MRT and CIO) as predictors during the validation

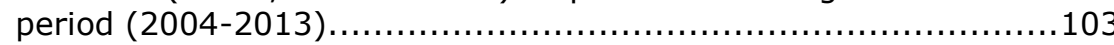




\title{
List of Abbreviations and Symbols
}

\author{
Abbreviations \\ BS \\ BSS \\ CAPE \\ ACC \\ CCD \\ CDF \\ CDR \\ CHIRPS \\ CIO \\ Clim \\ CMAP \\ CMORPH \\ CTPD \\ DEM \\ DMI \\ DJF \\ ECMWF \\ EIO \\ ENSO \\ EOF \\ ER SST \\ FEWSNET \\ FSP \\ GCM \\ GEWEX \\ GHA \\ GIS \\ GTS \\ GOES \\ GPCC \\ GPI \\ GPCP \\ GribSat-B1 \\ GTS \\ ICPAC \\ IDW \\ IGAD \\ IOD \\ Brier score \\ Brier Skill Score \\ Convective Available Potential Energy $\left(\mathrm{J} \mathrm{kg}^{-1}\right)$ \\ Anomalies of Correlation Coefficients \\ Cold Cloud Duration. \\ Cumulative Distribution. \\ Climate Data Record. \\ Climate Hazards Group Infra-Red Precipitation with \\ Station data \\ Central Indian Ocean \\ Climatology \\ CPC Merged Analysis of Precipitation. \\ Climate Prediction Centre (CPC) Morphing technique. \\ Centennial Trends Precipitation Dataset \\ Digital Elevation Model. \\ Dipole Mode Index \\ December, January, February \\ European Centre for Medium-Range Weather \\ Forecasts. \\ Eastern Indian Ocean. \\ El Niño Southern Oscillation. \\ Empirical Orthogonal Functions. \\ Extended Reconstructed Sea Surface Temperature. \\ Famine Early Warning Systems Network. \\ ITC Foundation Scholarship Program \\ Global Circulation Models. \\ Global Energy and Water Cycle Experiment. \\ Greater Horn of Africa \\ Geographical Information System. \\ Global Telecommunication Network \\ Geostationary Operational Environmental Satellite \\ Program. \\ Global Precipitation Climatology Centre. \\ GOES Precipitation Index. \\ Global Precipitation Climatology Project. \\ Gridded Satellite Infrared data. \\ Global Telecommunication Network \\ (IGAD) Climate Prediction and Applications Centre. \\ Inverse Distance Weighting \\ Intergovernmental Authority on Development. \\ Indian Ocean Dipole.
}




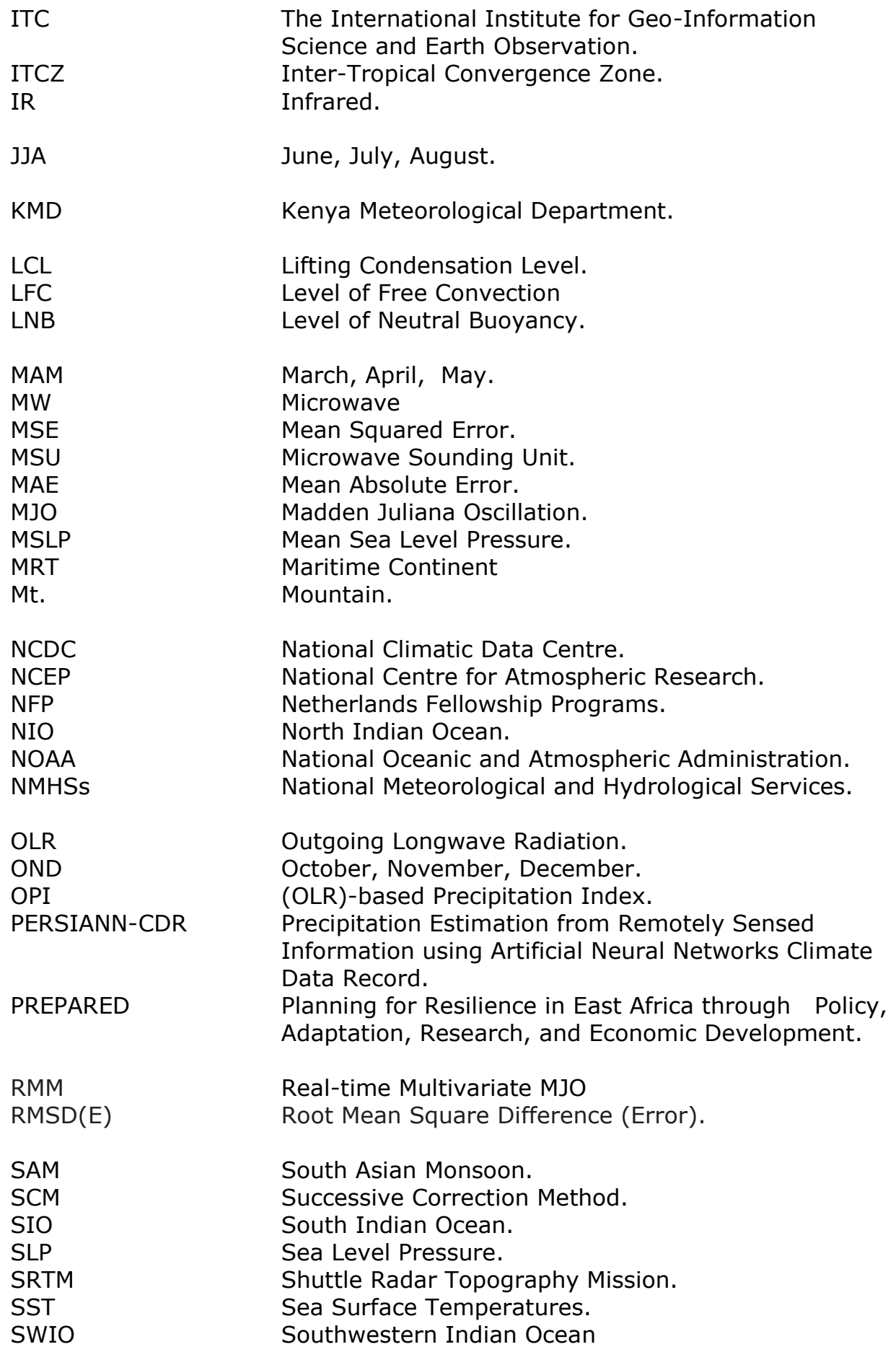

National Climatic Data Centre.

National Centre for Atmospheric Research. Netherlands Fellowship Programs.

North Indian Ocean.

National Oceanic and Atmospheric Administration. National Meteorological and Hydrological Services.

Outgoing Longwave Radiation.

October, November, December.

(OLR)-based Precipitation Index.

Precipitation Estimation from Remotely Sensed Information using Artificial Neural Networks Climate Data Record.

Planning for Resilience in East Africa through Policy, Adaptation, Research, and Economic Development.

Real-time Multivariate MJO

Root Mean Square Difference (Error).

South Asian Monsoon.

Successive Correction Method.

South Indian Ocean.

Sea Level Pressure.

Shuttle Radar Topography Mission.

Sea Surface Temperatures.

Southwestern Indian Ocean 
TAMSAT

TARCAT

TRMM-3B43

TMPA (3B42 v7)

USGS

USAID

WCRP

SST

SWIO
Tropical Applications of Meteorology using Satellite and ground based observations.

TAMSAT African Rainfall Climatology And Time series. Tropical Rainfall Measuring Mission v 3B43

Tropical Rainfall Measuring Mission Multi-satellite Precipitation Analysis version 7.

United States Geological Survey.

US Agency for International Development.

World Climate Research Program.

Sea Surface Temperature.

Southern West Indian Ocean 


\section{Symbols}

\begin{tabular}{|c|c|}
\hline$\alpha_{g}$ & weighing factor of rain gauge data \\
\hline$\alpha_{s}$ & weighing factor of satellite rainfall data \\
\hline$P(s)$ & probability of satellite data \\
\hline$E\left(\varepsilon_{g}\right)$ & monthly averaged rain gauge errors (mm month ${ }^{-1}$ ) \\
\hline$E\left(\varepsilon_{s}\right)$ & monthly averaged satellite errors \\
\hline$P(g \mid s)$ & $\begin{array}{l}\text { likelihood function of rain gauge data given by the } \\
\text { satellite estimates }\end{array}$ \\
\hline Atan & Inverse Tangent $\left(\tan ^{-1}\right)$ \\
\hline$b c$ & value after bias correction \\
\hline$s_{c}$ & bias corrected CHIRPS rainfall data (mm month ${ }^{-1}$ ) \\
\hline$C C$ & Pearson's product-moment correlation coefficient (\%) \\
\hline$\sigma_{s}$ & $\begin{array}{l}\text { standard deviations of the satellite rainfall data }(\mathrm{mm} \\
\left.\text { month }^{-1}\right)\end{array}$ \\
\hline$\sigma_{g}$ & $\begin{array}{l}\text { standard deviations of the rain gauge rainfall } \\
\text { data( }\left(\mathrm{mm} \text { month }^{-1}\right)\end{array}$ \\
\hline deg & degree. \\
\hline$\partial W / \partial t$ & change of precipitable water in time. \\
\hline$\nabla \cdot Q$ & is the divergence of water vapor \\
\hline$E$ & is surface evapotranspiration ( $\mathrm{mm}$ ) \\
\hline$Q_{w}$ & transport cross the west $\left(\mathrm{kg} \mathrm{ms}^{-1}\right)$ \\
\hline$Q_{E}$ & transport cross the east $\left(\mathrm{kg} \mathrm{ms}^{-1}\right)$ \\
\hline$Q_{N}$ & transport cross the north $\left(\mathrm{kg} \mathrm{ms}^{-1}\right)$ \\
\hline$Q_{S}$ & transport cross the south $\left(\mathrm{kg} \mathrm{ms}^{-1}\right)$ \\
\hline$Q_{u}$ & zonal moisture transport. \\
\hline$Q_{v}$ & meridional moisture transport. \\
\hline OF & $\begin{array}{l}\text { is the total advected water vapour mass inflow } \\
(\mathrm{kg} / \mathrm{ms})\end{array}$ \\
\hline Omega & vertical velocity of pressure $\left(\mathrm{mb} \mathrm{s}^{-1}\right)$ \\
\hline IF & $\begin{array}{l}\text { is the total advected water vapour mass inflow } \\
(\mathrm{kg} / \mathrm{ms})\end{array}$ \\
\hline$A$ & area of interest \\
\hline$P$ & rainfall \\
\hline$\frac{-1}{g}$ & upward acceleration due to gravity \\
\hline$P_{S}$ & $\begin{array}{l}\text { surface pressure level ( } 850 \mathrm{mb} \text { ) for moisture budget } \\
\text { considered }\end{array}$ \\
\hline$P_{t}$ & $\begin{array}{l}\text { top pressure level ( } 200 \mathrm{mb} \text { ) for moisture budget } \\
\text { considered }\end{array}$ \\
\hline$d p$ & infinitesimal in the pressure \\
\hline$t$ & time \\
\hline$I$ & is the length equivalent of $1^{\circ}$ \\
\hline$d \varphi$ & infinitesimal change in latitudes \\
\hline$d \lambda$ & infinitesimal change in longitude \\
\hline$\varepsilon$ & error. \\
\hline$E V$ & eigenvalue. \\
\hline$F_{1}$ & mean squared error by correlation component \\
\hline$F_{2}$ & mean squared error by variance component \\
\hline$F_{3}$ & mean squared error by mean component \\
\hline
\end{tabular}


$f_{i}$

$g$

$\bar{g}$

J

$\mathrm{Kg}$

$m$

$\mathrm{mm}$

$\mathrm{Mb}$

MSLP

$N$

$x_{N P}$

$x_{M}$

$D^{i}$

$\beta$

$O_{i}$

$f_{i}$

OF

$P$

q

$Q$

$R_{d}$

$S$

2-m

$T_{v p}$

$T_{v e}$

D

$u$

V

W

$W_{r}$

$W_{\text {trig }}$

$W_{\text {deg }}$

$\pi$

$Z_{s}$

mean squared error contributions by each component to the total error

rain gauge data $(\mathrm{mm})$

mean of the rain gauge data $\left(\mathrm{mm}\right.$ month $\left.^{-1}\right)$

joules.

Air temperature in kelvin

kilogram.

meter.

millimeters.

millibar

Mean Sea level Pressure (mb)

Number of samples.

spatial dimension in pattern analysis

data points in pattern analysis

points representing sea surface residues

regression coefficients.

observed rainfall estimates $\left(\mathrm{mm}\right.$ month $\left.^{-1}\right)$

forecasted rainfall estimates $\left(\mathrm{mm}\right.$ month $^{-1}$ )

outflow $\left(\mathrm{kg} \mathrm{ms}^{-1}\right)$

probability

specific humidity $\left(\mathrm{kg} \mathrm{kg}^{-1}\right)$

moisture budget $(\mathrm{kg} / \mathrm{ms})$

gas constant of dry air $\left(\mathrm{J} \mathrm{kg}^{-1} \mathrm{~K}^{-1}\right)$

satellite rainfall data $(\mathrm{mm})$

mean of the satellite rainfall data $\left(\mathrm{mm} \mathrm{month}{ }^{-1}\right)$

2 meter surface temperature surface $(k)$

Temperature of an adiabatically rising air parcel $(k)$

Temperature of the environment $(k)$

Del.

zonal wind $\left(\mathrm{m} \mathrm{s}^{-1}\right)$

meridional wind $\left(\mathrm{m} \mathrm{s}^{-1}\right)$

omega $\left(\mathrm{mb} \mathrm{s}^{-1}\right)$

wind magnitude $\left(\mathrm{m} \mathrm{s}^{-1}\right)$

wind direction in radians

wind direction in degrees

pi

Z-score 




\section{Chapter 1}

\section{General Introduction}

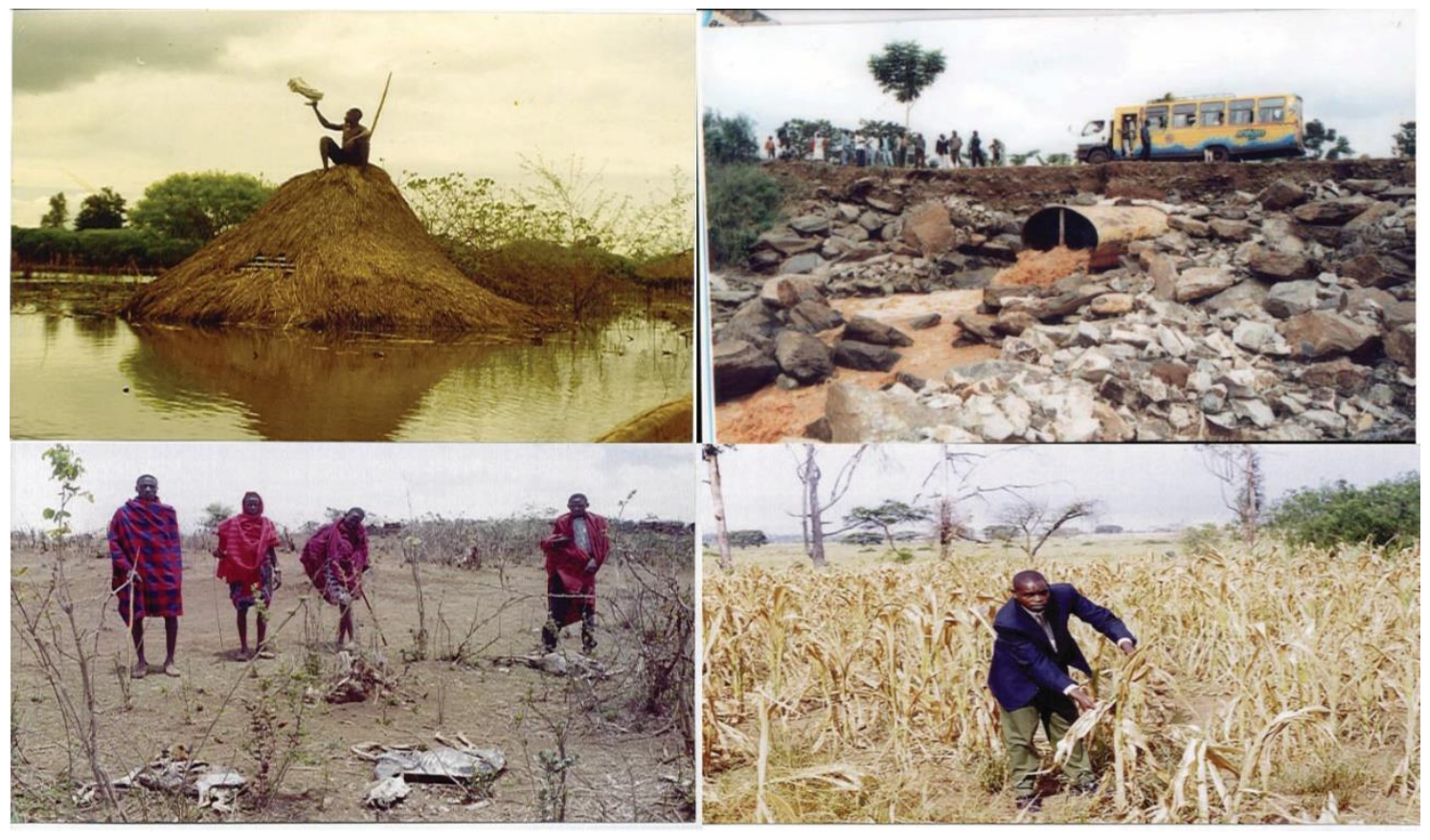




\subsection{Background}

\subsubsection{Scientific and societal relevance}

Seasonal rainfall prediction refers to the expected state of the weather in coming months. The main objective is to provide useful information regarding expected rainfall variability to a wide range of possible decision makers. Two approaches are adopted for the predictions (Stockdale et al., 2010), the first is where dynamical mathematical equations are utilized using high-level computing systems available in few forecasting regions over the world. Its main challenge been defining initial and boundary conditions of the General circulation model (GCM). Further, in areas of dominant convective systems, the challenge of parameterization of localized convections within a subgrid, like topographic processes are not adequately addressed by the coarse spatial scales of GCM models. Empirically approach is the second and is more flexible and involves using long-term historical data to predict the future. This thesis explains the latter approach where satellite rainfall data are utilized to locally characterise rainfall variability at high spatial scale for improved rainfall predictions.

\subsubsection{Scientific Relevance}

East Africa is in the equatorial tropics, and seasonal rainfall comes when the Inter-Tropical Convergence Zone (ITCZ) lies over the equator as it migrates between $150 \mathrm{~S}$ and $150 \mathrm{~N}$, between January and July respectively (Ogallo, 1988). The convergence leads to the ascent of air masses, cooling, condensation and formation of convective rainfall (Schneider, Bischoff, \& Haug, 2014). As such the region is characterized by two main rainy seasons: the "long rains" in March-May (MAM), and the "short rains" in October-December (OND). The long and short-term refer to the long/short period and high/low rainfall intensity. A third rainfall season occurs during the northern summer (June to September) but affects a small area over western Kenya and parts of Uganda. The MAM rainfall prediction is particularly challenging partially because its variability is not well understood. As such most researchers have concentrated on OND rainfall season with results showing close links with El Niňo-Southern Oscillation (ENSO) (Indeje, Semazzi, \& Ogallo, 2000). Interestingly, observations show that March and April rainfall regimes differ from that of May (Camberlin \& Okoola, 2003) suggesting different teleconnections. Further, recent review work over eastern Africa by (S. E. Nicholson, 2017) observed the need to treat MAM months separately as they have different forcing. This thesis has considered these observations and although all seasons are considered in this research, prediction tests are concentrated on MAM season.

Poor rain gauge distributions over the region like many African countries hinder research. The spatial and temporal inconsistencies of rain gauge data (Villarini \& Krajewski, 2008) affect the development and validation of the long term forecasting models. However, rain gauges provide the most 
direct representations of rainfall and offer useful information in modelling regarding local rainfall processes that are not accurately parameterized by the Global Circulation Models (GCM) (Dibike \& Coulibaly, 2007). Use of satellite rainfall estimates to complement poor rain gauge network is preferred in many parts of the world. Further, satellite-derived rainfall products have good coverage and are consistency in time (Joyce, Janowiak, Arkin, \& Xie, 2004; Sorooshian et al., 2000) and can estimate rainfall in remote areas like the high elevated areas. Although, these products have been validated globally and some regionally (Feidas, Lagouvardos, Kotroni, \& Cartalis, 2005), their comparisons with ground observations show large discrepancies. It is therefore vital for them to be adjusted using locally available rain gauge data to improve their characterisation of local processes. Seven commonly used satellite products (TARCAT, CHIRPS v2, TRMM-3B43, CMORPH v1, PERSIANN-CDR, CMAP and GPCP) were utilized. Although these products can replicate rainfall patterns over the region applying bias correction to locally improved rain gauge data is crucial. In choosing the bias correction approach, it is crucial that satellite rainfall product maintain its accuracy in areas of poor rain gauge data. The Bayesian approach was applied to CHIRPS v2 ( among best in accuracy and with long climatology) to improve its representativeness of local rainfall variability.

Knowing the sources of moisture is essential in understanding rainfall variability. East Africa is bounded by the Indian Ocean to the east and is a large source of moisture. However, the eastern parts of the region especially northern Kenya is semiarid attributed to Turkana jets(S. E Nicholson, 2016). Conversely, the western part including Burundi, Rwanda, Uganda and Lake Victoria experiences wet conditions almost throughout the year. To answer this differences monthly Moisture budget between the surface $(850 \mathrm{mb})$ and near the tropopause $(200 \mathrm{mb})$ and Omega $(\mathrm{mb} \mathrm{s}-1)$ profile was assessed to determine the source of moisture related to rainfall variability. Further, since the extreme wetness and dryness over the region are associated with IOD and ENSO, to understand the influence of these modes on moisture distributions, Dipole Mode Index (DMI) and Nino 3.4 are utilized during different phases of IOD.

The driving force of the atmospheric variability is better achieved when the processes interacting the air-sea are understood. Seasonal rainfall predictions are driven by either internal or external forces that enhance rainfall occurrence. The external forcings include Volcanoes, solar variations and minimally on human activities (Stockdale et al., 2010). The internal forcings, of Sea Surface Temperature (SST) anomalies related to El Niňo-Southern Oscillation (ENSO) are commonly utilized, in predictions. However, SSTs indices over the western Pacific and the Indian Ocean are thought to contribute more to the prediction's skill than the ENSO (Funk et al., 2008). The predictability using SST anomalies is highest over the tropics, because of lower natural variability than high latitude region hence the atmosphere react directly to SST changes (Rowell, 1998). The Madden Juliana Oscillations (MJO) is an intra-seasonal oscillation with a characteristic timescale of 30-60 days propagating eastwards at the speed of $5 \mathrm{~ms}-1$ (Madden \& Julian, 1994). It is utilized in understanding weather and Climate variations and has been linked to convective activities over Africa as do the equatorial Rossby and Kelvin waves during the monsoons (Matthews, 2004). MJO influences the oceanic circulations (Wilson, Gordon, \& Kim, 2013) that impact on rainfall variability 
over East Africa. However, most studies have concentrated on MJO high temporal scale, but review work on its impacts on African rainfall (Zaitchik, 2017) noted a need to expand the MJO research to longer timescale because of its teleconnections to ENSO and IOD. In this study, monthly and seasonal RMM MJO magnitudes are utilized to determine the air-sea interactions by use of convective variables and SST indices to improve rainfall predictions. This approach especially the long-term use of MJO has not been applied over the region and offer important information to the science community regarding its connection to extreme wet and dry events.

\subsubsection{Societal Relevance}

Accurate seasonal rainfall predictions are vital for agricultural planning and water resource management. Over East Africa, rain-fed agriculture is the main source of economy and provision of subsistence food. The persistent extreme climate of drought and floods over eastern Africa during the rainfall seasons (S. E Nicholson, 2016) have impacted negatively to the population increasing deaths and poverty. It can be understood that a lot of resources are put in place before rainfall season in contemplation of the incoming rains. The resources can be lost when unexpected extreme weather occur and this effect can be minimized by improving the predictions. This study captures the small scale rainfall variability particularly from topographic effects that the GCM coarse spatial resolutions may not adequately address. Consequently, the awareness would increase the effectiveness, especially in agricultural planning. Besides, the policymakers and the Meteorological department issuing forecast would be much more informed thereby improving their predictions.

\subsubsection{Problem Statement}

East Africa seasonal rainfall is very variable in space and time. The complex terrain of the high elevated areas, inland large water bodies and low land over coastal areas bordering the Indian Ocean modify the rainfall processes. Consequently, rainfall predictability is more challenging affecting the livelihood and economy of this region which largely dependent on rain-fed agriculture (Haile, 2005). The GCM models used in seasonal rainfall predictions are too coarse to accurately parameterize these localized processes like convections over the region. It is therefore important to use an approach that is more flexible to scale variations.

A rainfall data with high spatial distribution and consistent in time is vital for long-term applications. However, East Africa like many developing worlds suffers from poor rain gauge network (Stockdale et al., 2010) making research on improvements of rainfall predictions challenging. Furthermore, the point rain gauge observations are not representative of remote areas like over mountainous (Kidd et al., 2012). Currently, there numerous satellite rainfall products that can complement the sparse rain gauges. It is essential to assess the performance of several products to determine the most appropriate to characterise different rainfall regimes over the region. East 
Africa has complex topography and few studies have looked into the impact they have on rainfall retrieval by satellite data.

Although these products are globally and some regional bias corrected, they often show substantial differences relative to ground measurements attributed to local and external factors that require systematic consideration (Abera, Brocca, \& Rigon, 2016; AghaKouchak, Mehran, Norouzi, \& Behrangi, 2012). Further, some of these products were validated with limited rain gauge data which may not adequately characterise rainfall variability over the region. As such it is important to locally bias correct the selected rainfall product with an updated rain gauge data to improve the representativeness before application.

To link the large scale to rainfall variability require knowledge of the dominant moisture source for the convection developments. Although East Africa is bounded by Indian ocean attributed to being the main source of moisture (S.E Nicholson, 1996) it continues to experience extreme dry spells during the rainfall seasons (C. Funk et al., 2014). This is not well understood as the rains are regularly expected during ITCZ overpass. It affects mainly the long rainfall seasons, which show little connection to ENSO (Lyon \& DeWitt, 2012). It is, therefore, crucial to account for the precipitable moisture source and the impacts of DMI to moisture distributions during different phases of IODs.

Atmospheric variations are part of the general circulations, therefore, understanding the air-sea interactions, would help improve rainfall predictions. The sea surface temperatures are a good representative of the seas and their interactions with the atmosphere, because of their long-term memory of atmospheric variations. This help determines the most appropriate rainfall predictors. Madden Julian Oscillation is a primary tropical intra-seasonal circulation. It is useful in understanding weather and climate. Many applications have used its high temporal scale to relate to rainfall variability. However, recent review (Zaitchik, 2017) Work has recommended its long-term application because of its possible links to ENSO and IOD. This has been applied elsewhere (Curtis \& Gamble, 2016) and this thesis shows its application over East Africa with special emphasis on extreme wet and dry events. It has been associated with Indian monsoon in high temporal scale (Wilson et al., 2013) and linked to contrasting regional rainfall variability over the western highlands and coastal areas of parts of East Africa (Pohl \& Camberlin, 2006b). This study takes the research further by using MJO long term (monthly and seasonal) variability to understand the air-sea interactions influencing rainfall over East Africa.

\subsubsection{Main Objective And Research Questions}

The main objective of this study is to empirically improve Seasonal rainfall predictions using satellite data over East Africa

To achieve this objective, four specific objectives corresponding to the 4 main chapters are formulated as follows: 
1.Assess the performance of Satellite-Derived Rainfall Products Relative to Ground Observations over East Africa.

2.Determine the accuracy of the most suitable satellite-derived rainfall product by locally applying Bayesian bias correction to CHIRPS V2 rainfall estimates for climate studies.

3. Assess moisture distribution influence on rainfall variability during different phases of IOD over East Africa .

4. Assess the MJO Circulation Influence on Air-Sea Interactions for Improved Seasonal Rainfall Predictions over East Africa.

\subsubsection{Thesis Outline}

This dissertation is structured in publishable chapters besides the general introduction and the synthesis, four of them are the published articles, or submitted to, an ISI journal.

Chapter 2: Assessments of some of the commonly used satellite-derived rainfall products (TARCAT, CHIRPS v2, TRMM-3B43, CMORPH, PERSIANN-CDR, CMAP and GPCP) over East Africa relative to locally gridded $\left(0.05^{\circ}\right)$ rain gauge data. The products are assessed of their ability to characterize the different rainfall regimes spatially and temporally. Further, topography impacts on their retrieval performance. CHIRPS V2, TRMM-3B43 and CMORPH performance outperformed others but CHIRPS was more favorable based on its long climatology suitable for this study.

Chapter 3: Assessment of the application of Bayesian bias correction to CHIRPS v2 monthly rainfall estimates to minimize the bias before application. The approach is based on hypothesis that mean error are consistent with time. Adequate amount of bias were reduced mainly of underestimations related to rainfall magnitude and topographic effects.

Chapter 4: Assessment of moisture distribution influence on rainfall variability during different phases of Indian Ocean Dipole (IOD). Firstly, the dominant source of precipitable moisture was determined by calculating moisture budget between the surface $(850 \mathrm{mb})$ and near tropopause $(200 \mathrm{mb})$ over East Africa and its impact on rainfall variability by use of Era interim reanalysis data. Since over the equatorial tropics, convective systems are dominant thermodynamic (CAPE in $\mathrm{JKg}^{-1}$ ) and dynamics described by MSLP $(\mathrm{mb})$, the vertical profile of Omega $\left(\mathrm{mbs}^{-1}\right)$ were utilized to determine convective areas. Dipole mode Index and Nino 3.4 were used to determine the Indian Ocean Dipole (IOD) forcing during different phases of IOD.

Chapter 5: Assessment of the impact of RMM MJO amplitudes to rainfall variability over East Africa was carried out to improve its predictability using ERA-Interim reanalysis data at different timescales. First, the RMM MJO indices were compared to convective variables of CAPE in $(\mathrm{JKg}-1)$, Omega (mb s-1), $\operatorname{MSLP}(\mathrm{mb}), 2 \mathrm{~m}$ surface temperature $(\mathrm{k})$ and total moisture budget $(\mathrm{kg} \mathrm{m}-1 \mathrm{~s}-$ 1) to determine the impact of MJO circulation to convective processes. 
Secondly, the ocean contribution was determined by comparison of SST forcing on 2-m surface temperature and MJO related convections. The MAM MJO indices modulate low-level moisture influx from the Indian Ocean and the SST time series from the southwestern Indian Ocean, central Indian Ocean and within the Maritime Continent were most suitable predictors of the MAM moisture budget, a proxy of rainfall.

Chapter 6: This chapter outlines the conclusions of the obtained results, and the challenges encountered citing recommendations for future research. 
Chapter 2

\section{An Assessment of Satellite-Derived Rainfall Products Relative to Ground Observations over East Africa ${ }^{1}$}

1 This chapter is based on:

Kimani, M. W., Hoedjes, J. C. B., \& Su, Z. B. (2017). An Assessment of Satellite-Derived Rainfall Products Relative to Ground Observations over East Africa. Remote Sensing, 9(5). doi:10.3390/rs9050430 


\begin{abstract}
Accurate and consistent rainfall observations are vital for climatological studies in support of better agricultural and water management decision-making and planning. In East Africa, accurate rainfall estimation with an adequate spatial distribution is limited due to sparse rain gauge networks. Satellite rainfall products can potentially play a role in increasing the spatial coverage of rainfall estimates; however, their performance needs to be understood across space-time scales and factors relating to their errors. This study assesses the performance of seven satellite products: Tropical Applications of Meteorology using Satellite and ground-based observations (TAMSAT), African Rainfall Climatology And Time series (TARCAT), Climate Hazards Group InfraRed Precipitation with Station data (CHIRPS), Tropical Rainfall Measuring Mission (TRMM-3B43), Climate Prediction Centre (CPC) Morphing technique (CMORPH), Precipitation Estimation from Remotely Sensed Information using Artificial Neural Networks Climate Data Record (PERSIANN-CDR), CPC Merged Analysis of Precipitation (CMAP), and Global Precipitation Climatology Project (GPCP), using locally developed gridded $\left(0.05^{\circ}\right)$ rainfall data for 15 years (19982012) over East Africa. The products' assessments were done at monthly and yearly timescales and were remapped to the gridded rain gauge data spatial scale during the March to May (MAM) and October to December (OND) rainy seasons. A gridbased statistical comparison between the two datasets was used, but only pixel values located at the rainfall stations were considered for validation. Additionally, the impact of topography on the performance of the products was assessed by analyzing the pixels in areas of highest negative bias. All the products could substantially replicate rainfall patterns, but their differences are mainly based on retrieving high rainfall amounts, especially of localized orographic types. The products exhibited systematic errors, which decreased with an increase in temporal resolution from a monthly to yearly scale. Challenges in retrieving orographic rainfall, especially during the OND season, were identified as the main cause of high underestimations. Underestimation was observed when elevation was $<2500 \mathrm{~m}$ and above this threshold; overestimation was evident in mountainous areas. CMORPH, CHIRPS, and TRMM showed consistently high performance during both seasons, and this was attributed to their ability to retrieve rainfall of different rainfall regimes.
\end{abstract}

Keywords: satellite-derived rainfall estimates; rain gauge; topography; seasonality; East Africa 


\subsection{Introduction}

Accurate rainfall measurements are very important for many applications, such as hydrological modelling, agricultural practices, and climate studies. Rain gauge measurements provide the most direct measurement of rainfall, but over East Africa their networks are often spatially and temporally limited. Satellite-derived rainfall products may complement the sparse rain gauge data as they have an advantage of wide and consistent coverage (Sorooshian, Hsu et al. 2000, Joyce, Janowiak et al. 2004, Dinku, Ceccato et al. 2011). Their estimates are mainly derived from thermal infrared (IR) sensors on board geostationary satellites, and passive and active microwave (MW) sensors on board low Earth-orbiting satellites. Some products combine IR- and MW-based estimates, thus taking advantage of the high temporal resolution of IR platforms and the better accuracy in rainfall estimation of MW sensors. Most of these satellite-derived rainfall products have been validated globally and regionally (Adler, Huffman et al. 2003, Feidas, Lagouvardos et al. 2005) but there are still large discrepancies with ground-based observations at the subregional level, where these data are applied (Dinku, Ceccato et al. 2007). Furthermore, the uncertainties of these products depend on the season and climate (Adeyewa and Nakamura 2003, Duan, Liu et al. 2016). Maggioni et al. (Maggioni, Sapiano et al. 2016),

who studied the uncertainties of high-resolution satellite rainfall products, found that the systematic and random errors presented in these products were responsible for the inaccuracies in the retrieval of high rainfall rates.

Diem et al. (Diem, Hartter et al. 2014) assessed three high-resolution satellite products over Western Uganda on daily, monthly, and seasonal timescales against ground-based observations. The results show good rainfall detection, but challenges in retrieving orographic rainfall were experienced. The products underestimated the amount of rainfall in high-altitude areas (Mashingia, Mtalo et al. 2014) over Northeastern Tanzania.

Dinku et al. [3] studied the East Africa region and explored the effect of mountains and arid climates on the performance of four satellite rainfall products. Their study attributed the low performance to the use of infrared sensors, as they considered warm cloud 'not precipitating.' For example, single infrared sensor products showed the lowest performance over high-altitude areas, due to their limitations in retrieving different rainfall regimes. Satellite rainfall products that included rain gauge data in their bias correction tended to outperform those that did not (Hirpa, Gebremichael et al. 2010, Thiemig, Rojas et al. 2012, Cattani, Merino et al. 2016).

Asadullah et al. (Asadullah, McIntyre et al. 2008) evaluated monthly rainfall estimates of satellite rainfall products, revealing that they reproduced spatial and seasonal rainfall patterns, but had shortcomings in accurately retrieving the amount of rainfall. Historical rain gauge measurements were also used to determine the suitability of these products for hydrological and climatological applications over the region. Maidment et al. (Maidment, Grimes et al. 2013) evaluated model-based and satellite-derived rainfall estimates, and found that satellite-derived products produced rainfall patterns that were similar to ground-based observations. However, evaluating these products was challenging due to the inclusion of Global Telecommunication Network (GTS) rain gauge data, which also are included in the validation data. It is important to include updated rain gauge networks to increase the independence of the evaluation. 
While satellite products are updated from time to time, improved independent climatological data would improve the assessment of these products. This necessitates the continual comparison between products, especially before their application.

Although the Global Precipitation Climatology Centre (GPCC) gauge network is widely used to validate satellite products and shows good performance, its coarse resolution ( 0.5$)$ requires local corrections before the data can be used in applications (Funk, Peterson et al. 2014). Recent comparisons between the Centennial Trends precipitation dataset (CTPD) over the greater horn of Africa have indicated a great decline in rain gauges used by GPCC (Funk, Verdin et al. 2015). As a result, GPCC shows a higher absolute error (31\%) than the CTPD $(21 \%)$, which has more rain gauges. The decline in rain gauge distributions is a global problem that needs to be addressed so that societal needs that depend on information from such data is not compromised. The Intergovernmental Authority on Development (IGAD) Climate Prediction and Applications Centre (ICPAC) in collaboration with regional meteorological organizations have developed gridded rain gauge data $\left(0.05^{\circ}\right)$. These data include all available rain gauge measurements for the region that have been quality controlled. An upgrade of climatological data has filled some of the data gaps, which was the intention in creating the new dataset, thus making it preferable for use in sub-regional applications.

This study aims to assess the spatial and temporal performance of seven satellite precipitation products: Tropical Applications of Meteorology using Satellite and ground-based observations (TAMSAT), African Rainfall Climatology And Time series (TARCAT), Climate Hazards Group InfraRed Precipitation with Station data (CHIRPS), Tropical Rainfall Measuring Mission (TRMM-3B43), Climate Prediction Centre (CPC) Morphing technique (CMORPH), Precipitation Estimation from Remotely Sensed Information using Artificial Neural Networks Climate Data Record (PERSIANN-CDR), CPC Merged Analysis of Precipitation (CMAP), and Global Precipitation Climatology Project (GPCP), and the influences of elevation variability and seasonality of rainfall types in relation to their errors. The East Africa region was chosen for its high rainfall variability and the complexity of the terrain. Monthly and yearly assessments of the products were carried out over the period of 19982012. Rain gauge observations from the ICPAC gauge network were exploited as reference data for assessment during the main rainy seasons.

Section 2.2 explains the methodology. Section 2.3 provides the results of the study, Section 2.4 discusses these results, and Section 2.5 presents the conclusions.

\subsubsection{Study Region and Data}

East Africa (Figure 2.1) experiences two main rainy seasons. 

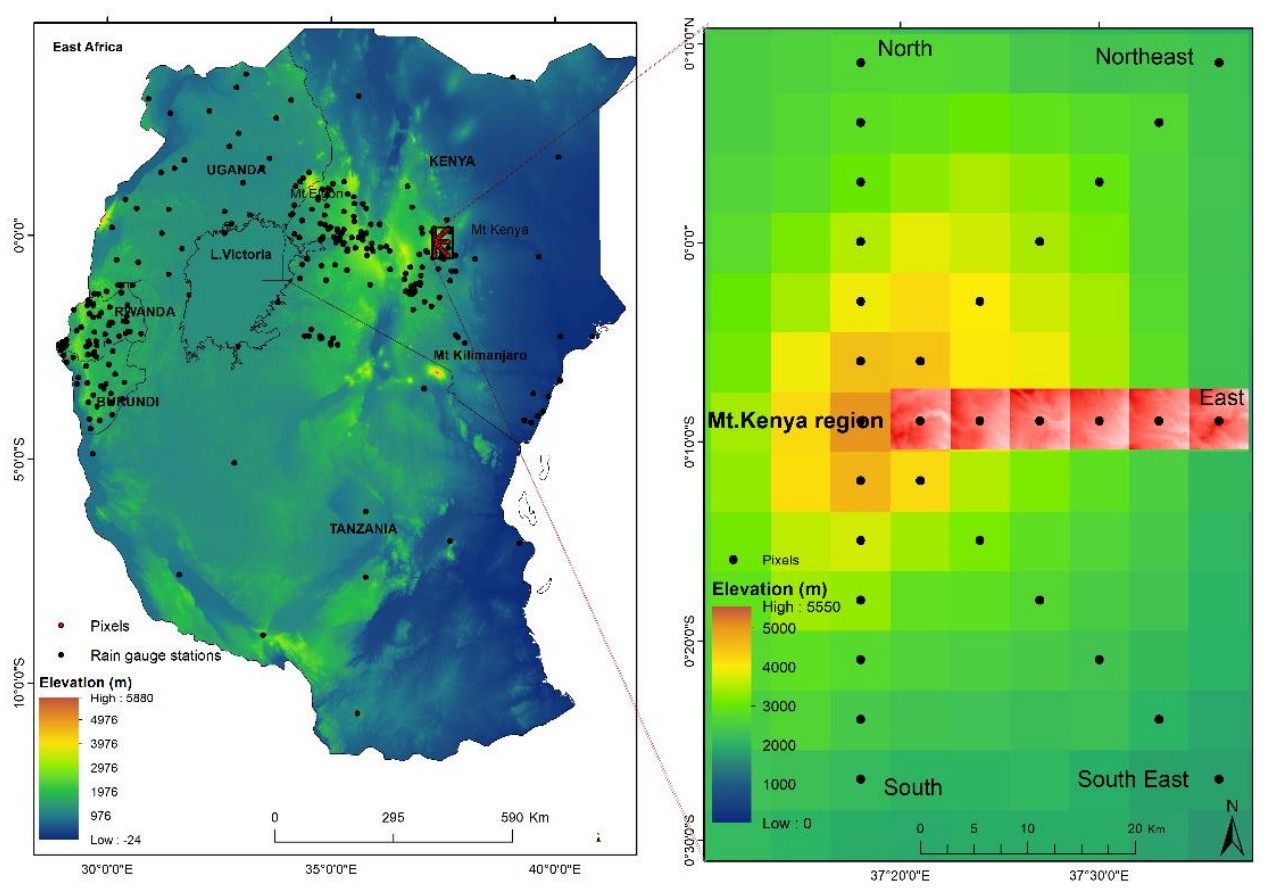

Figure 2. 1: Map of East Africa, with Shuttle Radar Topography Mission (SRTM) 90 $\mathrm{m}$ digital elevation model and the highlighted pixels (red) were among the pixels used to analyze the elevation variabilities to the eastern direction. Mount Kenya region elevation map is zoomed over the selected pixels within areas of high negative bias. Rain gauge stations are in black.

The first occurs during the months of March, April, and May (MAM), referred to locally as the 'long' rainy season, and the second occurs during the months of October, November, and December (OND). The MAM rainy season has more rainy days and more intense rainfall, hence the name 'long rains.' Conversely, the OND rainy season has fewer rainy days than the MAM and rainfall is less intense. The rainy seasons are driven by the seasonal cycle of the Inter-Tropical Convergence Zone (ITCZ). The ITCZ migrates from $15^{\circ} \mathrm{S}$ to $15^{\circ} \mathrm{N}$ between January and July. This low-pressure zone is characterized by convective activities that lead to increased precipitation (Schneider, Bischoff et al. 2014). The rising air descends over the subtropical high-pressure zones, while the cold air of those highs replaces the warm ascending air, forming a circulation referred to as the Hadley circulation. Convergence in the ITCZ is enhanced by a moisture influx from easterly and westerly flows during the MAM and OND seasons. The easterly winds occur mainly during the transition between the northern and southern hemisphere summer monsoons and are enhanced by local topographic effects. Nicholson (Nicholson 2016) studied the Turkana Jet climatology and showed that the direction and force of tropospheric winds may enhance wetness or dryness over the region. The study associated the Turkana jet stream with aridity over North-eastern Kenya, Somalia, and Southern Ethiopia. Furthermore, the study revealed that the seasonality of the low-level (850 $\mathrm{mb}$ ) winds influenced convective and orographic rainfall occurrences. This means 
that wind flow can enhance or minimize the uncertainties of the satellite-derived rainfall estimates depending on the type of rainfall regime.

Monthly gridded $\left(0.05^{\circ} \times 0.05^{\circ}\right)$ rain gauge data were obtained from the ICPAC regional office in Nairobi, through the Kenya Meteorological Department (KMD). This dataset was created using interpolated, quality controlled rain gauge measurements from 284 rainfall stations over East Africa. The GeoCLIM tool with the inverse distance weighting (IDW) interpolation was used to grid the rain gauge data. The GeoCLIM tool developed by Tamuka Magadzire of the United States Geological Survey (USGS) Famine Early Warning Systems Network (FEWSNET) is a climatological tool for rainfall, temperature, and evapotranspiration analysis. It was aimed at supporting the US Agency for International Development's (USAID) Planning for Resilience in East Africa through Policy, Adaptation, Research, and Economic Development (PREPARED) Project and Global Climate Change activities. It is user-friendly and has been used with success in East Africa. The IDW is widely known for its robustness in computing ability (Zhang, Qi et al. 2014). Overall, the approach was found suitable over East Africa. Stations within the study region are shown in Figure 2.1.

TAMSAT, African Rainfall Climatology and Time series (TARCAT v 2.0) is a 30+ year gridded product. It is an updated product from TAMSAT, which is derived from Meteosat thermal infrared cold cloud duration (CCD) fields and recalibrated using available climatological datasets over African countries. The data have a spatial resolution of $0.0375^{\circ}$ and a daily/decadal/monthly temporal resolution. TARCAT covers the African continent, and data are available from January 1983 to the near present. Further data details can be found in Maidment et al. (Maidment, Grimes et al. 2014) and Tarnavsky et al. (Tarnavsky, Grimes et al. 2014).

CHIRPS is a $35+$ year quasi-global dataset developed by the United States Geological Survey (USGS) Earth Resources Observations and Science Centre and the University of California Santa Barbara Climate Hazards Group. CHIRPS is an upgrade of the original CHIRP product, and now also includes data from rain gauge stations. It has a spatial resolution of $0.05^{\circ}$, and a daily/pentad/monthly temporal resolution. It uses TRMM multi-satellite precipitation analysis version 7 to calibrate the CCD rainfall estimates. The product covers the area between $50^{\circ} \mathrm{N}$ and $50^{\circ} \mathrm{S}$, and data are available from January 1981 to the near present. CHIRPS v.1.8 data were used. Further details can be found in a study by Funk et al. (Funk, Peterson et al. 2014), and an assessment of its performance relative to other products is provided in research by Tote et al. (Tote, Patricio et al. 2015).

The TRMM-3B43 product consists of the monthly accumulations of three-hourly TRMM-3B42 and monthly GPCC data. The data have a spatial resolution of $0.25^{\circ}$, cover $50^{\circ} \mathrm{N}$ to $50^{\circ} \mathrm{S}$, and are available from January 1998 to mid-April 2015. Although this algorithm no longer provides observations, its climatological records are useful for climate studies that require historical data to understand the rainfall variability over the region, and can also be used as background information in bias corrections for better planning. Further details can be found in a study by Huffman et al. (Huffman, Adler et al. 2007).

The CMORPH is a global precipitation dataset with high spatial and temporal resolution. It uses microwave sensors for rainfall measurements and geostationary satellite infrared imageries to transport estimates between two successive microwave images. The missed estimates result from temporal gaps in microwave 
imageries. The CMORPH daily temporal resolution Version 1.0 (v1.0/crt), which blends rain gauge and satellite precipitation products, was used in this study.

It covers $60^{\circ} \mathrm{N}$ to $60^{\circ} \mathrm{S}$, and data are available from January 1998 to the near present. The data have a spatial resolution of $0.25^{\circ}$. Further details can be found in Reference (Joyce, Janowiak et al. 2004).

PERSIANN-CDR is a National Climatic Data Centre (NCDC) Climate Data Record (CDR) of the National Oceanic and Atmospheric Administration (NOAA). It contains daily rainfall estimates that were derived using the PERSIANN algorithm at a spatial resolution of $0.25^{\circ}$. It covers $60^{\circ} \mathrm{N}$ to $60^{\circ} \mathrm{S}$ over the period between 1 January 1983 and 31 December 2012. It is generated from the PERSIANN-CDR algorithm using the Gridded Satellite Infrared data (GribSat-B1) infrared data as input, and the rainfall estimates are bias corrected using the GPCP monthly data. Monthly accumulations were used. Further details can be found in Reference (Ashouri, Hsu et al. 2015).

The CMAP dataset was derived from several satellite products, the National Centre for Atmospheric Research (NCEP/NCAR) reanalysis precipitation estimates, and GPCC rain gauge data. The satellite estimates included the GOES Precipitation Index (GPI), the Outgoing Longwave Radiation (OLR)-based Precipitation Index (OPI), estimates from the Special Sensor Microwave/Imager (SSM/I) and those based on the Microwave Sounding Unit (MSU). The combined products from these sources are used to produce pentad and monthly CMAP data. The spatial resolution is $2.5^{\circ}$, and data are available from January 1979 to the near present. The area between $90^{\circ} \mathrm{N}$ and $90^{\circ} \mathrm{S}$ is covered by the product. Further details can be found in Reference (Xie and Arkin 1997).

The GPCP algorithm provides a global precipitation product at a monthly and daily temporal resolution. It was developed by the World Climate Research Program (WCRP) and the Global Energy and Water Cycle Experiment (GEWEX). It combines precipitation products from infrared, passive microwave sources and rain gauge observations. It is sensitive to low rain gauge distribution, especially in high-altitude areas if the gauges used are not adequate to characterize the spatial rainfall variability (Nijssen, O'Donnell et al. 2001). Version 2, which was used in this study, has a spatial resolution of $2.5^{\circ}$, a monthly temporal resolution, covers $90^{\circ} \mathrm{N}$ to $90^{\circ} \mathrm{S}$, and data are available from January 1979 to the near present. Further details can be found in Reference (Adler, Huffman et al. 2003).

Wind data were derived from the monthly means of daily means of low-level (850 $\mathrm{mb}$ ) zonal $(u)$, and meridional $(v)$ wind component model outputs, from the ERAInterim reanalysis data obtained from of the European Centre for Medium-Range Weather Forecasts (ECMWF). The months of March, April, May, October, November, and December, were used. The data have a spatial resolution of $0.75^{\circ}$ and are available from January 1979 to the present.

Elevation data were downloaded from the Shuttle Radar Topography Mission (SRTM) 90-m DEM (Digital Elevation Model) website (www. cgiar-csi.org/data/srtm-90mdigital-elevation-database-v4-1). The $5^{\circ}$ spatial resolution tiles were mosaicked over the East Africa region through Geographical Information System (GIS) functionality.

\subsection{Methodology}




\subsubsection{Assessments of Spatial and Temporal Characteristics}

Both the gridded rain gauge data and corresponding satellite-derived rainfall estimates were averaged over 15 years (1998-2012), for each of the months of the 'long' 'short' and rainy seasons. To allow for the comparison of all seven satellite rainfall estimates with the gridded rain gauge scales, they were converted to monthly temporal resolution. For the spatial scale, two approaches were tested: resampling by use of the nearest neighbour, and bilinear interpolations to $0.05^{\circ}$ gridded rain gauge scales. For the study area, the nearest neighbour showed the highest accuracy with a root mean square difference $(R M S D)$ within $200 \mathrm{~mm} / \mathrm{month}$, while that of the bilinear approach was approximately up to $1000 \mathrm{~mm} /$ month. The nearest neighbour minimizes the loss of pixel values from the original image when downscaled to finer scales (Suwendi \& Allebach, 2008). This is an important aspect in retaining the originality of the satellite rainfall values. Validation was accomplished by considering point-topoint comparisons of the extracted satellite-derived rainfall estimates and corresponding gridded rain gauge data from the 284 rainfall stations distributed over the region. The comparison was done monthly and yearly. Continuous statistics of correlation ( $C C)$, centered RMSD, standard deviations $(\sigma)$, and mean bias were used to quantify the relationships. Taylor diagrams (Taylor, 2001) were used for pattern analysis, equations (2.1)-(2.4)).

$$
\begin{gathered}
c c=\frac{\frac{1}{N} \sum_{i=1}^{N}\left(s_{i}-\bar{s}\right)\left(g_{i}-\bar{g}\right)}{\sigma_{s} \sigma_{g}} \\
R M S D=\sqrt{\frac{1}{N} \sum_{i=1}^{N}\left(s_{i}-g_{i}\right)^{2}} \\
\sigma_{s}=\sqrt{\frac{1}{N} \sum_{i=1}^{N}\left(s_{i}-\bar{s}\right)^{2}} \\
\sigma_{g}=\sqrt{\frac{1}{N} \sum_{i=1}^{N}\left(g_{i}-\bar{g}\right)^{2}}
\end{gathered}
$$

where $s_{i}$ are the satellite rainfall estimates, $g_{i}$ is the gridded rain gauge data, over bar is the mean, $\sigma_{s}, \sigma_{g}$ are the respective standard deviations of the satellite $(s)$ and gridded rain gauge datasets $(g)$, and $N$ is the number of samples considered. The mean squared error (MSE) criterion was used to evaluate the overall accuracy of the 
monthly satellite rainfall products for each month of the rainy season. The MSE was decomposed into three terms: error in the mean, variance, and correlation, as shown in Equation (2.5) (Gupta, Kling, Yilmaz, \& Martinez, 2009).

$$
M S E=2 \cdot \sigma_{s} \cdot \sigma_{g} \cdot(1-c c)+\left(\sigma_{s}-\sigma_{g}\right)^{2}+(\bar{s}-\bar{g})^{2}
$$

where $\bar{s}$ and $\bar{g}$ are the respective means of the satellite (s) and gridded rain gauge ( $g$ ) data.

The relative contribution of each of these components to the overall MSE can be computed as shown in Equations (2.6)-(2.9).

$$
\begin{gathered}
f_{i}=\frac{F_{i}}{\sum_{i=1}^{3} F_{i}} \\
F_{1}=2 \cdot \sigma_{s} \cdot \sigma_{g} \cdot(1-c c) \\
F_{2}=\left(\sigma_{s}-\sigma_{g}\right)^{2} \\
F_{3}=(\bar{s}-\bar{g})^{2}
\end{gathered}
$$

where $F_{i}$ represents the error component terms given in Equation (2.5); correlation $\left(F_{1}\right)$, variance $\left(F_{2}\right)$, and mean $\left(F_{3}\right)$, respectively. The three components contribute to the total MSE for the specific month and the largest value of the three would, therefore, be the dominant contributor to the total error.

Furthermore, the quality of each of the satellite products was temporally assessed using corresponding gridded rain gauge data on a yearly basis by use of the mean bias (Equation (2.10)). Similar to monthly assessments, only the rainfall values of pixels collocated at the 284 rainfall stations were considered.

$$
\text { Mean Bias }=\frac{\sum_{i=1}^{N}\left(s_{i}-g_{i}\right)}{N}
$$

\subsubsection{Assessments of Seasonal Influences}

Although East Africa can be dominated by convective rainfall, the presence of mountains induces orographic rainfall and the two coexist with one type being more dominant than the other during the rainy seasons. In this study, the seasonality of the dominant rainfall type for each season was established with the aid of mean low $(850 \mathrm{mb})$ wind flow. Since moisture influx to the high elevated areas is induced by winds, the direction of wind flow during the rainy months is important. The peak rainfall months of April and November for the MAM and OND seasons, respectively, 
were used to establish these links. Equations (2.11)-(2.13) provide the description of the wind analysis.

$$
\begin{gathered}
W_{r}=\sqrt{\left(u^{2}+v^{2}\right)} \\
W_{\text {trig }}=\operatorname{atan}\left(\frac{u}{v}\right) \\
W_{\text {deg }}=W_{\text {trig }} \times\left(\frac{180}{\pi}\right)
\end{gathered}
$$

where $u$ and $v$ are the east-west (zonal) and north-south (meridional) wind components of model output in $m s^{-1}$, and $W_{r}$ is the wind magnitude. Wind magnitude is converted to wind direction $\left(W_{\text {trig }}\right)$ in radians and then to degrees $\left(W_{\text {deg }}\right)$.

\subsubsection{Assessments of Topographic Impacts}

The presence of different landscapes that include mountains, low lands, and inland water bodies in East Africa can greatly affect rainfall variability at a small distance. Assessments of the elevation variations within the pixels were done to the original $90 \mathrm{~m}$ spatial scale corresponding to selected pixels on the eastern side of Mount Kenya, which was identified as having a large bias. Further, assessments were made of the effects of the elevation variability on the performance of the satellite rainfall products. For compatibility of the two data sets, the elevation map was resampled using the nearest neighbour to a $0.05^{\circ}$ spatial scale of the satellite rainfall mean bias. The effect of resampling on the elevation values was minimal and the relationship between elevation and bias was similar in resampled and nonresampled elevations. Pixels were selected from the point of the highest negative bias (Mount Kenya) to the north, south, east, northeast, and southeast. The mean bias derived from the rainfall averages (1998-2012) were extracted for the peak rainfall months of April and November. These two months have the highest rainfall amount during the MAM and OND rainfall seasons. For each product, changes in mean bias from one elevation range to another, as represented by different pixels, were determined.

\subsection{Results}

\subsubsection{Performance of Monthly Satellite Rainfall Products}


In this section, the patterns of monthly rainfall averages from the gridded $\left(0.05^{\circ}\right)$ rain gauge data and corresponding satellite rainfall product (TARCAT, CHIRPS, TRMM, CMORPH, PERSIANN-CDR CMAP, and GPCP) were compared. Grid-based statistical comparison between the two datasets was used, while a point-based comparison between the rain gauges and the satellite pixels that contain the rain gauges were used for validation.

Figure 2.2 shows the Taylor diagrams that describe the monthly performance of satellite-derived rainfall estimates in relation to the gridded rain gauge data across East Africa, for the MAM and OND rainy seasons. During the MAM season, the performance of all satellite products is lower when rainfall intensity is high. CHIRPS, CMORPH, and TRMM show the highest correlation coefficient $(c C)(>0.7)$ and lowest RMSD. Conversely, TARCAT, PERSIANN-CDR, CMAP, and GPCP showed poor performance. TARCAT has been developed primarily for drought monitoring applications. This optimization for low rainfall intensities could explain the poor performance during months with heavy rain. Moreover, TARCAT's single (IR) sensor algorithm is not conducive to achieving high accuracy rainfall estimates.

During the OND rainy season, rainfall amounts decreased compared to MAM, but the products showed a general decrease in performance. The decrease in the performance of the products was an indication that their performance was not only influenced by the rainfall intensity per se, but also by the rainfall regimes. The lowest performance was, however, observed during the peak rainfall month of November. This was demonstrated by the decreased $c c$ and increased RMSD. CHIRPS, CMORPH, and TRMM-3B43 similarly had the highest performance for the MAM season.
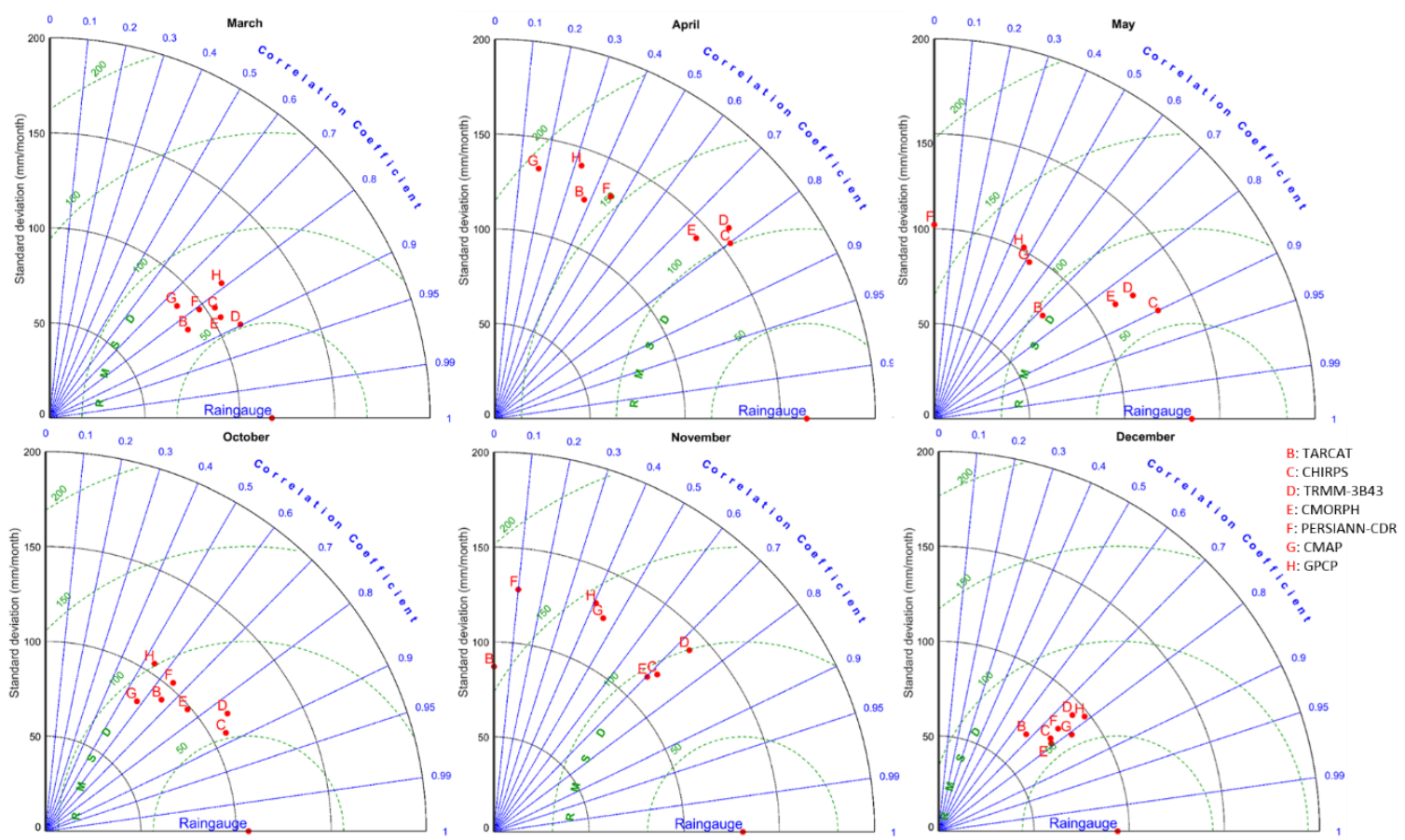
Figure 2. 2:Taylor diagrams displaying a statistical comparison between gridded rain gauge data and seven satellite-derived rainfall products per month for the wet months from March to May and October to December over a period of 15 years (1998-2012).

Figure 2.3 shows the correlation, variance, and mean error contributions to MSE for each satellite product with respect to the 284 rainfall stations considered for validation. It clearly shows that nearly all the satellite rainfall products showed large correlation and mean error contributions. This is an indication of discrepancies between the two datasets in detection and retrieval capability.

The products showed varying detection and retrieval potentials for the six months considered. It is remarkable that all products showed a high ability to represent spatial rainfall variability, as indicated by the lowest variance errors $(<0.2)$.
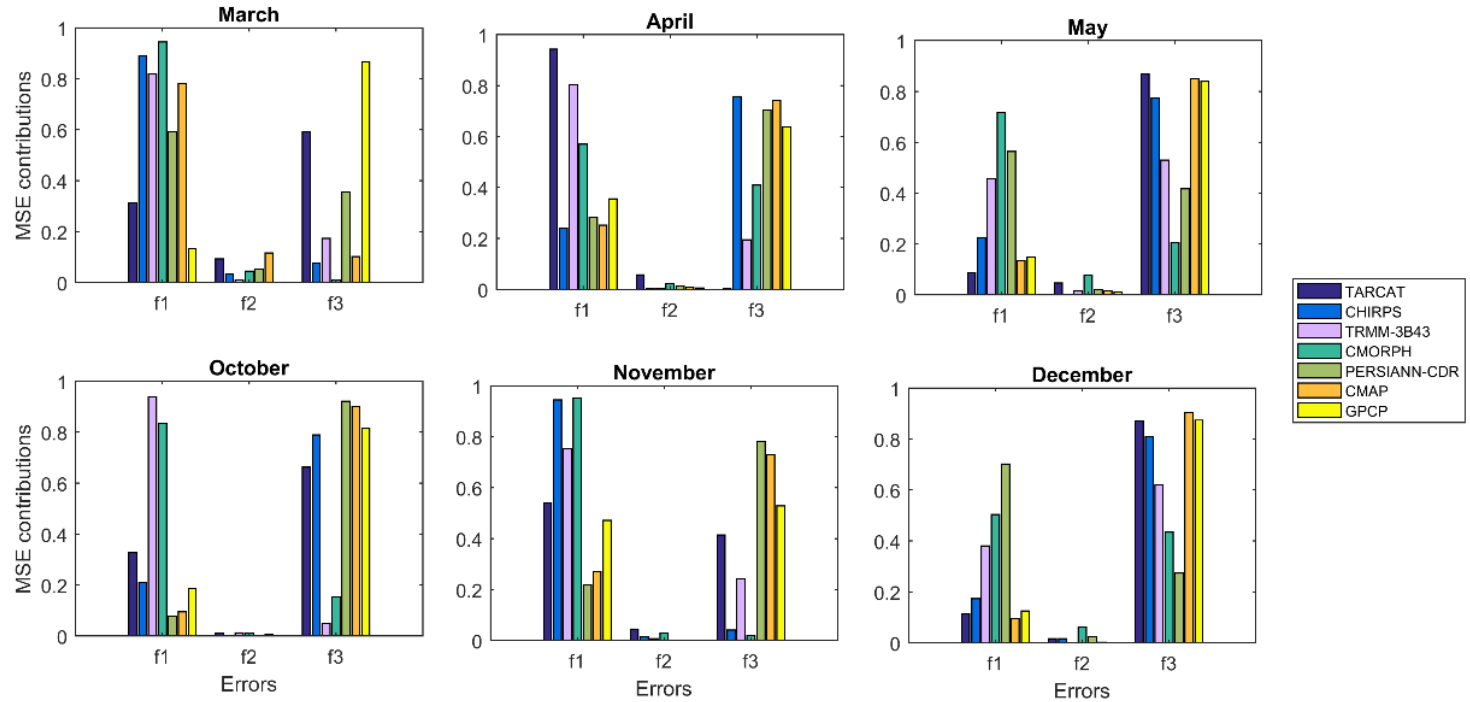

Figure 2. 3: Mean squared error (MSE) contributions by the correlation ( $f 1$ ), variance (f2), and the mean (f3) components derived from the satellite averages of the rainfall estimates (1998-2012) with respect to the rain gauge data.

Figure 2.4 shows bias variations for each product per year during the peak rainfall month (April) of the MAM season. All products apart from CHIRPS and TRMM-3B43 have varying large biases. TARCAT and CMORPH also have a low bias, but with remarkable underestimations around the year 2001 which was one of the driest year over the region(C. Funk et al., 2014). This reflects the fact that TARCAT was optimized for accurate rainfall estimation during drier periods. Although CMAP has a slightly higher bias, it shows consistency. PERSIANN-CDR and GPCP show the highest bias variations. Furthermore, the two products show similar trends, which is expected, as GPCP data are used for the calibration of PERSIANN-CDR. Their similar patterns of bias are an indication of a systematic bias which may be 
attributed to the input rain gauge. The GPCP is sensitive to rain gauge distributions (Li \& Fu, 2005) as is PERSIANN-CDR (Miao, Ashouri, Hsu, Sorooshian, \& Duan, 2015).
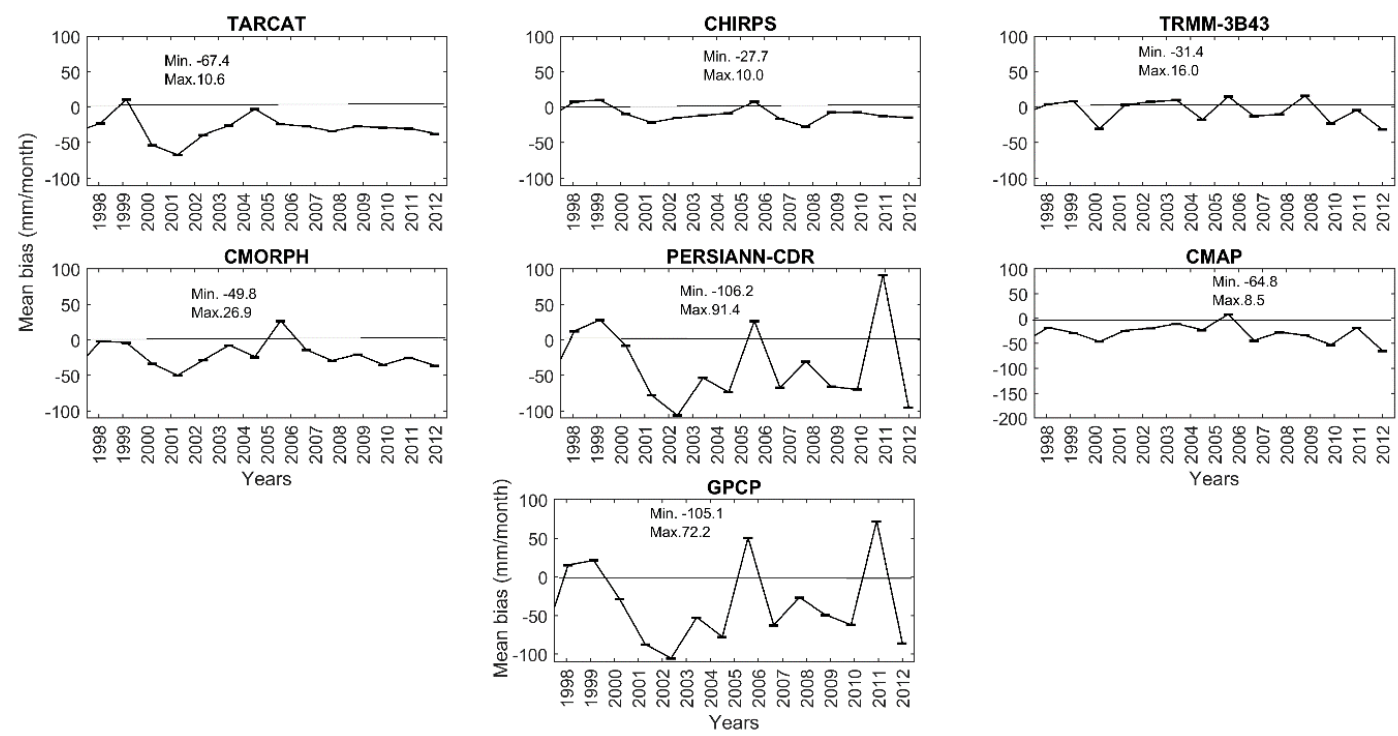

Figure 2. 4: Monthly mean bias ( $\mathrm{mm} / \mathrm{month}$ ) of satellite rainfall products in April (1998-2012).

Figure 2.5 shows the bias variations for each product per year during the peak rainfall month (November) of the OND season. During this season, the bias of the satellite products were more uniform, with a general underestimation by TARCAT in 2006, a year in which East Africa received heavy rainfall (Gamoyo, Reason, \& Obura, 2015). It is remarkable that CMAP shows a general uniform low bias throughout the years. TRMM shows overestimation from 2003-2004, which were among the driest years observed over the region. From the two peak months (April and November) a significant observation is the reduction of the mean bias in November compared with April, and, in general, systematic underestimation is observed for most products with the reduction of rainfall concurring with previous results. 

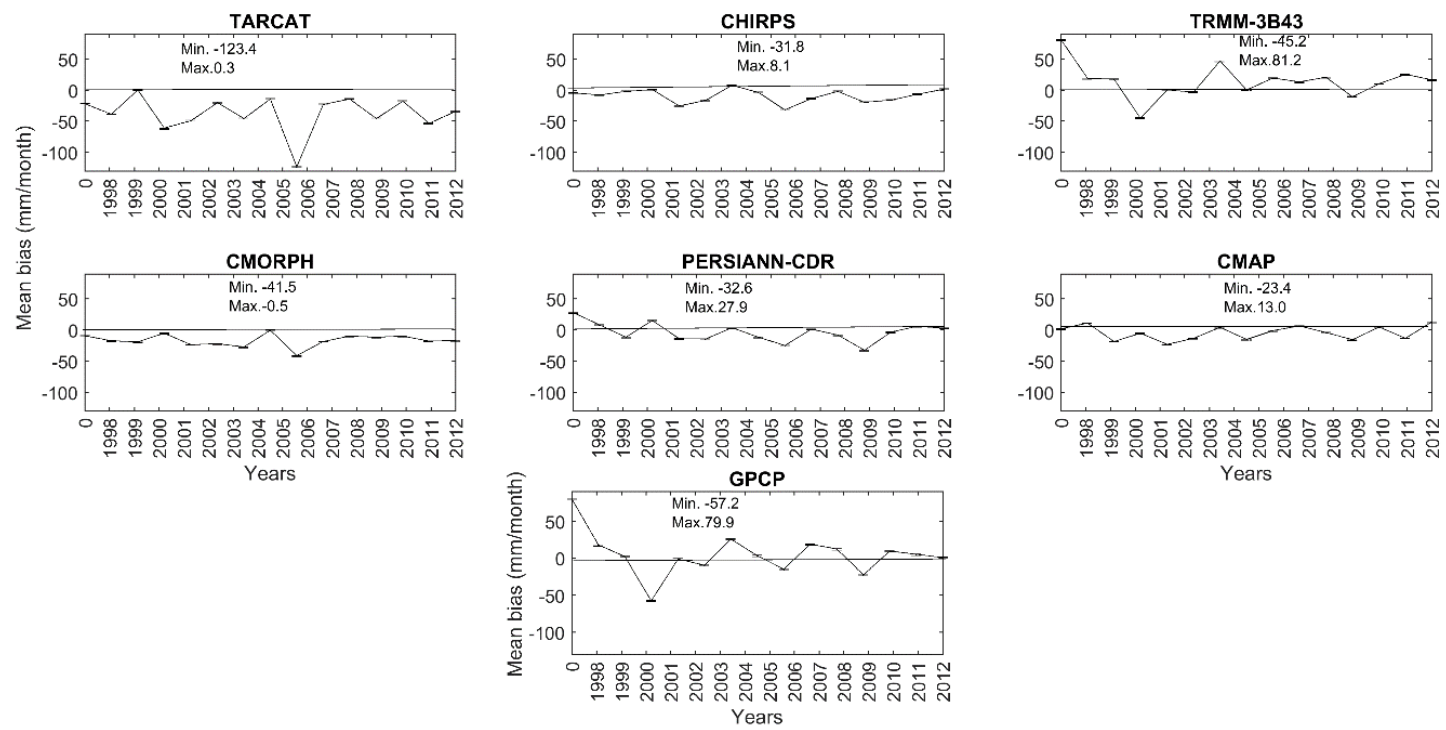

Figure 2. 5: Monthly mean bias ( $\mathrm{mm} / \mathrm{month}$ ) of satellite rainfall products in November (1998-2012).

\subsubsection{Seasonal Influences on the Performance of Satellite Products}

The link between the performance of satellite rainfall products and different rainfall regimes (convective and orographic processes) in retrieving rainfall over East Africa was assessed by analyzing wind patterns. It is worth noting the role of the wind direction in determining the dominant rainfall regime over the region. Figure 2.6 shows the low $(850 \mathrm{mb})$ mean wind direction patterns. During the season of MAM (as represented by the month of April) rainfall is both convective and orographic. Wind convergence (westerlies and easterlies) along Lake Victoria and Uganda, on the Kenyan border enhances convective systems, while orographic rainfalls occur over the highlands. Satellite rainfall products can detect more convective rainfall due to the use of infrared sensors in retrieval. This is observable in the spatial maps of less mean bias for the month of April in Figure 2.7 in areas of wind convergence. Negative bias was more dominant and corresponded to areas of higher rainfall amounts, particularly around Mount Kenya, which is within the Kenyan highlands (Figure 2.1). It is worth noting that spatial maps include Pemba and Zanzibar, which are Tanzania's islands, and in this analysis Zanzibar is the area with the largest negative bias ( $<-300 \mathrm{~mm} / \mathrm{month}$ ) because there was no rain gauge data over this area.

When considering inland areas, the largest negative biases are found in the Kenyan highlands. All products except CHIRPS, TRMM-3B43, and CMORPH showed large underestimations over this area. This can be attributed to their ability to retrieve the rainfall of different regimes that coexist during this season. TARCAT showed the highest underestimation, which can be attributed to its single infrared sensor that 
failed to capture warm orographic rainfall. The coarse resolution of CMAP and GPCP could have contributed to them missing the localized high rainfall in high ground areas, while PERSSIAN-CDR (which is calibrated with GPCP) shows similar patterns. Other areas of high bias are the Lake Victoria region, which all products seemed to underestimate, except CMORPH and TRMM-3B43, which both showed overestimation. Over Southern and Central Tanzania (in the high-altitude areas), CHIRPS and TRMM-3B43 showed overestimation of high rainfall amounts.
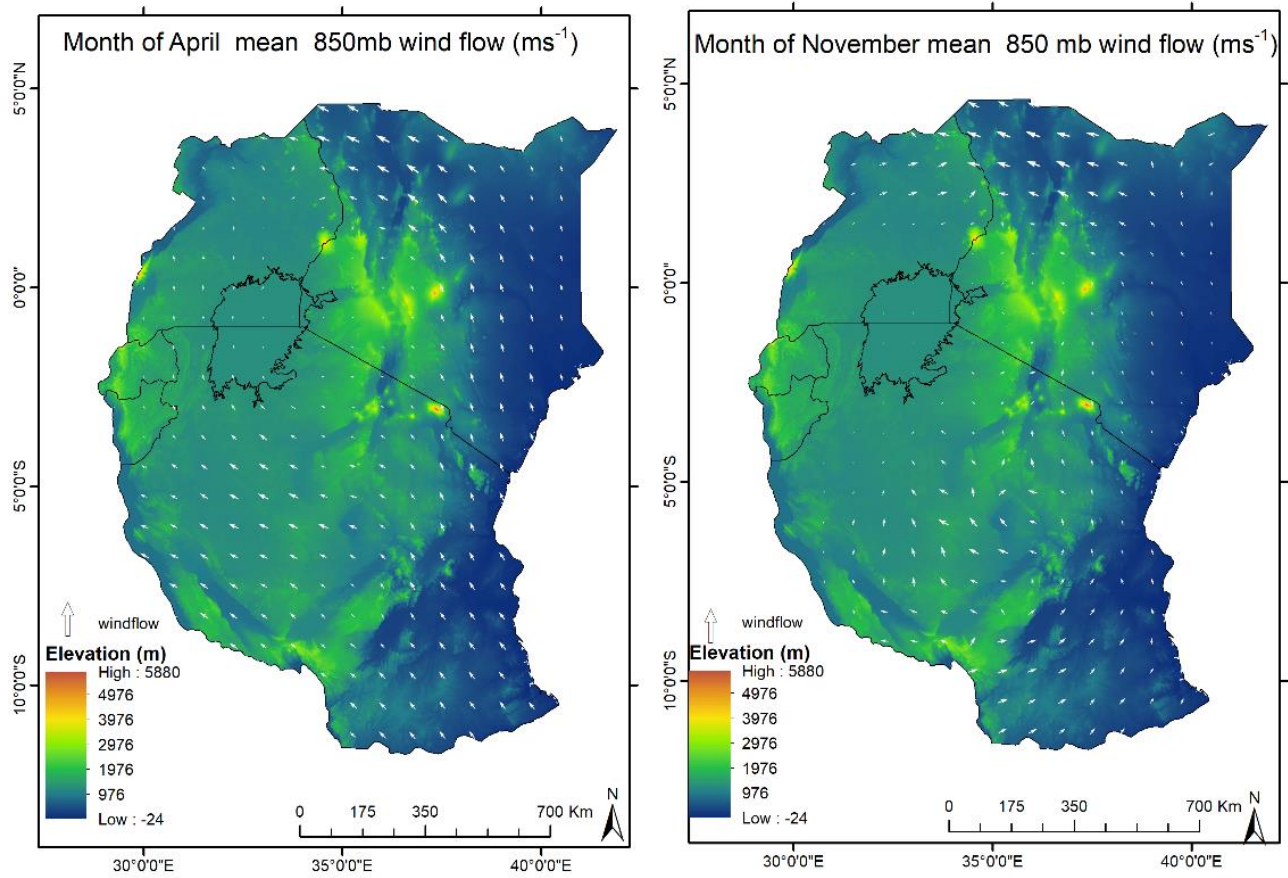

Figure 2. 6: Mean low level $(850 \mathrm{mb})$ wind direction flow during the months of April and November (1998-2012) over the region of East Africa. The size of the wind arrow indicates the wind magnitude strength (the larger the arrow head, the higher the wind speed). 

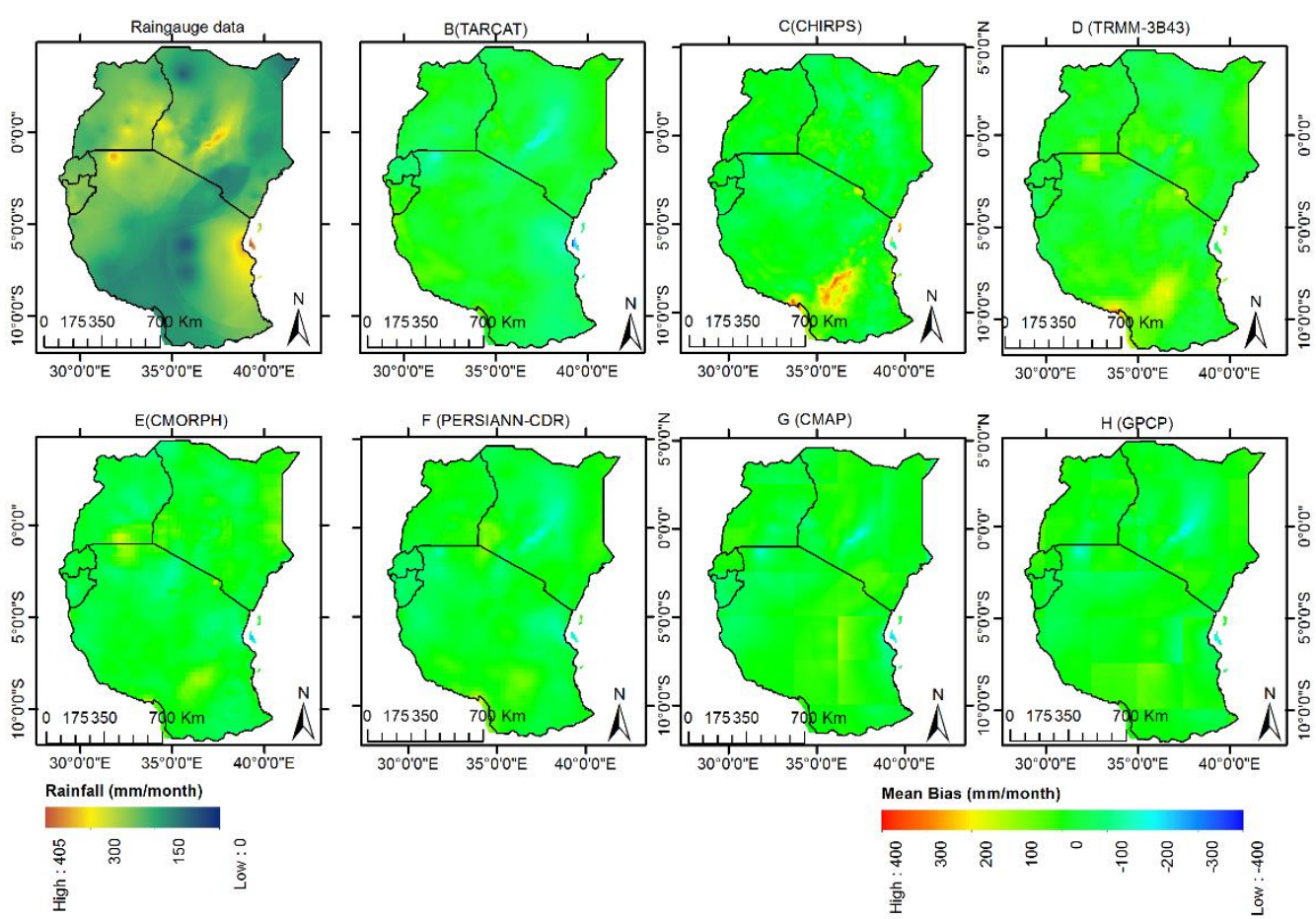

Figure 2. 7: Mean bias derived from averages in April (1998-2012) between satellite rainfall estimates and corresponding gridded rain gauge data for East Africa.

The month of November (Figure 2.8) was marked with a decreased rainfall amount in most parts of the region except for the Kenyan highlands and the Lake Victoria areas. During the OND season (as represented by the month of November), orographic rainfall dominated. Figure 2.6 shows this seasonality as a change in the mean direction of the low $(850 \mathrm{mb})$ level wind flow. In the month of April, southeasterly winds from the Indian Ocean dominate and import moisture influx to the region. However, in the month of November, the winds become diffluent as they enter inland, reducing the influx of moisture inland. This reduces inland rainfall in November, as it is shown that most rain occurs over the central highlands of Kenya. This results from the trapped moisture on the elevated areas, which is inhibited further inland by the highlands. Furthermore, the south-easterly winds cut off moisture over Northeast and East Kenya. Consequently, the negative bias of the satellite products seems to increase over the Kenyan highlands. Unlike the month of April, where CHIRPS, TRMM-3B43, and CMORPH showed low biases, in the month of November during the OND season, the negative bias was evident. This is an indication that although they differ in rain rate retrieval performance, all products have difficulties in accurately retrieving orographic rainfall. A positive bias over Lake Victoria by TRMM, CMORPH, and PERSIANN-CDR was evident. However, the overestimation observed over Central Tanzania in April was reduced (except for 
TARCAT) as it was observed mainly during MAM season It can be understood that

TARCAT is sensitive to low rainfall amounts as it is designed for drought monitoring.
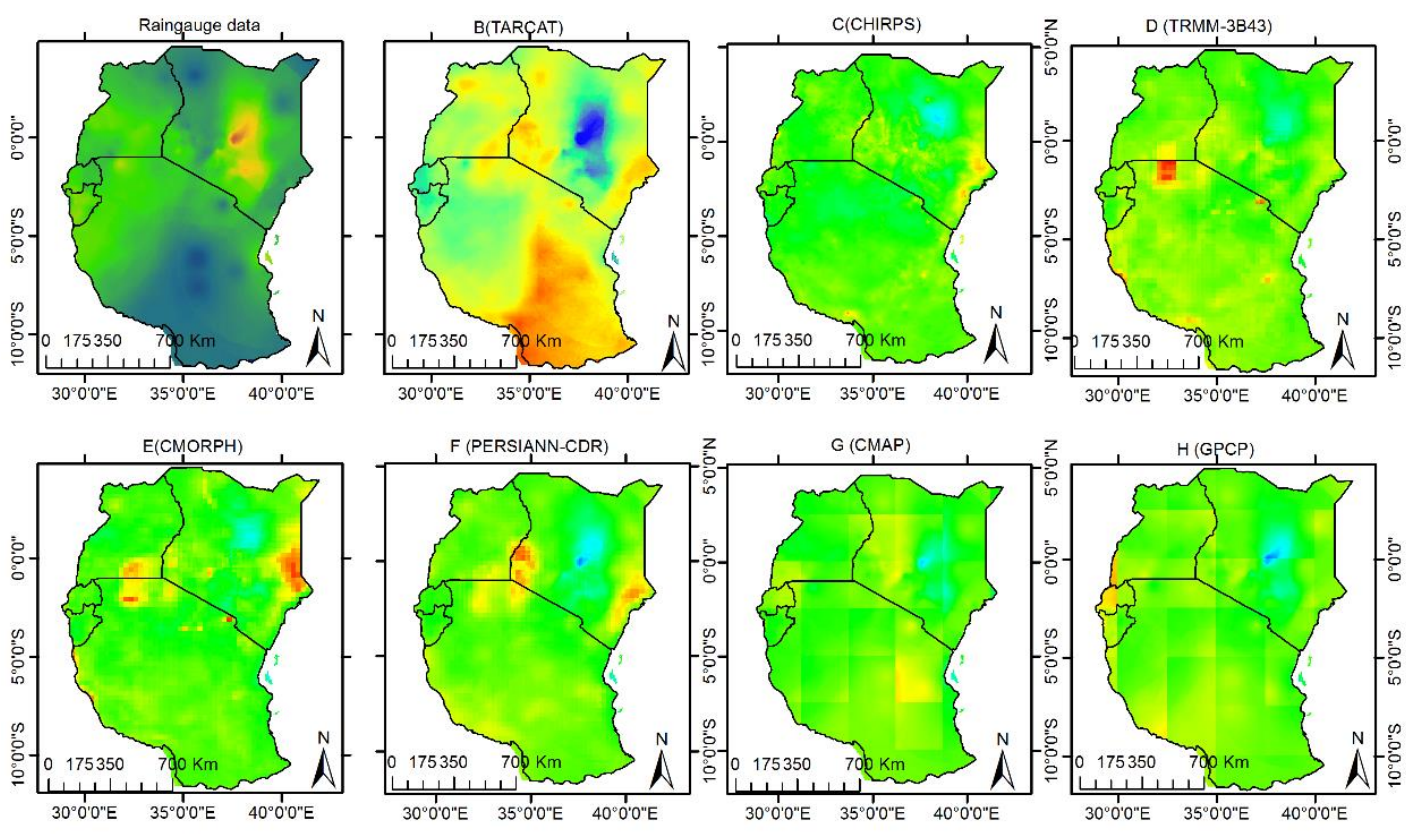

Rainfall (mm/month)
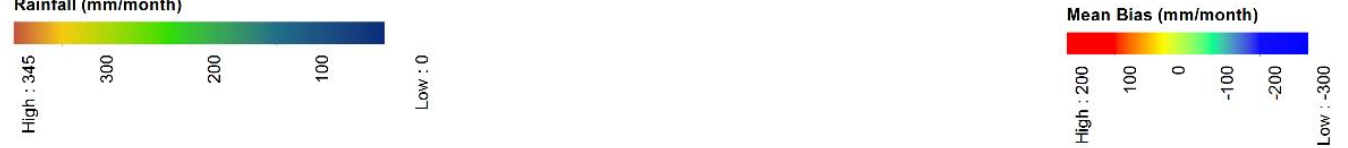

Figure 2. 8: Mean bias derived from averages in November (1998-2012) between satellite rainfall estimates and corresponding gridded rain gauge data for East Africa.

Quantification of the spatial mean bias was done using correlation maps. Figures 2.9 and 2.10 show spatial maps of the correlation coefficients of satellite rainfall products with respect to the corresponding rain gauge data for the months of April and November. In April (Figure 2.9), it is clearly shown that low (0.1) correlation coefficients (insignificant at a $95 \%$ confidence level) by the products were in high rainfall areas, especially around Lake Victoria. In November (Figure 2.10), rainfall amounts reduced, and the performance of the products also improved, which is particularly visible in the increase of the correlation coefficients. This is in agreement with earlier findings during the MAM season, where increased rainfall amounts resulted in decreasing the satellite product's performance. 

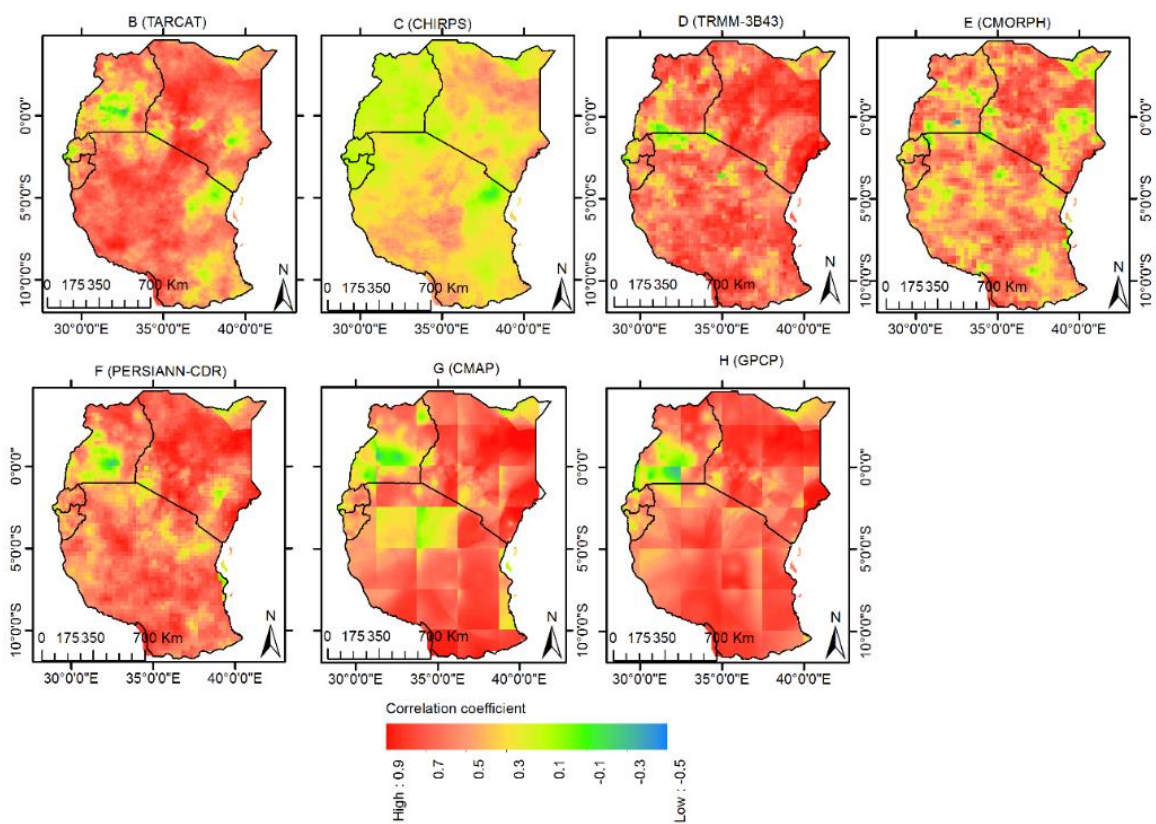

Figure 2. 9: Correlation coefficients derived from rainfall averages in April (1998-2012) between satellite rainfall estimates and corresponding gridded rain gauge data for East Africa.
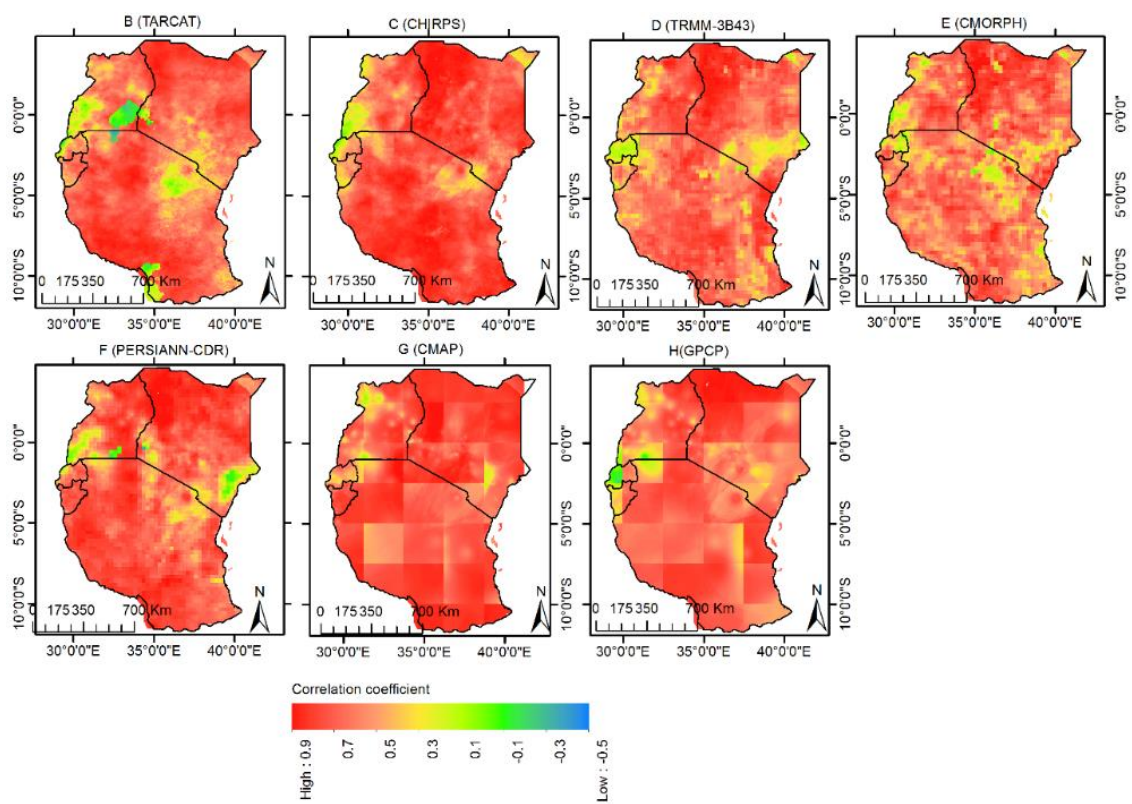
Figure 2. 10: Correlation coefficients derived from rainfall averages in November (1998-2012) between satellite rainfall estimates and corresponding gridded rain gauge data for East Africa.

\subsubsection{Topographic Influence on the Performance of Satellite Products}

Topographic impacts on the performance of each product were investigated by analyzing elevation variations where large underestimations were identified in satellite rainfall products in high ground areas within the Mount Kenya region. Figure 2.11 shows the elevation variations within selected pixels (Figure 2.1) which are to the eastern side of Mount Kenya, part of the area with the largest negative bias. The elevation was extracted from the 90-m DEM values that corresponds to the $0.05^{\circ}$ area. As can be observed from this figure, elevation variations within the pixels decrease as the elevation increases from $1500 \mathrm{~m}$ to $4500 \mathrm{~m}$. This is observable by the number of pixels with different elevation values in one pixel. It is therefore evident that at the pixel scale $\left(0.05^{\circ}\right)$, elevation variation impact is minimal. Further, assessments of the cause of the large bias were done by considering each product's mean bias in the peak months of April and November of the MAM and OND seasons, respectively. Pixels for analysis were selected from five directions which are the north, south, east, northeast, and southeast of Mount Kenya. The western side was omitted, as a lower bias was observed on that side. Bias values for each product for the two rainy months were extracted, as was the corresponding elevation for a number of the pixels. The mean bias variability for each product relative to changes in elevation from pixel to pixel was determined. Figures 2.12 and 2.13 show the scatter plots of bias variations for each month to the respective pixel's mean elevation value. It is evident during the month of April (Figure 9) that CHIRPS and TRMM-3B43 showed overestimation mainly above $2500 \mathrm{~m}$. This is attributed to high rainfall amounts in high ground areas during the MAM season. It is good to note that the two showed overestimations around Lake Victoria in previous findings, and this can be understood by the trend that these two areas receive the highest rainfall over the region. Conversely, TARCAT, PERSIANN-CDR, CMAP, and GPCP show underestimations. It can be understood that both convective and orographic rainfall coexist during this season of MAM. The underestimation is more evident to the southeast and the south, which corresponds to the mean wind flow directions. In addition, during this season there is an increase of negative bias with an increase in height, which can be attributed to increased stratifications in deep convections during the MAM season. Elevation impacts related to orographic rainfall occur at low levels compared to convective systems, and this is clearly observed below $2500 \mathrm{~m}$. Microwave-based products like TRMM-3B43 show the least topographic effect as they are able to retrieve different rainfall regimes, unlike infrared-based products, which consider warm orographic clouds as nonprecipitating. During this season, the wind is southerly, parallel to the Kenyan highlands, and stronger. Consequently, the negative bias is more evident to the southern and south-eastern part of Mount Kenya in all the products and varies with elevation changes.

As shown in Section 4.2, orographic rainfall is more dominant during the OND season, as less convergence is experienced over the region. It is evident from Figure 12 that all the products show underestimations that correspond with elevation variations to the eastern and north-eastern side of Mount Kenya. This follows the 
wind patterns, as in November the wind is on the north-easterly side of Mount Kenya and low in speed. Further, the decrease in deep convective systems during this season is shown by fewer overestimations observed by the same products (CHIRPS and TRMM-3B43). In addition, it can be shown that an increase in negative bias, which was evident during the MAM season, is minimal and is only evident near the transition level $(2500 \mathrm{~m})$. Again, similar to the analysis for April, below about 2500 $m$ the effects of elevation are evident on all products.

Overall, during the two months, CHIRPS, CMORPH, and TRMM-3B43 showed the lowest negative bias in both rainfall regimes, which is similar to a study that shows they perform well in high elevated areas [8].

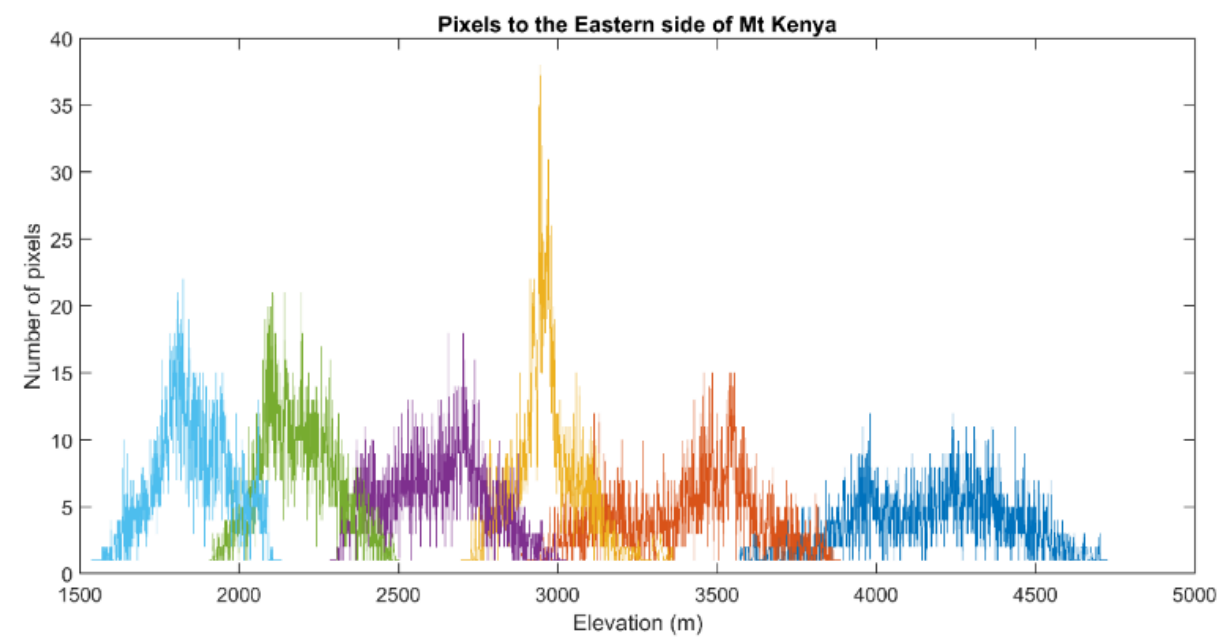

Figure 2. 11: Elevation $(m)$ variations of selected pixels from near Mount Kenya eastward, which are among the areas identified with a high negative bias of varying magnitudes by all satellite rainfall products. Different colors represent the elevation variabilities from one satellite pixel to another. 

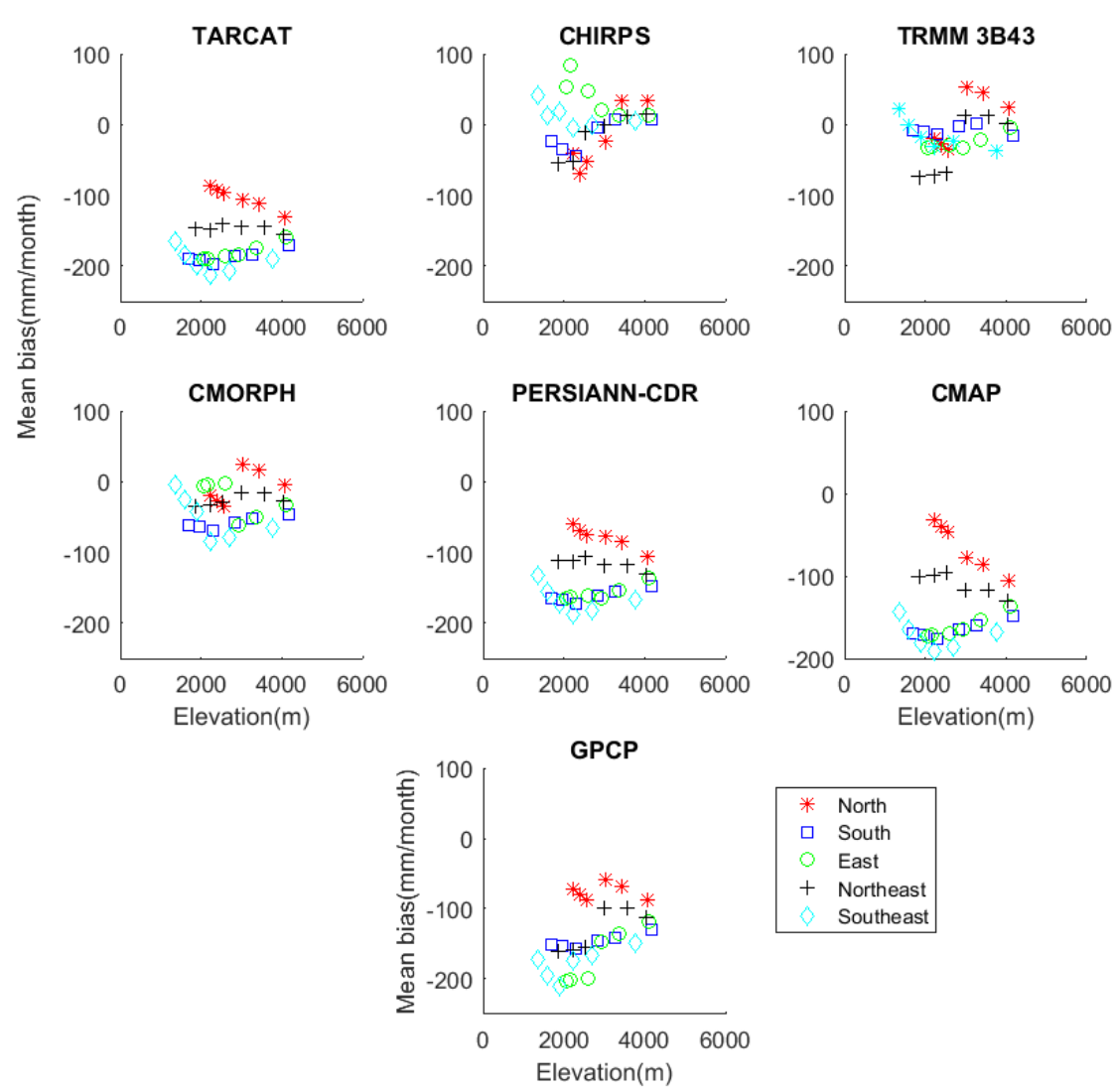

Figure 2. 12: Scatter plots of the mean bias of satellite rainfall estimates in relation to the elevation variations derived from the rainfall averages (1998-2012) with respect to the rain gauge data during the peak rainfall month of April of the MAM season, over the Kenyan highlands where Mount Kenya is located. The five directions from Mount Kenya to the north, south, east, northeast, and southeast are shown for each product. 

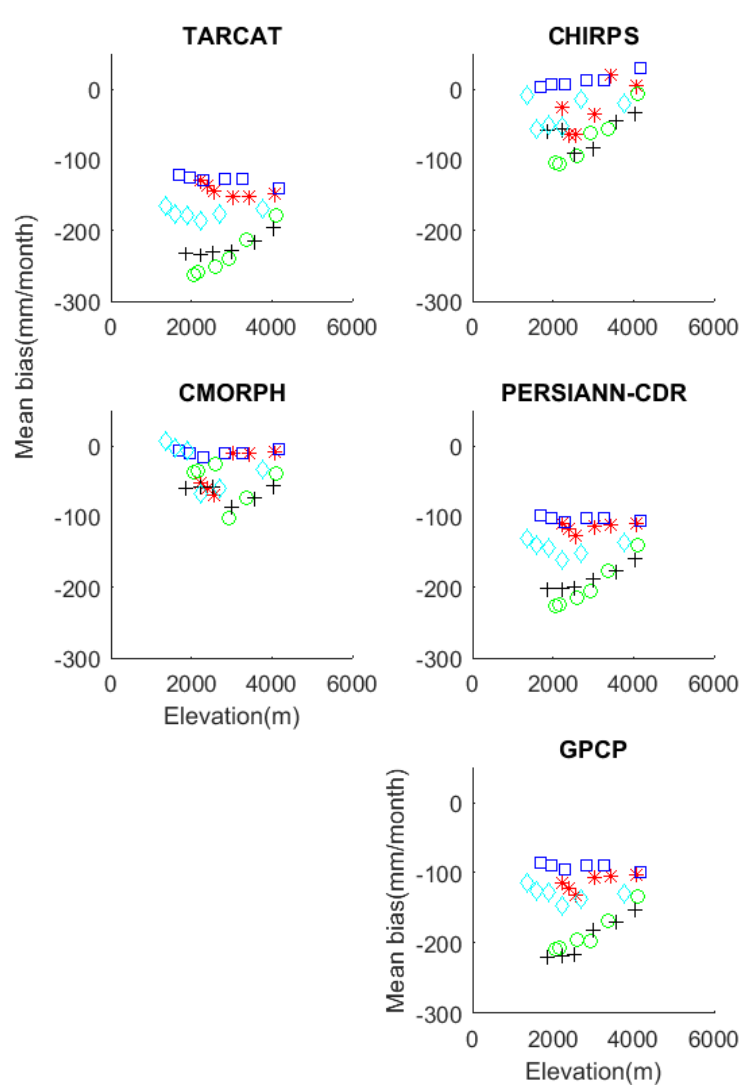
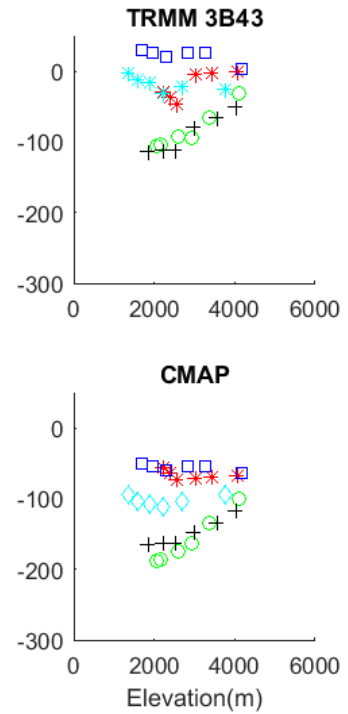

$$
\begin{array}{|ll|}
\hline * & \text { North } \\
\square & \text { South } \\
& \text { East } \\
+ & \text { Northeast } \\
& \text { Southeast } \\
\hline
\end{array}
$$

Figure 2. 13: Mean bias of satellite rainfall estimates in relation to the elevation variations derived from the rainfall averages (1998-2012) with respect to the rain gauge data during the peak rainfall month of November in the OND season, over the Kenyan highlands where Mount Kenya is located. The five directions from Mount Kenya to the north, south, east, northeast, and southeast are shown for each product.

\subsection{Discussion}

This study assessed the spatial and temporal performance of seven satellite-derived rainfall products: TARCAT, CHIRPS, TRMM (3B43), CMORPH, PERSIANN-CDR, CMAP, and $G P C P$, in relation to the gridded rain gauge data over East Africa. These evaluations are essential in promoting the use of satellite-derived rainfall estimates in water resource management applications and agricultural practices. Additionally, the inter-comparison between these products in relation to the gridded rain gauge data will enable end users to select the appropriate products for a given season and application. The products were converted to monthly spatial scales and resampled using nearest neighbour resampling to the spatial scale $\left(0.05^{\circ}\right)$ of the rain gauge data. The evaluation was conducted at two temporal scales, monthly and yearly. 
The monthly satellite rainfall products showed close agreement with the gridded rain gauge data in the spatial representation of rainfall in most areas. Error metrics revealed that only about $10 \%$ of the total mean squared errors is contributed by the variance of the satellite rainfall products. The discrepancies of the satellite rainfall products and rain gauge data showed an increase with an increase in the rainfall amount. This was evident during the peak rainfall months of April and November. These results concurred with a recent study (Maggioni, Sapiano, \& Adler, 2016) that indicated that satellite rainfall products have both systematic and random errors, and that these increase with an increase in rainfall amounts. The products differed in their performances, with TRMM-3B43 and CMORPH showing the highest performance in both monthly and yearly evaluations. In high elevated areas, all products except for CHIRPS, TRMM-3B43, and CMORPH showed significant underestimations.

A yearly analysis of bias showed a reduction in mean bias. It was also observed that PERSIANN-CDR and GPCP had a similar bias trend, which was attributed to their high sensitivity to rain gauge distributions (Gebremichael et al., 2003; Miao et al., 2015 ) over the region, which are also included in these algorithms. The two products also showed high fluctuating bias, which indicated that their errors are random. In yearly analysis of bias, TARCAT showed the highest underestimation $(-123.4 \mathrm{~mm}$ month $^{-1}$ ) in November 2006. During this month, heavy rainfall was experienced over East Africa causing floods (Gamoyo et al., 2015), and these findings clearly confirm that TARCAT can underestimate heavy rainfall.

In addition, seasonality corresponded with the existence of different rainfall regimes. This aspect was well captured by the seasonal low-level $(850 \mathrm{mb})$ winds' mean direction. This study showed that during the MAM seasons, convective systems were dominated by the low-level wind convergence between the westerlies and easterlies, which mainly occurred around Lake Victoria and in Western Kenya (the Kenya/Uganda border). Furthermore, the south easterlies enhanced rainfall in relation to the orientation of high-altitude areas. All products showed low performance in retrieving high rainfall amounts during the peak rainfall month of April; however, CHIRPS, TRMM-3B43, and CMORPH showed less bias over high ground areas. During the OND season, the wind diffluence divided into southeasterly and north-easterly directions as it entered inland from the Indian Ocean. Moisture influx inland was then reduced and, consequently, convergence activities became minimal.

The differences in product performance were attributable to their input data, hence their limitation in capturing different rainfall regimes. Rainfall retrieval derived from infrared imageries relate cold clouds to high rainfall rates (Maidment et al., 2014), but over mountainous areas, warm cloud orographic processes drive most of the rainfall over East Africa. Consequently, IR-based satellite products underestimate rainfall over high-altitude areas. PERSIANN-CDR uses infrared only data as an input, and as such it underestimates warm orographic processes. This is particularly the case during the OND season when rainfall is dominantly orographic induced. However, the products could detect areas of rainfall occurrence, indicated by the significant correlation coefficient of $>0.5$ during this season by all the products. TARCAT is an example of a single infrared sensor product (Diem, Hartter, Ryan, \& Palace, 2014), and showed the lowest performance in retrieving orographic rainfall; it uses gauge data for calibration from a climatological dataset-not real-timewhich is a completely different approach adopted to solve the low density of gauge observations for this area. In areas where elevation is $>2500 \mathrm{~m}$ (such as over the Kenyan highlands, where Mount Kenya is located), the products showed large 
underestimation. The remarkable performance by CHIRPS and TRMM-3B43 can be attributed to the direct inclusion of rain gauge data and microwave images during calibration. However, for $\mathrm{CMORPH}$, interpolated microwave rainfall retrieval using infrared imageries may have affected its performance.

Error characteristics of satellite rainfall products in mountainous areas reveal topographic impacts, which are associated with systematic errors. The cause of the low negative bias over the high ground areas around the Mount Kenya region was then investigated in the peak rainfall months of April and November during the MAM and OND seasons, respectively. Use was made of spatial mean bias maps (Figures 7 and 8) to extract the mean bias of selected pixels. Variations of elevation within individual satellite products' pixels relative to their mean biases were investigated. This was to determine how elevation changes within each pixel could be related to the variability in the products' bias. Results showed minimal elevation variations within individual pixels. Further, assessments were done on the effects of the elevation variability from pixel to pixel related to the performance of each satellite rainfall product. Pixels were selected from areas of the highest negative bias to the north, south, east, northeast and southeast of Mount Kenya, and these orientations were chosen to establish which sides of Mount Kenya have the largest impact. For each product, changes in the mean bias from one month to another, which represent the MAM and OND rainfall seasons respectively, were determined. For the pixels considered, elevation variations from pixel to pixel are related to the satellite rainfall products' performance. The impact is both seasonal and varies from one product to another. During the MAM season, as represented by the peak rainfall month of April, when both convective and orographic rainfall coexisted, both overestimation and underestimation were observed. CHIRPS and TRMM-3B43 showed slight overestimation when the elevation was above $2500 \mathrm{~m}$ and underestimations when elevation was below this, while others show underestimations. The overestimations are associated with high rainfall amounts common in the mountainous areas and similar to what was observed over the Lake Victoria region. The elevation impact is similar to a study (Bharti \& Singh, 2015) whose findings revealed $3100 \mathrm{~m}$ to be the level above which overestimation occurs and below which underestimation is observed for (TRMM)3B42 V7. The difference in the cut-off elevation shows the dependence on geographical location and season, and varies from product to product. The deep convective systems during the MAM season coexist with stratified clouds which are warmer and at a lower level, and this was associated with a negative bias at high levels. During the OND season, orographic rainfall becomes more dominant as less convergence is experienced over the region. This is evident by the slight reductions in overestimations by both CHIRPS and TRMM-3B43. Similar to the MAM season, underestimations by all products when elevation was $<2500 \mathrm{~m}$ was observed, mainly to the windward side to the east and northeast of Mount Kenya. The windward side receives more orographic rainfall than the leeward side (southern to southeast). CHIRPS, CMORPH, and TRMM-3B43 showed the lowest negative bias, while TARCAT, PERSIANN-CDR, CMAP, and GPCP showed the highest (similar to the MAM season).

However, the elevation variations relative to bias are more evident in the retrieval of different rainfall regimes. The presence of orographic rainfall induced by differences in elevation to the windward side of Mount Kenya is the main cause of the large negative bias of the products. Generally, CHIRPS, CMORPH, and TRMM$3 \mathrm{~B} 43$ showed the lowest negative bias in both rainfall regimes, which is similar to a 
study [8] that shows they perform well in high elevated areas. However, the elevation variations relative to bias are more evident in the retrieval of different rainfall regimes. The low negative bias shown by CHIRPS, CMORPH, and TRMM-3B43 in both rainfall regimes is similar to the study (Duan, Liu, Tuo, Chiogna, \& Disse, 2016), in which assessments of these products at high temporal resolutions on elevated areas was successful. Over Southern Tanzania and Northeastern Kenya, large sparse rain gauge data were used during the interpolation. As a result, the overestimations observed by all products at varying magnitudes were not satisfactorily explained. This leaves a gap that can be resolved by an increased rain gauge network.

\subsection{Conclusions}

Although satellite-derived rainfall products have been evaluated globally and to some extent also regionally, there are significant variations in their performance levels, especially due to the geographical location, climate, and rainfall regime. Certain products have advantages over others in some regions or climates, while other products may be more appropriate for different climates or regions. There is, therefore, a need to quantify any uncertainties before selecting the appropriate product for a specific region. Although studies have indicated topography as one factor that contributes to the uncertainties of these products over East Africa, the relationship of seasonality to elevation impacts has not been addressed. In this study, seven satellite rainfall products (TARCAT; CHIRPS; TRMM-3B43; CMORPH; PERSIANN-CDR; CMAP; and GPCP) of different spatial scales were assessed spatially and temporally, using gridded $\left(0.05^{\circ}\right)$ rainfall data over East Africa over a period of 15 years (1998-2012). Assessments were made on the impacts of elevation variability and seasonality to the products' errors. All products were converted to monthly spatial scales and resampled using the nearest neighbour approach of $0.05^{\circ}$ geo-reference. The assessments were done for both monthly and yearly scales, and pixels collocated at the 284 rainfall stations were used for validation. The findings of this study are as follows:

All the products were able to replicate rainfall patterns in space and time, but showed systematic errors in rainfall retrieval that decreased with an increase in rainfall amounts (>100 $\mathrm{mm} / \mathrm{month}$ ). The systematic errors were mainly in underestimations and showed seasonality as they were larger during the OND rainy season than during the MAM rainy season. The errors were more evident in a monthly timescale but decreased in a yearly timescale.

The large underestimations were caused by the products' inability to retrieve orographic rainfall, that is more dominant during the OND season on the windward (east and northeast) side of the Mount Kenya region due to moisture influx from the Indian Ocean. Although the use of IR satellite data offers certain advantages, notably in terms of temporal and spatial resolution, they showed the largest errors in retrieving this rainfall regime. This mainly affected TARCAT and PERSIANN-CDR, but TARCAT was affected more due to its use of a single sensor that limits its capabilities of retrieving the rainfall of different rainfall regimes. It can be understood that orographic clouds are relatively warm as they are caused primarily by kinetic turbulence, rather than convection. The study revealed that products using microwave imageries for rainfall retrieval showed fewer errors in the retrieval 
of orographic based rainfall. TRMM-3B43, which is microwave-based, showed the fewest errors in retrieving this rainfall type. Likewise, CMORPH utilizes passive microwave data to generate rainfall and had good performance. Although CHIRPS uses Cold Cloud Duration (CCD) for rainfall retrieval, the estimates are calibrated using the Tropical Rainfall Measuring Mission Multi-satellite Precipitation Analysis version 7 (TMPA 3B42 v7) and this is attributed to its good performance. However, CHIRPS and TRMM-3B43 overestimated high rainfall amounts.

Elevation variation is closely related to orographic rainfall developments and hence to the satellite rainfall products' performance. This effect is more evident during the OND season, as low-level wind enhances rainfall on the windward side, particularly over the Mount Kenya region. The study revealed that when elevation was $<2500 \mathrm{~m}$, the products showed underestimations. The overestimations were mainly observed during the MAM season, which is associated with increased rainfall amounts enhanced by deep convective systems, and CHIRPS and TRMM-3B43 were more affected. Possible cirrus cloud effects are also attributed to these errors.

Products' input data affected their performances in rainfall retrieval. Products using multiple sensors performed better than those with single sensors, especially if the sensors were on different platforms. This increased their ability to retrieve different types of rainfall over East Africa. This mainly affected TARCAT and PERSIANN-CDR, which use only infrared sensors. In addition, TARCAT showed greater impact because it uses a single sensor (infrared) that limits the retrieval of different rainfall regimes. The distribution of the rain gauges used in calibration also affects their performance, and thus there is a need to regularly update the algorithms with denser rain gauge data where applicable. This affects the way each product varies in performance from region to region. This was attributed to the underperformance of GPCP over the region.

The satellite products considered are therefore applicable over East Africa, but errors in high ground areas need to be considered during the OND season, especially for products using only infrared sensors. To reduce orographic effects, elevation and wind direction data are recommended to be included as input data in the development of algorithms to improve the accuracy of orographic rainfall retrieval. 
Chapter 3

\section{Bayesian Bias Correction of Satellite Rainfall Estimates for Climate Studies ${ }^{2}$}

2 This chapter is based on:

Kimani, M. W., Hoedjes, J. C. B., \& Su, Z. B. (2018). Bayesian Bias Correction of Satellite Rainfall Estimates for Climate Studies. Remote Sensing, 10(7). doi:10.3390/rs10071074. 


\begin{abstract}
Advances in remote sensing have led to the use of satellite-derived rainfall products to complement the sparse rain gauge data. Although these products are globally and some regional bias corrected, they often show substantial differences relative to ground measurements attributed to local and external factors that require systematic consideration. A decreasing rain gauge network inhibits the continuous validation of these products. Our proposal to deal with this problem was to use a Bayesian approach to merge the existing historical rain gauge information to create consistent satellite rainfall data for long-term applications. Monthly bias correction was applied to Climate Hazards Group Infrared Precipitation with Stations (CHIRPS v2) using a corresponding gridded $\left(0.05^{\circ}\right)$ rain gauge data over East Africa for 33 years (1981-2013). The first 22 years were utilized to derive error fields which were then applied to independent CHIRPS data for 11 years for validation. Assessments of the approach's influence on the rainfall estimates spatially and temporally were explored. Results showed a significant spatial reduction of the underestimation and overestimation of systematic errors at both monthly and yearly scales. The reduced errors increased with increased rainfall amounts, hence was less so in the relatively drier months. The overall monthly reduction of Root Mean Square Difference (RMSD) was between $4 \%$ and $60 \%$, and the Mean Absolute Error (MAE) was between $1 \%$ and $63 \%$, while the correlations improved by up to $21 \%$. Yearly, the RMSD was reduced between $17 \%$ and $49 \%$, and the MAE between $13 \%$ and $48 \%$, while the increase in correlations was between $9 \%$ and $17 \%$. Decreased yearly bias correction corresponded with years of high rainfall associated with El Niño. Results for the assessments of the effectiveness of the Bayesian approach showed that it was more effective in reducing systematic errors related to rainfall magnitudes, but its performance decreased in areas of sparse rain gauge network that insufficiently represented rainfall variabilities. This affected areas of deep convection, leading to minimal overestimation reductions associated with the cirrus effect. Conversely, significant corrections were during years of low rainfall from shallow convections. The approach is suitable for long-term applications where consistencies of mean errors can be assumed.
\end{abstract}

Keywords: Bayesian bias correction; satellite rainfall; rain gauge; East Africa 


\subsection{Introduction}

Rainfall data is vital for many applications such as climate studies, water resource management, and agriculture. As its accurate spatial and temporal representations can improve socio-economic planning. Rain gauges provide the most direct representations of rainfall, but their distribution over land are sparse, especially in mountainous areas (Kidd et al., 2012), and being point observations, they lack spatial representativeness (Villarini \& Krajewski, 2008). However, they offer useful information in modelling regarding local rainfall processes that are not accurately parameterized by the Global Circulation Models (GCM) (Dibike \& Coulibaly, 2007). Alternative uses of satellite rainfall products are increasing because of their high spatiotemporal coverage. However, these products often exhibit large discrepancies with ground measurements (Feidas, Lagouvardos, Kotroni, \& Cartalis, 2005; Sorooshian et al., 2000), and the errors need to be reduced to make the products more representative of the local rainfall variability. Although some of these products are globally validated (Adler et al., 2003; Arkin \& Xie, 1994; Krajewski, Ciach, McCollum, \& Bacotiu, 2000) and some at regional scales (Maidment et al., 2013; Tote et al., 2015), relatively few efforts have been made to reduce the often-large errors that occur at local scales. Studies (Abera et al., 2016; AghaKouchak et al., 2012; Kimani, Hoedjes, \& Su, 2017) have found that satellite rainfall products have systematic errors that cause overestimations/underestimations, especially in high elevated areas (Kimani et al., 2017). Although rain gauge data have low spatial distributions, their direct way of measuring rainfall are still vital as a reference to the local rainfall variability. For better representations of local rainfall processes, the inclusion of all available quality controlled rain gauge data merged with satellite products can enhance the products' future applications. Different methods have been proposed to reduce satellite rainfall estimates errors. A study by (Abera et al., 2016) applied bias correction using empirical cumulative distribution (CDF) maps on a seasonal basis for hydrological applications in the upper Blue Nile in Ethiopia. To reduce temporal rainfall variability, a seasonal timescale was utilized. However, in high elevated areas, areas near inland water bodies, and those with maritime influences, high rainfall variabilities are experienced. As such, the choice of temporal scale may differ from place to place. It is worth noting that the effectiveness of bias correction on rainfall products may also differ from location to location and consideration of spatial scale is of great importance. Quantile mapping approach was applied by (Maurer \& Pierce, 2014) to bias correct rainfall products and they observed that the approach improved estimates in some locations, while it degraded in others. However, it is crucial that the applied method does not necessarily change the

product's original rainfall estimates. Therefore, the consistencies of the systematic errors corrected are worthy of consideration. Mateus et al. (Mateus, Borma, da Silva, Nico, \& Catalao, 2016) assessed the performance of two bias correction methodssuccessive correction method (SCM) and optimal interpolation and qualitative analysis-and visual inspections showed better results by SCM. However, the study noted the limitation of this approach in defining the optimal weight of the error distributions. Elsewhere, (Vila, de Goncalves, Toll, \& Rozante, 2009) evaluated satellite rainfall estimates combined with high-resolution rain gauge data using different bias correction methods based on an additive, multiplicative, and merged scheme approach. The evaluation was carried out on a monthly basis in different 
rainfall seasons and with different rain gauge networks. The results revealed that the choice of both the temporal and spatial scale of the rain gauge data was vital for adequate bias correction. In their study, the merged scheme showed the best results. Nevertheless, this approach is more suitable for real-time applications and in many areas of the world, the degradation of the rain gauge network is a common problem due to the lack of maintenance. Furthermore, for climate studies and other long-term applications, real-time data is not applicable.

A probabilistic Bayesian approach was applied by (Tian, Peters-Lidard, \& Eylander, 2010) on high temporal resolution rain gauge data. Historical rain gauge and satellite data were used to create a satellite estimates-rain gauge data relationship, which is applicable in the absence of real-time rain gauge data. The approach worked well even in areas of low rain gauge distributions, but over corrections were observed in some areas. However, it is understandable that rainfall variability differs from place to place and the impact of rain gauge distribution needs to be determined. It is a fact that over the world, rain gauge distributions are decreasing (Stokstad, 1999), especially in African countries due to their cost of maintenance. Their availabilities to validate the increasing satellite rainfall products may be affected by inconsistencies caused by the low network. Despite this, they offer useful information on the local rainfall variabilities. Over equatorial East Africa, few studies like (Dinku et al., 2007) have used high-resolution ground data to bias-correct satellite rainfall estimates for hydrological applications. It is crucial to have longterm bias correction because of the accumulation of errors in time and for externally induced errors, particularly in areas that experience high rainfall variability (Kimani et al., 2017).

We proposed a Bayesian approach that could be used with the existing historical rain gauge information to create consistent satellite rainfall data for long-term applications. This approach assumes consistencies in time for the average errors in both datasets. As such, the error weight derived from their climatology is considered to be representative of a given area. In our approach, we converted the probability into independent variables to apply a linear relationship using the least square techniques (O. Talagrand, 1997). This approach is superior to other methods in that it does not always modify the estimates during corrections, but considers the mean error consistencies of the input data in time. Therefore, the corrected satellite estimates approach the uncorrected state in areas of poor rainfall representations arising from sparse rain gauge distribution. This way, the satellite rainfall estimates remain close to the original state in areas of inconsistent rain gauge data. A longterm (1981-2013) temporal scale bias correction was applied to the Climate Hazards Group Infrared Precipitation with Stations (CHIRPS v2). The product was chosen based on its high spatial resolution and lengthy climatology suitable for climate studies to help end users in planning (Seiz \& Foppa, 2011). Furthermore, a recent study by (Kimani et al., 2017) over East Africa showed a close correspondence of CHIRPS v2, Tropical Rainfall Measuring Mission (TRMM)3B43, and the Climate Prediction Center (CPC) morphing technique (CMORPH) with ground observations. However, in that study, all the satellite products assessed exhibited large biases in high elevated areas. Although CHIRPS is globally bias corrected using some of the rain gauge data used in this study, the data mainly come from the Global Telecommunication System (GTS). The GTS stations are sparse and may therefore not accurately represent the rainfall variability over the region.

This study assessed the performance of the Bayesian approach in reducing systematic errors on CHIRPS v2 rainfall estimates relative to regional gridded rain gauge data. The assessments on the effectiveness of the method were on a monthly 
and yearly basis. This paper has six sections. Section 1 presents the introduction; Section 3.1 gives a brief description of the Material and data used, Section 3.2 describes the Bayesian approach and methods of evaluation; Section 3.3 presents the results, discussions of the results are in Section 3.4 while our conclusions are in Section 3.5.

\subsubsection{Material and Data}

Two monthly rainfall datasets were used in this study and included CHIRPS v2 rainfall estimates and rain gauge data. CHIRPS is a quasi-global dataset developed by the United States Geological Survey (USGS) Earth Resources Observations and Science Centre and the University of California Santa Barbara Climate Hazards Group. It has a spatial resolution of $0.05^{\circ}$, and a daily/pentad/monthly temporal resolution. It uses TRMM multi-satellite precipitation analysis version 7 to calibrate the Cold Cloud Duration (CCD) rainfall estimates. The product covers the area between $50^{\circ} \mathrm{N}$ and $50^{\circ} \mathrm{S}$, and data are available from January 1981 to the near present. Further details of CHIRPS v2 used in this study can be found in (C. C. Funk et al., 2014), and an evaluation of its performance relative to other products in (Tote et al., 2015).

The gridded $\left(0.05^{\circ}\right)$ rain gauge was from the Intergovernmental Authority on Development (IGAD) Climate Prediction and Application Centre (ICPAC). Although the data includes global telecommunication stations, ICPAC includes data from other stations sourced from the five countries (Kenya, Uganda, Tanzania, Burundi, and Rwanda) (Figure 3.1). This move was prompted by the decreasing rain gauge distributions, especially in developing countries, partially due to the cost and lack of skilled personnel. In East Africa, the decreasing trend is worrying, and the only solution is to grid the available rain gauge data (Funk et al., 2015) to preserve their information. It is in this context that the member states of East African countries brought together their available data from all the operational stations of the National Meteorological and Hydrological Services (NMHSs). They interpolated and quality controlled the rain gauge measurements from 284 rainfall stations. They used the GeoCLIM.

("GeoCLIM,")("GeoCLIM,")("GeoCLIM,")("GeoCLIM,")("GeoCLIM,")("GeoCLIM,")("G eoCLIM,")("GeoCLIM,")("GeoCLIM,")("GeoCLIM,")tool with inverse distance weighting (IDW) (J. Zhang, Qi, Langston, Kaney, \& Howard, 2014). The Tamuka Magadzire of the United States Geological Survey (USGS) Famine Early Warning Systems Network (FEWSNET) developed GeoCLIM for rainfall, temperature, and evapotranspiration analysis. The gridded data have been used regionally for hazard and regional rainfall predictions, and recently for the evaluation of satellite rainfall data (Kimani et al., 2017).

Elevation data was downloaded from the Shuttle Radar Topography Mission (SRTM) $90 \mathrm{~m}$ Digital Elevation Model (DEM)(Reuter, Nelson, \& Jarvis, 2007). The $5^{\circ}$ spatial resolution tiles were then mosaicked over East Africa as shown in Figure 1 by using the Geographical Information System (GIS) functionality. 


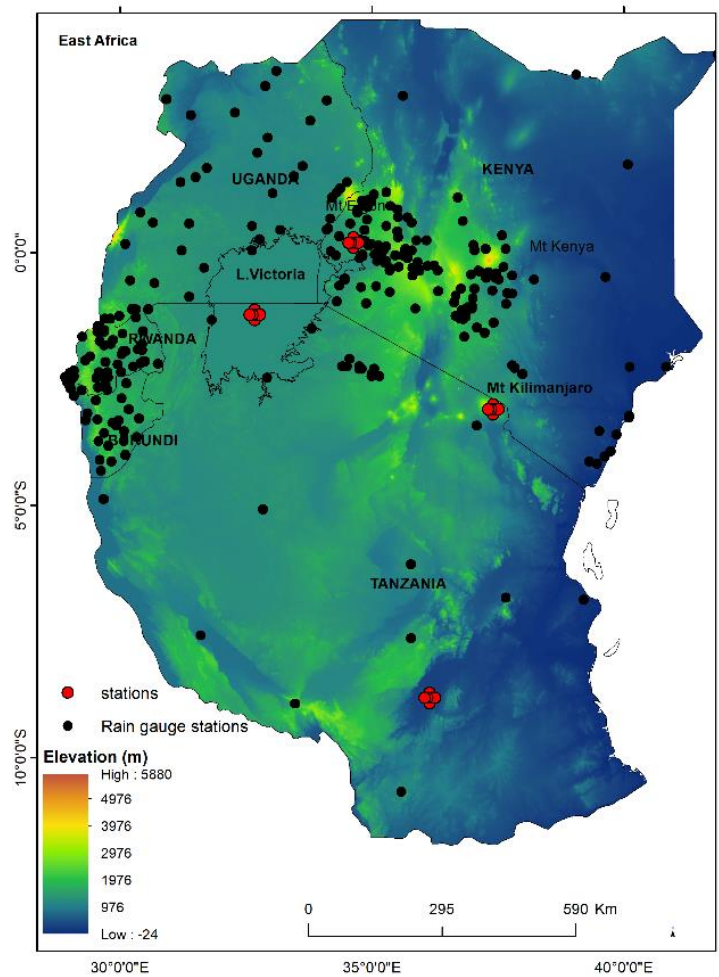

Figure 3. 1: Map of East Africa with the Shuttle Radar Topography Mission (SRTM) $90 \mathrm{~m}$ digital elevation model. Rain gauge station distributions used for gridding are highlighted in black. In red are the selected pixels for assessments.

\subsection{Methodology}

We first describe the Bayesian method and then explain the training and testing procedures.

\subsubsection{Bayesian Method}

A Bayesian method is a probabilistic approach that merges data from different sources (Carlin \& Louis, 1996) to obtain the optimal representative values from the input datasets. It is based on spatial transformation and uses the variances of the input datasets. In this study, it was used to adjust monthly CHIRPS satellite rainfall estimates using the gridded rain gauge data for 33 years (1981-2013) in two steps. First, training data from 22 years (1981-2002) were used to derive bias fields for the multi-annual monthly averages of each month. The monthly averaged bias fields were then used to correct independent satellite rainfall estimates during an 11-year (2003-2013) validation period. The hypothesis of the approach was the temporal consistency of average errors. It was carried out at a $0.05^{\circ} \times 0.05^{\circ}$ spatial scale for 
both datasets, but for compatibility, the CHIRPS data were resampled using the nearest neighbour interpolation (Suwendi \& Allebach, 2008) to match the georeference of the rain gauge data. The resampling approach is robust in reprocessing algorithms according to this study and has been applied successfully in other areas (Tan et al., 2015).

\subsubsection{Training Period}

The Bayes theorem (Carlin \& Louis, 1996) aims to obtain the maximum likelihood of $P(s \mid g)$, which is the conditional probability of the satellite estimates (s) given the gridded rain gauge data $(g)$, equation (3.1).

$$
P(s \mid g)=\frac{P(s) P(g \mid s))}{P(g)}
$$

where $P(s), P(g \mid s)$ denotes the probability of satellite data and likelihood function of rain gauge data given by the satellite estimates, respectively. Since the gridded rainfall data distribution is known, $P(g)=1$, then Equation (3.1) reduces to Equation (3.2).

$$
P(s \mid g)=P(g \mid s) P(s)
$$

Following (Olivier Talagrand, 1997), the least squares estimation can be used to simplify the data assimilation problems to linear relationships and Equation (3.2) is changed from the probabilistic form into independent variables.

Assuming the monthly averaged errors $(\varepsilon)$ of the satellite rainfall estimates and the gridded rain gauge data to be unbiased and consistent in time, $E$ is the expected value as in Equation (3.3).

$$
E\left(\varepsilon_{g}\right)=E\left(\varepsilon_{s}\right)=0
$$

The variances $\left(\sigma^{2}\right)$ of each dataset can be related to the errors $(\varepsilon)$, assuming the errors are uncorrelated (Equations (3.4) and (3.5)). $\sigma$ is the standard deviation described in Section 3.2. 


$$
\begin{aligned}
& E\left(\varepsilon_{g}^{2}\right)=\sigma_{g}^{2} \\
& E\left(\varepsilon_{s}^{2}\right)=\sigma_{s}^{2}
\end{aligned}
$$

Bias-corrected satellite estimates are linearly combined with the gridded rainfall data and the uncorrected satellite rainfall estimates (Equation (3.6)). The weighing factors, $a_{g}$ and $a_{s}$, are dependent on the respective variances. The higher the variance value, the lower the corresponding weighting factor. Implying that in areas where variance of rain gauge data is high, the bias correction is minimal.

$$
\overline{s_{c}}=\alpha_{g} \bar{g}+\alpha_{s} \bar{s}
$$

With the overbars denoting the averaged values for each month in the 22 years training dataset, Equation (3.6) assumes the bias-corrected satellite estimates (in this case CHIRPS) denoted as ' $s$ ' with a subscript ' $c$ ' to be unbiased as their errors are consistent during the training period. The sum of the CHIRPS estimates' weighing factor, $a_{s}$ and the gridded rain gauge weighting factor, $a_{g}$, equals one (Equation (3.7)).

$$
\alpha_{g}+\alpha_{s}=1
$$

$S_{c}$ will be the best estimate of $g$ if the weighing factors $a_{g}$ and $a_{s}$ are chosen to minimize the mean squared error of the corrected satellite estimates $S_{c}$ following Equations (3.8)-(3.11).

$$
\begin{gathered}
\sigma_{c}^{2}=\overline{\left(s_{c}-g\right)}=\overline{\left|\alpha_{g}\left(s_{c}-g\right)+\left(1-\alpha_{g}\right)\left(s_{c}-g\right)\right|^{2}} \\
\frac{\partial \sigma_{c}^{2}}{\partial \alpha_{g}} \rightarrow 0 \\
\sigma_{c}^{2}=\left(\overline{s_{c}}-\bar{g}\right)^{2} \\
\sigma_{c}^{2}=\alpha_{g}^{2} \sigma_{g}^{2}+\left(1-\alpha_{g}\right)^{2} \sigma_{s}^{2}
\end{gathered}
$$




$$
\alpha_{g}=\frac{\sigma_{s}^{2}}{\sigma_{g}^{2}+\sigma_{s}^{2}}
$$

This leads to

$$
\alpha_{s}=\frac{\sigma_{g}^{2}}{\sigma_{g}^{2}+\sigma_{s}^{2}}
$$

Equations (3.12) and (3.13) imply that the weights of the satellite estimates and the corresponding rain gauge data are related to the inverse of their variances. The weighting factors correct the average satellite estimates for each month during the 22 years training period using the linear relationship shown in Equation (3.6) which can be rewritten as Equation (3.14).

$$
\overline{s_{c}}=\bar{s}+\frac{\sigma_{s}^{2}}{\sigma_{s}^{2}+\sigma_{g}^{2}}(\bar{g}-\bar{s})=\bar{s}+\alpha_{g}(\bar{g}-\bar{s})
$$

Equation (14) implies that when the variance of the reference (rain gauge) data is

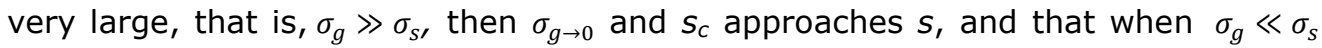
$\sigma_{g \rightarrow 1}$ and $s_{c}$ approaches $g$.

\subsubsection{Testing Period}

In this section, the Bayesian approach is described using the error fields derived during training with the monthly data. The CHIRPS and bias-corrected CHIRPS estimates comparison with corresponding rain gauge data was conducted on a monthly and yearly basis. The mean bias fields were derived from the satellite estimates for each month using Equation (3.15). The subscript ' $i$ ' stands for the time step.

$$
\text { mean bias }=\frac{1}{n} \sum_{i}^{N}\left(s_{c i}-g_{i}\right)
$$

The bias is then subtracted from the satellite data of each corresponding month (subscript ' $i$ ') using Equation (3.16). 


$$
s_{c i}=s_{i}-\text { mean bias }
$$

\subsubsection{Evaluation of Bias Corrected CHIRPS Rainfall}

Validation of bias correction of CHIRPS rainfall estimates was carried out for 11 years (2003-2013) between the raw and bias-corrected CHIRPS (bc) relating to the gridded rain gauge data on a monthly and yearly basis. Continuous statistics of the correlation coefficient ( $C C)$, RMSD, standard deviations $(\sigma)$ (Equations (3.17)(3.19)), MAE (Equation (3.20), and mean bias (Equation (3.21)) were used to quantify their relationships. For visualization, Taylor diagrams (Taylor, 2001) and spatial maps were utilized.

$$
\begin{gathered}
c c=\frac{\frac{1}{N} \sum_{i=1}^{N}\left(s_{i}-\bar{s}\right)\left(g_{i}-\bar{g}\right)}{\sigma_{s} \sigma_{g}} \\
R M S D=\sqrt{\frac{1}{N} \sum_{i=1}^{N}\left(s_{i}-g_{i}\right)^{2}} \\
\sigma_{g(s)}=\sqrt{\frac{1}{N} \sum_{i=1}^{N}(g(s)-\overline{g(s)})^{2}}
\end{gathered}
$$

where the overbar stands for the respective mean satellite estimates $(s)$, the gridded rain gauge datasets $(g), g(s)$ is either the gridded rain gauge or satellite dataset, and $N$ is the number of samples considered.

$$
M A E=\frac{1}{n} \sum_{i=1}^{N}\left[s_{i}-g_{i}\right]
$$




$$
\text { Mean bias }=\frac{1}{N} \sum_{i=1}^{N}\left(s_{i}-g_{i}\right)
$$

\subsubsection{Assessments of Bayesian Approach Performance}

East Africa has complex terrain, comprising of lakes, mountains, and lowlands. As a result, the high elevated areas and Lake Victoria influence local rainfall variability. As such, further assessments were carried out to determine the performance of the Bayesian approach in eradicating CHIRPS biases on an annual basis. Pixels within the areas of lowest Bayesian performance were assessed using CHIRPS and biascorrected CHIRPS rainfall estimates relative to rain gauge data. These included areas of large uncorrected overestimations over Mt. Elgon, Southern Tanzania, Lake Victoria, and Mt. Kilimanjaro (Figure 1). Scatter plots and MAE were used to quantify these relationships.

\subsection{Results}

\subsubsection{Assessments of Bias-Corrected CHIRPS Estimates}

\subsubsection{Monthly Assessments}

This section describes the monthly assessments of bias correction of CHIRPS rainfall estimates using rain gauge data over East Africa during a validation period of 2003 to 2013 . Figure 3.2 presents the Taylor diagrams displaying the error metrics before (CHIRPS) and after bias corrections (abbreviated with a 'bc') during the wet months of March to May, and October to December. These results showed that the Bayesian approach significantly improved the accuracy of the CHIRPS estimates as indicated by the reduced RMSD and increased correlations for all months. The biases showed seasonality and occurred more during OND when compared to the MAM months. During OND, the orographic processes were more dominant and more challenging for the infrared-based satellite rainfall products [13]. The bias increased with an increase in rainfall magnitudes [11] and were largest in April and November. These are the peak rainfall months of the MAM and OND seasons, respectively. These observations of bias dependence on rainfall amounts concurred with [10] over other parts of Africa. 

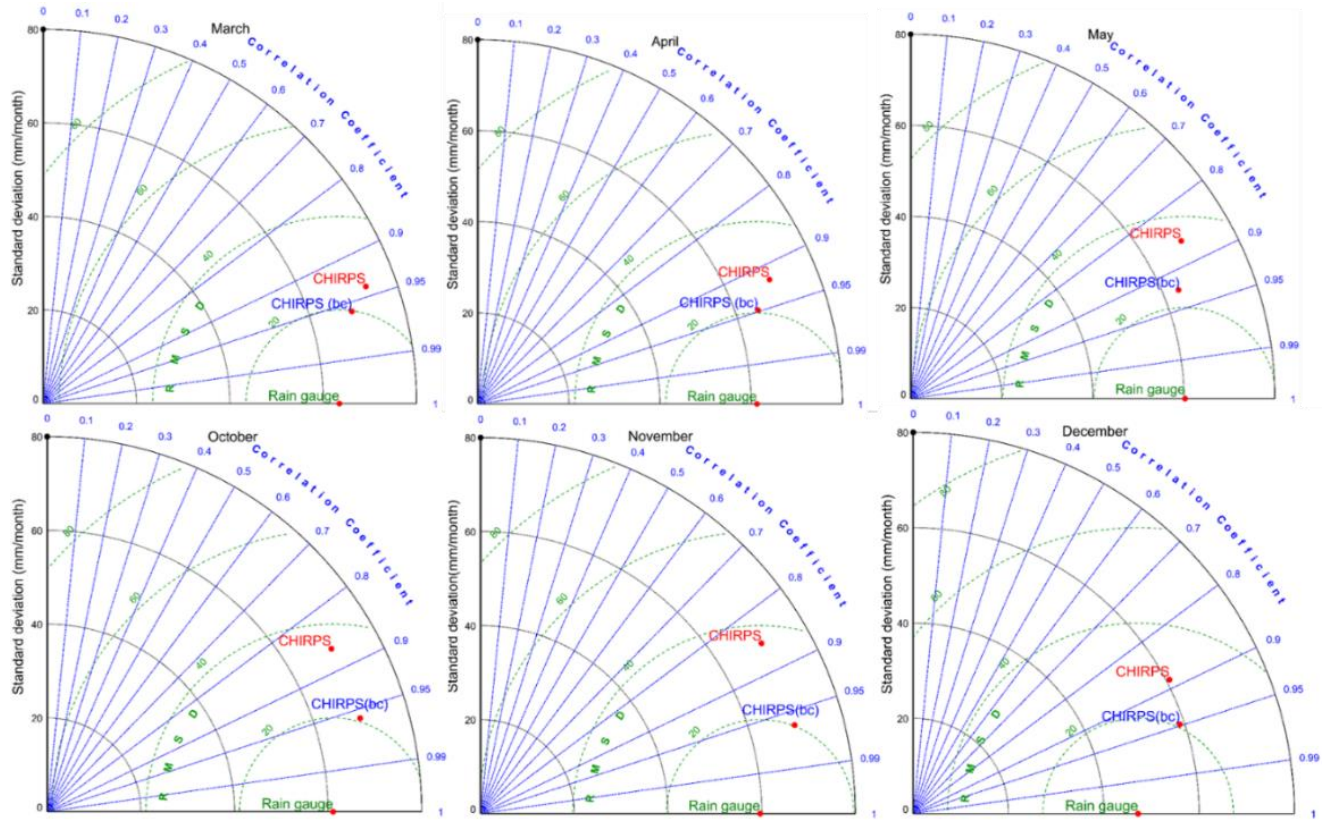

Figure 3. 2: Monthly Taylor diagrams displaying the statistical comparison between the Climate Hazards Group Infrared Precipitation with Stations (CHIRPS) (red) and bias-corrected CHIRPS (bc) (blue) estimates with corresponding rain gauge data (green) as the reference. Shown are the wet months of the rainfall seasons (MarchMay and October-December) over a period of 11 years (2003-2013). The azimuthal angle represents the correlation coefficient; radial distance is the standard deviation ( $\mathrm{mm} /$ month), and green contours represent RMSD ( $\mathrm{mm} / \mathrm{month})$.

Figure 3.3 presents the results of the relatively dry months of January, February, and June through September and showed a significant reduction of biases. It was evident that there were increased error magnitudes than during the wet months, mainly from June-September. These errors are attributable to orographic processes during the northeast (January through February) and southeast (June through September) monsoon period. The high grounds inhabit moisture influx inland, thereby limiting the rainfall occurrence to the high ground areas. In their study (Kinuthia \& Asnani, 1982; S.E Nicholson, 2016), associated Turkana Jets that run parallel to the highlands cause rainfall variabilities during the south-east monsoon season. 

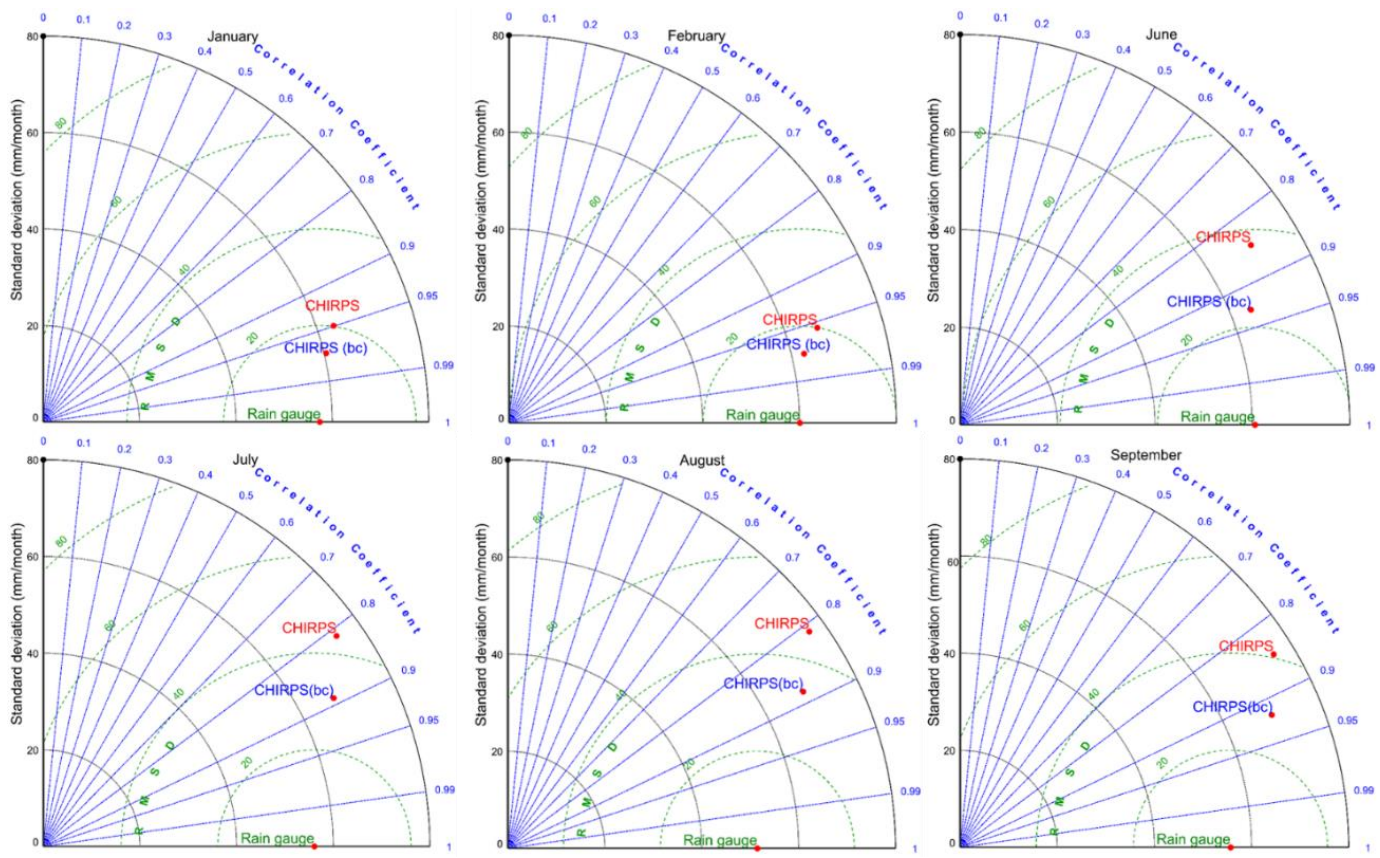

Figure 3. 3: Same as for Figure 3.2, but for the relatively drier months of January, February, June-August and September.

Figure 3.4 shows the mean bias (2003-2013) derived from CHIRPS and the biascorrected CHIRPS (bc) relative to rain gauge data for April and May, August, and November. The three wet seasons are representative of March-May, June-August, and October-December, respectively. The spatial patterns display areas of underestimations and overestimations and indicate the areas of improvement after Bayesian applications. It is evident that increased bias followed areas of the highest rainfall amounts. Consequently, the largest underestimations (negative bias) were observed in highly elevated regions of Mt. Kenya in November, around Mt. Elgon in August, and over the coastal areas bordering the Indian Ocean in May. This confirmed that the CHIRPS monthly estimates underestimated high rainfall amounts [29]. These findings were also in line with (AghaKouchak et al., 2012), where observed systematic errors increased with increased rainfall amounts. Evidently, in April, which is the peak rainfall month of MAM, the mean biases were well distributed and attributable to mixed rainfall regime characteristics. Additionally, overestimations (positive bias) were evident in areas around Lake Victoria, eastern parts of Kenya, and Southern Tanzania in April and May. The overestimations arose from cirrus effects common to infrared based products using a cold cloud temperature threshold as they consider the cold cirrus clouds that occur in deep convections as precipitating (AghaKouchak et al., 2012). It was evident that the approach adequately reduced overestimations except over Southern Tanzania, which showed sparse rain gauge stations (Figure 3.1) and may therefore not have 
well-represented rainfall variability. Similarly, a study by (Tian et al., 2010) used the probability distribution to adjust satellite rainfall estimates and associated overcorrections for the misrepresentation of rainfall variability in sparse rain gauge areas. It is recommended that this approach is sensitive to the inconsistencies of the reference data and does not necessarily modify the satellite rainfall estimates.

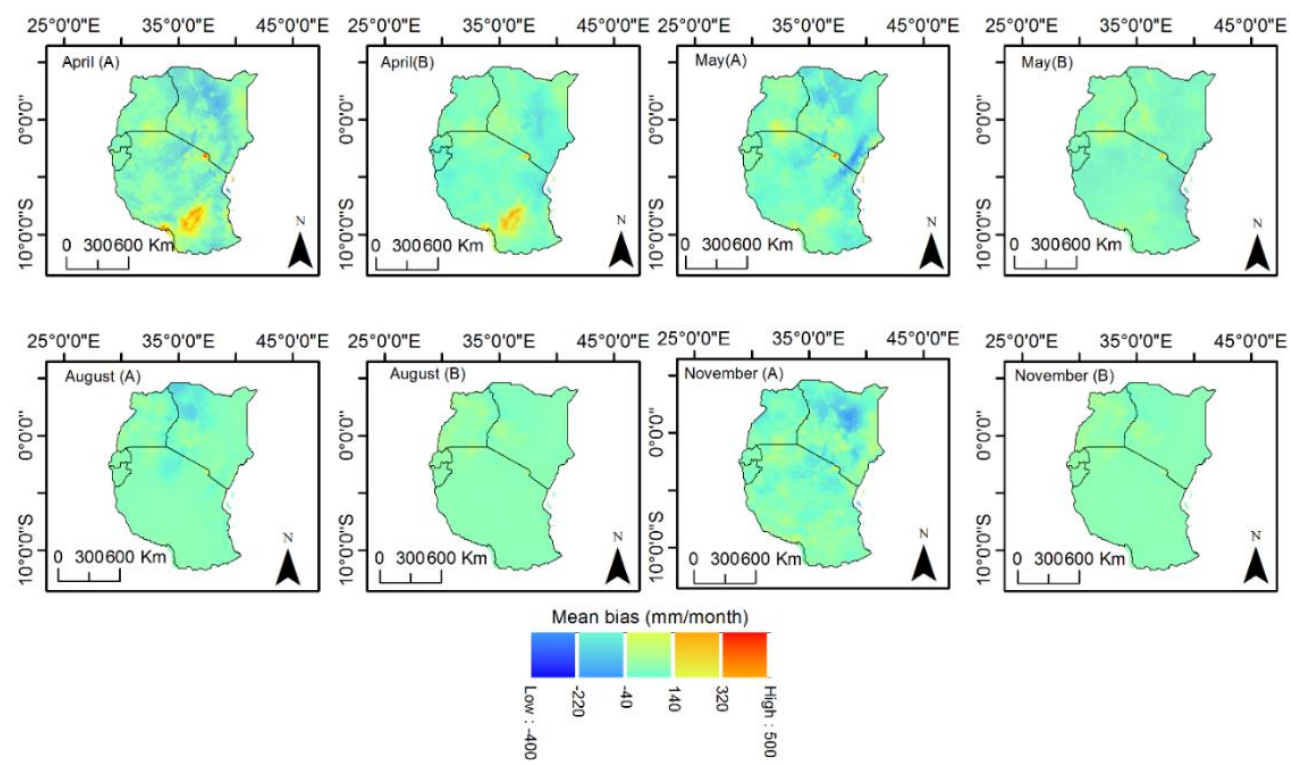

Figure 3. 4: Monthly mean bias derived from averages (2003-2013) of rain gauge data and satellite rainfall estimates of CHIRPS $(A)$ and bias corrections (CHIRPS (bc)) (B).

Table 3.1 shows a summary of the monthly error statistics for all months before and after bias corrections and the change of errors in percentages. It was evident the bias-corrected CHIRPS (bc) estimates showed reductions in RMSD and MAE errors and an increase in correlations. One notable observation was the low percentage change in correlations during the relatively dry months. Further observations showed that these months corresponded with the southeast and northeast monsoon months of June through September and December-February, respectively. Therefore, it was evident that the systematic errors locally induced by topographic effects were also externally influenced by the largescale circulations. The low linearity arose from abrupt rainfall variability, hence increasing the average error inconsistencies in time assumed in the Bayesian approach. The overall monthly reduction of RMSD was between $4 \%$ and $60 \%$, and the MAE was between $1 \%$ and $63 \%$, while the correlations increased up to $21 \%$. 
Table 3.1: Statistics for the monthly spatial evaluation.

\begin{tabular}{|c|c|c|c|c|c|c|c|c|c|c|}
\hline Months & CC & $\frac{\text { CC }}{\text { (bc) }}$ & $\begin{array}{c}\text { Change } \\
(\%)\end{array}$ & RMSD & $\frac{\text { RMSD }}{\text { (bc) }}$ & $\begin{array}{c}\text { Change } \\
(\%)\end{array}$ & MAE & $\frac{\text { MAE }}{\text { (bc) }}$ & $\begin{array}{c}\text { Change } \\
(\%)\end{array}$ & $\begin{array}{c}\text { Rainfall } \\
(\mathrm{mm} / \mathrm{month})\end{array}$ \\
\hline Jan & 0.95 & 0.98 & 2 & 23.1 & 13 & -45 & 17.6 & 9 & -49 & 88 \\
\hline Feb & 0.96 & 0.97 & 2 & 23.1 & 15 & -37 & 14.9 & 10 & -31 & 70.3 \\
\hline Mar & 0.87 & 0.9 & 3 & 40.1 & 31 & -22 & 24.7 & 23 & -9 & 105.5 \\
\hline Apr & 0.47 & 0.61 & 14 & 64.3 & 48 & -25 & 43.1 & 28 & -35 & 155.1 \\
\hline May & 0.77 & 0.94 & 17 & 49.5 & 25 & -50 & 36.2 & 20 & -45 & 103.5 \\
\hline Jun & 0.87 & 0.97 & 10 & 22.8 & 10 & -58 & 15.8 & 6 & -61 & 38.4 \\
\hline Jul & 0.89 & 0.98 & 9 & 20.1 & 8 & -60 & 12 & 5 & -63 & 31.9 \\
\hline Aug & 0.89 & 0.98 & 9 & 24.1 & 11 & -56 & 14.2 & 6 & -57 & 38.8 \\
\hline Sep & 0.92 & 0.97 & 6 & 19.3 & 13 & -34 & 13.3 & 8 & -43 & 39.4 \\
\hline Oct & 0.95 & 0.95 & 0 & 21.1 & 19 & -11 & 16.9 & 15 & -11 & 87.1 \\
\hline Nov & 0.72 & 0.94 & 21 & 41.4 & 27 & -35 & 29.3 & 23 & -22 & 129.5 \\
\hline Dec & 0.92 & 0.92 & 0 & 27.2 & 26 & -4 & 20.7 & 20 & -1 & 127 \\
\hline
\end{tabular}

\subsubsection{2: Yearly Evaluations}

This section describes the annual spatial evaluation of the CHIRPS and biascorrected CHIRPS (bc) rainfall estimates relating to the rain gauge data during the validation years (2003-2013). Figures 3.5 and 3.6 show the Taylor diagrams displaying the error metrics of the RMSD and correlations and their respective standard deviations. It was evident that in all of the years, the CHIRPS rainfall estimates were adjusted towards the rain gauge data as indicated by the reduced RMSD and increased correlation coefficients. Large differences occurred in the years associated with El Niño (2003 and 2006) and the least during the relatively drier year (2005). Therefore, it was clear that systematic errors accumulated with increased rainfall, especially during anomalous years and it is worth noting that the seasonality over East Africa corresponded with the observed bias. This shows the importance of a long-term correction period that is inclusive of the known external variabilities. A notable observation of increased bias was in the year following El Niño, for example, the years 2004, 2007, and 2010. El Niño occurred towards the end of the year in October through December and increased rainfall in the months following may have arisen from recycled water. 

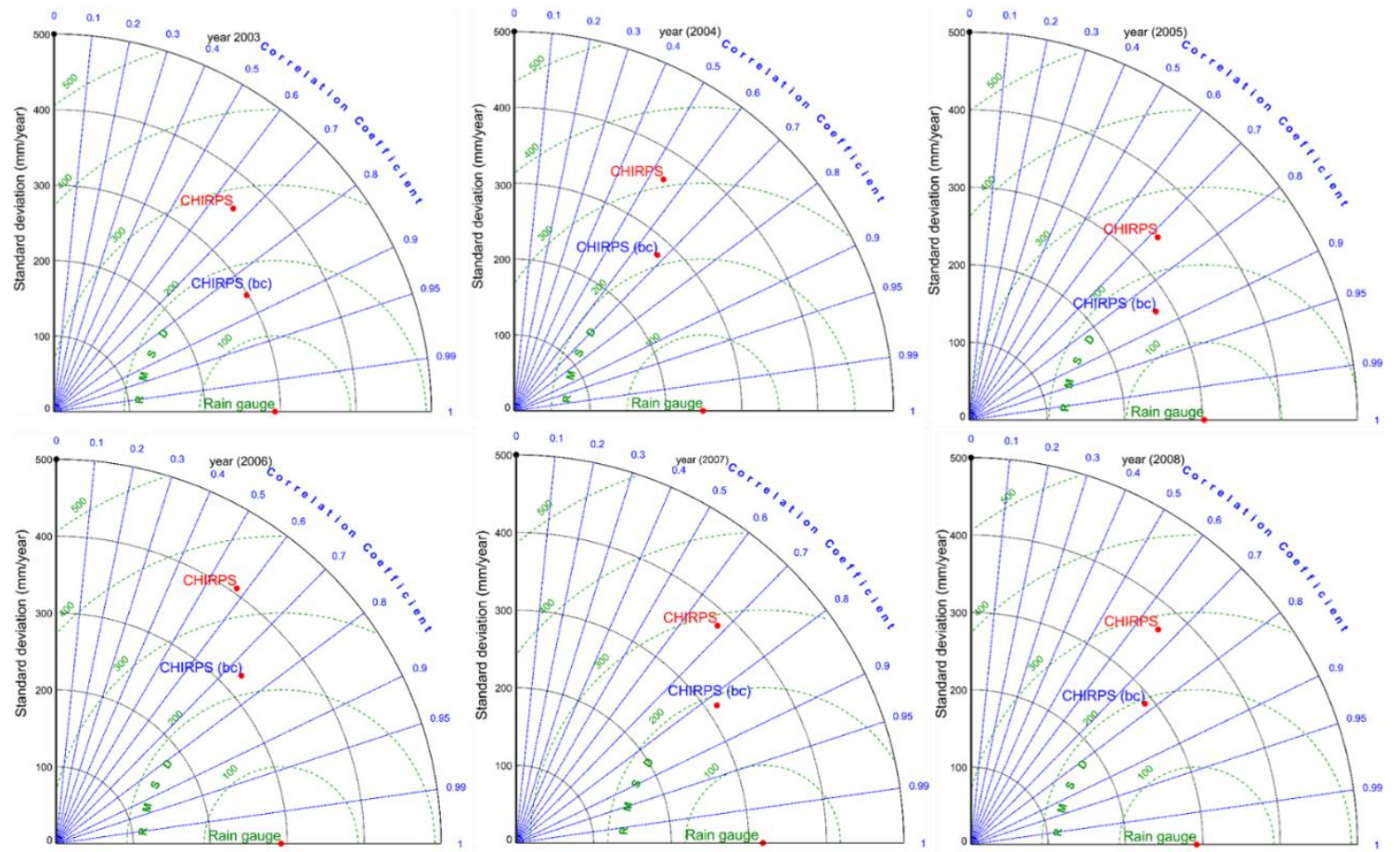

Figure 3. 5: Taylor diagrams displaying the statistical comparison between the CHIRPS (red) and bias-corrected (blue) CHIRPS estimates with corresponding rain gauge data (green) as the reference for years 2003-2008. The azimuthal angle represents the correlation coefficient; the radial distance represents the standard deviation ( $\mathrm{mm} /$ year), and the green contours represent RMSD ( $\mathrm{mm} /$ year).

Figure 3.7 shows the spatial mean bias distribution during the anomalous wet years of 2003 and 2006, the relatively dry (2005), and standard (2008) years. Similar to the monthly analysis, underestimations were evident before bias correction. The Bayesian approach substantially reduced the biases over the high elevated areas of Mt. Kenya in 2006, which was also an El Niño year. Similarly, overestimations were evident around Lake Victoria, Southern Tanzania, near Mt. Elgon, and North-eastern Kenya. Large uncorrected overestimations were observed, particularly in the southern parts of Tanzania and around Mt. Kilimanjaro, which are areas of poor rain gauge network (Figure 3.1). 

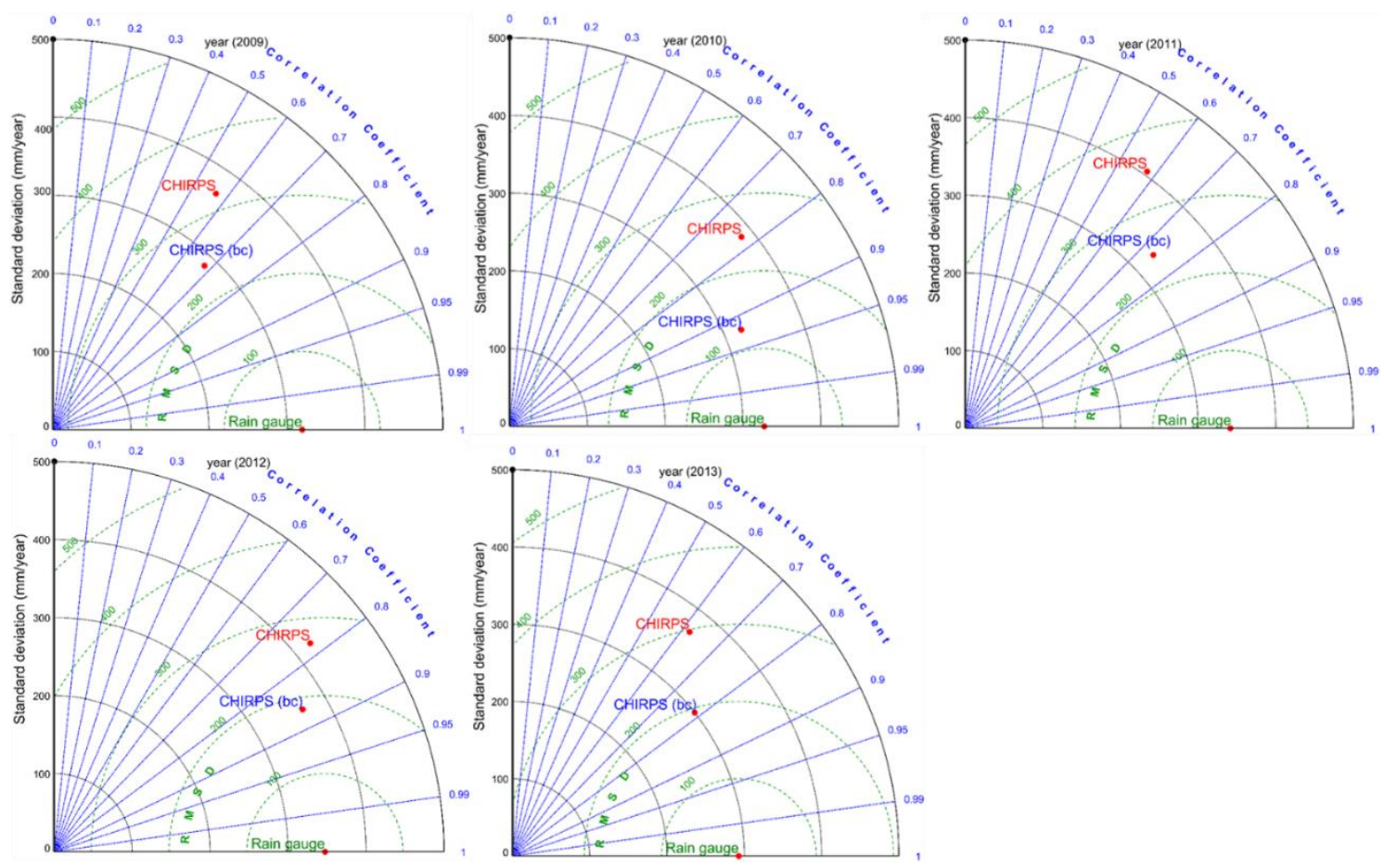

Figure 3. 6: As per Figure 3.5, but for the years 2009-2013. 


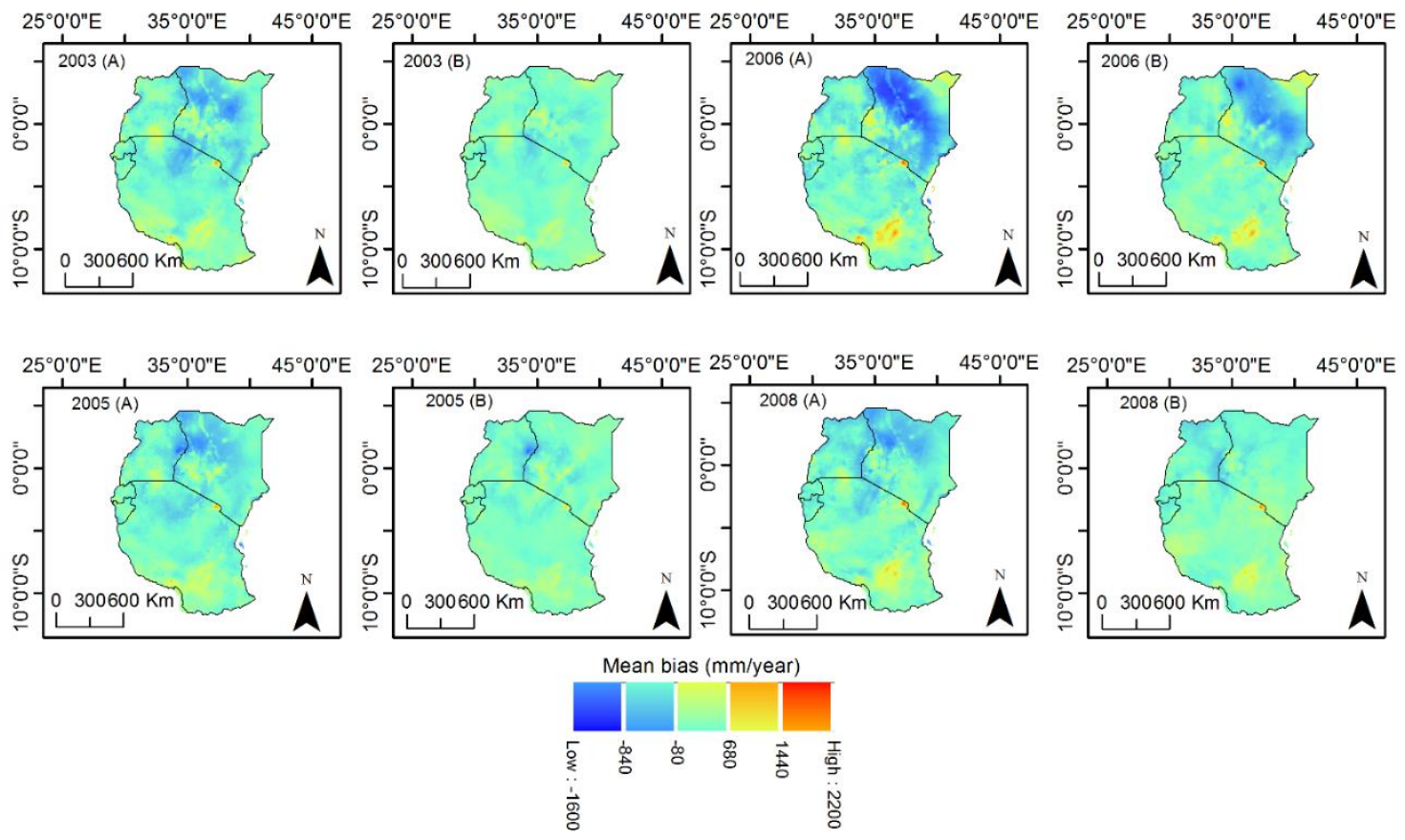

Figure 3. 7: Yearly spatial bias patterns derived from the averages of the anomalous wet years (2003 and 2006), the dry (2005), and standard (2008) of the CHIRPS and bias-corrected CHIRPS (bc) abbreviated as $(A, B)$, respectively, relative to the rain gauge data.

Table 3.2 shows a summary of the yearly error statistics before and after bias corrections, and the change of errors in percentages. There was a remarkable decrease in the RMSD and MAE as well as an increase in correlations after bias corrections. Similar to the monthly analysis, the errors corrected showed a dependence on rainfall magnitude, but also on rainfall regime. As such, the years 2003, and 2009, which were also El Niño years, did not correspond to the highest mean rainfall as EI Niño occurred during the short rainfall period of OND. However, the years after (2004 and 2010), had higher rainfall that spread to the MAM rainfall season. Similarly, in 2007 and 2010, the years following El Niño, there was increased rainfall and a correspondingly high percentage of errors corrected. It is worth noting that during the relatively dry year (2005), the percentage of RMSD and MAE corrected was high (46\%). This can be attributable to the fact that CHIRPS estimates are designed for drought monitoring, hence there are more consistent mean errors during dry years. In (AghaKouchak et al., 2012), it was observed that the systematic errors were seasonal, hence the importance of understanding the rainfall distribution during the year in a given area. 
Table 3.2: Statistics for the yearly spatial evaluation.

\begin{tabular}{|c|c|c|c|c|c|c|c|c|c|c|}
\hline \multirow{2}{*}{$\begin{array}{r}\text { Years C } \\
2003\end{array}$} & \multirow{2}{*}{$\begin{array}{r}\text { CC } \\
0.7\end{array}$} & $\begin{array}{c}\text { Change } \\
(\%)\end{array}$ & RMSD & $\begin{array}{l}\text { RMSD } \\
\text { (bc) }\end{array}$ & \multicolumn{2}{|c|}{$\begin{array}{l}\text { Change } \\
(\%)\end{array}$} & MAE & $\begin{array}{c}\text { Change } \\
(\%)\end{array}$ & \multicolumn{2}{|c|}{$\begin{array}{c}\text { Rainfall } \\
\text { (mm/year) }\end{array}$} \\
\hline & & 0.88 & 17 & 264 & 145 & -45 & 197 & 107 & -46 & 847 \\
\hline 2004 & 0.54 & 0.68 & 14 & 277 & 183 & -34 & 206 & 131 & -36 & 962 \\
\hline 2005 & 0.72 & 0.86 & 15 & 241 & 138 & -43 & 178 & 96 & -46 & 772 \\
\hline 2006 & 0.58 & 0.74 & 16 & 449 & 324 & -28 & 312 & 225 & -28 & 1234 \\
\hline 2007 & 0.68 & 0.83 & 15 & 276 & 155 & -44 & 199 & 107 & -46 & 951 \\
\hline 2008 & 0.66 & 0.78 & 12 & 270 & 168 & -38 & 201 & 123 & -39 & 917 \\
\hline 2009 & 0.57 & 0.68 & 11 & 256 & 178 & -30 & 195 & 131 & -33 & 887 \\
\hline 2010 & 0.77 & 0.92 & 15 & 261 & 134 & -49 & 187 & 97 & -48 & 943 \\
\hline 2011 & 0.58 & 0.74 & 16 & 348 & 290 & -17 & 258 & 224 & -13 & 911 \\
\hline 2012 & 0.78 & 0.87 & 9 & 258 & 205 & -21 & 191 & 155 & -19 & 866 \\
\hline 2013 & 0.62 & 0.79 & 17 & 316 & 264 & -17 & 239 & 204 & -15 & 847 \\
\hline
\end{tabular}

\subsubsection{Analysis of Bayesian Performance}

In addition, pixels within the areas of lowest Bayesian performance were assessed using the yearly CHIRPS and bias-corrected (bc) rainfall estimates relative to rain gauge data. Nine pixels from Mt. Elgon, Southern Tanzania, Lake Victoria, and Mt. Kilimanjaro were considered (Figure 3.1). Figure 3.8 shows the scatter plots of the uncorrected CHIRPS rainfall estimates and MAE change in percentage after correction. A linear relationship was evident, indicating that as the CHIRPS rainfall estimates increased, the effectiveness of the approach reduced. Further results also showed that for the 11 years of analysis, overestimations were dominant except over Mt. Elgon, which showed isolated incidences of underestimation. CHIRPS overestimates in areas of high rainfall, and this is likely to be attributable to cirrus effects in those areas of deep convection (Kimani et al., 2017). Table 3.3 shows a summary of the yearly statistics for the 11-year validation period on Bayesian performance analysis over Mt. Elgon, Southern Tanzania, Lake Victoria, and Mt. Kilimanjaro. These were the areas of largest uncorrected overestimations. The results showed that over the four regions, the lowest MAE in the uncorrected CHIRPS corresponded to the highest percentage of error corrected. This suggests that the retrieval capability of CHIRPS determines the magnitude of errors corrected due to the average error consistencies. Consequently, the MAE errors corresponded to rainfall magnitude, suggesting overestimations increase in years of high rainfall. As such, the relatively dry year of 2005 had substantial MAE errors corrected. 
Furthermore, observations showed that although each region received different amounts of rainfall in different years, the percentage change in the MAE showed a similar pattern. An example was in the year 2009 over the Mt. Elgon and Lake Victoria areas, where the lowest MAE in CHIRPS rainfall were $49.4 \mathrm{~mm} /$ year and $273.5 \mathrm{~mm} /$ year, respectively. Consequently, the corrected MAE were the highest (38\% and 44\%). Similarly, over Southern Tanzania, in 2007, the lowest MAE in CHIRPS was $175.6 \mathrm{~mm} / \mathrm{year}$, and corresponded to the highest percentage (50\%) of corrected errors. In Mt. Kilimanjaro in 2005, the lowest MAE error in CHIRPS was $1140.4 \mathrm{~mm} /$ year and also coincided with the highest percentage error corrected of $23 \%$. These errors of overestimations were attributable to the cold cirrus effect, which infrared based algorithms including CHIRPS consider as precipitating. The Bayesian approach showed little skill in eradicating these errors, partly due to the low misrepresentation of rainfall variability in areas of poor rain gauge distribution in these areas. As such, the rain gauge data were inconsistent in time. 

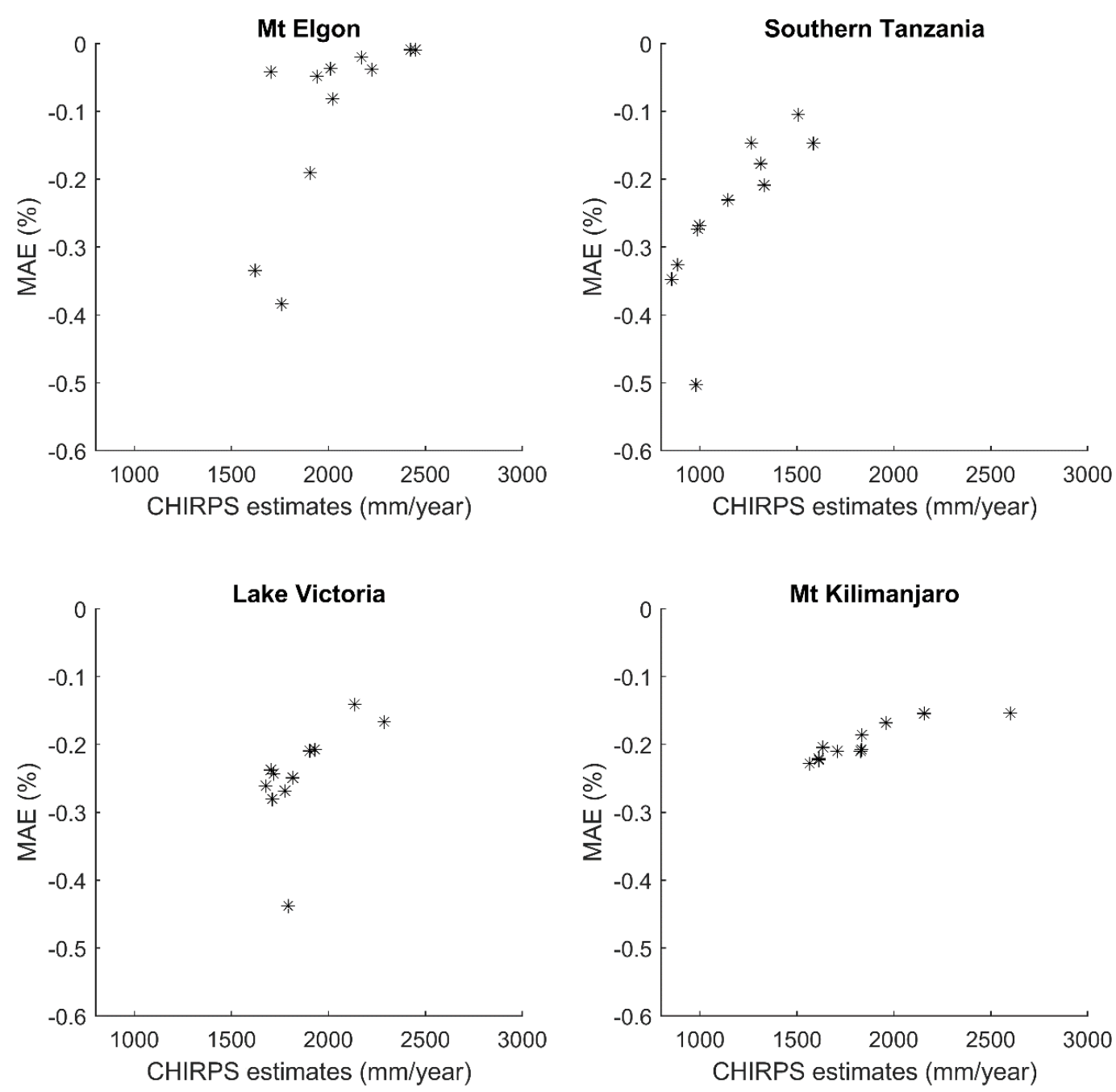

Figure 3. 8: Yearly scatter plots for of pixels in areas of lowest bias correction.

Table 3.3: Statistics for the yearly Bayesian performance analysis.

\begin{tabular}{ccccccc}
\hline & Mt Elgon & \multicolumn{3}{c}{} & & \multicolumn{2}{c}{ Southern Tanzania } \\
\hline \multirow{2}{*}{ Years } & MAE & MAE & Change & MAE & MAE & Change \\
& & $(\mathrm{bc})$ & $(\%)$ & & $(\mathrm{bc})$ & $(\%)$ \\
2003 & 105.2 & 85.2 & -19 & 270.9 & 182.6 & -33 \\
2004 & 167.3 & 160.3 & -4 & 423.0 & 334.7 & -21 \\
2005 & 56.2 & 37.4 & -33 & 254.3 & 166.0 & -35 \\
2006 & 771.7 & 764.8 & -1 & 601.4 & 513.0 & -15 \\
\hline
\end{tabular}


Bayesian Bias Correction of Satellite Rainfall Estimates for Climate Studies

\begin{tabular}{ccccccc}
\hline 2007 & 143.9 & 137.0 & -5 & 175.6 & 87.3 & -50 \\
2008 & 113.1 & 103.9 & -8 & 498.3 & 410.0 & -18 \\
2009 & 49.4 & 30.5 & -38 & 383.2 & 294.8 & -3 \\
2010 & 182.9 & 176.0 & -4 & 322.6 & 234.3 & -27 \\
2011 & 347.9 & 341.0 & -2 & 844.4 & 756.1 & -10 \\
2012 & 728.5 & 721.6 & -1 & 329.6 & 241.3 & -27 \\
2013 & 188.8 & $\begin{array}{c}181.9 \\
\text { Lake Victoria }\end{array}$ & -4 & 602.8 & 514.5 & -15 \\
& \multicolumn{7}{c}{ Mt Kilimanjaro } \\
& MAE & $\begin{array}{c}\text { MAE } \\
\text { (bc) }\end{array}$ & $\begin{array}{c}\text { Change } \\
\text { (\%) }\end{array}$ & MAE & MAE & Change \\
2003 & 504.6 & 384.8 & -24 & 1167.7 & 907.7 & $(\%)$ \\
2004 & 492.6 & 372.8 & -24 & 1254.7 & 994.7 & -21 \\
2005 & 459.2 & 339.4 & -26 & 1140.4 & 880.5 & -23 \\
2006 & 720.4 & 600.5 & -17 & 1692.8 & 1432.8 & -15 \\
2007 & 577.6 & 457.8 & -21 & 1238.9 & 978.9 & -21 \\
2008 & 446.3 & 326.5 & -27 & 1685.8 & 1425.9 & -15 \\
2009 & 273.5 & 153.7 & -44 & 1548.5 & 1288.5 & -17 \\
2010 & 481.2 & 361.4 & -25 & 1239.0 & 979.1 & -21 \\
2011 & 851.9 & 732.0 & -14 & 1399.5 & 1139.5 & -19 \\
2012 & 572.6 & 452.8 & -21 & 1272.8 & 1012.8 & -20 \\
2013 & 427.1 & 307.3 & -28 & 1178.0 & 918.0 & -22 \\
\hline
\end{tabular}

\subsection{Discussion}

This study assessed the Bayesian bias correction on CHIRPS v2 using the regionally gridded rain gauge data provided by the ICPAC over East Africa. Although CHIRPS includes some of the rain gauge data used in this study, they were a small percentage derived mainly from the GTS. The ICPAC gridded dataset incorporates all of the available quality controlled meteorological and hydrological rain gauge data from East African member states. Furthermore, a recent study by (Kimani et al., 2017) on the commonly used satellite products including CHIRPS over the region, showed large discrepancies with ground data, especially in high elevated areas. This study aimed to reduce these errors mainly caused by local effects by using Bayesian methods. The correction was on a monthly scale, which is relevant for long-term applications of 33 years (1981-2013). The usage of the approach assumes the mean errors of the input data are consistent in time. The results from the monthly analysis showed that the approach significantly reduced the systematic errors in all months from January to December with varying magnitudes. The corrected biases were 
mainly of underestimations affecting the high elevated areas attributable to orographic processes. Overestimations affected the areas around Lake Victoria and low-lying areas to the eastern parts of East Africa and Southern Tanzania. This is attributable to the cirrus effects caused by the assignment by infrared sensors in satellite products of all cold clouds as precipitating. It is suggested the cirrus effect affects areas of poor rain gauge networks areas as they misrepresent rainfall variability. As such, the rain gauge data were inconsistent with time, which is an assumption in this approach, hence the low effectiveness of bias correction over those areas. This observation concurred with that in (Trejo, Barbosa, PenalozaMurillo, Moreno, \& Farias, 2016) where at monthly time scales, CHIRPS overestimated low rainfall amounts and underestimated high rainfall amounts. However, the underestimations were associated with local processes, while overestimations were more likely to arise from cirrus effects occurring in deep convection (Sassen, Wang, \& Liu, 2009). Consequently, cirrus effects are observed mainly in months of increased rainfall in April and May. The study further revealed that during the southeast and northeast monsoon months of June to September and December to February, low linearity improvements were observed as indicated by corrections change. The inhibition of rainfall further inland from the low-level diffluence of the monsoon winds leads to the dominance of orographic processes (Kimani et al., 2017). Consequently, the rainfall variability in Eastern Kenya and Southern Tanzania coincided with Turkana low-level jets (Kinuthia, 1992; S.E Nicholson, 2016), which link the local rainfall variabilities to external influences. These abrupt changes lead to increased rainfall variabilities, hence the reduced linearity assumed in the Bayesian approach.

The yearly analysis showed an increase of the corrected biases attributable to the reduced rainfall variability. Similar to monthly assessments, the underestimations in corrected data were more dominant over the high elevated areas. Similarly, overestimations were observed in areas around Lake Victoria, Mt. Elgon, Eastern Kenya, and Southern Tanzania. These are areas of poor rain gauge distribution, and the misrepresentation of rainfall variabilities led to a reduction in the minimal errors. Consequently, the CHIRPS rainfall estimates approached its uncorrected state. One advantage of the method the incorporation of the error variance in the correction, and the correction only applies when the reference dataset is reliable, and errors are systematic, not random. Although 2006, which was also an El Niño, received the highest rainfall, the percentage of errors corrected was not equivalently high. This suggests that the errors are not only dependent on rainfall magnitude, but on distribution in time. El Niño years occur during the October-December rainfall months, which also have fewer rain days when compared to the March-May rainfall months (Indeje, Semazzi, \& Ogallo, 2000). Consequently, the years following the El Niño years were observed to have high rainfall and a large percentage of bias were also corrected. This high rainfall after El Niño is suggested to arise during the MAM rainfall months. However, it is worth noting that East Africa has high rainfall variability and the yearly analysis presented here is for the whole region. This observation is essential as the systematic errors occur more with increased rainfall amounts, and also depend on the distribution of rainfall in time and space.

Further annual assessments of the performance of Bayesian approach were conducted on selected pixels centered in areas of large CHIRPS overestimations. Nine pixels from each region over Mt. Elgon, Southern Tanzania, Lake Victoria, and Mt. Kilimanjaro were selected. MAE in percentage change of CHIRPS and biascorrected CHIRPS relative to rain gauge data were used to quantify the relationships. Results showed that CHIRPS overestimated in all years (2003-2013) over those 
areas except for a few incidences of underestimation over Mt. Elgon. Furthermore, the MAE percentage change showed a linear relationship with rainfall magnitudes. An increase in rainfall magnitude corresponded with a decrease in the percentage of MAE change. This showed that there were uncorrected errors during high rainfall periods. It is understandable that cirrus coexists in deep convective systems (Sassen et al., 2009) that are also related to high rainfall amounts. Overestimations in the cirrus effect have also been observed in infrared based products in Eastern Africa (Young, Williams, Chiu, Maidment, \& Chen, 2014). The years 2005, 2007, and 2009 showed the lowest annual rainfall in these regions, and consequently, the highest MAE percentage change. The designation of CHIRPS is for dry conditions; hence the mean errors are consistent in time, hence an increased Bayesian performance. Similar findings in a recent study (Paredes-Trejo, Barbosa, \& Kumar, 2017) showed that CHIRPS had low rainfall detection during the wet season. The Bayesian approach showed low skill in reducing errors attributed to cirrus effects in areas of poor rain gauge network due to the misrepresentation of rainfall variability.

\subsection{Conclusions}

Rain gauge distributions are on the decline, and satellite rainfall estimates are increasingly used to complement the sparse network. However, rain gauges continue to be used as reference data to validate the incoming satellite products as they offer the most direct information on local rainfall variabilities. This is understandable in developing countries where other ground observations like weather radar are too expensive. However, considering the decreasing trend in rain gauge density, other measures like gridding the available gauge data are preferred. As such, validation exercises are enhanced, which may otherwise become increasingly compromised in the future. This impact may be much more severe for long-term data applications. This study assessed the applicability of the Bayesian approach with an existing historical rain gauge dataset to create consistent satellite rainfall data for long-term applications. The gridded rain gauge dataset was developed by ICPAC to safeguard the decreasing rain gauge information over East Africa.

CHIRPS was chosen based on its close correspondence with rain gauge datasets when compared to other commonly used products over the region (Kimani et al., 2017). However, CHIRPS, like other satellite-derived products, exhibit systematic errors that vary from place to place. In mountainous areas like East Africa, the retrieval of topographic processes is challenging. These biases need to be reduced to increase the effectiveness of this product over the region. It is understandable that high elevated areas play a significant role in water availability and minimizing these errors would improve the representative of the CHIRPS estimates. Furthermore, as CHIRPS has a high $\left(0.05^{\circ}\right)$ spatial scale, it can be used for future reference for the incoming coarser satellite products. The study aimed at temporally and spatially evaluating how CHIRPS rainfall estimates compared with the gridded rain gauge data in magnitude and distributions after bias correction. For the Bayesian correction, a historical dataset of 22 years of data was used as the calibration dataset, and the ensuing 11 years were used for the validation.

Monthly analysis showed that CHIRPS estimates had systematic errors mainly of underestimations arising in high elevated areas and their surroundings. The approach adequately reduced them in both wet and relatively dry months. The study 
revealed large biases emerged during the wet months and less so for the relatively drier months. This is understandable as the CHIRPS algorithm has been optimized for drought monitoring, that is, for better accuracy during drier periods. As such, in April, which is the peak rainfall month of the March to May rainfall season, the biases were distributed over East Africa. In May, they were observed near the Lake Victoria region and coastal areas of Kenya where high rainfall is experienced during this month. During the south-east monsoon month of August, they were situated on the border between Kenya and Uganda following the highest rainfall amounts in the June through August rainfall season. However, low linearity improvements of the negative biases were observed during the southeast and northeast monsoon months in June to September and December to February, respectively. These were attributable to indirect rainfall variability related to external factors in high elevated areas. The study revealed that these monsoons influenced orographic processes, reducing further inland impacts. Furthermore, the Bayesian approach assumes linear relationships between rainfall variability and the mean errors. Overestimations were dominant over Lake Victoria, Southern Tanzania, Mt. Elgon, Eastern Kenya, and the Kilimanjaro region. These biases were attributable to cirrus effects, which in IR based products (like CHIRPS) often results in an overestimation of precipitation. Adequate bias reduction was observed except in a few areas over Southern Tanzania and part of Lake Victoria where misrepresentation due to the sparse rain gauge network affected the correction. It is worth noting that inconsistencies of average errors, due to sparse rain gauge distributions were attributable to CHIRPS large uncorrected errors in those areas. A remarkable difference in the approach to other methods is its ability to leave the satellite estimates close to the uncorrected state when the reference data is inconsistent in time. The overall monthly average reduction indicates that the RMSD reduced between $4 \%$ and $60 \%$, and the MAE between $1 \%$ and $63 \%$, while the correlations improved by up to $21 \%$, as shown in Table 1 .

The yearly analysis showed an increase in the corrected biases which is associated to the reduced rainfall variability at this scale. Similar to monthly findings, the corrected underestimations were more dominant on high elevated areas and were in areas of high rainfall magnitudes that showed seasonality. The study observed that the corrected biases were more during years of high rainfall magnitude. Although large biases were evident during El Niño year of 2006 which also has highest rainfall amount, not all El Niño years showed similar results. This is understandable as El Niño years occur during the October-December rainfall months, but its effect spreads to the March-May rainfall months. As a result, the year that followed was observed to have high rainfall, hence an increased in the biases corrected. An example is shown in the 2003, 2006, and 2009 El Niño years whereby an increased rainfall average amount was observed a year after in 2004, 2007, and 2010. Consequently, a higher percentage of bias were corrected. This observation is vital as the systematic errors are increased with increased rainfall amounts, but are also dependent on the distribution of the rainfall in time. The overall yearly average reduction indicated that the RMSD was reduced by between $17 \%$ and $49 \%$, and the MAE was reduced by between $13 \%$ and $48 \%$, while the correlations increased by between $9 \%$ and $17 \%$, as shown in Table 2 .

Further assessments of the performance of the Bayesian approach were carried out using selected pixels (Figure 1) in areas of substantial uncorrected bias. These areas included Mt. Elgon, Southern Tanzania, Lake Victoria, and the Mt. Kilimanjaro areas. Nine pixels from the areas with the largest overestimations were used for the extraction of average rainfall for CHIRPS, and bias-corrected CHIRPS (bc) and 
compared with the corresponding rain gauge dataset. The percentage change in MAE quantified their relationships. This analysis indicated that CHIRPS considerably overestimated rainfall in those areas of sparse rain gauge distributions. The highest corrected MAE were observed in the years of the lowest MAE. Observations showed that the years 2005, 2007, and 2009 had the lowest annual rainfall in these regions, and consequently, the highest MAE decrease. Although each region received different amounts of rain over the validation period, the errors in corrected estimates showed a similar trend. The lowest MAE before correction corresponded with the highest percentage of corrected errors spatially and temporally. This can be understood as shallow convections in cirrus effects are minimal. Conversely, in the years and areas of deep convections, cirrus clouds increase. However, in areas of relatively dense rain gauges, cirrus related errors are minimized. For example, in the year 2009 over the Mt. Elgon and Lake Victoria areas, the lowest MAEs observed before correction were $49.5 \mathrm{~mm} /$ year and $273.5 \mathrm{~mm} /$ year, respectively. Consequently, those were the areas of highest corrected $\mathrm{MAE}$, at $38 \%$ and $44 \%$, respectively. Similarly, over Southern Tanzania, in the year 2007, the lowest MAE was $175.6 \mathrm{~mm} /$ year, and was consistent with the highest corrected MAE of $50 \%$. In Mt. Kilimanjaro, in 2005, the lowest MAE error was $1140.6 \mathrm{~mm} /$ year and coincided with the highest percentage improvement of $23 \%$. Therefore, overcorrections were adequately addressed spatially and temporally when rainfall was low in areas of sparse rain gauges, but remain unaddressed in deep convection attributed to monsoons. This effect was minimal in densely distributed rain gauge areas due to the increased representation of rainfall variability.

The Bayesian approach is recommended to adjust rainfall estimates of other algorithms with long-term historical records that are representative of rainfall variability of the area under consideration. The method is suitable for the reduction of systematic errors, especially in high elevated regions. It is, however, sensitive to sparse rain gauge distributions in regions of deep convective systems due to cirrus effects that cause overestimations. Therefore, with a good quality rain gauge network, the approach works better in those areas. It is recommended to have the reference data of a higher or equal spatial scale for higher rainfall spatial representation. 
Chapter 4

\section{An assessments of moisture distribution influence on rainfall variability during different phases of Indian Ocean Dipole over East Africa3}

3 This chapter is based on:

Kimani, M. W. Hoedjes, J. C. B. Su, Z. B. 2019: An assessments of moisture distribution influence on rainfall variability during different phases of Indian Ocean Dipole over East Africa. Journal of Geophysical Research, Atmospheres, under review. 
An assessments of moisture distribution influence on rainfall variability during different phases of Indian Ocean Dipole over East Africa

\begin{abstract}
The impact of moisture distribution to rainfall variability over East Africa during different phases of Indian Ocean Dipole (IOD) was assessed using Era interim Reanalysis dataset for 33 years (1981-2013). Advected moisture is the dominant source of precipitation and evaporation contribution is minimal affecting mainly Lake Victoria region. Eastern boundary contributes the largest inflow from the Indian Ocean. Monthly rainfall averages closely correspond to total moisture budget except during the southwest monsoon when stable conditions enhance dryness. Areas of moisture convergence correspond to convective areas represented by increased vertical motions. Yearly analysis of vertical velocity (mb s-1) showed a dominance of low-level moisture convergence over eastern parts bordering the Indian Ocean while mid-troposphere (500-700 mb) influences the western regions convergences. Empirical Orthogonal Functions (EOF 1,2) of moisture were utilized to determine the impact of the Dipole Mode Index (DMI) and Nino 3.4 to moisture distributions during different phases of IOD.DMI showed the largest influence during ITCZ overpass explaining $>60 \%$ and less during southwest monsoon months. EOF2 contributed $31 \%$ influence in May attributed to DMI with little impact from Nino3.4. EOF1 showed significant correlations (0.60) with DMI in August enhancing easterly moisture flux during southwest monsoon leading to reduced moisture from Indian Ocean evidenced by negative correlations $(-0.63)$ in November. Nino 3.4 negatively correlated with EOF1 in May and November during positive IOD of -0.80 and -0.76 respectively. The early onset of southwest monsoon in May during El Niño year suppresses moisture influx from the Indian Ocean.
\end{abstract}

Keywords: East Africa, moisture, Indian Ocean Dipole 


\subsection{Introduction}

Rainfall is an essential component of the water cycle and understanding its variability in space and time is crucial in water resource management and for agricultural planning. Sources and transport of precipitable moisture are vital in understanding rainfall variability (Trenberth, 1999). Over the tropics, integrated moisture budget corresponds to rainfall variability (Muller, Back, O'Gorman, \& Emanuel, 2009b). Further, a recent study over East Africa by (Souverijns, Thiery, Demuzere, \& Van Lipzig, 2016) who associated moisture variability and local feedbacks to the largest percentage of rainfall variability.

Precipitable moisture is either evaporated from the region or advected from other places. Over East Africa, Lake Victoria is the largest inland water body and is a source of moisture that influences rainfall variability to the neighbourhood (Sun, Xie, Semazzi, \& Liu, 2015). Advected moisture to the region comes from the Indian Ocean that borders it to the east and west associated with the Atlantic Ocean and Congo basin (S.E Nicholson, 1996). The mechanism controlling moisture advection from the two sources are inter-related. For example, a study by (A. P. Williams et al., 2012) observed moisture influx from Congo to be influenced by the surface pressure gradient between the Indian Ocean and Atlantic. Further,observation linked mid-tropospheric stable air transport from southern tropical Indian Ocean (STIO) to dry conditions over the Greater Horn of Africa (GHA). Concurring with the latter findings, Yang et al. (2015) observed advected moisture from the Indian Ocean to be stable throughout the year and become unstable during March-May (MAM) and October-December (OND) seasons. Moisture influx from Atlantic and Congo and is associated with a third rainfall season in June-August (JJA) affecting western parts of Kenya and Uganda (T. D. Davies, Vincent, \& Beresford, 1985; S.E Nicholson, 1996; A. P. Williams et al., 2012). However, a study by (Camberlin \& Philippon, 2002) observed MAM season to be associated with moisture influx from Congo.

Different methods have been applied to establish the relationship between moisture budget and rainfall such as the use of General Circulation Model (GCM)(Jin, Kitoh, \& Alpert, 2011), physical model (Muller, Back, O'Gorman, \& Emanuel, 2009a) and statistical approach (Neelin, Peters, \& Hales, 2009) (Yang et al., 2015; Q. Zhang, $\mathrm{Xu}$, Chen, \& Zhang, 2011). The results show close correspondence, but the relationships are geographically based. An example is a work by (Shi, Hao, \& Shao, 2014) who observed a poor relationship between rainfall and atmospheric moisture in dry areas implying that high moisture content may not necessarily result in increased rainfall depending on the climate of the region. It is partly associated with interactions between local processes and large-scale circulations (Kimani et al., 2017; Sun et al., 2015). The interaction may be remote such as the Pacific and the Indian Ocean which influences rainfall variability over the Lake Victoria (K. Williams, Chamberlain, Buontempo, \& Bain, 2015) and through zonal wind (Levin, Zipser, \& Cerling, 2009).

East Africa is in the equatorial region which is dominated by convective systems. Advected moisture convergences are observed to correlate with convection (Xie et al., 2014). CAPE $\left(\mathrm{J} \mathrm{kg}^{-1}\right)$ has been used to infer convection as it represents instability and low-level moisture (Holley, Dorling, Steele, \& Earl, 2014) and has been observed to follow ITCZ pattern (Meukaleuni, Lenouo, \& Monkam, 2016). Davies et al. (2013) used combined thermodynamic (CAPE), dynamic variables of vertical velocity (Omega) $\left(\mathrm{mb} \mathrm{s}^{-1}\right)$ at pressure $700 \mathrm{mb}$ level and moisture budget $\left(\mathrm{kg} \mathrm{m}^{-1} \mathrm{~s}^{-1}\right)$ to infer convection. However, in areas that experience ITCZ additional consideration of MSLP 
An assessments of moisture distribution influence on rainfall variability during different phases of Indian Ocean Dipole over East Africa

$(\mathrm{mb})$ and $2 \mathrm{~m}$ Surface temperature $(\mathrm{K})$ can enhance the delineation of convergence areas.

It is essential to determine the forcing behind moisture distribution. IOD (Saji, Goswami, Vinayachandran, \& Yamagata, 1999; Webster, Moore, Loschnigg, \& Leben, 1999) is one of the mechanisms that remotely influences East Africa rainfall (Behera et al., 2005). El Niño-Southern Oscillation (ENSO) (Philander, Lau, Pacanowski, \& Nath, 1989) is associated with October-December rainfall over the region (Indeje et al., 2000; Ogallo, 1988). For example, a study by (Mapande \& Reason, 2005) linked Nino 3.4 that represent ENSO to moisture influx from Congo that influences October-April over western Tanzania. Similarly, Zavala et al.(2005) observed nonlinear relationships between Madden Julian Oscillation (MJO) which is an intra-seasonal oscillation with ENSO suggesting progression of impacts to annual scale. The IOD oscillations are said to be triggered by ENSO (X. Wang \& Wang, 2014), although a recent study by (H. Wang, Murtugudde, \& Kumar, 2016) showed that it could occur independently. The two ocean indices impact on moisture influx to East Africa. For example, a study by Pohl et al. (2006a) observed low-level moisture influx from the Indian Ocean that caused wetness over the Kenya highland and coastal areas and linked it to MJO phases. Wilson et al. (2013) found MJO over the eastern Indian Ocean to be related to negative IOD during the dry spell over East Africa. More work is essential to further understanding of how the two indices are related to moisture advection over the region.

The paper is structured as follows: Material and data explained in section 4.1. Monthly moisture budget and its components calculations, comparison to rainfall convective Indices and influence of IOD are described in section 4.2. Results are presented in Section 4.3 while conclusions and discussions are in Section 4.4.

\subsubsection{Material and data}

East Africa (Figure 4.1) borders the Congo basin to the west and the Indian Ocean to the east. Convergence in the ITCZ is enhanced by a moisture influx from easterly and westerly flows during the MAM and OND seasons. The southwest monsoon occurs between June and September affecting mainly the western parts of East Africa. 


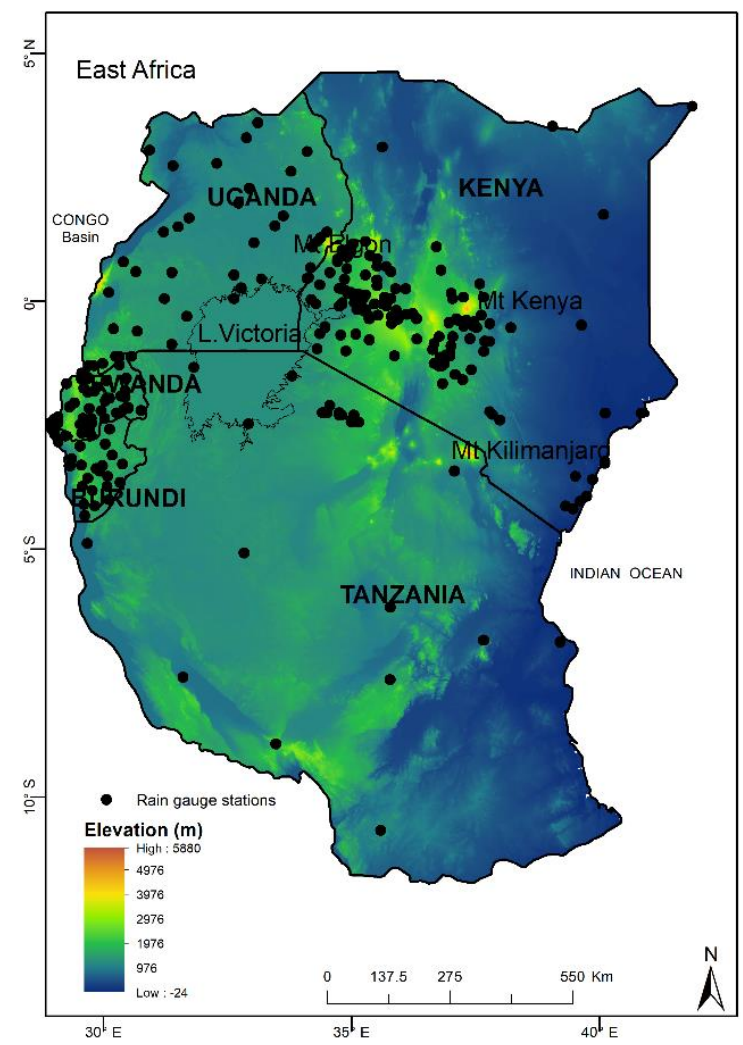

Figure 4. 1: Map of East Africa, with Shuttle Radar Topography Mission (SRTM) 90 $m$ digital elevation model. The black dots represent rainfall stations gridded and used in locally bias correcting CHIRPS rainfall data for 33 years (1981-2013).

We used CHIRPS v 2.0 monthly rainfall data developed by the United States Geological Survey (USGS) Earth Resources Observations and Science Centre and the University of California Santa Barbara Climate Hazards Group. To improve the local representability of the data, a Bayesian bias correction was carried out using gridded $\left(0.05^{\circ}\right)$ data from an in-situ rain gauge network applied by (Kimani et al. 2018) over the same region. The CHIRPs v2 was observed to be most reliable after evaluating seven satellite precipitation products over the region (Kimani et al. 2017) and in bias correction more rain gauge stations than previously merged with CHIRPS v2 were used.

The atmospheric variables were obtained from the ERA-Interim reanalysis data of the European Centre for Medium-Range Weather Forecasts (ECMWF) and included evapotranspiration, $2 \mathrm{~m}$ surface temperature, Mean Sea level Pressure (MSLP), wind vectors and Convective Available Potential Energy (CAPE) and vertical velocity of pressure (Omega) (mb s-1). Further, the reanalysis data were used to calculate moisture budgets, using variables at the spatial resolution of $0.75^{\circ}$ every month but resampled using the nearest neighbour method to $0.05^{\circ}$ spatial resolution. 
An assessments of moisture distribution influence on rainfall variability during different phases of Indian Ocean Dipole over East Africa

Zonal $(\mathrm{U})$, meridional $(\mathrm{V})$ wind ( $\mathrm{ms}-1)$ components and corresponding specific humidity $(\mathrm{kg} \mathrm{kg}-1)$ between the surface $(850 \mathrm{mb})$ and top $(200 \mathrm{mb})$ pressure levels were used to calculate the moisture budget. The $2 \mathrm{~m}$ surface temperature, CAPE, Omega and MSLP were used to infer convection areas.

Having identified the spatial convection distribution during negative and positive IOD, the remote link between moisture advection to the different phases of IOD were investigated. Since IOD years correspond with those of ENSO, the analysis included DMI and Nino 3.4with respect to first two dominant moisture modes (EOF 1 and 2). Monthly Nino 3.4 indices data were downloaded from the National Oceanic and Atmospheric Administration (NOAA) (Rayner et al., 2003) and Dipole Mode Index from (Saji \& Yamagata, 2003).

\subsection{Methodology}

\subsubsection{Estimation of moisture budget}

Atmospheric moisture budget on a column of air from the surface to a given pressure level is estimated as shown in equation (4.1).

$$
\frac{\partial W}{\partial t}=-\nabla \cdot Q+E-P
$$

Where $\partial \mathrm{W} / \partial \mathrm{t}$ is the change of precipitable water in time, $\nabla . \mathrm{Q}$ is the divergence of water vapour across the atmospheric column's boundaries, $E$ is surface evapotranspiration, and $\mathrm{P}$ is the rainfall. From equation (4.1) can be rewritten to equation (4.2).

$$
-\nabla \cdot Q=\frac{I F}{A}-\frac{O F}{A}
$$

Where $A$ is the area of the interest, OF and IF are the total advected water vapour mass outflow and inflow respectively. Substituting equation (4.2) into equation (4.1) yield Equation (4.3).

$$
P=\frac{I F-O F}{A}+E-\frac{\partial W}{\partial t}
$$

Assuming the change in atmospheric precipitable water to be very small on longterm (monthly) scale which is our interest in this study, i.e. neglecting $\partial \mathrm{W} / \partial \mathrm{t}$, equation (4.3) yields equation (4.4). 


$$
E-P=\frac{O F-I F}{A}=\nabla \cdot Q
$$

Therefore for E-P to balance moisture budget, inflow per unit area is considered negative and consequently outflow as positive.

Atmospheric large-scale circulations transport moisture to and from the study area through four directions, to the north, south, east and west. Calculating the total moisture budget by considering the zonal $\left(\mathrm{Q}_{\mathrm{u}}\right)$ and meridional $\left(\mathrm{Q}_{\mathrm{v}}\right)$ transport yield the equations (4.5-4.6).

$$
\begin{aligned}
& Q_{u}=\frac{-1}{g} \int_{P_{s}}^{P_{t}} q(x, y, p, t) u(x, y, p, t) d p \\
& Q_{v}=\frac{-1}{g} \int_{P_{s}}^{P_{t}} q(x, y, p, t) v(x, y, p, t) d p
\end{aligned}
$$

Where $q$ is the specific humidity as a function of latitude $(x)$, longitude $(y)$, pressure $(\mathrm{p})$, and time (t). $\mathrm{P}_{\mathrm{s}}$ and $\mathrm{P}_{\mathrm{t}}$ are the surfaces $(850 \mathrm{mb})$, and top (200 $850 \mathrm{mb}$ ) pressure levels. The computation of moisture crossing the four boundaries enclosing East Africa as in equations (4.7-4.10).

$$
\begin{gathered}
Q_{w}=\int_{\varphi_{1}}^{\varphi_{2}} Q_{u}\left(\lambda_{1}, y, t\right) \cdot I d \varphi \\
Q_{E}=\int_{\varphi_{1}}^{\varphi_{2}} Q_{u}\left(\lambda_{2}, y, t\right) \cdot I d \varphi \\
Q_{S}=\int_{\lambda_{1}}^{\lambda_{2}} Q_{v}\left(x, \phi_{1}, t\right) \cdot I \cdot \cos \varphi_{1} d \lambda \\
Q_{N}=\int_{\lambda_{1}}^{\lambda_{2}} Q_{v}\left(x, \phi_{2}, t\right) \cdot I \cdot \cos \varphi_{2} d \lambda
\end{gathered}
$$

Where $Q_{w}, Q_{E}, Q_{S}$ and $Q_{N}$ is the moisture transport cross the west, east south and north boundaries, respectively. 'I' is the length equivalent of $1^{\circ}$, while the $\varphi_{1}, \varphi_{2}$ and $\lambda_{1}, \lambda_{2}$ are the latitudes and longitudes of the south, north, and west, east boundaries respectively. Estimation of moisture budget $(\mathrm{kg} / \mathrm{ms})$ over the study area is as described in equation (4.11). Moisture inflow to the east and north are considered positive, while to the west and south are negative. 
An assessments of moisture distribution influence on rainfall variability during different phases of Indian Ocean Dipole over East Africa

$$
Q_{T}=Q_{W}-Q_{E}+Q_{S}-Q_{N}
$$

To determine the dominant moisture source, whether is from evaporation or advected from outside, a recycling ratio is used (Zangvil, Portis et al. 2004) (equation 4.12).

$$
R=\frac{E}{E+\frac{I F}{A}}
$$

Where $\mathrm{E}$ refer to the portion of moisture that is evaporated from the region.

Monthly moisture budget and its components are compared to corresponding rainfall over East Africa. The spatial patterns of rainfall minus evaporation and moisture correlation fields are determined using Pearson correlation (equation 4.13) for April, May, August and November. The months represent seasonal rainfall of MAM,JJA and OND.

$$
c c=\frac{\frac{1}{N} \sum_{i=1}^{N}\left(y_{i}-\bar{y}\right)\left(x_{i}-\bar{x}\right)}{\sigma_{y} \sigma_{x}}
$$

Where $y$ and $x$ stand for the two variables in comparison, the overbar is their respective mean, $\sigma$ their corresponding standard deviation and $N$ the number of samples considered.

\subsubsection{Moisture budget comparison with convection variables}

Since East Africa is within the tropics and the convection systems are dominant, further analysis with CAPE, Omega, $2 \mathrm{mT}$ and MSLP were carried out to determine convective areas and their relationships to advected moisture.

CAPE characterizes the thermodynamic state of the atmosphere and is calculated from the difference between the temperature of an adiabatically rising air parcel $\left(T_{v p}\right)$ and that of the environment $\left(T_{v e}\right)$. Two specific pressure levels ( $L C L$ and $\left.L N B\right)$ are multiplied with the gas constant of dry air $\left(R_{d}\right)$ (Emanuel, Neelin, \& Bretherton, 1994) as described in equation (4.14).

$$
C A P E=\int_{L F C}^{L N B} R_{d}\left(T_{v p}-T_{v e}\right) d \ln (p)
$$

Development of CAPE needs adequate low-level moisture which may be advected or evaporated from the region. Besides the spatial distribution analysis of convective variables, further analysis of spatial Omega vertical profile is performed within a 
rectangular area enclosing East Africa between $\left(29^{\circ} \mathrm{E}\right.$, and $42^{\circ} \mathrm{E}$, and $12^{\circ} \mathrm{S}$, and $\left.5^{\circ} \mathrm{N}\right)$. Further to determine the moisture convergence level the average Omega magnitude for East Africa land mask was determined. The analysis is carried during the representative months concurring with other analysis for the dry 1984 (A) and 2001(C), and wet (1997 and 2006) years from the surface (1000 mb) to near tropopause $(200 \mathrm{mb})$.

\subsubsection{Assessments of Indian Ocean Dipole forcing}

The IOD/ENSO influence on moisture distribution was assessed. Use was made of the leading inter-annual modes (EOF1 and 2) of moisture budget since they capture moisture variability. EOF 1 explains between $(27-50) \%$ of moisture variability while EOF2 explains (15-19)\%. First the contribution of moisture relative to the two modes were spatially described. Further the time series of each mode were compared with DMI and Nino 3.4 during positive, negative and neutral phases of IOD using scatter plots. This was aimed at determining the influence of DMI and ENSO to moisture distribution related to each mode during the three phases. The phases are based on (Guo, Liu, Sun, \& Yang, 2015) classifications of positive and negative IOD years. In this study a few of those years within the study period are considered corresponding to wet $(1982,1983,1994,1997,2003,2006,2007,2012)$ and dry $(1981,1984,1989,1996,1998,2001,2005,2010)$ years.

\subsection{Results}

\subsubsection{Analysis of moisture budget and rainfall}

Moisture budget and its components are compared to corresponding rainfall patterns over East Africa. Figure 4.2 is the mean (1981-2013) monthly plots and show the close correspondence of total moisture budget (QT) except in June through September that positive moisture corresponds to dry conditions. Further observation shows that moisture budget peaks during rainfall onset months in March and October while the rainfall peak lags one-month latter during MAM and OND rainfall seasons respectively. This concurs with a study by (Loriaux, Lenderink, \& Siebesma, 2016) that atmospheric forcing precedes a high-intensity event. Out of the four boundaries $Q_{w}, Q_{E}, Q_{S}$ and $Q_{N}$ it is evident the dominant moisture inflow is through the Easterly boundary $\left(\mathrm{Q}_{\mathrm{E}}\right)$ and follows the rainfall patterns. Outflow is largest in February attributed to onset on northeast monsoon that inhibits inland moisture influx from the Indian Ocean. Further, the lowest moisture influx is observed in May and is associated with the southwest monsoon that inhibits moisture influx further inland (Wei \& Bordoni, 2016). The latter is further supported by (Kinuthia \& Asnani, 1982; S.E Nicholson, 2016) studies that have shown the interaction of Turkana jets with Kenya highlands enhancing low-level diffluence. 
An assessments of moisture distribution influence on rainfall variability during different phases of Indian Ocean Dipole over East Africa

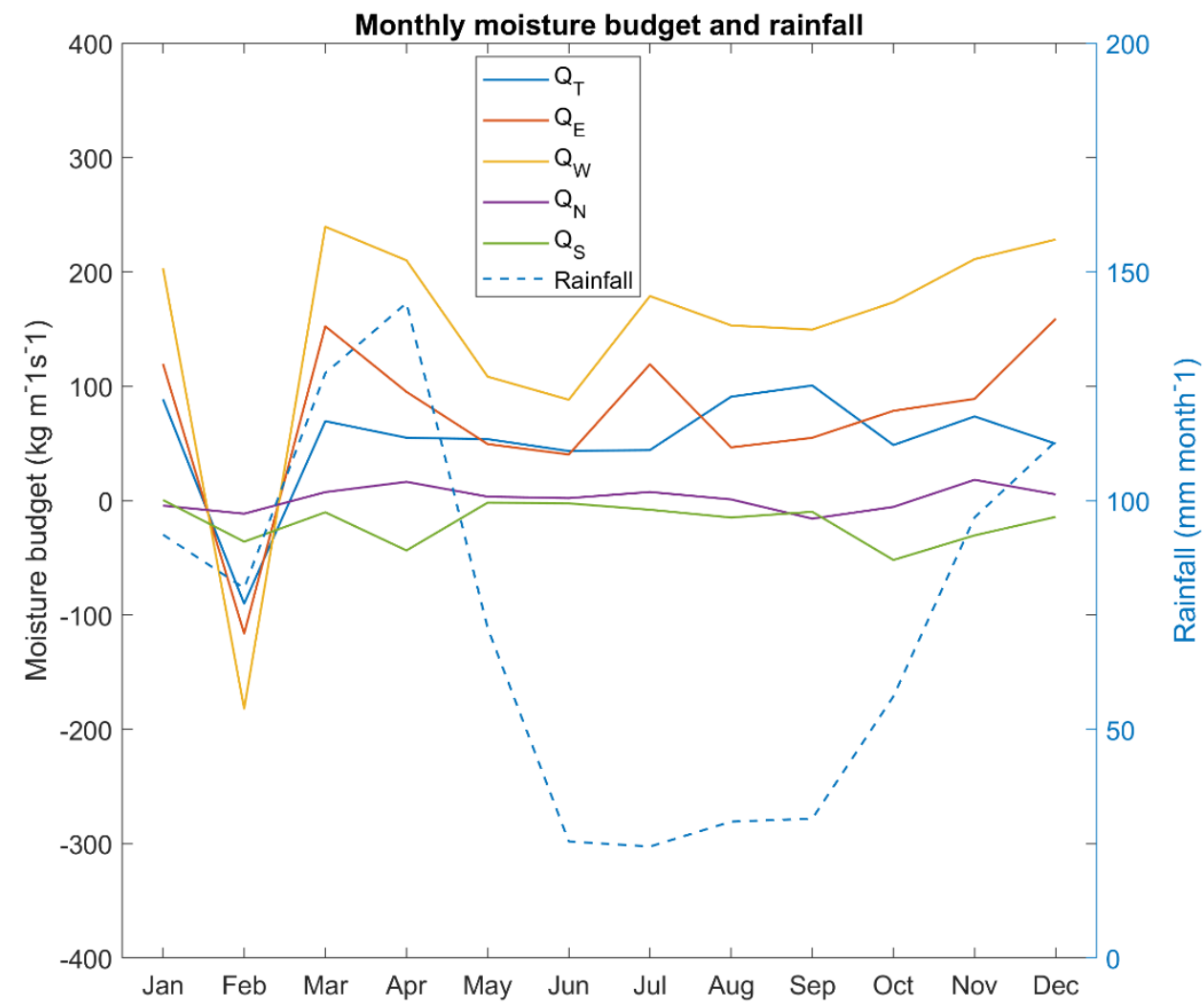

Figure 4. 2: Monthly averages (1981-2013) of total moisture budget flux and its components through the four boundaries; eastern $\left(\mathrm{Q}_{E}\right)$, western $\left(\mathrm{Q}_{\mathrm{w}}\right)$, southern $\left(\mathrm{Q}_{\mathrm{s}}\right)$ and northern $\left(\mathrm{Q}_{\mathrm{N}}\right)$ and the total moisture budget $\left(\mathrm{Q}_{\mathrm{T}}\right)\left(\mathrm{kgm}^{-1} \mathrm{~s}^{-1}\right)$ and corresponding rainfall over East Africa.

Spatial patterns of moisture fluxes and rainfall averages (1981-2013) and their corresponding correlations are shown in Figure 4.3 for April, May, August and November representing the three rainfall seasons. High rainfall is observed over Lake Victoria and the high elevated areas especially Mt Kenya and Mt Elgon (Figures 4.3e-h). Although both rainfall and moisture spatial patterns are similar (Figures 4.3a-d), negative correlations are evidence in moisture convergence areas. This is especially over western Kenya and parts of northern Uganda in April (Figures 4.3iI). The anti-correlations are attributed to shallow convections embedded within the large-scale moisture field. This concurs with a study by (L. Davies et al., 2013) that observed random convections in a weakly forced regime to be anti-correlated with largescale variables. During the southwest monsoon between June-August less advected moisture occurs over the region from the Indian Ocean. This further proven by southwest-northeast orientations of correlations patterns. Further, a 
study by (Vigaud, Lyon, \& Giannini, 2017) observed a reduction of rainfall in May over East Africa caused by the early onset of the Indian monsoon. The positive relationships in November are attributed to forced convection over the high ground areas particularly the Kenya highlands.
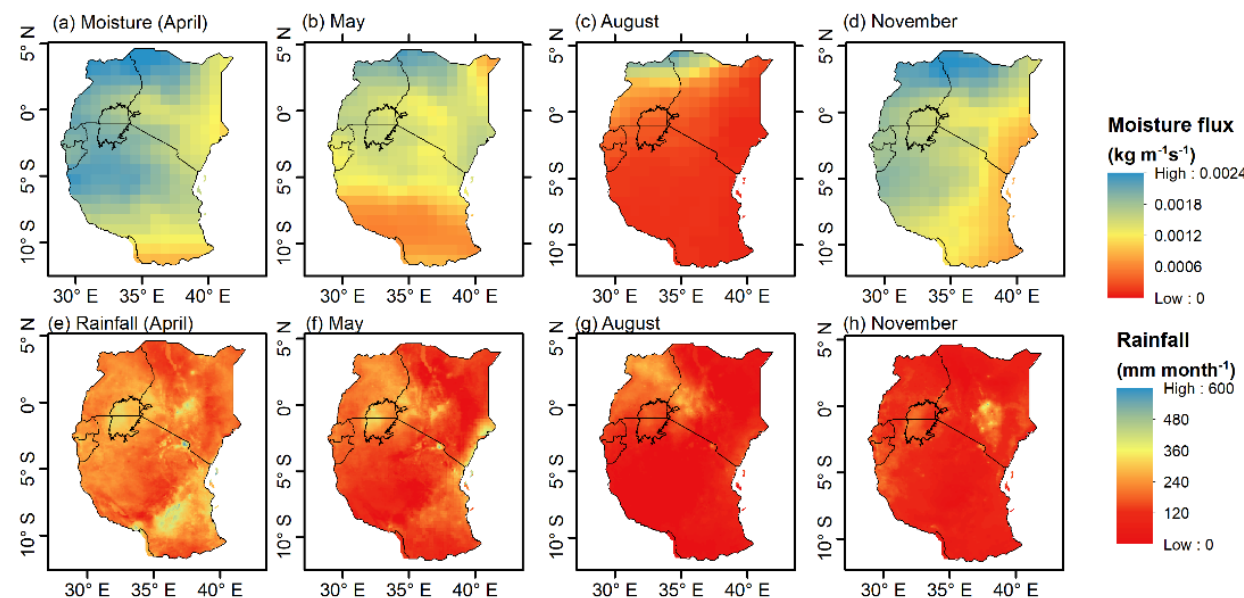

Rainfall

(mm month ${ }^{-1}$ )

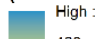

(i) CC (April)
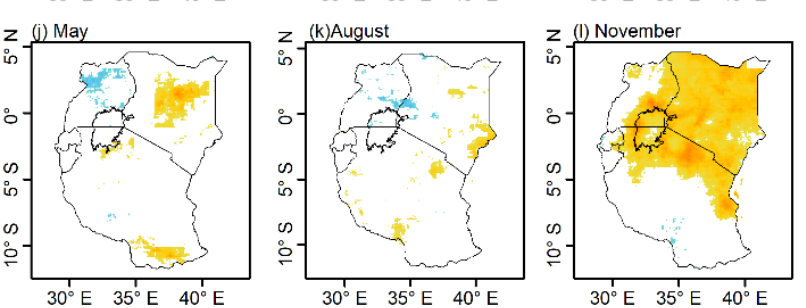

cc

Moisture flux: rainfall

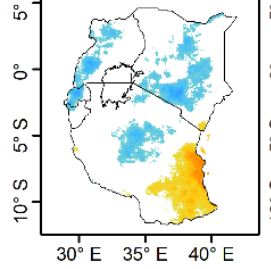

$30^{\circ} \mathrm{E} \quad 35^{\circ} \mathrm{E} \quad 40^{\circ} \mathrm{E}$

$30^{\circ} \mathrm{E} \quad 35^{\circ} \mathrm{E} \quad 40^{\circ} \mathrm{E}$

$30^{\circ} \mathrm{E} \quad 35^{\circ} \mathrm{E} \quad 40^{\circ} \mathrm{E}$

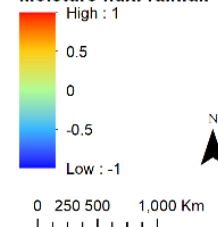

Figure 4. 3: Mean (1981-2013) monthly rainfall ( $\mathrm{mm})$, and integrated (surface: $850 \mathrm{mb}$, top: $200 \mathrm{mb}$ pressure levels) column moisture budget ( $\mathrm{Kg} \mathrm{m}^{-1} \mathrm{~s}^{-1}$ ) and their correlations over East Africa. Only correlations that are significant at 95\% confidence level are shown.

\subsubsection{Analysis of adverted Moisture and convection variables}

East Africa is within the tropics, and convective systems are therefore dominant especially during ITCZ. To understand convection relationship to moisture variability, both thermodynamic (surface temperature, CAPE) and dynamic variables (Omega, MSLP) are utilized to determine convection areas. Monthly moisture fluxes are compared with each of these variables shown in Figures 4.4-4.6. It is evident low MSLP (Figure 4.4e-h) correspond to areas of increased moisture (Figures 4.4ad) and is supported by their negative correlations. In April no significant correlations are observed which is attributable to increased local processes and nonlinear interactions with moisture flux. In May moisture convergence is observed over Uganda and coastal area the negative correlations observed. 
An assessments of moisture distribution influence on rainfall variability during different phases of Indian Ocean Dipole over East Africa
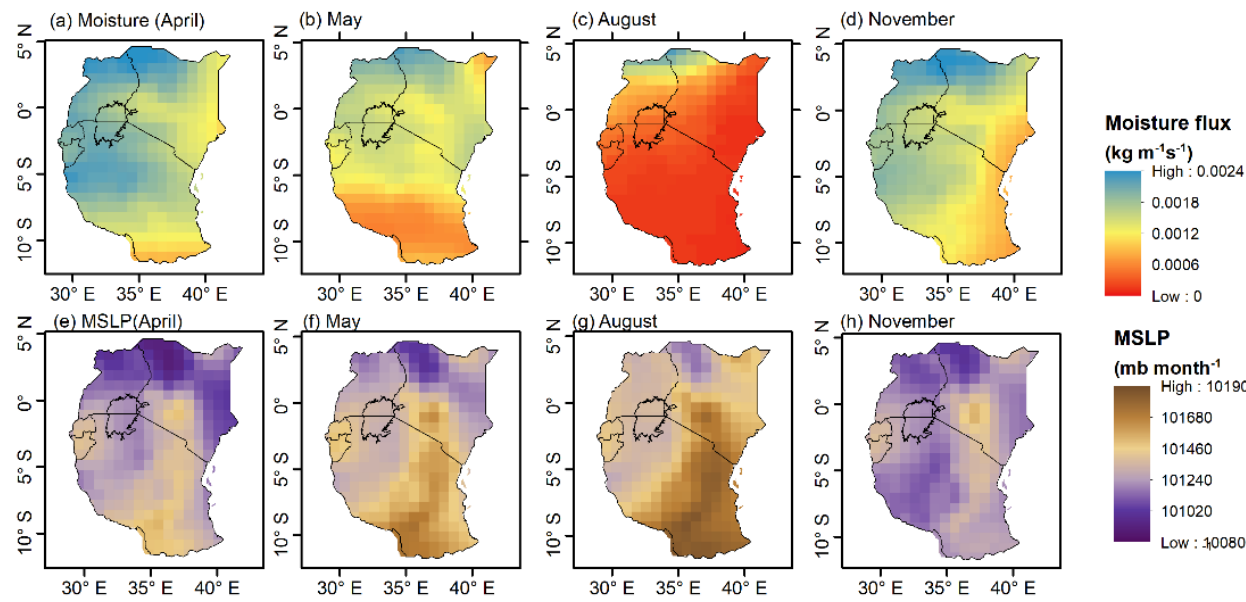

MSLP

(mb month -1 $^{-1}$

101680

101680
101460

101240

101020
Low : -100800
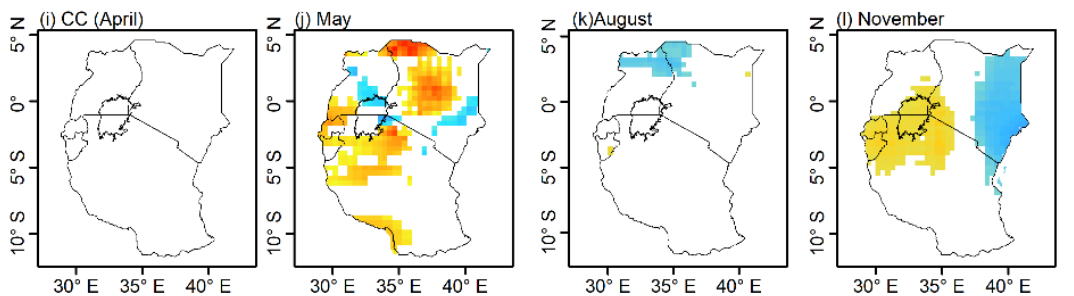

cc

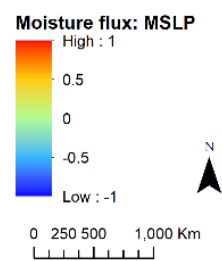

Figure 4. 4: Same as figure 4 but for MSLP

CAPE and moisture flux distributions are shown in Figure 4.5. It is observed the two have similar spatial patterns in some areas especially over Lake Victoria, and Uganda with high values of CAPE (Figure 4.5e-h) observed in areas of high moisture contents (Figure 4.5a-d). Areas with more moisture correspond to convective instability (Figure 4.5i). The negative correlation patterns in areas of increased moisture suggest that increased largescale forcing is anti-correlated with CAPE distributions. This concurs with (L. Davies et al., 2013) study that observed the strength of convection to be negatively correlated with large-scale variables. It can be suggested that largescale systems attributed to ITCZ cause anti-correlations. However, during southwest monsoon shallow convections corresponds with moisture distribution especially to the eastern part bordering the Indian Ocean. It is also evident that April follows the southeast-northwest orientation suggesting the southeasterly moisture influx. Alternatively, in August which is also part of southwest monsoon period the negative correlations follow southwest-northeast orientation suggesting eastward moisture flux (T. D. Davies et al., 1985). In areas of moderate moisture influx, positive correlations are evident. Similar observations are also seen in figure 4.6 with Omega suggesting in areas of moisture convergence forced convections are dominant. The negative/positive correlations with CAPE/Omega are associated with scale differences arising from local forced convection in large scale field (L. Davies et al., 2013). 

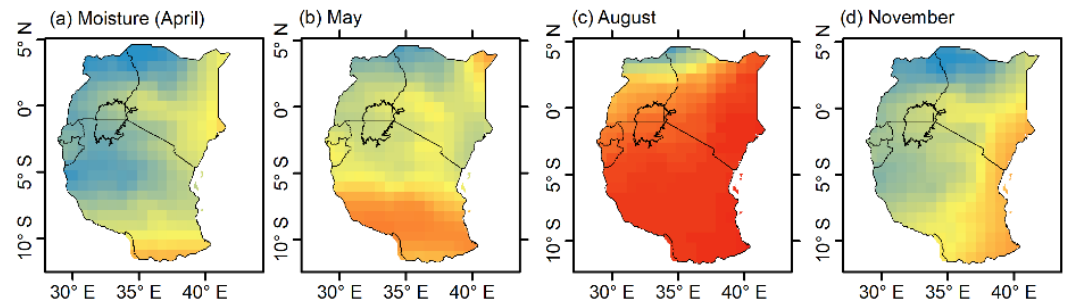

Moisture flux

$\left(\mathbf{k g ~ m}^{-1} \mathbf{s}^{-1}\right)$
High $: 0.0024$

0.0018

0.0012

0.0006
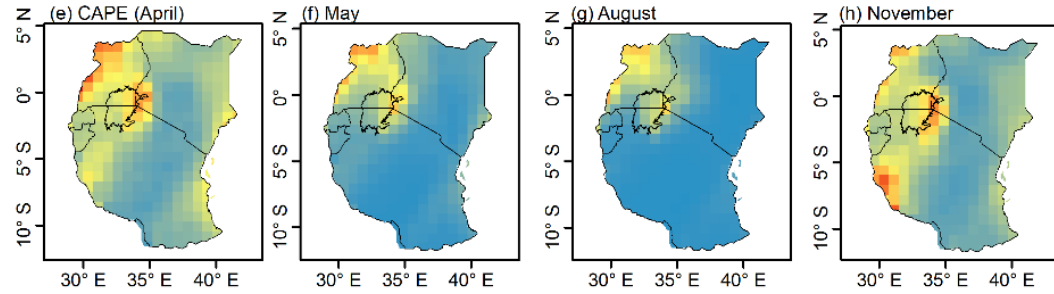

CAPE

$\left(\mathrm{J} \mathrm{kg}^{-1}\right)$ High : 1000

750

500

250
Low : 0
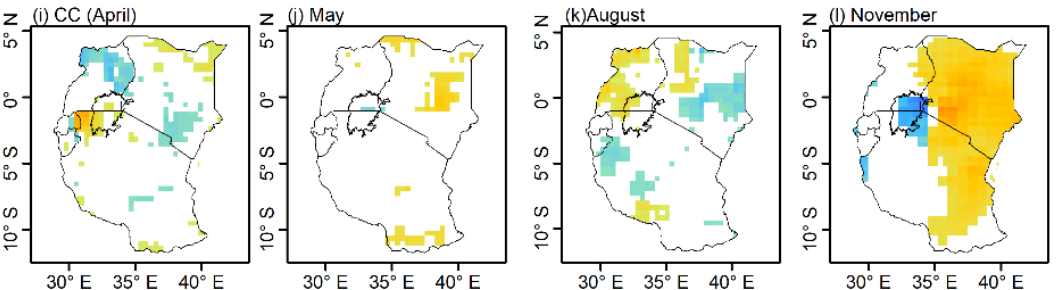

CC Moisture flux:CAPE Moisture flux:CAF
High : 1

Figure 4. 5: Monthly CAPE (J/kg) spatial distribution and correlation coefficients between with corresponding moisture budget $\left(\mathrm{Kgm}^{-1} \mathrm{~s}^{-1}\right)$ from their averages (1981-2013) over East Africa. 
An assessments of moisture distribution influence on rainfall variability during different phases of Indian Ocean Dipole over East Africa
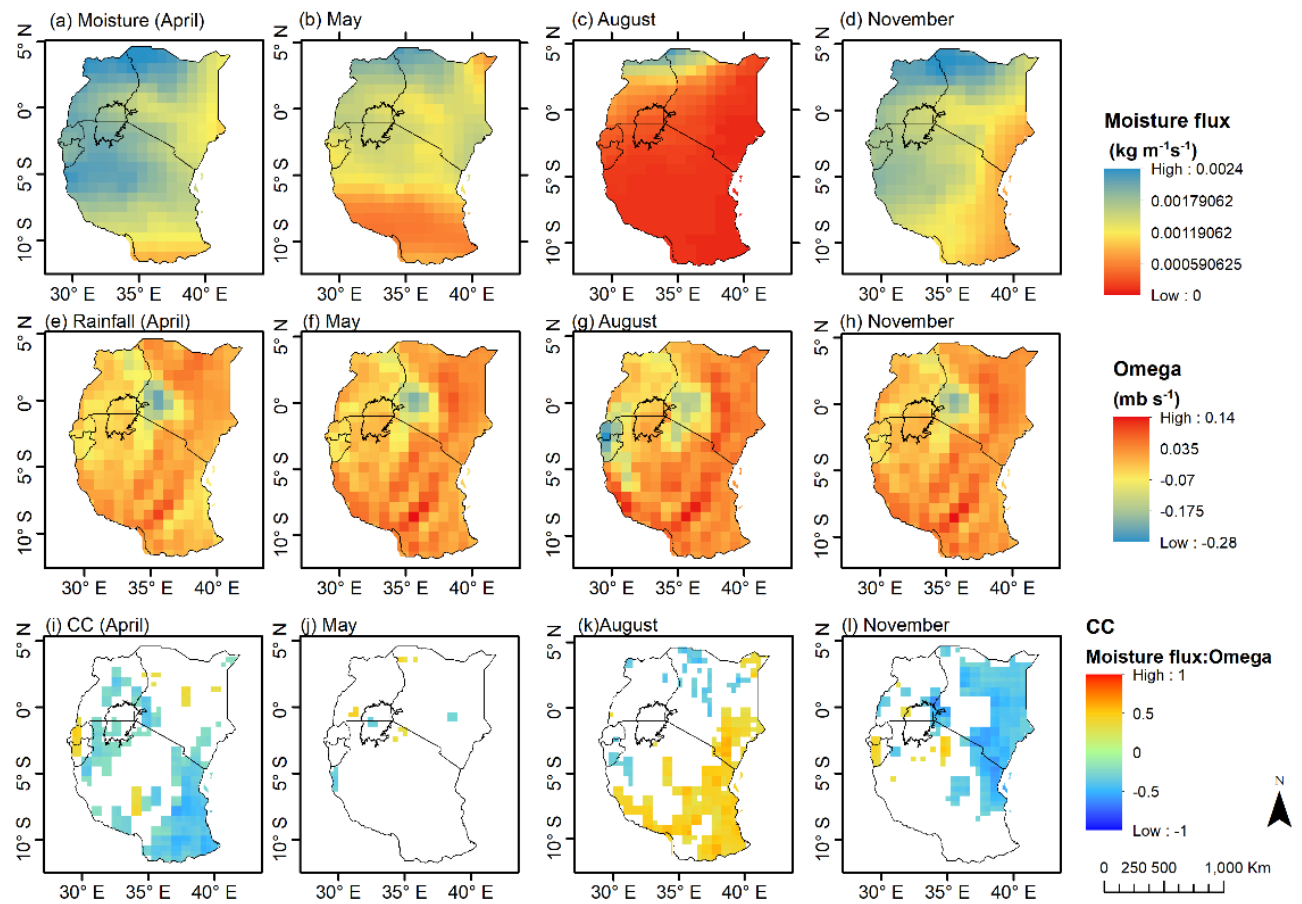

Figure 4. 6: Same as figure 4 but for Omega $\left(\mathrm{mb} \mathrm{s}^{-1}\right)$

Figure 4.7 shows the surface temperature and moisture fluxes spatial maps and their corresponding correlation patterns. It evident high temperatures (Figure 4.7eh) are observed to the eastern part bordering the Indian Ocean. Relatively low temperatures are also evident in areas of moisture convergence (Figure 4.7a-d) including western Kenya and Uganda. It can be understood therefore that surface temperatures enhance moisture convergence in those areas. However in semiarid areas of northern and eastern Kenya, high surface temperatures correspond to areas of low moisture which may be attributed to evaporation. This concurs with a recent study by (S.E Nicholson, 2016) that attributed the Turkana jets to aridity which may be thought of as enhancing low level cloud evaporation. Relatively lower surface temperatures are also observed over Lake Victoria region and the high elevated areas of Mt Kilimanjaro, Rwanda and Burundi. The high elevated areas with low temperatures are associated with altitude while low Lake temperatures are associated with Lake-land temperature contrast that is suppressed by the largescale circulation (Sun et al., 2015). Similar findings by (Nagarajan, Yau, \& Schuepp, 2004) of a study on the effect of small Lakes, and atmospheric heat and moisture budget observed land-lake temperature contrast is reduced by the advected fluxes. Correlation patterns with moisture flux (Fig 4.7i-4.7l), with positive correlations in areas of moisture convergence evident in April and August. No significant correlations are observed in May which is attributable to nonlinear relationships attributable to southwest monsoon onset, thereby reducing moisture convergence. Negative correlations observed in November are associated with low temperatures along the highland areas. 

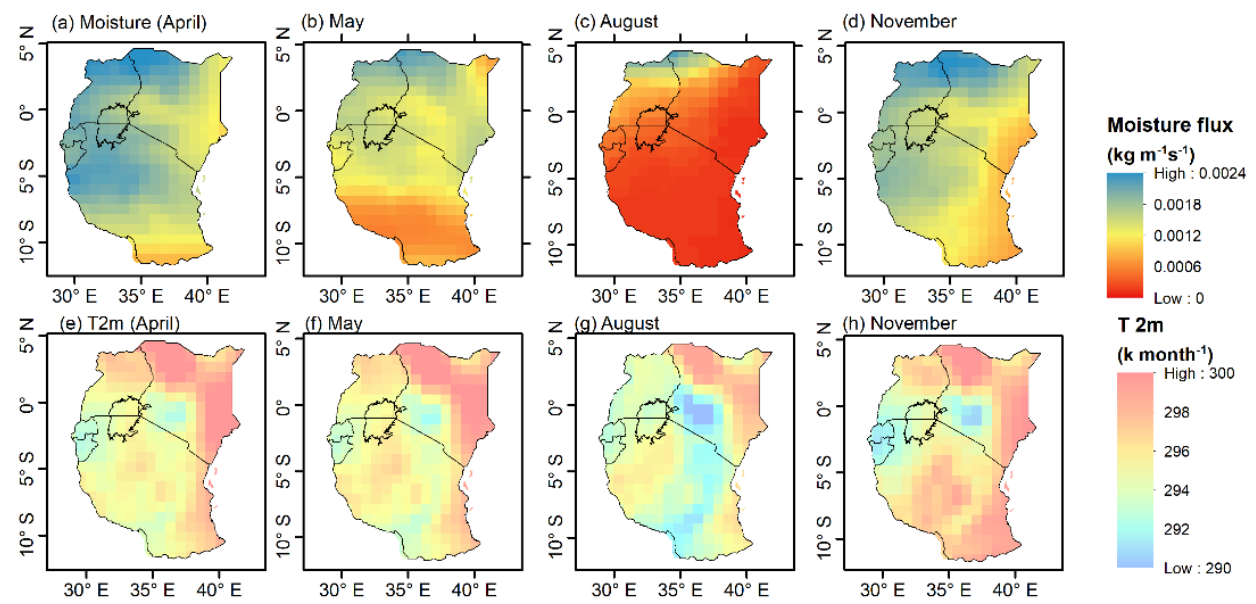

T $2 \mathrm{~m}$

(k month ${ }^{-1}$ )

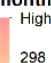

298

296

294

292
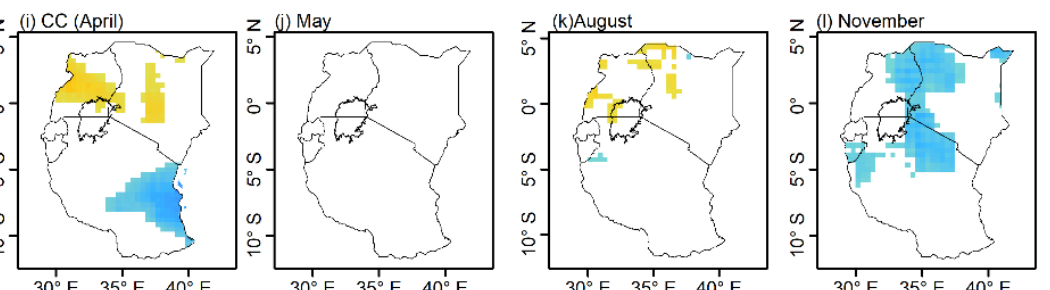

CC

Moisture flux:T2m

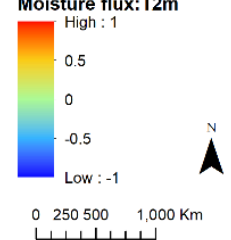

Figure 4. 7: Same as figure 9 but with 2-m surface temperature $(K)$ abbreviated as $T 2 m$.

Moisture convergence vertical profile during dry $(1984,2001)$ and wet $(1997,2006)$ years are assessed to determine the level of moisture convergence and source. Figures 4.8-4.11 show the Omega spatial and average vertical profiles from the surface $(1000 \mathrm{mb})$ to near tropopause $(200 \mathrm{mb})$ for the four months. East Africa experiences convective activities in both eastern and western parts which are separated by the Kenya highlands. The eastern rift valley includes the Mt Kenya region while the western include Rwanda, Burundi and Lake Victoria region. In April rising motions to the western parts (Figures 4.8a-d) are evident, while the eastern side (bordering the Indian Ocean ) sinking motions are dominant. This is particularly during the wet years which are also positive IOD/El Niño year in 1997 and 2006 (Figures $4.8 \mathrm{~b}$ and $4.8 \mathrm{~d}$ ). Conversely, the dry years, are dominated by sinking motions between $35-40^{\circ}$ longitude and general reduction of vertical motions to the western region (Figures $4.8 \mathrm{a}$ and $4.8 \mathrm{c}$ ). Areal average Omega vertical profile over the region (Figure 4.8e) show rising motions from the surface to $500 \mathrm{mb}$ level during the wet years while in dry years vertical motions are restricted to near surface. It is suggested that the low-level moisture convergence from the Indian Ocean contribute to the increased wetness to the western region. During the dry years, rising motions are experienced within a shallow layer up to $800 \mathrm{mb}$ level and is attributed to advected moisture at that level attributed from the Indian Ocean. 
An assessments of moisture distribution influence on rainfall variability during different phases of Indian Ocean Dipole over East Africa
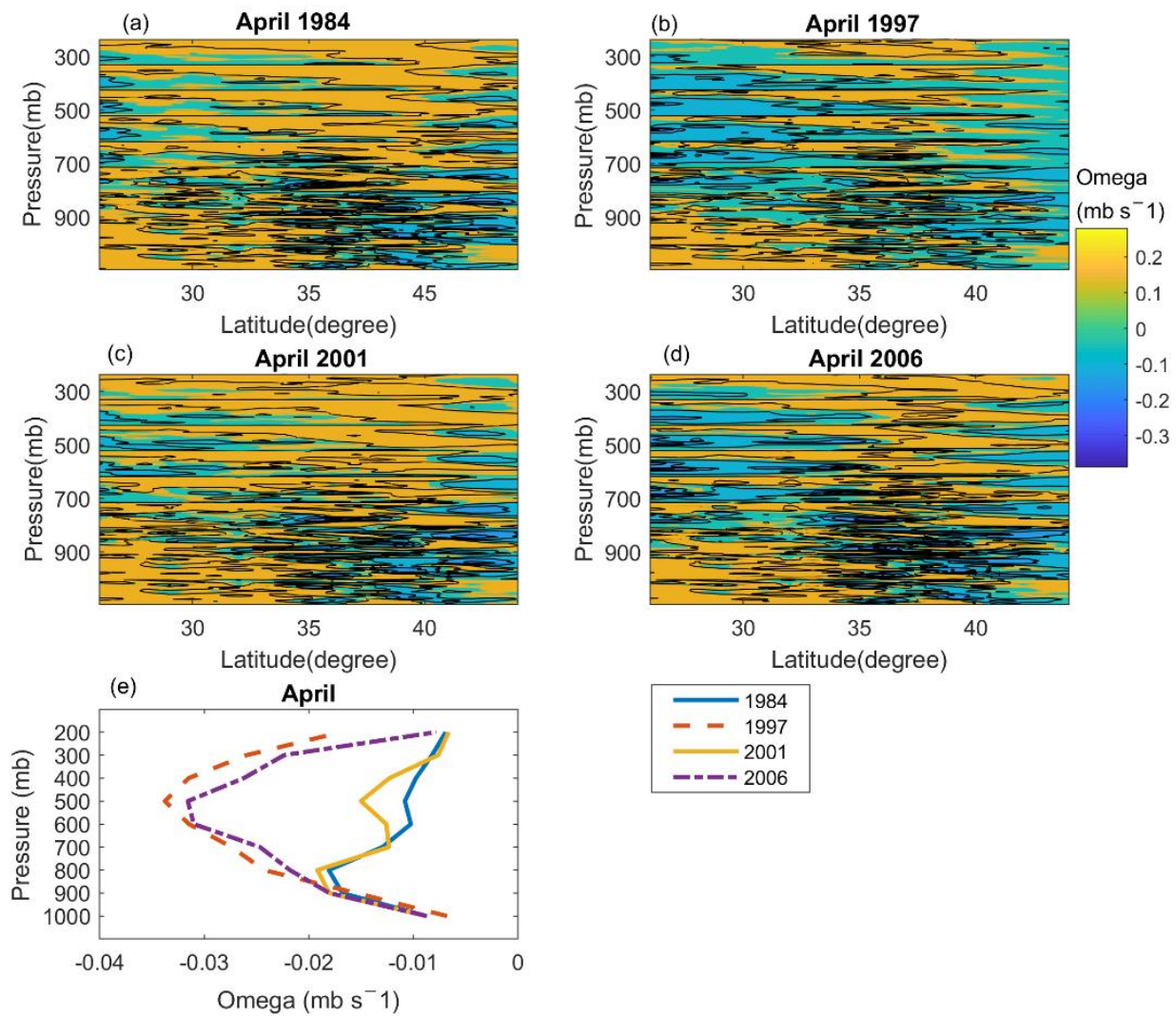

Figure 4. 8: Month of April Omega $\left(\mathrm{mb} \mathrm{s}^{-1}\right)$ over East Africa during the dry 1984 (Figure 4.8a) and 2001 (Figure 4.8c), and relatively wet 1997 (Figure 4.8b) and 2006 (Figure $4.8 d$ ) ) years from the surface $(1000 \mathrm{mb}$ ) to near tropopause (200 $\mathrm{mb}$ ) within a rectangular area enclosing East Africa between $29^{\circ} \mathrm{E}$, and $42^{\circ} \mathrm{E}$, and $12{ }^{\circ} \mathrm{S}$, and 5 o $\mathrm{N}$. Average Omega within the land mass was used to determine the moisture convergence levels (Figure 4.8e).

Figure 4.9 shows the Omega vertical profile in May. It clearly shows increased sinking motions especially to the eastern parts indicated by positive Omega. As a result, dry mid to upper troposphere are evident, and moisture influx is limited to surface convections over the eastern region. Evidently reduced eastern moisture convergence impact reduced convections to the western region and this is well understood as moisture is cutoff further inland at the onset of southwest monsoon. Furthermore, the average vertical profiles (Figure 4.9e) show temporal dominance of sinking motions except the year 2006. A study by (Camberlin, Fontaine, Louvet, Oettli, \& Valimba, 2010) observed that an early onset of Indian monsoon correlated with early cessation of March-May rainfall season suggesting stability partially contributed by the monsoons. According to a recent study by (S.E Nicholson, 2016) Somali jet causes reduced rainfall over Northern Kenya during June through September monsoon period. 

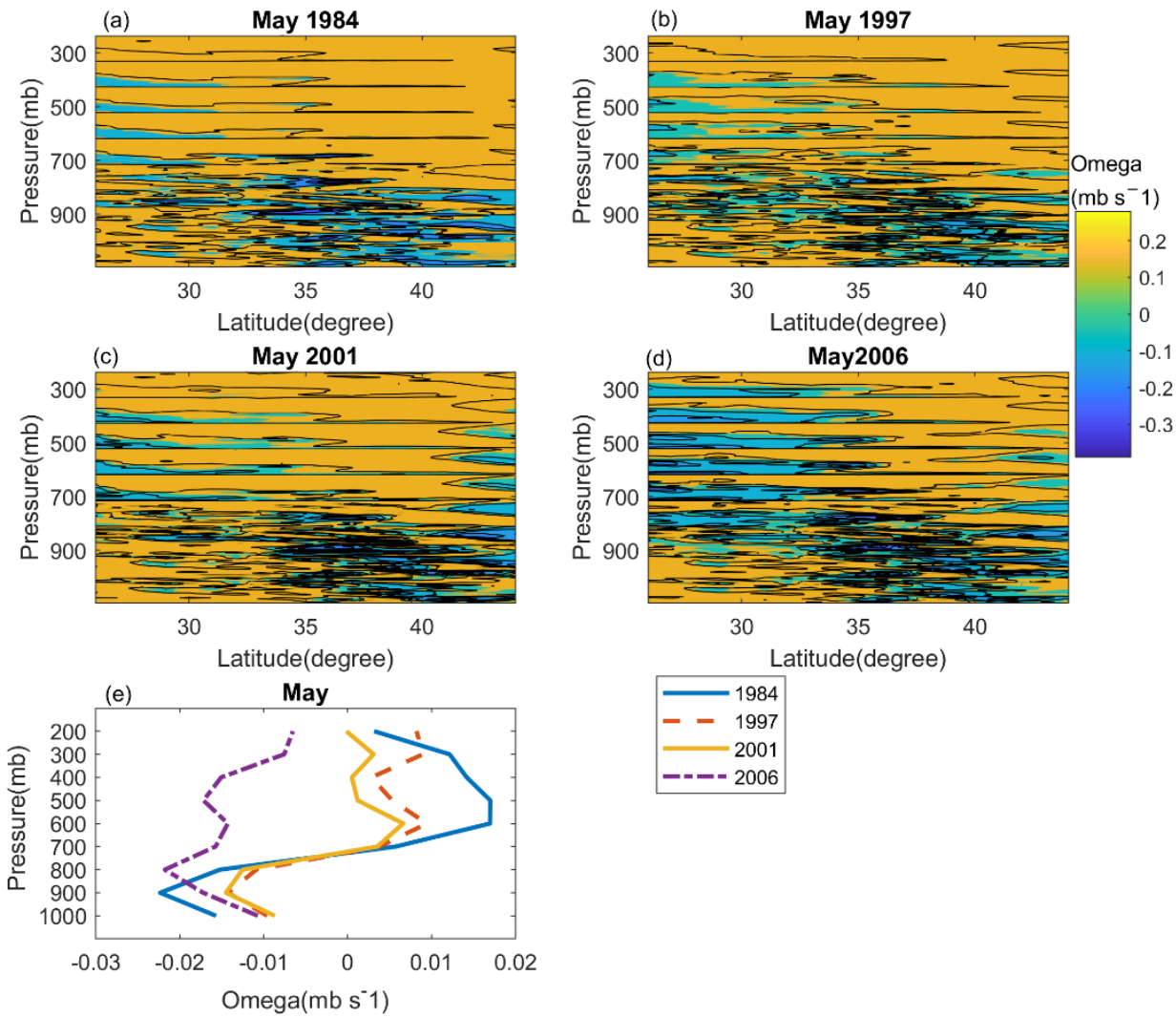

35 Latitude(degree)

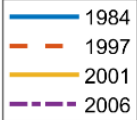

Figure 4. 9: Same as figure 4.8 but for the month of May

Figure 4.10 is August analysis and similar to May the spatial patterns of Omega show increased sinking motion especially to the eastern part of East Africa. However, the western part maintains a low level to upper-level convergences observed from about $800 \mathrm{mb}$ level. It is clear the moisture influx from the Indian Ocean is minimal. However, the western part continued moisture convergence is suggested to be from the west. The average vertical profile (Figure 4.10e) show dominance in stable conditions with only a small layer at the surface in 2006 that stabilizes in mid-level of $600 \mathrm{mb}$. In their study (Segele, Lamb, \& Leslie, 2009) attributed largescale circulation and SST to influence rainfall over the Horn of Africa during the southwest monsoon from June -September. 
An assessments of moisture distribution influence on rainfall variability during different phases of Indian Ocean Dipole over East Africa
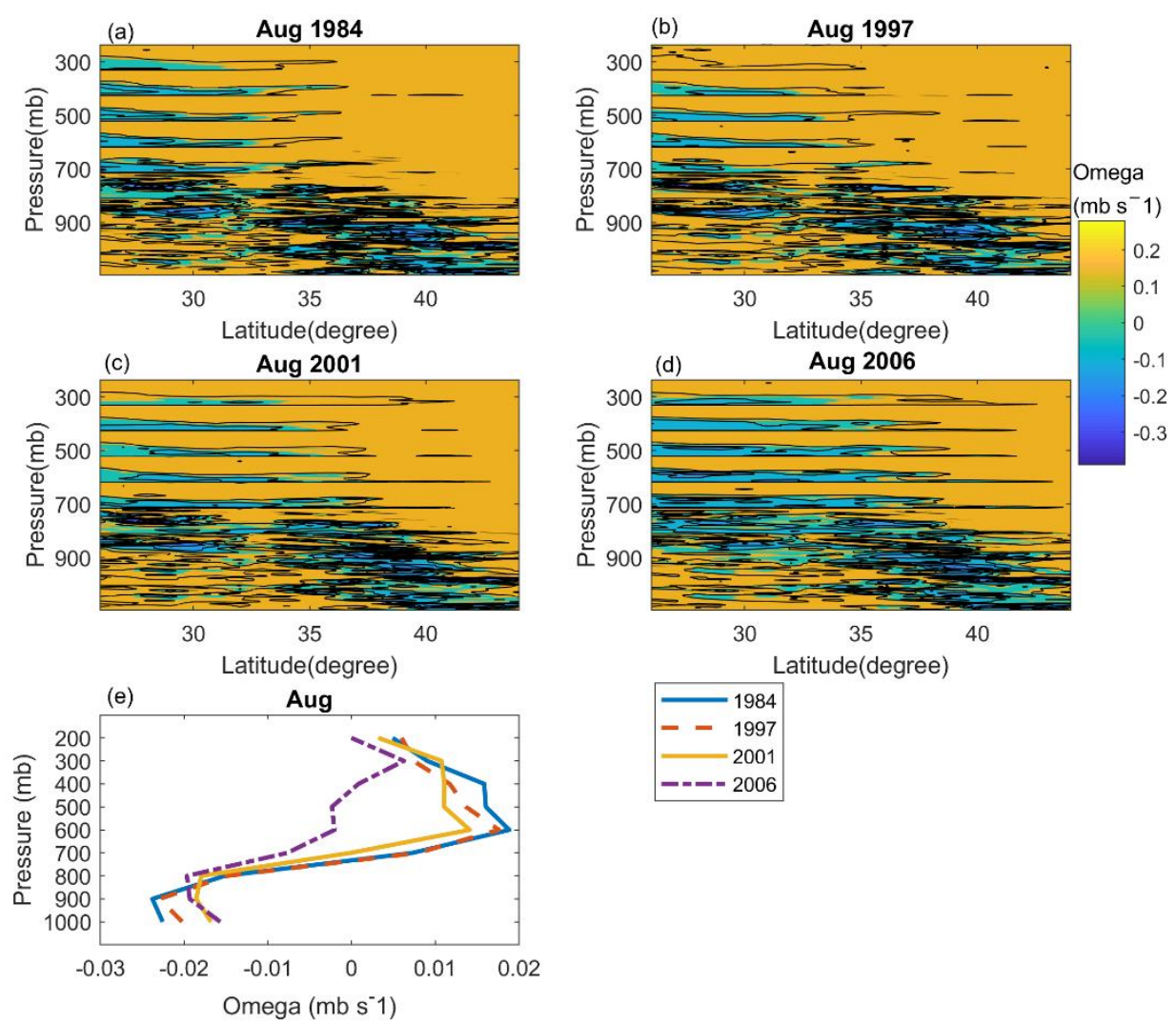

Figure 4. 10: Same as figure 4.8 but for the month of August

Figure 4.11 describes the month of November showing increased rising motions to the western part particularly in 1997 and 2006 El Niño years. However, the sinking motions are still evident over the central region between $35-40^{\circ} \mathrm{E}$ especially, during the dry years. The average (1981-2013) plot of Omega (Figure 4.11e) during the wet years show the rising motions from the surface to about $600 \mathrm{mb}$ level and decreases upward to near tropopause at $300 \mathrm{mb}$. During the dry years (Figures $4.11 \mathrm{a}$ and $4.11 \mathrm{c}$ ) the rising motions are restricted to lower surfaces up to $700 \mathrm{mb}$ and decreases upward up to level $400 \mathrm{mb}$. The study further associated increased rainfall to enhanced westerlies attributed to pressure difference over the Gulf of Guinea and Arabian Peninsula which attributes the large-scale dynamical processes to enhance convective activities(A. P. Williams et al., 2012). The westerlies are also associated with Madden-Julian Oscillation (MJO) oscillations (Pohl \& Camberlin, 2006a). Further, Nicholson et al. (2013), on the relationships of rainfall variability over Western equatorial Africa, attributed SST-rainfall relationships to atmospheric -Ocean links. In this study, what is demonstrated by Omega vertical profile is that the atmosphere over the eastern part is stable in mid to upper troposphere and moisture influx through south-easterly flow occur during the ITCZ in MAM and OND rainfall seasons. The sinking motions are attributed to Turkana jets (Kinuthia \& Asnani, 1982; S.E Nicholson, 2016) is enhanced during the monsoons (especially 
south-west) from May through September. It is also observed that although moisture convergence is reduced during the monsoon period, the western flow is constantly experienced throughout the year explaining the wet western areas and relatively dry eastern part.
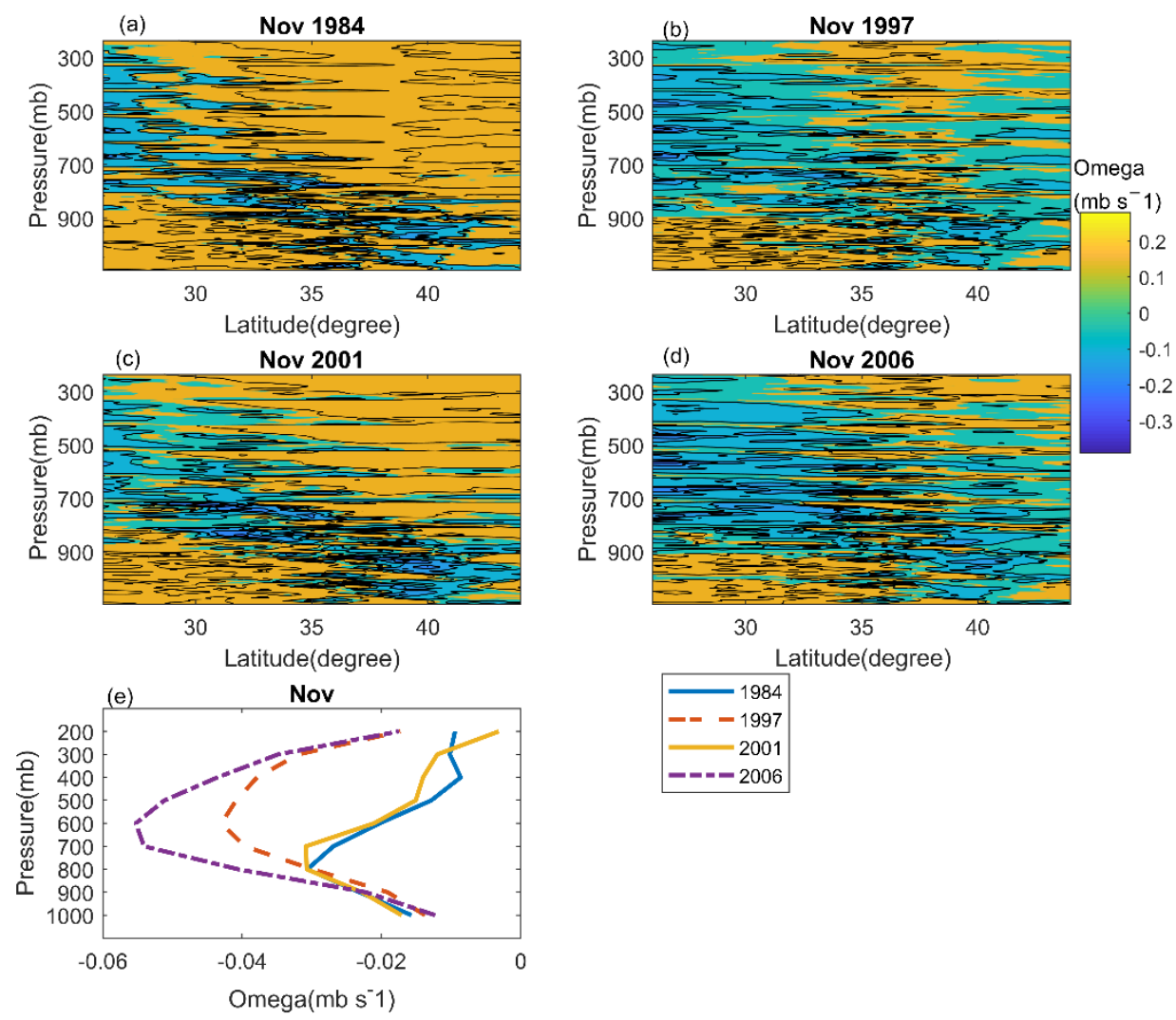

Figure 4. 11: Same as figure 4.8 but for the month of November

\subsubsection{Indian Ocean Dipole forcing}

The EOF 1 and 2 were used to assess the influence of IOD /ENSO on moisture budget distributions. EOF1 showed the largest influence during the main rainfall months associated with ITCZ (April and November) explaining 63\% and $65 \%$ respectively. During southwest monsoon months (May, August) EOF1 explains $43 \%$ and $47 \%$ respectively.EOF2 explains $31 \%$ in May and $<20 \%$ in the other 3 months.

Figures 4.12 show the map composites of moisture distributions associated with the two modes during positive IOD which also corresponds with El Niño years. It is evident EOF1 is associated with more wet conditions compared to EOF2 except in November where EOF2 explains more wet conditions than EOF1. 
An assessments of moisture distribution influence on rainfall variability during different phases of Indian Ocean Dipole over East Africa
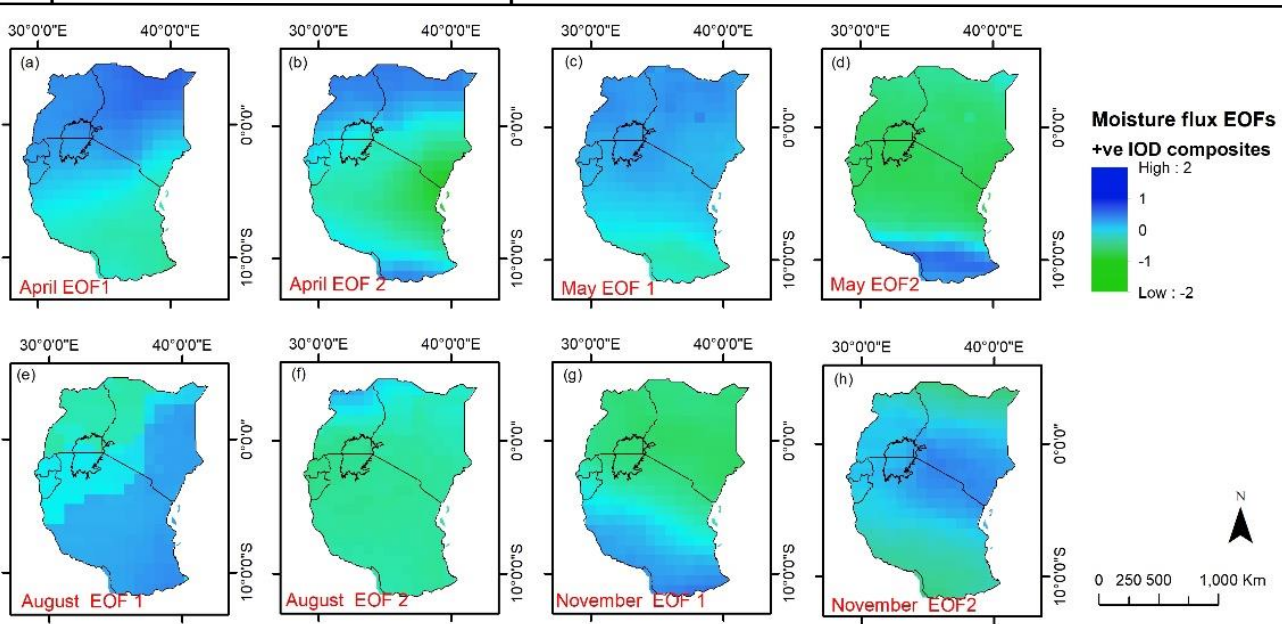

Figure 4. 12: shows composite spatial distribution of EOFs for moisture budget $\left(\mathrm{kgm}^{-1} \mathrm{~s}^{-1}\right)$ distribution derived from monthly means (1981-2013) during the positive phase of Indian Ocean dipole (+ve IOD).

Figure 4.13 shows the moisture distributions related to the two EOFs during the dry years (negative IOD). Similar to the wet years, EOF2 exhibit drier conditions than EOF1 except in November when moderate wet conditions are observed in November associated with EOF2.
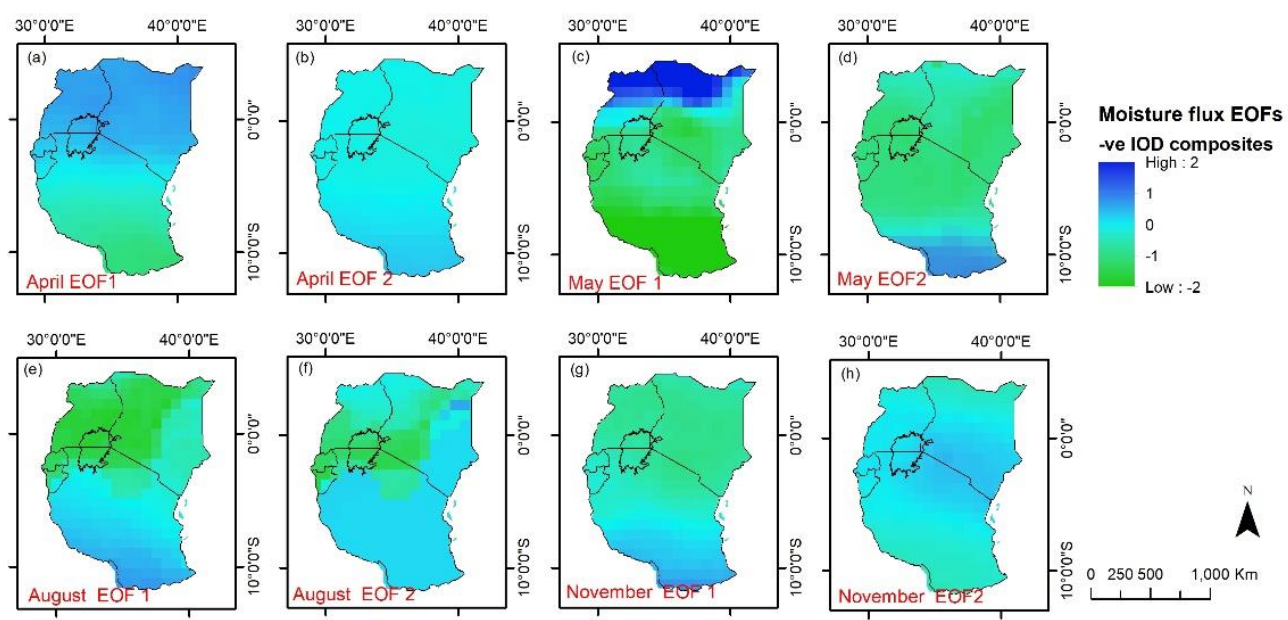

Figure 4. 13: Shows composite spatial distribution of EOFs for moisture budget $\left(\mathrm{kgm}^{-1} \mathrm{~s}^{-1}\right)$ distribution derived from monthly means (1981-2013) during the negative phase of Indian Ocean dipole(-ve IOD).

To further understand the influences of IOD and ENSO forcing, the two time series of EOF1 and 2 were compared with corresponding DMI and Nino 3.4. Figures 4.14 and 4.15 are the scatter plots describing EOF1 and 2 comparisons with DMI during 
the three phases of IOD. It is evident that DMI influences moisture budget distributions during the wet and dry years. It is also evident that the relationships of both EOFs to DMI is more linear during positive IODs (Figure 4.14). However, the significance of positive /negative correlations during positive IOD were observed in August and November respectively. Since in August easterly moisture influx is more dominant as it coincides with southwest monsoon, it is evident positive IOD enhances this flow with a positive correlation (0.60).

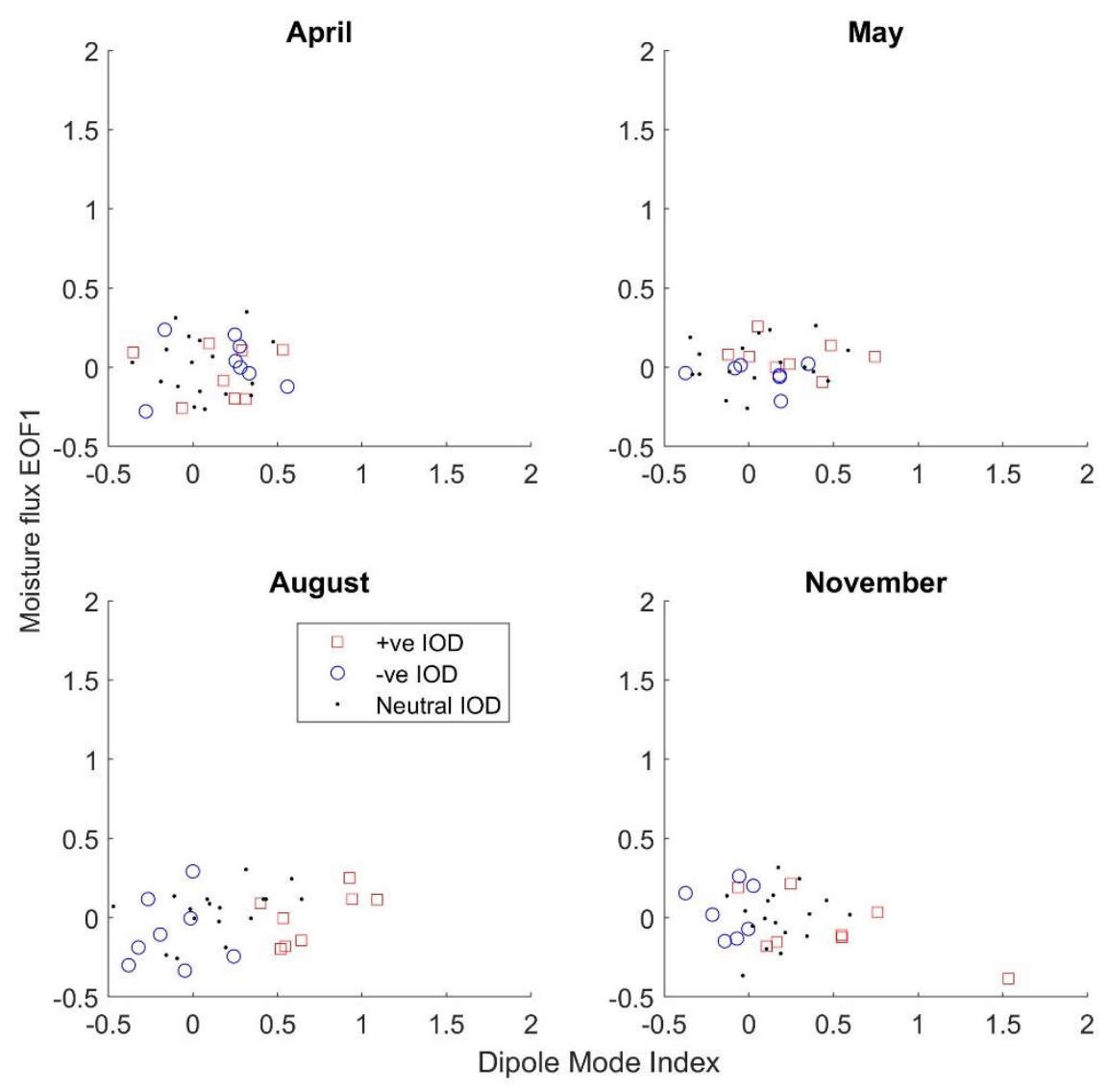

Figure 4. 14 : Scatter plot of EOF 1 against Dipole mode Index during positive(+ve) negative(-ve), and neutral, Indian Ocean Dipole (IOD) years.

Consequently, in November moisture influx is reduced and is indicated by negative correlations (-0.63). During negative IOD the relationships become more nonlinear (Figure 4.15), hence no significant relationships are observed. 
An assessments of moisture distribution influence on rainfall variability during different phases of Indian Ocean Dipole over East Africa

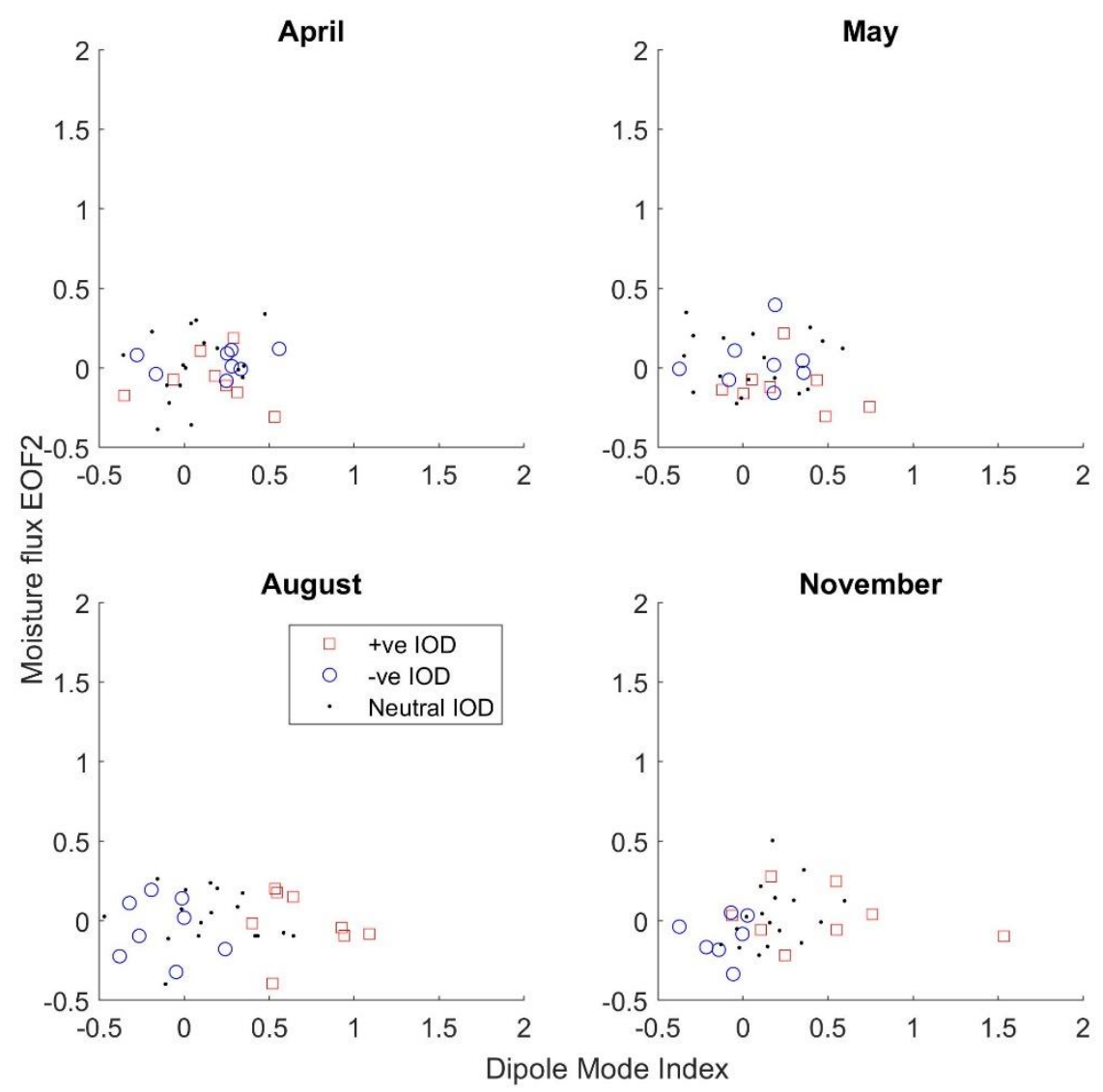

Figure 4. 15: Scatter plot of EOF 2 against Dipole mode Index during positive(+ve) negative(-ve), and neutral Indian Ocean Dipole (IOD) years.

Figures 4.16 and 4.17 show The scatter plots of Nino 3.4 and the EOF1 and 2 . However, it is observed that EOF1 and Nino 3.4 have a clear negative correspondence in May during both negative and positive IOD (Figure 4.16). This suggests that ENSO negatively impact moisture influx during positive IOD and positive effect during negative IOD observable this month. This was evidenced by significant correlations of -0.80 and -0.76 respectively. In November a negative correlation of -0.84 was also observed. It can be understood that in May an early onset of southwest monsoon is detectable and reduced moisture influx in May follows an early onset of the monsoon. This study suggests therefore that an early onset of southwest monsoon can reduce moisture influx in November, during ENSO year. 


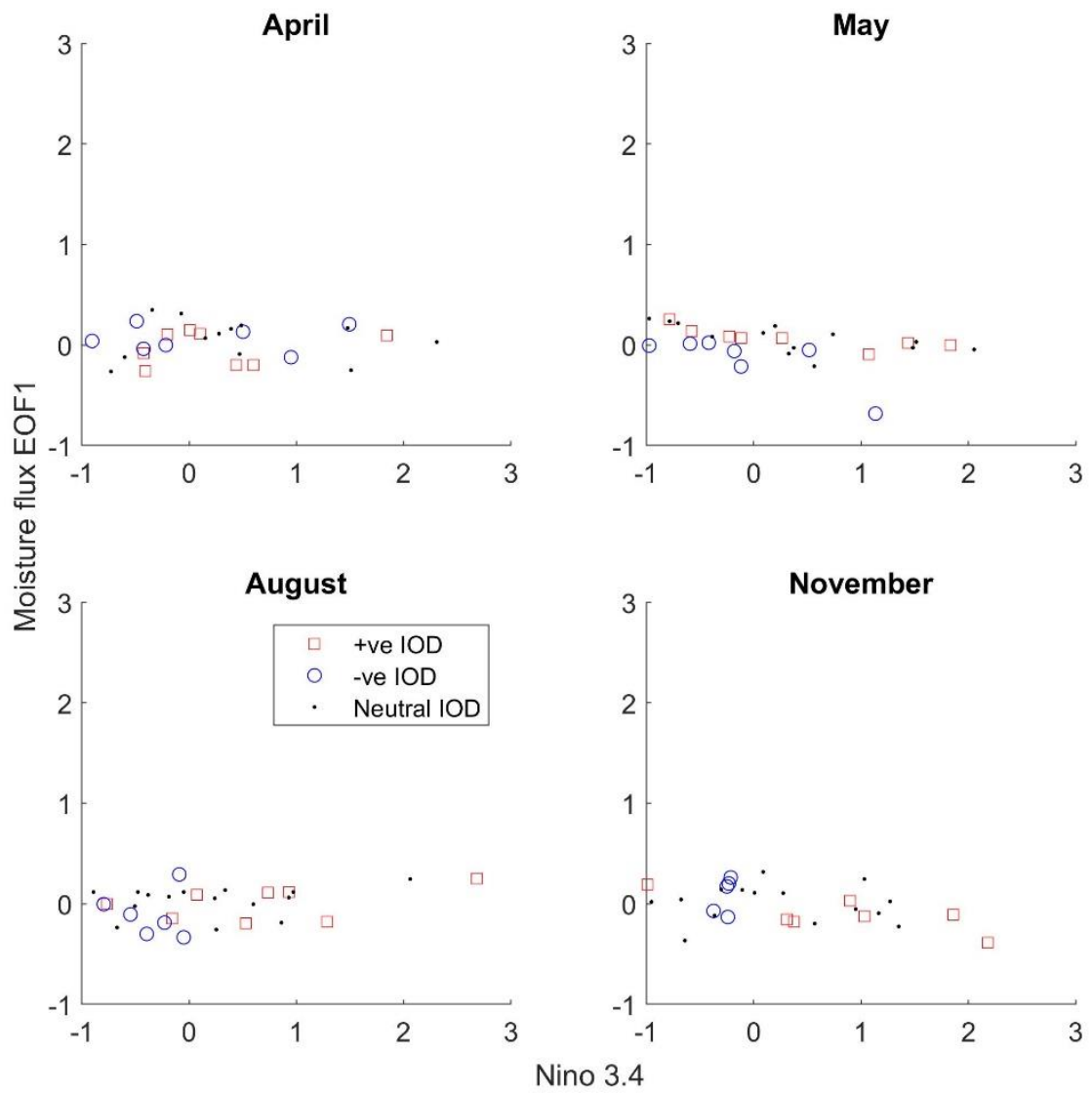

Figure 4. 16: Scatter plot of EOF 1 against Nino 3.4 during positive (+ve) negative (-ve), and neutral Indian Ocean Dipole (IOD) years.

Although a study by ( $\mathrm{H}$. Wang et al., 2016) observed that IOD variability might be isolated to ENSO, it is also evident during negative IOD (Figure 4.17) in May, EOF1 negatively correspond to Nino 3.4. It is suggested that during the early onset of the southwest, some IODs may be related to ENSO (X. Wang \& Wang, 2014). Further, a study by (Gadgil, Vinayachandran, Francis, \& Gadgil, 2004) observed that Equatorial Indian Ocean Oscillation (EQUINOO) which is an atmospheric component of IOD is related to ENSO. It can be understood therefore that moisture variability represented by the EOF1 is closely linked to IOD and is impacted negatively when it coincides with ENSO through enhancement of southwest monsoon. EOF2 showed no significant linear correspondence with Nino 3.4. 
An assessments of moisture distribution influence on rainfall variability during different phases of Indian Ocean Dipole over East Africa

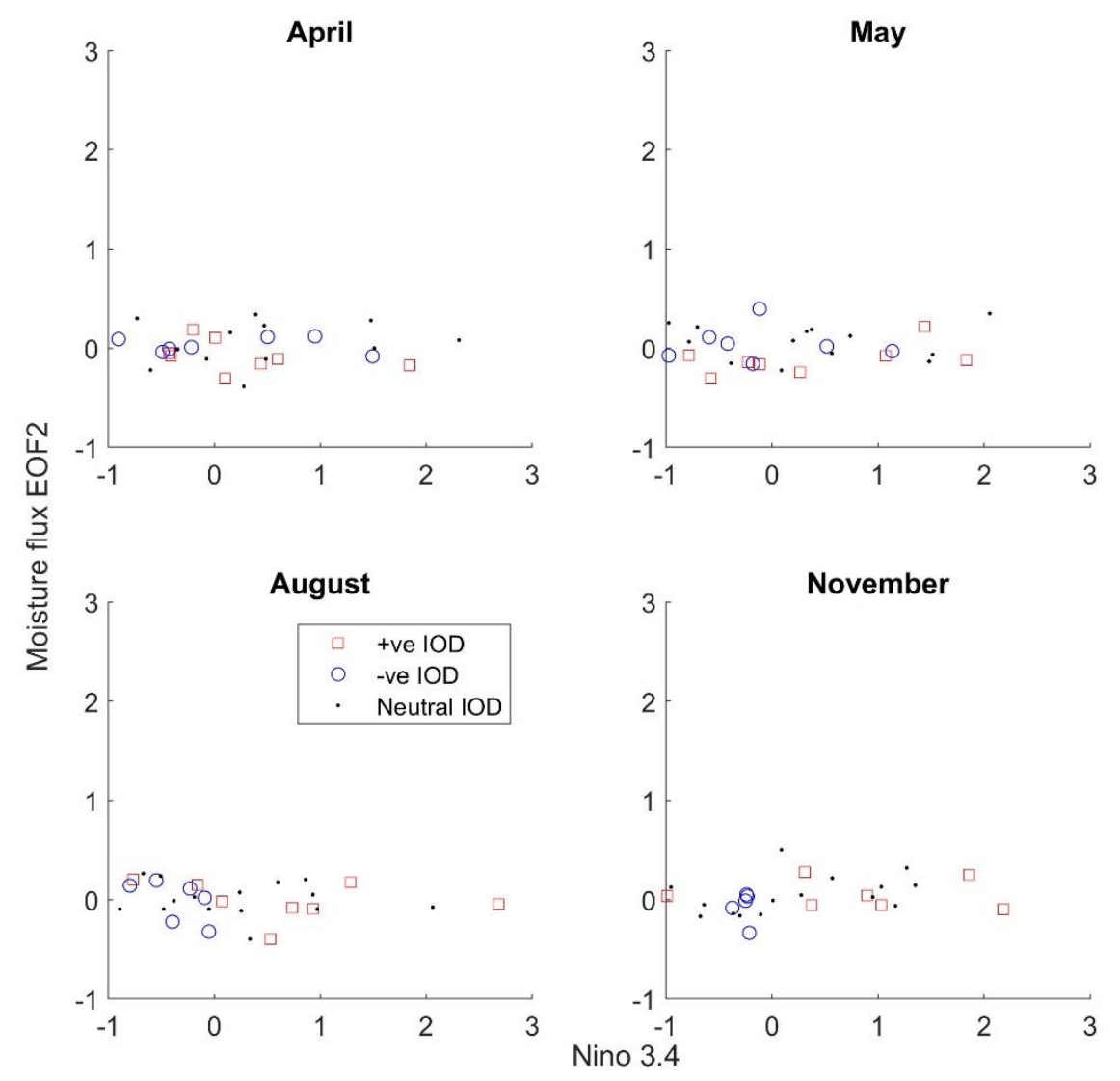

Figure 4. 17: Scatter plot of EOF 2 against Nino 3.4 during positive(+ve) negative(-ve), and neutral Indian Ocean Dipole (IOD) years.

\subsection{Conclusions and Discussion}

East Africa rainfall is highly variable even though it borders the India Ocean to the East and has inland water bodies like Lake Victoria. To understand this contradiction this study seeks to understand the moisture budget contribution to rainfall variabilities and the influence of DMI/ENSO during different phases of IOD. Results on monthly analysis showed insignificant recycling ratio. Therefore, advected moisture is the most dominant source of precipitation. The contribution from evaporation mainly affects Lake Victoria and surrounding areas. Moisture enters the region dominantly through the eastern boundary $\left(\mathrm{Q}_{E}\right)$ from the Indian Ocean. This occurs through low-level moisture convergence especially during ITCZ overpass affecting March-May and October-December main rainfall months. The mid and upper-level moisture influx is inhibited by sinking motions associated with Turkana jets and the Kenya highlands. Further mid tropospheric moisture flow from Congo enhances convection over the western parts of the region. The southern boundary 
influx stable air during southwest monsoon and rainfall is limited to the high elevated areas of Kenya highlands through orographic processes. Although spatial patterns of rainfall and moisture budgets show close correspondence, their correlation coefficients were negative in areas of moisture convergence over western Kenya through to northern Uganda. The anti-correlations are attributed to shallow convections embedded within the largescale moisture field suggesting differences in spatial scale. This was observed mainly during ITCZ over pass when strong south easterlies converges over the region. During southwest monsoon the reduced Indian ocean moisture influx limit the flow and the locally induced convection and Congo flow enhances convections. Temporally moisture budget and rainfall showed close correspondence except in June through September as moisture fluxes correspond with stable atmosphere leading to dryness. To understand how moisture distributions are related to convection both dynamic and thermodynamic variables were utilized. Monthly moisture fluxes derived from the moisture budget magnitudes were compared with surface temperature, CAPE, Omega and MSLP to infer convection areas. Low MSLP correspond to areas of increased moisture suggesting moisture influx follow ITCZ movements. However, in April no significant correlations were observed which is attributable to increased local processes. Similarly, CAPE and Omega showed similar spatial patterns to moisture, with CAPE showing negative correlation in areas of moisture convergence. This is associated with scale differences in forced local convections within largescale moisture distributions. This was further supported by positive correspondence of Omega and moisture distributions over moisture convergence areas particularly in April. During southwest monsoon Indian Ocean moisture influx inhabit moisture convergence resulting into shallow convections and consequence positive correlations. These areas include eastern parts of East Africa including the Kenya highlands and over northern Uganda.

The Omega vertical profiles from the surface $(1000 \mathrm{mb})$ to near tropopause (200 $\mathrm{mb})$ for relatively dry $(1984,2001)$ and wet $(1997,2006)$ years were examined. This was aimed at determining spatial moisture distribution and the levels of convergences. The Spatial distributions were analyzed within the rectangular area between $29^{\circ} \mathrm{E}$, and $42^{\circ} \mathrm{E}$, and $12^{\circ} \mathrm{S}$, and $5^{\circ} \mathrm{N}$ enclosing East Africa. The levels of convergence were further determined by considering East Africa landmass moisture averages. The result showed convergence to the eastern/western part bordering the Indian Ocean/including Lake Victoria, Rwanda, Burundi and Uganda and were separated by the highlands. During the wet years especially those related to positive IOD/EINiño, convective activities represented by the rising motions are experienced on both eastern and western parts. Low-level moisture convergence from the east and mid-tropospheric convergences from the west enhance wetness over the region. Conversely, during the dry years, the eastern moisture influx is inhibited by lowlevel divergence attributed to Turkana jets. As such, moisture is cutoff further inland hence the western part experiences shallow convection. Consequently, the eastern part becomes dry except over the Kenya highlands where orographic processes support moisture rise. Further observations show that the eastern convections are enhanced by low-level moisture advection from the Indian ocean while the westerly part is dominated by both mid-level advection ( $500-700 \mathrm{mb})$ and low-level moisture from the Indian Ocean. The dominance of either east or west advection is seasonal. During the MAM rainfall season represented by April, convection dominates both east and west, and average Omega shows the rising motion from the surface indicating more westerly moisture influx. In May the eastern convection is reduced by the low-level divergent motions evidenced by increased positive 
An assessments of moisture distribution influence on rainfall variability during different phases of Indian Ocean Dipole over East Africa

Omega and attributed to the early onset of the Indian monsoons. Similarly, in August the sinking motion to the east is increased while the western continue to experience shallow rising motions from easterly moisture flow from Congo. This leads to convective activities over western Kenya and part of Uganda. Similarly, sinking motions are evident in November over the eastern part while the western mid-level convergence continues to be experienced. These findings indicate that sinking motions are dominant over the eastern part limited to low-level moisture influx and is highest during the south-west monsoon period, while the mid and upper troposphere is generally dry. It is thus demonstrated that moisture dominantly enters East Africa from the Indian ocean through low-level convergence during ITCZ overpass, by south-easterlies. Further, moisture enters through the midtroposphere from the west associated with the Congo basin and is enhanced during the south-west monsoon period. It was also observed that easterly flow is enhanced during positive IODS and suppressed during negative IODs. The Kenya highlands acts as a sink to moisture budget flow. It is suggested that rainfall variability is influenced by the strength of the south-east monsoons that advect moisture from the Indian Ocean therefore related to IOD. Further investigation on the influence of IOD/ENSO to moisture budget distribution during the different phases ( positive/negative/neutral) of IOD were carried out. Same months of April, May, August and November were considered. The spatial contribution of moisture flux during different phases related to the two dominant modes (EOF1,2) map composites of dry and wet years were used to relate to DMI and ENSO (Nino3.4).

Empirical Orthogonal Functions (EOF 1,2) of moisture were utilized to determine the impact of the Dipole Mode Index (DMI) and Nino 3.4 to moisture distributions during different phases of IOD. EOF1 represent wetter conditions than EOF2.DMI showed the largest influence during ITCZ overpass explaining $>60 \%$ and less during southwest monsoon months. EOF2 contributes the largest influence of $31 \%$ influence in May attributed to DMI, and the relationships were nonlinear.EOF1 showed both linear and nonlinear relationships attributed to both DMI and ENSO (as represented by Nino 3.4).DMI corresponded well with moisture flux distributions during the wet years with a more linear relationship corresponding to positive IODs but become more nonlinear during negative IOD. The study observed that linearly DMI corresponded with moisture influx from the west during southwest monsoon as was evidenced by significant correlation (0.60) in August. Increased southwest monsoon strength showed a negative impact on moisture influx from the Indian Ocean as evidenced by negative correlations $(-0.63)$ during positive IOD. Nino 3.4 showered significant negative correlation with EOF1 in May and November during positive IOD of -0.80 and -0.76 respectively. This implies that EOF1during positive IOD corresponding with El Niño Moisture influx is suppressed and is observable in May and November. The early onset of southwest monsoon in may during El Niño year suppresses moisture influx from the Indian Ocean. This explains the reduced rainfall during positive IOD that corresponds with ENSO because of the enhanced early onset of southwest monsoon which is also part of the Indian monsoon. These conclusions are based on the linear relationships between the dominant moisture modes during the anomalous wet/dry years. 
Chapter 5

\section{An assessment of MJO Circulation Influence on Air-Sea Interactions for Improved Seasonal Rainfall Predictions over East Africa ${ }^{4}$}

${ }^{4}$ This chapter is based on:

Kimani, M. W. Hoedjes, J. C. B. Su, Z. B. 2019: An assessment of MJO Circulation Influence on Air-Sea Interactions for Improved Seasonal Rainfall Predictions over East Africa Journal of Climate, under review. 


\begin{abstract}
Rainfall variability affects agriculture planning and water resource management. In extreme flood and drought events, lives and properties are destroyed. This study aims to improve East Africa seasonal rainfall predictability by determining the impact of Real-time Multivariate (MaddenJulian Oscillation) MJO (RMM) amplitudes on rainfall based on ERA-Interim reanalysis at different timescales. The SST forcing on 2-m surface temperature related to MJO convections was used to test the predictability of the March-April-May (MAM) rainfall season, covering a period of 33 years (1981-2013). Pearson correlation patterns, composite maps and regression analyses were applied, and the Brier score (BS) and Anomalies of Correlation Coefficients (ACC) were utilized as validation metrics. Seasonal timescale MJO over Africa ( $M J O$ 1) and the Western Hemisphere ( $M J O$ 8) exhibited the highest correlations $(-0.74$ and 0.53$)$ with moisture budget and $2-\mathrm{m}$ surface temperatures, respectively. An early MAM MJO peak enhances extreme wetness/dryness during MAM, while the late peak corresponds to moderate dryness/wetness. The October-December seasonal rainfall intensity corresponds to that of MAM. The MAM MJO modulates low-level moisture influx from the Indian Ocean Convergence Zone that extends over the western part bordering the Congo Basin. The SST time series from the southwestern Indian Ocean, central Indian Ocean and within the Maritime Continent were applied to a lagged stepwise regression model as predictors of the MAM moisture budget, a proxy of rainfall, exhibiting the highest skill at lag 4, with a BS of 0.02 and an ACC of 0.82 . MJO has a major impact on the MAM rainfall dynamics, and inclusion of MAM MJO1 and 8 magnitudes improves its prediction.
\end{abstract}

\title{
5.1 Introduction
}

Rainfall over East Africa is very variable in space and time and occurs during two main rainfall seasons, i.e., March to May (MAM) and October to December (OND), in the Inter-Tropical Convergence Zone (ITCZ). Although MAM is the primary rainfall season upon which both water resource management and agricultural planning depend, predicting its variability remains a challenge, with extreme drought and flood events increasing impoverishment and causing economic setbacks. The MAM rainfall season experiences different teleconnections each month (S. E Nicholson, 2017). For example, a study by (Camberlin \& Philippon, 2002) found that spatial rainfall distributions in March and April differed from those in May, suggesting a division among months. General circulations related to El Niño Southern Oscillation (ENSO) (Philander et al., 1989) and Indian Ocean dipole (IOD) events (Saji et al., 1999; Webster et al., 1999) have been shown to affect rainfall in East Africa (Indeje et al., 2000; Ogallo, 1988). Although these findings have predominantly been linked to OND rainfall, some are associated with the MAM season (Camberlin \& Philippon, 2002). The 2010-2011 La Nina dry spell of affected both the MAM and OND rainfall season, but only the latter was predicted (Lyon \& DeWitt, 2012). In an earlier study on the influence of La Nina on African rainfall by 
(S. E Nicholson \& Selato, 2000), a dry spell was observed to have originated in the Indian and Atlantic oceans. These basins are also linked to the predictability of ENSO (Frauen \& Dommenget, 2012). On an interannual timescale, the Mean sea level pressure (MSLP) and SST over these basins influence the MAM rainfall onset and cessation over Eastern Africa (Camberlin \& Okoola, 2003). The cooling and warming over the Indian and South Atlantic oceans are associated with high and low MSLP anomalies, respectively, that influence enhanced equatorial easterlies and surface divergence over East Africa.

Knowing the dominant source of moisture is essential in understanding rainfall variability. As the ITCZ passes over the equator, a large degree of moisture flux from the Indian Ocean to the Horn of Africa enhances rainfall variability (S.E Nicholson, 1996). The general position of the ITCZ therefore influences the wetness or dryness over East Africa (Souverijns et al. 2016). According to a study by Nicholson (1996), the ITCZ's movement is regulated by the strength of subtropical highs and the westerlies. Because the westerlies are associated with MJOs (Pohl \& Camberlin, 2006a), their interactions are of interest in understanding rainfall variability across the region. MJO is an intraseasonal oscillation with a timescale of 30-60 days; it initiates from the Indian Ocean (Matthews, 2008), propagating eastwards at a speed of $5 \mathrm{~m} \mathrm{~s}$ ${ }^{1}$ (Madden \& Julian, 1994). Its circulations help explain weather and climate variations and are associated with convective activity over Africa, similar to the equatorial Rossby and Kelvin waves during monsoons (Matthews, 2004). Real-time multivariate MJO series (RMM1 and RMM2) describe MJO strength and the location of its convective center (Wheeler and Hendon 2004). They are derived from the first two empirical orthogonal functions (EOFs) of combined daily mean fields of outgoing longwave radiation (OLR) and 850$\mathrm{mb}$ and 200-mb zonal winds.

Significant correlations of the MJO and East Africa rainfall exist on an interannual timescale (Pohl \& Camberlin, 2006a). Similarly, the oscillations are linked to those over the oceans. For example, the MJO over the Indian Ocean and Maritime Continent corresponds to convection over the eastern Indian Ocean during negative IOD events (Wilson et al., 2013). The MJO indices at $70^{\circ}$ and $80^{\circ} \mathrm{E}$ (both over the Indian Ocean) and $120^{\circ} \mathrm{W}$ (over the Pacific region) influence East Africa during early March and late May rainfall (Berhane \& Zaitchik, 2014). The changes emerge from the interaction of large-scale circulation and local processes related to the low-level Somali jet. In an evaluation on the impacts of African rainfall, (Zaitchik, 2017) noted that the MJO has teleconnections to ENSO and IOD circulations and recommended additional research.

The Walker Circulation (Bjerknes, 1969) has an upper arm over the Congo Basin (Cook \& Vizy, 2016) and is associated with cooling over the Gulf of Guinea during the June-October monsoon season (Neupane, 2016). (Laing, Carbone, \& Levizzani, 2011) observed that mesoscale convections are enhanced during the active phase of the MJO over equatorial Africa and suppression occurs during its weak phase.

The impact of RMM amplitudes on air-sea interactions was assessed on a monthly and seasonal timescale, covering a period of 33 years (1981-2013). First, the impact of enhanced MJO when the monthly and seasonal amplitude to rainfall $>1$ and convective variables are assessed. The convective variables include CAPE $\left(\mathrm{J} \mathrm{kg}^{-1}\right)$, integrated moisture budget $\left(\mathrm{kg} \mathrm{m}^{-1} \mathrm{~s}^{-1}\right)$ across the East 
An assessment of MJO Circulation Influence on Air-Sea Interactions for Improved Seasonal Rainfall Predictions over East Africa

Africa boundaries between the surface $(850 \mathrm{mb})$ to the near tropopause (200 $\mathrm{mb}), 2-\mathrm{m}$ surface temperature (K), MSLP (mb) and vertical velocity (omega) $\left(\mathrm{mb} \mathrm{s}^{-1}\right)$ at $700 \mathrm{mb}$. Second, the impact of MJO amplitude to extreme rainfall events predominantly related to ENSO/IOD is investigated using the average of all the RMM magnitudes. Third, a search for significant corresponding MAM SSTs was conducted within a rectangular area $\left(0^{\circ}-140^{\circ} \mathrm{E}\right.$ and $\left.35^{\circ} \mathrm{S}-20^{\circ} \mathrm{N}\right)$. The MJO over Africa and the Western Hemisphere (MJO 1, 8) were considered in determining the significant SST that induces atmospheric changes and the relationship compared with the 2-m surface temperature forced by SST. An annual stepwise regression prediction model for MAM seasonal rainfall is therefore based on the identified extracted SST indices at different lags. Section 5.2 describes the RMM MJO atmospheric-ocean impacts affecting MAM seasonal rainfall predictions. Section 5.3 provides the obtained results, and the discussion and conclusions presented in Section 5.4.

\subsection{Data and Methods}

\subsubsection{Data}

East Africa borders the Indian Ocean, which forms a source of moisture influx. Although there are two primary rainfall seasons, MAM and OND, a third season occurs during the southwest monsoon months from June to August (JJA), primarily over western Kenya and some parts of Uganda. The latter enhances agricultural production and water resource sectors and is therefore economically important to the region. In this study, although analysis included all seasons, improved prediction testing was applied to MAM because it is of the highest intensity and includes longer rainy days (a long rainfall season). Its prediction is therefore more significant to agricultural practices, among other applications. The MAM rainfall season experiences different teleconnections in each month (Nicholson 2017). For example, spatial rainfall distributions in March and April differ from the May distribution (Camberlin \& Philippon, 2002). In this study, monthly and seasonal timescales explained these differences.

Monthly rainfall data were obtained from the CHIRPS v2.0 dataset developed by the United States Geological Survey (USGS) Earth Resources Observation and Science Center and the University of California Santa Barbara Climate Hazards Group. In a study assessing satellite rainfall products using groundbased products over East Africa (Kimani et al., 2017), CHIRPS v2.0,TRMM$3 \mathrm{~B} 43$ and CMORPH v1 displayed the best performance of the seven satellite precipitation products evaluated. However, all products exhibited systematic errors that were predominantly locally induced, requiring they be minimized before application. CHIRPS was selected for this study based on its long climatology history, making it suitable for long-term applications. To improve CHIRPS' local rainfall representation, a Bayesian correction was applied, using the gridded data from an in situ rain gauge network (Kimani, Hoedjes, \& Su, 2018). Further assessment of CHIRPS' performance relative to other products may be found in Tote et al. (2015). 
Daily RMM amplitudes (Wheeler \& Hendon, 2004) were downloaded from the Australian Bureau of Meteorology website (Meteorology). The rainfall months' (MAM, JJA and OND) MJO indices were first examined between 1981-2013 to obtain the general trend. The MAM MJO magnitudes for each index were compared with corresponding rainfall and convection variables to assess the impact of MJO convections on East Africa convective rainfall. In addition, the monthly and seasonal averages of all the MJO indices were utilized to assess the impact of MJO circulation to extreme rainfall events related to IOD/ENSO. The atmospheric variables were obtained from ERA-Interim monthly means reanalysis model products (Dee et al., 2011) based on reanalysis data available from January 1979 to the present, with a spatial resolution of $0.75^{\circ}$. Zonal (U) and meridional (V) wind $\left(\mathrm{m} \mathrm{s}^{-1}\right)$ components and corresponding specific humidity $\left(\mathrm{kg} \mathrm{s}^{-1}\right)$ between the surface $(850 \mathrm{mb})$ and top $(200 \mathrm{mb})$ pressure levels were used to calculate the moisture budget and its components $\left(\mathrm{kg} \mathrm{m}^{-1} \mathrm{~s}^{-1}\right)$.

The ocean's influence on MJO circulations that impacts rainfall variability was investigated using the monthly extended reconstructed sea surface temperature (ER SST) v5 at a $2^{\circ}$ spatial resolution (Huang et al., 2017). Seasonal analyses were also utilized to determine relevant SST indices enforcing atmospheric changes.

\subsubsection{Methods}

\subsubsection{MJO amplitudes and Convective variables}

The calculations of moisture budget follow the description provided by (Shi et al., 2014), as in Equation (5.1). In addition, the total moisture budgets across the eastern, western, southern and northern boundaries enclosing East Africa were determined for comparison with MJO magnitudes to establish the effect of $\mathrm{MJO}$ circulations on moisture flow across the region.

$$
\frac{\partial W}{\partial t}=-\nabla \cdot Q+E-P
$$

where $\partial \mathrm{W} / \partial \mathrm{t}$ is the change in precipitable water over time (assumed to be zero); $\nabla . Q$ is the divergence of water vapor across the atmospheric column's boundaries; $E$ is the surface evapotranspiration $\left(\mathrm{mm} \mathrm{months}^{-1}\right)$; and $P$ is rainfall ( $\mathrm{mm}$ months ${ }^{-1}$ ). The moisture budget, combined with the omega at $700 \mathrm{mb}$, mean sea level (mb months ${ }^{-1}$ ), 2-m surface temperature (k months ${ }^{1}$ ) and convective available potential energy (CAPE: $\mathrm{j} \mathrm{kg}^{-1}$ months ${ }^{-1}$ ), were utilized to describe convective areas. In addition, monthly evapotranspiration, calculated as the difference between the reanalysis and locally bias-corrected CHIRPS v2 (Kimani et al., 2018), balanced the moisture budget. The 
An assessment of MJO Circulation Influence on Air-Sea Interactions for Improved Seasonal Rainfall Predictions over East Africa

atmospheric variables were all resampled using the nearest neighbor method at $0.05^{\circ}$ spatial scales to be compatible with the bias-corrected CHIRPS data. Real-time multivariate MJO series 1 and 2 (RMM 1, RMM 2), as described by (Wheeler \& Hendon, 2004), were utilized to define the various phases and magnitudes of the MJO. According to the present study, a strong MJO event is defined as an amplitude greater than 1 . The circulation indices characterize convection over eight geographical locations numbered 1 through 8, representing the Indian Ocean $(2,3)$, Africa and the Western Hemisphere $(1$, $8)$ and the Maritime Continent $(4,5)$ and Pacific $(6,7)$ regions, as described by (Wheeler \& Hendon, 2004). The approximate locations, as described by (Donald, Meinke, Power, Wheeler, \& Ribbe, 2004), are derived from combined empirical orthogonal functions of $850-\mathrm{mb}$ and $200-\mathrm{mb}$ zonal winds plus outgoing longwave radiation developed into a pair of principal component time series. The daily magnitude values of $\mathrm{MJO}$ were averaged individually every month for each of the eight indices when the amplitude was $>1$ for each MAM month. To characterize the relationship between convection variables and significant MJO indices, significant correlation coefficients at a $95 \%$ confidence level were determined. Similarly, each of the standardized MJO and rainfall indices were correlated monthly and seasonally to obtain a general view of the MJO and rainfall relationships. Z-score standardization was employed for all the variables before comparisons were conducted.

\subsubsection{Circulation forcing}

In this section, the average RMM indices and their corresponding magnitudes were compared with rainfall on monthly and seasonal scales to identify the impact of MJO circulation on rainfall variabilities. Particular focus on extremely dry and wet spells aimed to investigate the influence of MJO circulations. The dry/wet years correspond to negative/positive IODs. Identified SST indices related to MJO circulations were determined for the March to May rainfall season; however, JJA and OND rainfall seasons should be considered in the future. The surface temperature and total moisture budget across the four boundaries of East Africa were determined to be the most impacted by the MJO over Africa and the Western Hemisphere (MJO 1, 8). Because moisture budget is closely related to rainfall, it was used as a rainfall proxy (predictand), whereas lagged SST indices were used as predictors. Identification of suitable SST indices was performed in two steps by employing Pearson correlation patterns. First, coupling SST with the 2-m surface temperature helps describe the air-ocean interactions, the patterns of which are visually compared with $\mathrm{MJO}$ convections as described by air temperature and MJO 8 . Then, low-level wind $(850-\mathrm{mb})$ patterns were used to qualitatively describe zonal wind patterns and the area of low-level convergence.

\subsubsection{Prediction of MAM seasonal rainfall}

The MJO magnitudes over Africa and the Western Hemisphere were determined to be convective areas influencing rainfall variability over East Africa. The MJO 8 magnitude was used in identifying the SST indices related to MJO. Although rainfall is the primary predictand, moisture budget, which 
constitutes rainfall formation, was used as a rainfall proxy because of its consistent relationship with MJO magnitudes at seasonal scales. Determination of circulation variables from convective variables forced by SST was the next step. Based on monthly and seasonal analysis with MJO magnitudes, the surface temperature was identified as being most suitable, forced by SST, in influencing moisture influx to the region. The relationship between surface temperature and SST were utilized to identify the most influential ocean locations collocated with MJO forcing. The time series of SST standardized indices were then extracted and used as input in stepwise regression and run for different lags for skillful predictions.

\subsubsection{Model performance Evaluation}

The stepwise regression models for four lags were tested using both deterministic and probabilistic metrics. In this study, all the variables were standardized using the Z-score index (ZSI). For the probabilistic test, the Brier score (BS) (Roulston, 2007) was used and ACC (Wilks, 2011) were used for the deterministic test. An application of the BS standardized precipitation index (SPI) was applied and because ZSI and SPI are performed in similar manners (McKee, Doesken, \& Kleist, 1993), ZSI was used to determine the probability of the moisture budget as the predictand. The empirical probability of (Farahmand \& AghaKouchak, 2015) was utilized to derive a nonparametric standardized index equation (5.2), instead of using a parametric gamma equation. Moreover, a BS equation (5.3) and Brier skill climatology $\left(\right.$ BS $\left._{\text {clim }}\right)$ equation (5.4) were applied to determine the Brier skill score (BSS) equation (5.5). Further, the ACC equation (5.6) was also used as a validation metric.

$$
\begin{gathered}
p\left(x_{t}\right)=\left(\frac{(t-0.44)}{n+0.12}\right. \\
B S=\frac{1}{N} \sum_{j=1}^{N}\left(f_{j}-O_{j}\right) \\
B S_{\text {clim }}=\bar{o}(1-\bar{o}) \\
B S S=1-\frac{B S}{B S_{c l i m}} \\
A C C=\frac{\sum_{i}^{n} f_{j i}^{\prime} o_{j i}^{\prime}}{\left[\left\langle\sum_{i i}^{n} f_{j i}^{2}\right) X\left(\sum_{i}^{n} o_{j i}^{\prime}{ }^{2}\right\rangle\right]^{\frac{1}{2}}}
\end{gathered}
$$

where $n$ is the sample size, $t$ denotes the rank of the nonzero precipitation data, beginning with the smallest, and $\left(p\left(x_{t}\right)\right)$ is the corresponding empirical probability. Using this empirical approach, $f_{j}$ is the predicted probability of the event occurring according to the jth forecast, and $o_{j}$ is equal to 1 or 0 , 
An assessment of MJO Circulation Influence on Air-Sea Interactions for Improved Seasonal Rainfall Predictions over East Africa

depending on whether the event subsequently occurred or not. BS $_{\text {clim }}$ is the climatological probability, and o (with a bar) is the sample climatology derived from observation probability (mean). For the ACC computation, $f_{i}$ is the anomaly for the forecast (z-score absolute value) and observations; for a given lead month, $i$ is the target month and $\mathrm{n}$ is the period (10 years in this study).

\subsection{Results}

This section presents the results of the analysis of the RMM MJO air-sea interactions and is divided into three parts. The first part compares the magnitude of the individual RMM MJO indices' relationship with atmospheric variables related to convection. Second, the MJO circulation, represented by the average of all the indices related to extremely dry and wet years, was investigated. Third, the identification of SST indices related to the MJO convections were also used to test the MAM seasonal rainfall prediction.

\subsubsection{Comparison of MJO indices and convection variables}

This section presents the comparison of Mach-May analysis of the eight RMM MJO magnitudes to rainfall and convective variables on a monthly and seasonal timescale. First, based on the analysis of the daily MJOs for the study period (1981-2013), the highest (>3) MJO peaks occurred after three to four years. The magnitudes are more clearly defined for values $>1.5$, as the patterns become sporadic at lesser values. Furthermore, the high peaks seem to coincide a year before the onset of an extreme event occurs across the region. For example, high peaks of 1987-1988, 1996-1997, 2004-2005 and 2011-2012 are dry, wet, dry and wet years, respectively. This demonstrates that MJO circulation has a strong annual influence on extreme rainfall variability. Monthly analysis of enhanced MJO (monthly magnitudes $>1$ for $60 \%$ of the days in a month) determined for each phase compared with rainfall and convection variables exhibited inconsistent patterns. For each month, a different MJO phase is more dominant. There was an observed improvement in pattern consistencies at the seasonal scale (Figure 5.1), with the MJO indices over the Indian Ocean (MJO 3), Pacific Ocean (MJO 6) and Africa (MJO 1) exhibiting the highest magnitudes (Figure 5.1a) and corresponding to the extremely dry years of 1988, 2005 and 1981, respectively. The extremely wet year of 1997 was also determined to correspond with the active MJO 8 index. The moisture budget and surface temperature exhibited the highest significant correlations $(-0.74$ and 0.53$)$ with the MJO 1 and 8 indices, respectively (Figure 5.1b). According to this analysis, it is evident that the enhanced MJO over Africa suppresses an influx of moisture into East Africa. 


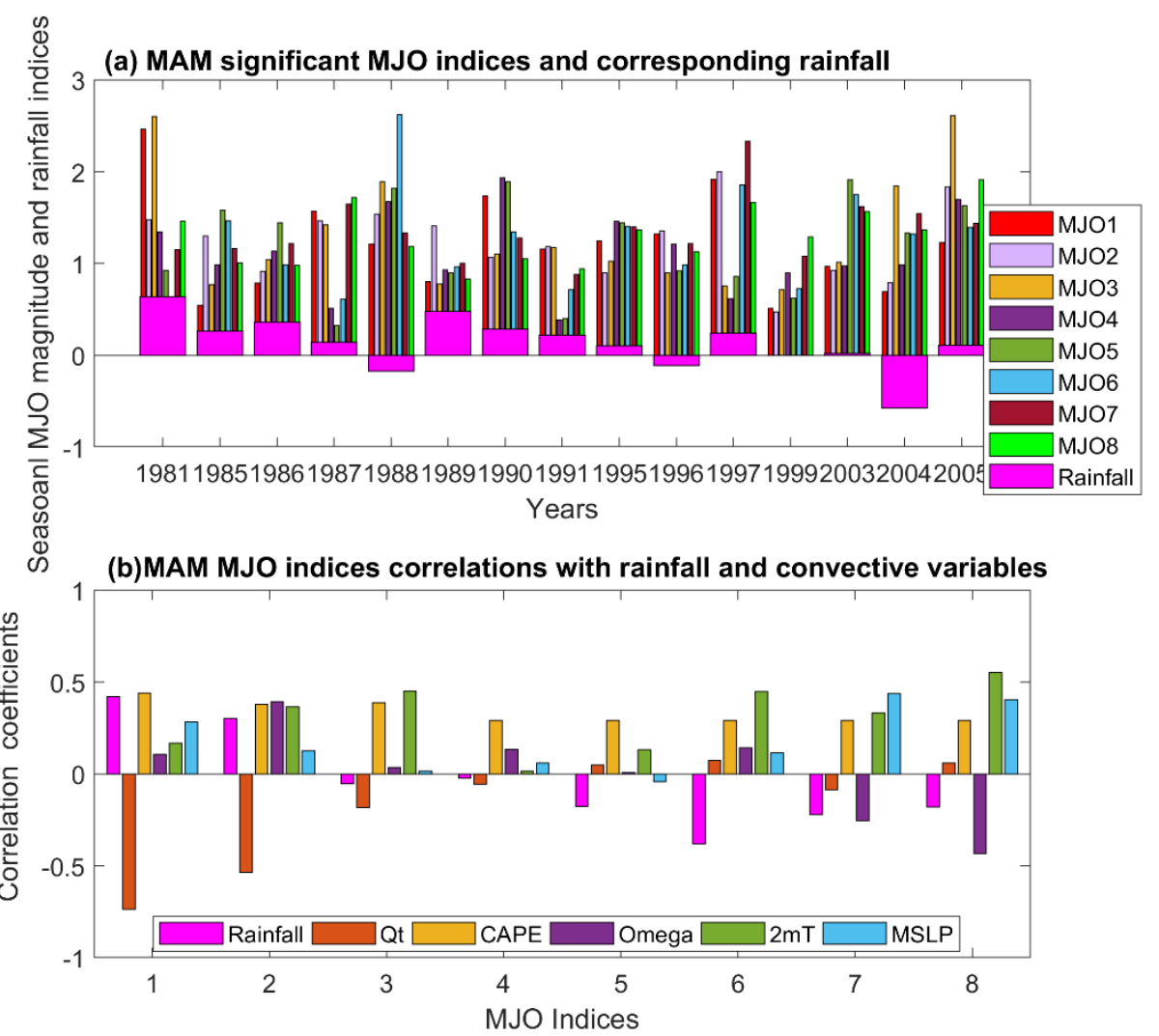

Figure 5. 1: Composite of seasonally significant (monthly amplitude >1) MAM RMM MJO indices and corresponding MAM (a) and correlation coefficients (b) between MAM MJO indices from (a) 1 to (h) 8 averaged amplitudes and convective variables (b). Significant correlations at the $95 \%$ confidence level are $>0.5$.

The enhanced MAM MJO patterns and JJA plots are presented in Figure 5.2a, and Figure $5.2 \mathrm{~b}$ presents the $\mathrm{MJO}$ patterns and OND rainfall indices. An enhanced MAM MJO is observed to be largely related with dry conditions, as indicated by negative rainfall values, with the exception of a few wet years, such as 1997. During the JJA rainfall season, the impact from an enhanced MAM MJO is observed to be opposite that for OND. For example, 1981, 1988 and 1986 are evident dry years (Figure 5.2a), with negative values indicating decreased rainfall, whereas during JJA, an increase in wetness is observed. Because the JJA season corresponds with the southwest monsoon, the MAM $\mathrm{MJO}$ that affects monsoon evolution also impacts the OND rainfall season. 
An assessment of MJO Circulation Influence on Air-Sea Interactions for Improved Seasonal Rainfall Predictions over East Africa

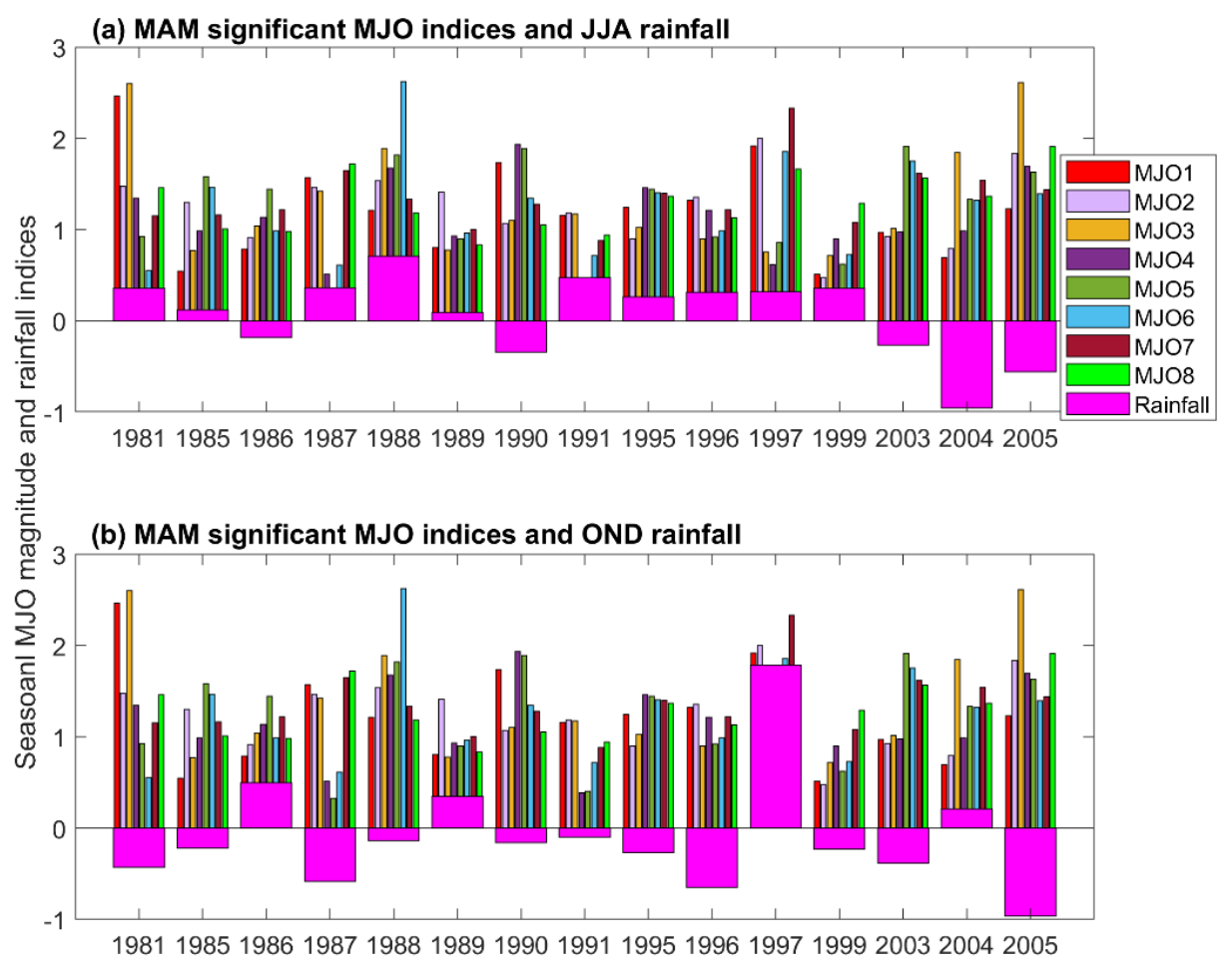

Figure 5. 2: Composite of seasonally significant (monthly amplitude $>1$ ) MAM RMM MJO indices and JJA (a) and OND (b) rainfall patterns.

\subsubsection{MJO circulation impacts}

In this section, the MJO circulation impact on extreme wet and dry conditions is explored using the average of all RMM MJO indices during the anomalous dry and wet years related to IOD, some of which also correspond to ENSO. Two scenarios are compared during these extreme years; first, when MJO is active in all 3 months of the March-May rainfall season and second, those years in which $\mathrm{MJO}$ is inactive. Figures $5.3 \mathrm{a}$ and $5.3 \mathrm{~b}$ and Figures $5.3 \mathrm{e}$ and $5.3 \mathrm{f}$ illustrate the MAM MJO active years, corresponding to dry and wet years, whereas Figures $5.3 \mathrm{c}$ and $5.3 \mathrm{~d}$ and Figures $5.3 \mathrm{~g}$ and $5.3 \mathrm{~h}$ depict the inactive MJO dry and wet years, respectively. During the MAM active years, the magnitude is highest in approximately March-April, after which there is a steady, decreasing trend. Furthermore, the MJO magnitude peaks either early in March to April or late in April to May, and the impact is different in both cases. When the peak onset occurs in early March, coinciding with a positive/negative IOD, the wet/dry conditions become more intense during the OND season.

An example of such an occurrence is exhibited during the 1981 and 1997 dry and wet conditions, respectively. Conversely, when MJO peaks in late May, the extreme conditions become more moderate, as exhibited during the 2005 and 2003 dry and wet years, respectively. The influence of the MJO magnitude to 
MAM rainfall variability was also observed by (Pohl \& Camberlin, 2006b). The MAM MJO magnitudes serve as a guide to estimate expected extreme events during the OND season when the MJO magnitude is > 2.5 in MAM.
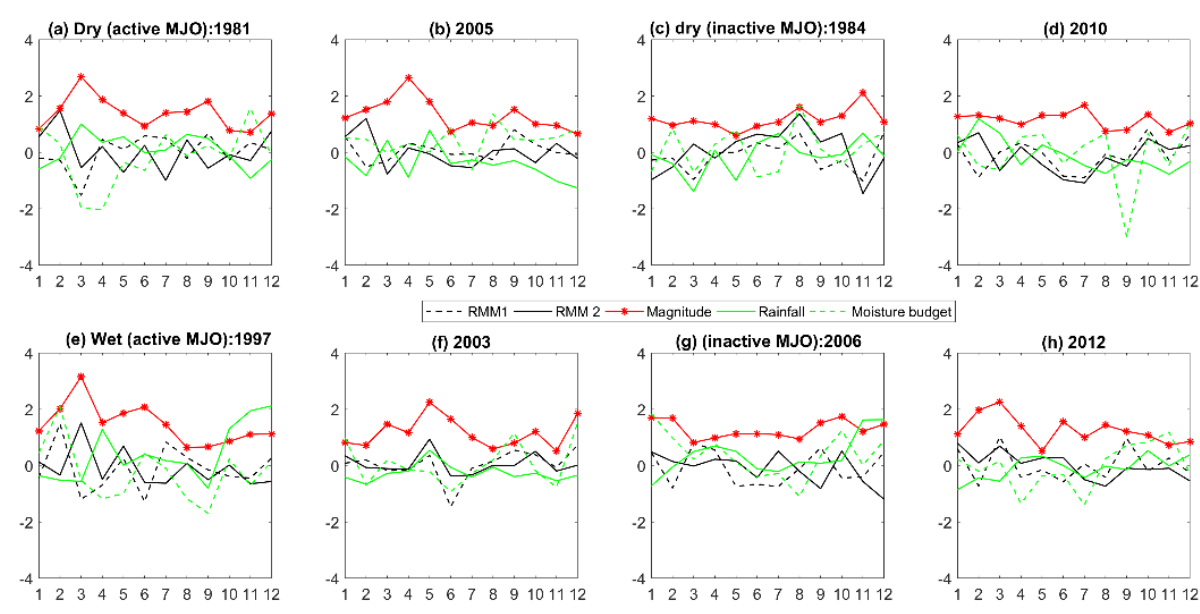

Figure 5. 3: Monthly time series averages of RMM MJO (RMM 1, 2 and magnitude and corresponding rainfall and total moisture budget indices across the four boundaries enclosing East Africa during the anomalous dry (5.3a-d) years associated with enhanced $M J O(60 \%$ days $>1)$ shown in and similarly, anomalous wet years (5.3e-h) with e and $f$ been MJO enhanced years.

Figure 5.4 depicts the seasonal spatial rainfall distributions of the early $\mathrm{MJO}$ active dry years in 1981 (Figure 5.6a-c) and late peak in 2005 (Figure 5.4df). 
An assessment of MJO Circulation Influence on Air-Sea Interactions for Improved Seasonal Rainfall Predictions over East Africa

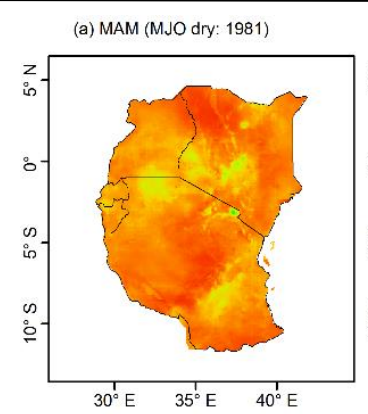

(b) JJA (MJO dry:1981)

(c) OND (MJO dry:1981)
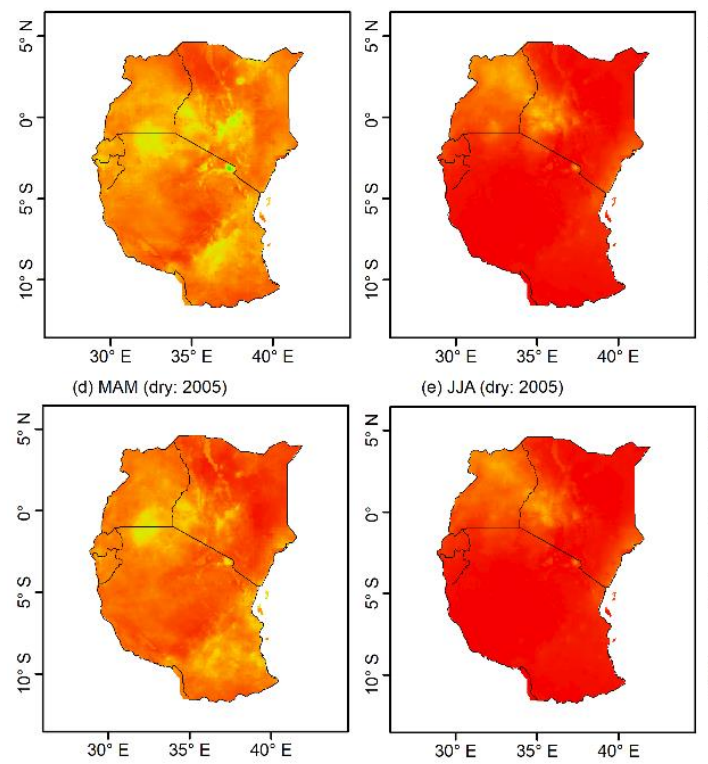

(e) JJA (dry: 2005)
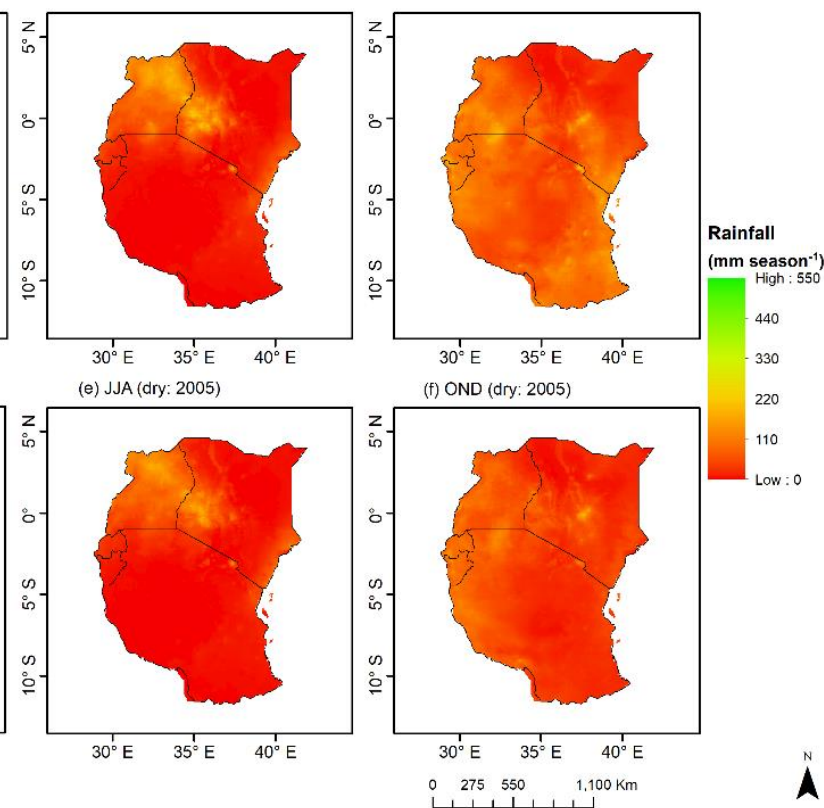

Figure 5. 4: Seasonal (MAM, JJA and OND) spatial rainfall distributions of the early (March-April) peak MJO active dry years in 1981 (Figure 5.4a-c) and late (April-May) peak in 2005 (Figure 5.4d-f).

Figure 5.5 shows the early peak of a wet year (1997, figure 5.5a-c) and late peak of a wet year (2003,figure $5.5 d-f)$. Figures 5.4 and 5.5 indicate a general increase in wetness/dryness in MAM corresponding to increased/decreased wetness/dryness in OND. This suggests the peak MAM MJO affects the overall amount of rainfall during the two rainfall seasons. McPhaden $(1999,2004)$ observed that MJO events preceded extreme wet events in 1997 and 2003. The present study establishes that in MAM rainfall months, the likely extreme event is detectable using MJO magnitudes. During the JJA rainfall season, the impact of the early or late peak of MJO is opposite that of OND. An early peak enhances wetness/dryness, whereas a late peak enhances moderate dryness/wetness. (Berhane \& Zaitchik, 2014) observed that MJO modulates the Turkana low-level jet, which is also associated with decreased rainfall during summer (JJA).

To further understand the MJO magnitude impact, Pearson correlation analysis was employed between East Africa annual rainfall and the MJO 


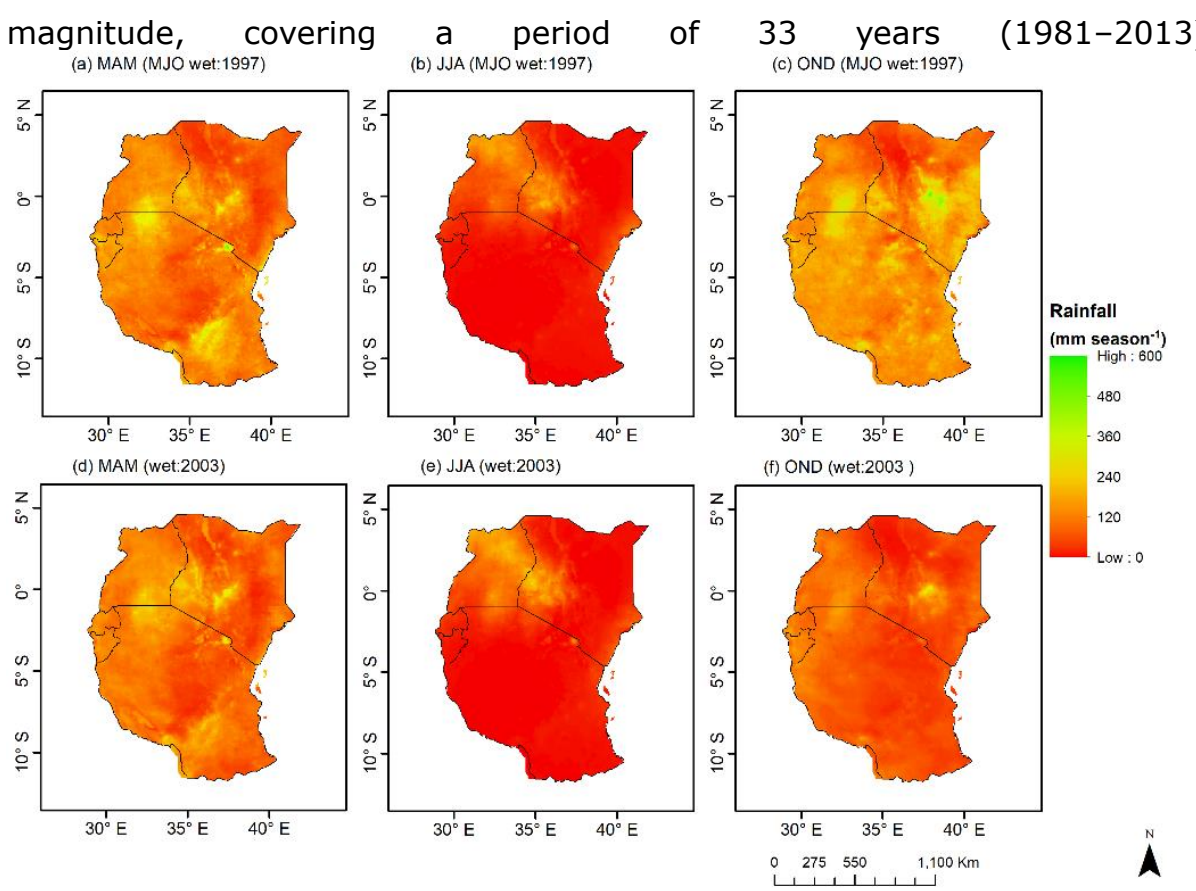

Figure 5. 5: Seasonal (MAM, JJA and OND) spatial rainfall distributions of the early (March-April) peak of wet year (1997, Figure 5.5a-c) and late (April-May) peak of a wet year (2003).

Figure 5.6 presents seasonal correlation patterns between RMM MJO magnitude averages and the corresponding rainfall for each rainfall season. Large areas with significant correlations are associated with the MAM season, and decreasing trends, such as those in OND, are associated with the least coverage. Further observations indicate areas of low-level wind convergence that correspond to positive correlations and western parts of the region that include the highlands. Negative correlations are observed in MAM and JJA in southern Tanzania, which is attributable to the strong advection from the Indian Ocean. These correlation patterns for the three seasons suggest the MJO circulations enhance a low-level influx of moisture from the Indian Ocean. This is demonstrated by wind patterns and is more defined in JJA, whereas low-level convergence in OND is directed toward the Congo Basin. This may explain the finding of (Pohl \& Camberlin, 2006a), who observed that MJO influence over the highlands and coastal areas is low as convergence areas are located in the western part of East Africa. During MJO influences, there is an influx of moisture into East Africa. 
An assessment of MJO Circulation Influence on Air-Sea Interactions for Improved Seasonal Rainfall Predictions over East Africa

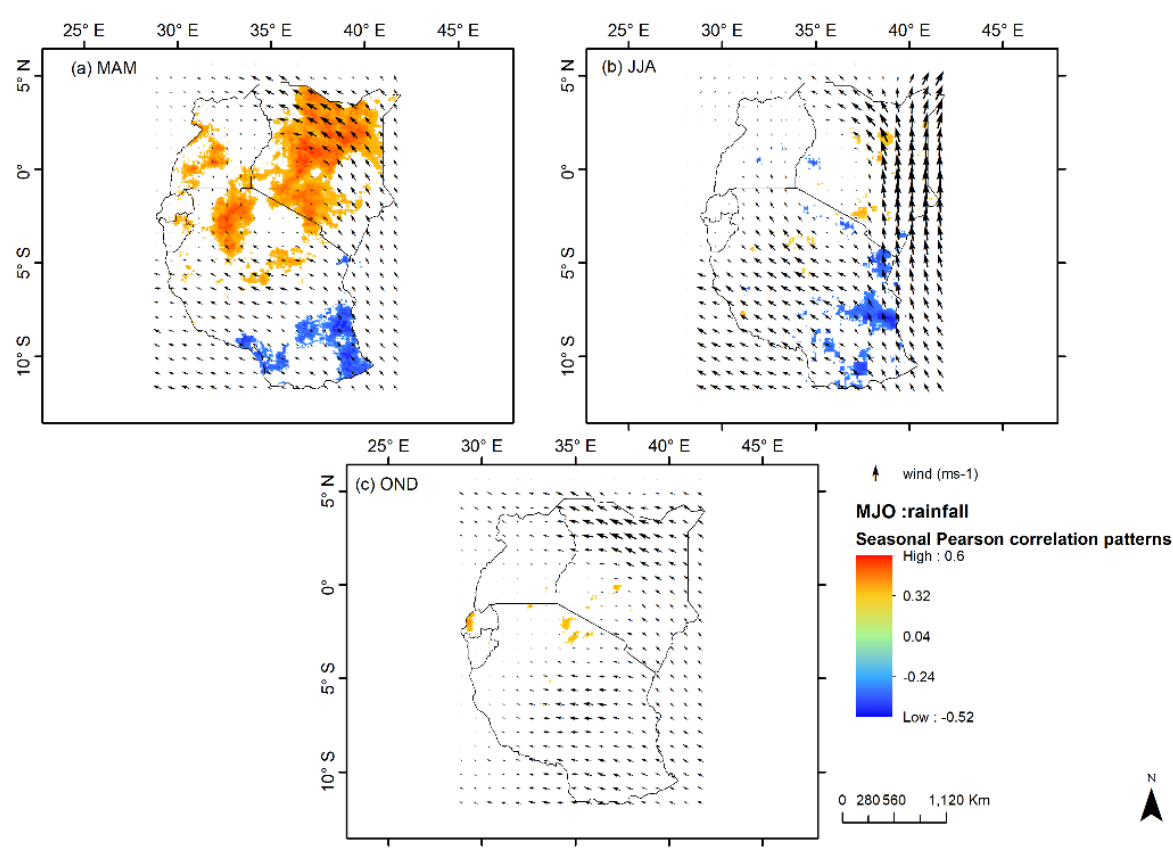

Figure 5. 6: Seasonal (MAM JJA and OND) Pearson correlation patterns of average RMM MJO (1981-2013) magnitudes and corresponding rainfall across East Africa. Only significant correlations at a 95\% confident level are displayed. Included are the low-level $(850-\mathrm{mb})$ wind patterns for the corresponding seasons.

\subsubsection{SST forcing}

In this section, the impact of MJO magnitude on both atmospheric and ocean circulations is investigated for the MAM season. First, a qualitative analysis of SST indices during extremely dry and wet years corresponding to an active and inactive $\mathrm{MJO}$ is described using composite maps. Figure 5.7 depicts the dry years (Figure 5.7a and 5.7b) of an inactive and active MJO, while Figure $5.7 \mathrm{c}$ and $5.7 \mathrm{~d}$ represent the wet years. Embedded are the low-level wind patterns $(850-\mathrm{mb})$. During the dry years of an active MJO, the area around southern Seychelles become warmer, and the horizontal winds are weakened as they converge to the area. Furthermore, the winds are less continental and more maritime continental as they flow toward East Africa. This enhances some moisture, which may explain the decreased dryness during active MJOs. A study by (Manatsa, Morioka, Behera, Matarira, \& Yamagata, 2014) associated changes in convection over the South Indian Ocean (SIO), which includes SWIO-delineated areas, to Mascarene high zonal movements. Similarly, during the wet MJO years, the central Indian Ocean warms; thus, convection again increases, reducing the wind speed to East Africa, causing it to be more maritime. The area over the central Indian Ocean, including the West Indian Ocean (WIO), is relatively cooler than the Maritime Continent. Eastern Indian Ocean (EIO) cooling is evident and includes parts of the 
Maritime Continent. In their study, (Wilson et al., 2013) observed that the MJO over the Indian Ocean and Maritime Continent increases during negative IOD. The 2-m surface temperature forced by SST links atmospheric and ocean circulations. The relationship of MJO 8 with circulation variables (2-m surface temperature) and SST with 2-m surface temperature is spatially described within a rectangular area, $0^{\circ} \mathrm{E}$ to $140^{\circ} \mathrm{E}$ and $35^{\circ} \mathrm{S}$ to $20^{\circ} \mathrm{N}$. The SST forcing to surface temperature was used as a link to establish oceanic locations where MJO circulations have influence. Since MJO 1, which represents convection over Africa, significantly correlates with moisture budget at a seasonal scale, the latter is used as a rainfall proxy. The relationship between 2-m surface temperature and SST and between 2-m surface temperature and MJO 8 were determined using correlation patterns. Time series of SST were then extracted in areas of significant correlations between the two patterns for the period covering 33 years (1981-2013).

(a) SST compoșite of dry,years

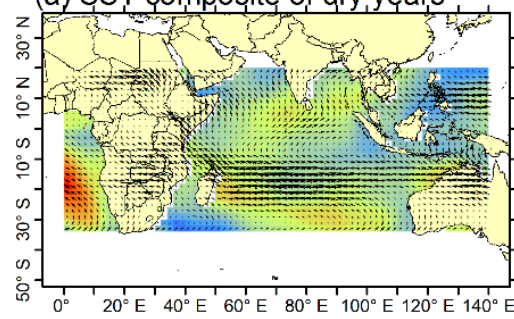

(c) SST composite of wet years

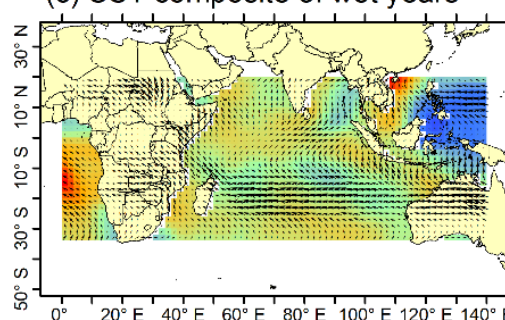

(b) SST composite of dry MJO years

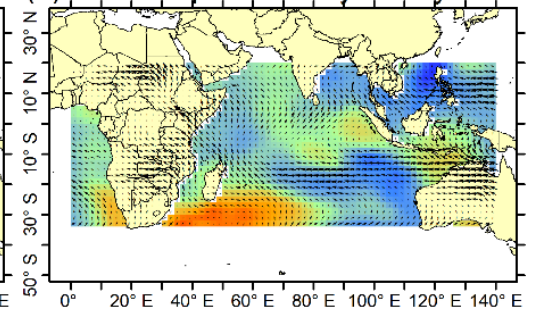

+ zonal wind $\left(\mathrm{ms}^{-1}\right)$

SST indices

Value

High : 2.06

1.1575

0.255

0.6475 (d) SST composite of wet MJO years

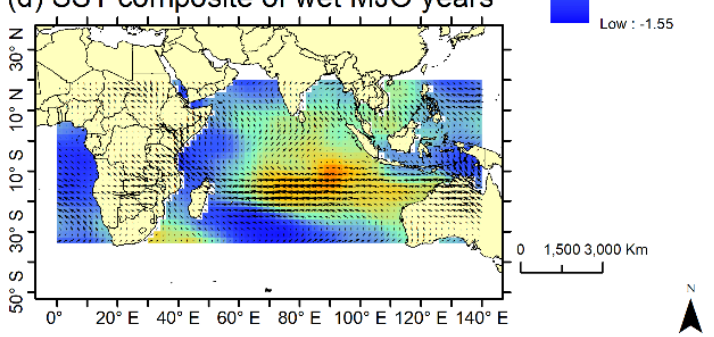

Figure 5. 7: Composite of sea surface temperature indices during the extremely dry inactive (1984, 2010) and active (1981, 2005) MJO years (Figure 5.7a and 5.7b, respectively). Wet inactive (2006, 2012) and active $(1997,2003)$ MJO years are presented in Figure 5.7c and 5.7d.

The areas identified are the Central Indian Ocean (CIO: $54-91^{\circ} \mathrm{E},-6^{\circ} \mathrm{S}-5^{\circ} \mathrm{N}$ ), Maritime Continent (MRT: $122^{\circ}-126^{\circ} \mathrm{E},-4^{\circ} \mathrm{S}-0^{\circ} \mathrm{N}$ ) and Southwest Indian Ocean (SWIO: $44-53^{\circ} \mathrm{E},-30^{\circ} \mathrm{S}-25^{\circ} \mathrm{N}$ ) as shown in Figure $5.8 \mathrm{~b}$. MJO 8 has an obvious negative influence on surface temperature over those locations, which may be understood as arising from the cooling of the atmosphere due to evaporation. Similarly, convections over the Congo Basin and western Kenya are also supported by the SST and MJO 8 correlation patterns (Figure $5.8 \mathrm{a}$ ). The index area over the Maritime Continent was limited because of multiple islands that may subsequently increase the bias. SST forcing on surface temperature was partially impacted by MJO circulations over the 
An assessment of MJO Circulation Influence on Air-Sea Interactions for Improved Seasonal Rainfall Predictions over East Africa

identified areas. As a result, the zonal wind (Figure 5.8b) influx moisture to East Africa converges in areas of convection. The surface temperature decreases over the Congo Basin as convections increase, limiting the westward moisture flow to East Africa. The extracted time series are then subjected to regression analysis for rainfall prediction (moisture budget as a proxy of rainfall).
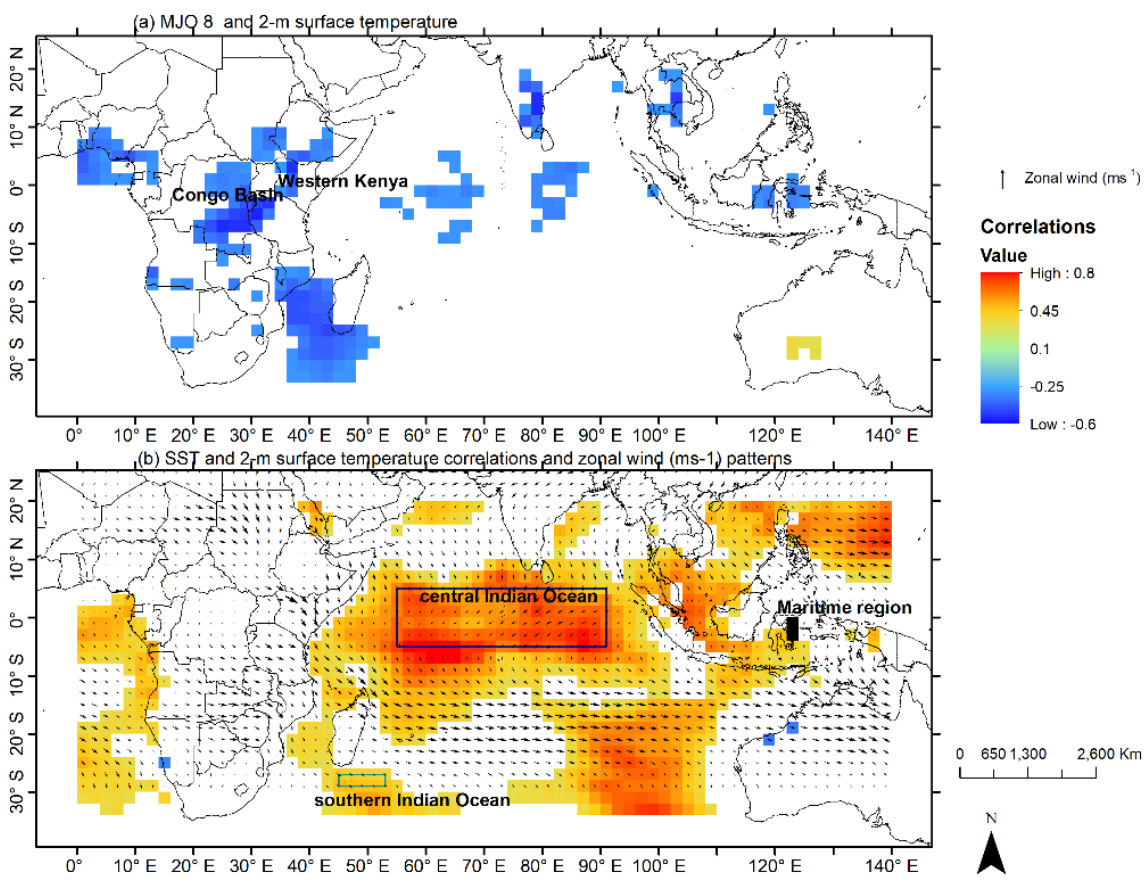

Figure 5. 8: March-May (MAM) Pearson correlation patterns of surface temperature and MJO 8 for the period 1981-2013 (a) and the correlations between surface temperature and SST. Only significant correlations at a 95\% confidence level are presented. Horizontal wind patterns showing areas of low-level convergence are depicted in the map.

\subsubsection{MAM seasonal Forecasting}

Stepwise regression analysis of the extracted SST indices were designated as predictors of moisture budget. In performing the regression analysis, the 33 years were subdivided into two parts, calibration (70\%) and validation (30\%). The lagged predictions against the estimated moisture budget are presented in Figure 5.9, and the quadratic equation was most suitable of lag 4. 

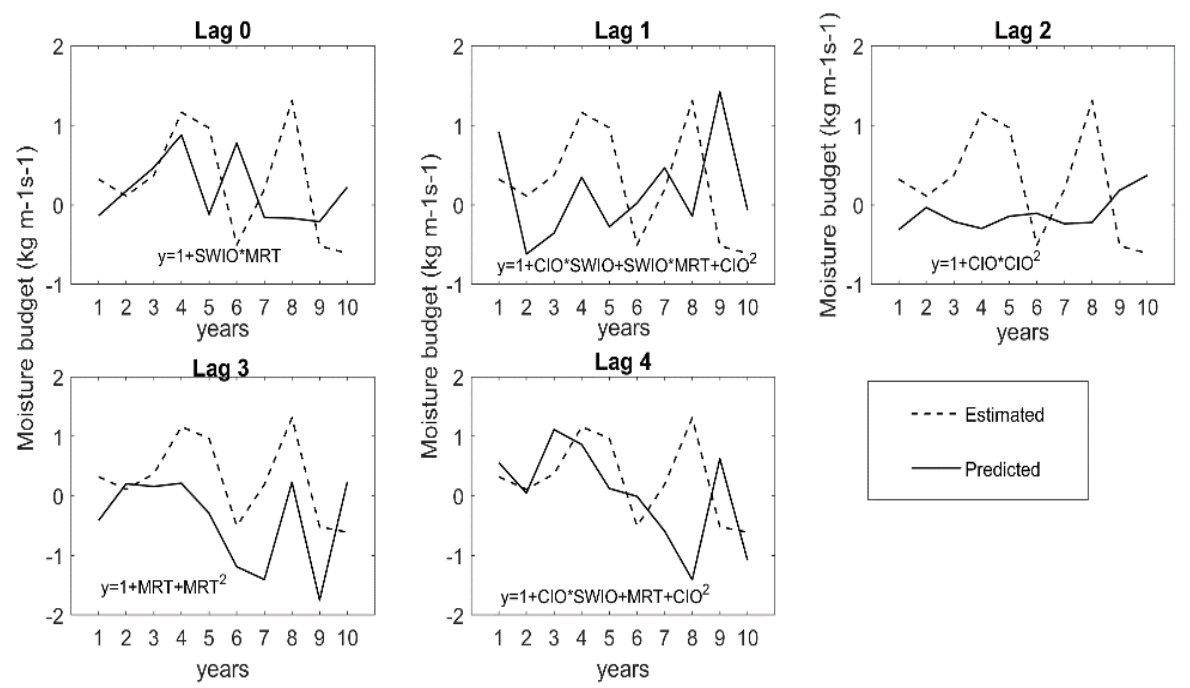

Figure 5. 9: Lagged March-May (MAM) prediction and estimated moisture budget $\left(\mathrm{kg} \mathrm{m}^{-1} \mathrm{~s}^{-1}\right)$ (rainfall proxy) patterns derived using SST indices over the Indian Ocean and Maritime Continent related to MJO circulations for the validation period 2004-2013.

Table 5.1 presents a summary of the Brier skill score and ACC, where the lowest Brier score and highest ACC denote the highest skills. The lag 4 Brier score of 0.02 and ACC of 0.82 is, therefore, determined to be the most skilful model.

Table 5. 1: Regression prediction model validation output for moisture budget $\left(\mathrm{kg} \mathrm{m}^{-1} \mathrm{~s}^{-1}\right.$ ) (rainfall proxy) indices as predictand and sea surface temperature $(\mathrm{k})$ indices extracted from three geographical locations (SWIO,MRT and CIO ) as predictors during the validation period (2004-2013).

\begin{tabular}{|c|c|c|c|c|c|c|}
\hline Model & lag & BS & BSS & BS clim & ACC & variables \\
\hline quadratic & 0 & 0.02 & 0.91 & 0.20 & 0.74 & SWIO, MRT \\
\hline quadratic & 1 & 0.04 & 0.80 & 0.20 & 0.50 & $\begin{array}{c}\text { CIO, SWIO, } \\
\text { MRT }\end{array}$ \\
\hline quadratic & 2 & 0.05 & 0.77 & 0.20 & 0.82 & $\mathrm{CIO}$ \\
\hline quadratic & 3 & 0.02 & 0.91 & 0.20 & 0.49 & $M R T$ \\
\hline quadratic & 4 & 0.02 & 0.91 & 0.20 & 0.82 & $\begin{array}{c}\text { CIO, SWIO, } \\
\text { MRT }\end{array}$ \\
\hline
\end{tabular}


An assessment of MJO Circulation Influence on Air-Sea Interactions for Improved Seasonal Rainfall Predictions over East Africa

\subsection{Conclusions and Discussion}

This study aims to establish the impact of MJO amplitude on air-sea interactions at different time scales that influence rainfall variability over East Africa for a period of 33 years (1981-2013). For atmospheric analysis, the relationship between the RMM amplitudes and convection variables was investigated using locally bias-corrected CHIRPS v2 rainfall (Kimani et al. 2018) and convective variables from omega, MSLP, 2-m surface temperature and CAPE. The RMM MJO (Wheeler and Hendon 2004) daily time series for the magnitude peaks during MAM, JJA and OND throughout the entire 33year period was also examined. MAM MJO magnitudes were the highest and seemed to correspond to extreme events (dry, wet). For example, the extreme conditions of 1987-1988, 1996-1997, 2004-2005 and 2011-2012 featured magnitudes $>3$. This suggests $M J O$ evolution has a strong link to extreme rainfall variability. Monthly time series analysis of individual indices when $\mathrm{MJO}$ is enhanced (magnitude $>1$ ) in MAM was further investigated. The results revealed that the $M J O$ relationship with rainfall and convective variables is inconsistent at that scale. This also suggests that the convective portion of MJO may not be detectable at a monthly scale in the region and that circulation may be more relevant. Because MJO circulation continues for 30-60 days, the circulation patterns end and are therefore not detectable at a monthly scale. This was further supported by a clearer pattern when comparisons were made using the seasonal (MAM) scale. MJO 3 over the Indian Ocean, Pacific (MJO 6) and Africa (MJO1) exhibited the highest magnitude. Although the correlations with rainfall are not significant, primarily attributed to local processes, moderately high $(-0.74)$ correlations with a moisture budget and $2-\mathrm{m}$ surface temperatures $(0.53)$ were observed. Since individual phases exhibited different impacts on rainfall and convective variables, an average of all the indices' magnitudes was used to compare with the full cycles of MJO circulations.

MJO circulation's impact on extreme wet and dry conditions was further explored using the average of all the RMM MJO indices during the anomalous dry and wet years associated with ENSO, some of which also correspond to IOD. Two scenarios were compared during these extreme years: first, when $M J O$ is active in all 3 months of the MAM rainfall season and second, the inactive years. During the MAM MJO active years, the magnitude is observed to be highest in approximately March-May, after which there is a steady, decreasing trend. Furthermore, the MJO magnitude peaks either early in March to April or late in April to May, and the impact is different in both cases. The early peak in March, coinciding with the positive/negative IOD, becomes more intense during the OND season.

This is exhibited in 1981 and 1997 by the extremely dry and wet years, respectively. Conversely, when the MJO magnitude peaks late in May, the extreme conditions become moderate as in 2005 (dry year) and 2003 (wet year). If the MAM MJO magnitude is determined to be $>2.5$, this can serve to indicate an expected extreme event will occur during OND. McPhaden $(1999,2004)$ observed that MJO events preceded extreme wet events in 1997 and 2003. However, the JJA rainfall season experiences the opposite effect as that of OND. An early peak enhances extreme wet/dry events, whereas a late 
peak enhances moderate dryness/wetness. This study establishes that in MAM rainfall months, likely extreme events are detectable using MJO magnitudes (magnitude >2.5). To further understand the MJO magnitude impact, Pearson correlation analysis was performed for East Africa's annual rainfall and MJO magnitude for a period of 33 years (1981-2013). Furthermore, low-level $(850-\mathrm{mb})$ wind patterns were used to describe areas of low-level convergence. Observations reveal areas of low-level wind convergence correspond to positive correlations and primarily cover western parts of the region, including the highlands and bordering the Congo Basin. Negative correlations were observed in MAM and JJA over southern Tanzania, which is attributable to strong advection from the Indian Ocean. The correlation patterns for the three seasons suggest the MJO circulations enhance low-level moisture influx from the Indian Ocean and converge to the western parts bordering the Congo basin. This was also demonstrated by wind patterns and is more defined in JJA and OND by the low-level convergence toward the Congo Basin. This may explain the observations by (Pohl \& Camberlin, 2006b) that the MJO influence over the highlands and coastal areas is low as convergence areas lie to the western part of East Africa.

The search for SST forcing related to MJO convections was performed within a rectangular area, $0^{\circ} \mathrm{E}$ to $140^{\circ} \mathrm{E}$ and $35^{\circ} \mathrm{S}$ to $20^{\circ} \mathrm{N}$. This area was determined based on its inclusion of the relevant centres of convections over the Indian Ocean identified through qualitative analysis. Pearson correlation patterns were analyzed between 2-m surface temperature and MJO 8 and between SST and 2-m surface temperatures for 33 years (1981-2013). The latter attempted to establish the convection areas based on SST forcing to $2-\mathrm{m}$ surface temperatures related to $\mathrm{MJO}$ convections. Significant locations were identified over MRT, CIO and SWIO, which also exhibited low-level (850-mb) winds convergence. The enhanced convection over the Maritime Continent, defined here as MRT, was linked to MJO by (Wilson et al., 2013) and associated with the suppression of East Africa rainfall. The area over SWIO was linked to Mascarene high zonal movements (Manatsa et al., 2014), which suggests a link between MJO circulations and synoptic systems. However, similar to the findings in this study is the cooling demonstrated by the negative correlations of $\mathrm{MJO}$ and 2-m surface temperature patterns. This is associated with conventional cooling (Behera \& Yamagata, 2001) in lower troposphere also experienced over the Congo basin.

Stepwise regression analysis of the extracted SST indices from the three centres was performed to determine the predictors of moisture budget a rainfall proxy. In performing the stepwise regression analysis, the 33-year study period was subdivided into two parts, $70 \%$ for calibration and $30 \%$ for validation. To validate the regression prediction, both deterministic and probabilistic metrics were employed. For the probabilistic test, BS was used, and ACC was used for the deterministic test. A lag 4 Brier score of 0.02 and ACC of 0.82 is, therefore, the most skilful model. The period is within the ENSO cycle and can, therefore, be used to predict extreme events.

The study concludes that, whereas the influence of MJO on rainfall during OND (and JJA) rainy seasons is fairly minor, MJO has a major impact on the rainfall dynamics during the MAM rainy season. Consequently, the inclusion of the MJO magnitude (notably for MJO 1 and MJO 8) can help improve seasonal forecasts for the MAM rainy season in East Africa 
Chapter 6

6. Synthesis 


\subsection{Overall conclusions}

Rainfall is an essential component of the water cycle and very variable in space and time, and when its variabilities are not correctly predicted, unforeseen extreme events like floods and drought may cause disasters leading to loss of lives and destruction of properties. The GCM models can provide high temporal resolution forecast but have challenges characterizing the sub-grid localized processes because of their coarse spatial scale and models' initialization challenges. An empirical approach is more flexible to scale adjustments but for seasonal rainfall predictions long-term consistent and good coverage rainfall data to represent rainfall of different characteristics regionally is required. This can then be used as a basis to determine the atmospheric and oceanic forcing linked to local processes. This thesis employs an empirical approach to improve rainfall predictions over East Africa using locally adjusted satellite rainfall data.

Seasonal rainfall prediction using the statistical approach is wholly dependent on the quality of input data to representing different rainfall regimes. East Africa has sparse rain gauge data, but similar to other regions there is excessive use of satellite-derived rainfall products to complement the poor rain gauges representations. However, these products have errors that depend on geographical location, rainfall regime and season. Choosing the most appropriate product to characterise rainfall variabilities of a given geographical location is crucial. Consequently, the first objective of this research dealt with determining the most suitable satellite rainfall product for the region considering spatial and temporal variabilities. The seven products considered include; TARCAT, CHIRPS v2, TRMM-3B43, CMORPH v1, PERSIANN-CDR, CMAP and GPCP. Gridded (0.050) rain gauge data that is quality controlled sourced from East Africa Meteorological and Hydrological member states by ICPAC were utilized on a monthly and yearly timescale for 15 years (1998-2012).

Further, since the region is mountainous, the topographic impacts on the products monthly rainfall estimates were determined. All the products were able to replicate rainfall patterns in space and time but showed systematic errors in rainfall retrieval that increased with an increase in rainfall amounts (>100 mm/month). The systematic errors were mainly in underestimations and showed seasonality as they were larger during the OND than during the MAM rainy season. The errors were more evident in a monthly timescale but decreased in a yearly timescale. The underestimations were attributed to the products' inability to retrieve orographic rainfall that is more dominant during the OND season. Products using only infrared sensors like TARCAT and PERSIANN-CDR were affected more, especially TARCAT which uses a single sensor which limits its capabilities of retrieving rainfall of different regimes. It can be understood that orographic clouds are relatively warm as they are caused primarily by kinetic turbulence, rather than convection. It follows the infrared sensor attribute low cloud temperature to high rainfall amounts and therefore excludes the relatively warm orographic rainfall.

Consequently, products using microwave imageries for rainfall retrieval showed fewer errors in the retrieval of this rainfall type on high elevated areas. These include TRMM-3B43, likewise, CMORPH v1 which utilizes passive 
microwave data to generate rainfall and CHIRPS v2 that is calibrated using the Tropical Rainfall Measuring Mission Multi-satellite Precipitation Analysis version 7 (TMPA 3B42 v7). Elevation variation is closely related to orographic rainfall developments and hence to the satellite rainfall products' performance. This effect is more evident during the OND season, as low-level wind enhances rainfall on the windward side, particularly over the Mount Kenya region. The study revealed that when elevation was $<2500 \mathrm{~m}$, the products showed underestimations. The overestimations were mainly observed during the MAM season, which is associated with increased rainfall amounts from deep convective systems, and the errors were attributed to cirrus clouds coexisting in deep convections. CHIRPS was among those most affected. The products' input data affected their performances. Products using multiple sensors performed better than those with single sensors, especially if the sensors were on different platforms. The multisensory increased their ability to retrieve rainfall of different types over the region. Those affected most are the TARCAT and PERSIANN-CDR, which use only infrared sensors. Also, TARCAT showed a greater impact because it uses a single sensor (infrared) that limits the retrieval of different rainfall regimes. The distribution of the rain gauges used in calibration also affects their performance, and thus there is a need to regularly update the algorithms with denser rain gauge data where applicable. This affects the way each product varies in performance from region to region. This was attributed to the underperformance of GPCP over the region. The satellite products considered are therefore applicable over East Africa, but errors in high ground areas need to be minimized before application. CHIRPS was chosen based on its long climatology and consistencies with gridded data and the next section deals with its bias corrections.

An assessments of the applicability of the Bayesian approach with an existing historical rain gauge dataset to create consistent satellite rainfall data for long-term applications is performed. The gridded rain gauge dataset from ICPAC was utilized. The CHIRPS product, like other satellite-derived products, exhibit systematic errors that vary from place to place. Although this product is globally bias corrected using local rain gauge data, regional gridded rain gauge data provided by the ICPAC includes the GTS used and incorporates other available quality controlled data sourced from Meteorological and Hydrological member states. Monthly analysis showed adequate amounts of errors were corrected particularly the orographic induced ones. Observed were biases uncorrected of over corrections mainly over the Lake Victoria during the MAM peak rainfall months of April and May attributed to cirrus effects coexisting in deep convections. Other areas where over corrections were observed include southern Tanzania. These two places have low rain gauge distributions not adequately able to represent the rainfall variability. Hence the CHIRPS over correction approached uncorrected states. It is commendable that the approach is sensitive to the temporal representation of rainfall variability and the bias-corrected estimates approach uncorrected states in poorly distributed states. The yearly analysis showed an increase of the corrected biases attributable to the reduced rainfall variability. The errors were dependant not only on rainfall magnitude but distribution in time. Although large biases were evident during the El Niño year of 2006 which also has the highest rainfall amount, not all El Niño years showed similar results.

The El Niño years occur during the October-December rainfall months, which also have fewer rain days when compared to the March-May (MAM) 
rainfall months. As a result more rainfall is experienced year after during MAM. For example, in the year 2003, 2006, and 2009 El Niño years increased average rainfall amount was observed a year after in 2004, 2007, and 2010, consequently, a higher percentage of bias was corrected. Annual assessments of the performance of the Bayesian approach were conducted on selected pixels centred in areas of large CHIRPS overestimations (uncorrected bias). These include areas over Mt. Elgon, Southern Tanzania, Lake Victoria, and Mt. Kilimanjaro. The method adequately reduced bias related to high elevated areas. Overcorrections were also significantly reduced, but in areas of poor rainfall representations, cirrus effects exhibited by CHIRPS overcorrections were uncorrected. The bias-corrected CHIRPS data was utilized for the investigations of atmospheric-sea interactions.

Determining precipitable moisture budget distribution and its influence on rainfall variability is essential in understanding rainfall variability. Evapotranspiration minus the adjusted CHIRPS data were used to balance the precipitable moisture budget as described in the next section. Calculation of the moisture budget was carried out between the surface (850 mb) and near the tropopause $(200 \mathrm{mb})$ within a rectangular box enclosing the region, between $29^{\circ} \mathrm{E}$, and $42^{\circ} \mathrm{E}$, and $12^{\circ} \mathrm{S}$, and $5^{\circ} \mathrm{N}$. Era-interim reanalysis data from European Centre for Medium-Range Weather Forecasts (ECMWF) were utilized for these computations. East Africa is in the equatorial tropics and convective systems are more dominant and computed moisture budget relationship with local bias corrected CHIRPS v2 rainfall data, and convective variables were established. The convective variables considered include Omega $(\mathrm{mb} \mathrm{s}-1)$, CAPE ( $\mathrm{kg}-1), \operatorname{MSLP}(\mathrm{mb})$ and $2 \mathrm{~m}$ surface temperature $(\mathrm{K})$ and were used to identify convective areas. Empirical Orthogonal Functions (EOF 1,2) of moisture were utilized to determine the impact of the Dipole Mode Index (DMI) and Nino 3.4 to moisture distributions during different phases of IOD. Nino 3.4 was included since most positive IOD also corresponds with ENSO. Monthly analysis showed an insignificant recycling ratio indicating the advected moisture is the most dominant source of precipitation. Contributions from evaporation are minimal affecting mainly the Lake Victoria and surrounding areas. Analysis of moisture budget and convective variables showed dominant low-level convergence from the Indian Ocean, and mid troposphere from the west suggested to come from the Congo basin. During the southwest monsoon, the eastern moisture influx is inhibited by diffluence motions associated with Turkana jets which are suggested to intensify during this period. Consequently, convection is limited to the western parts of the region. Omega vertical profile analysis during the wet $(1997,2006)$ years showed convergence to the eastern/western part bordering the Indian Ocean/including Lake Victoria, Rwanda, Burundi and Uganda were separated by the highlands. Conversely, during the dry years $(1984,2001)$ the eastern moisture influx is inhibited further inland by diffluence leaving the western part experiencing shallow convection from reduced low-level moisture while the eastern part remains dry except over the Kenya highlands where orographic convections are experienced. The Kenya highlands act as moisture sink separating East Africa into east and west convections which exhibited seasonality. It was observed that this easterly flow is enhanced during positive IODs (and El Niño) and suppressed during negative IODs ( and La Niña). Empirical Orthogonal Functions (EOF 1,2) of moisture were utilized to determine the impact of the Dipole Mode Index (DMI) and Nino 3.4 to moisture distributions during different phases of IOD. DMI showed the 
largest influence during ITCZ overpass explaining $>60 \%$ and less during southwest monsoon months. EOF2 explains the largest influence (31\%) in May attributed to DMI with little influence of Nino3.4. EOF1 is dominantly influenced by DMI but early onset of southwest monsoon in May corresponding with $\mathrm{El}$ Niño year suppresses moisture influx from the Indian Ocean leading to drier conditions in November. Further investigations on the seasonal and interannual processes involved in moisture distribution. The most dominant intraseasonal oscillation was investigated with the aim of improving seasonal rainfall predictions over East Africa.

East Africa experiences two major rainfall seasons in MAM and OND during ITCZ overpass. Even though MAM season is the longest and of highest intensity (long rains), its variabilities and prediction is still a challenge owing to the different mechanisms that are not well understood. The Real-time Multivariate (Madden-Julian Oscillation) MJO (RMM) amplitudes were utilized to identify air-sea interactions that influence rainfall variability of the region. The daily MAM MJO showed the highest peak occurring after three to four years with amplitude $>3$ and those below 1.5 mainly noisy. The high peaks were observed to coincide with the onset of a year before an extreme event over the region. Monthly analysis of individual $\mathrm{MJO}$ indices and rainfall were inhibited by noise, but some patterns were recognized. Although the patterns were distorted by increased noise, MJO over Maritime ( $\mathrm{MJO} 4$ ) and western hemisphere (MJO1 and 8) were most consistent. The patterns at seasonal timescale were more clear, as MJO oscillation takes 30-60 days. The moisture budget and 2-m surface temperature showed significant correlations $(-0.74$ and 0.53 respectively) with MJO 1 and eight respectively at the seasonal scale. Monthly averages of all the MJO indices revealed links to extremely dry and wet events over the region. An early MAM MJO peak enhances extreme wetness/dryness during MAM, while the late peak corresponds to moderate dryness/wetness. MJO circulations enhance low-level moisture influx from the Indian Ocean and converge to the western parts bordering the Congo basin. This was also demonstrated by wind patterns and is more defined in JJA and OND by the low-level convergence toward the Congo Basin. Pearson correlation patterns were analyzed between surface temperature and MJO 8 and similarly between SST and surface temperature. The latter individual index was aimed at establishing the convection areas based on SST forcing to 2-m surface temperatures. From the two patterns of correlations, areas common to both were over the ocean were used for extraction of SST indices monthly for the 33 years. Significant locations were identified over Maritime continent, Central Indian Ocean and southwest Indian ocean. Stepwise regression analysis of the extracted SST indices was performed to determine the predictors of moisture budget a rainfall proxy. Both deterministic and probabilistic validation metrics were employed. For the probabilistic test, BS was used, and ACC was used for the deterministic test. A lag 4 Brier score of 0.02 and ACC of 0.82 is, the most skilful model. The study observed that, whereas the influence of $\mathrm{MJO}$ on rainfall during OND (and JJA) rainy seasons is fairly minor, MJO has a major impact on the rainfall dynamics during the MAM rainy season. Consequently, the inclusion of the MJO magnitude (notably for MJO 1 and MJO 8) can help improve seasonal forecasts for the MAM rainy season in East Africa. 


\subsection{Challenges and Recommendations}

This thesis laid the foundation for prospective future works and recommendations based on the shortcomings encountered but could not be addressed within the current framework.

For the assessments of satellite-derived rainfall products, the thesis has shown that the selected satellite rainfall products (TARCAT, CHIRPS v2, TRMM-3B43, CMORPH, PERSIANN-CDR, CMAP and GPCP) accurately represent rainfall patterns over East Africa. However, they exhibit systematic errors related to rainfall magnitude and elevation changes with products using only infrared sensors been affected most. It is good to appreciate that in areas of complex terrain different rainfall regimes coexist. It was challenging to identify a suitable product for the region since most products make use of the infrared sensor for rainfall retrieval. It is not surprising that TRMM-3B43 and products using its estimates (CHIRPS and CMORPH) showed the best performance. It is recommended therefore for areas with complex terrain and coexistence of different rainfall regime to use multisensory products with microwave rainfall retrieval. Although the gridded rain gauge data is currently most updated, there are areas where rain gauges used in gridding are too sparse like over Tanzania including Mt Kilimanjaro. The Bayesian approach was applied to CHIRPS v2 to locally adjust the rainfall estimates to reduce systematic errors. It adequately reduced the bias especially of underestimations affecting the high elevated areas. However, because the approach is sensitive to rain gauge distributions, in areas of poor representation of rainfall characterisations the CHIRPS estimates remain close to their original states. It is recommended before application of this approach to perform long term rainfall analysis to be sure the rain gauge data is representative of area rainfall regimes. Also, a reference data of a higher or equal spatial scale to the satellite rainfall product is preferred for highest spatial representation of rainfall variability. The approach is recommended to adjust rainfall estimates of other algorithms with long-term historical records to capture external influences. Cirrus effects were observed to cause over corrections, but the effect was more in areas of deep convection and poor rain gauge network. Therefore in areas of possible localized convections like large inland water bodies and high elevated areas high rain gauge network is recommended for this application.

The impact of moisture distribution to rainfall variability over East Africa during different phases of Indian Ocean Dipole (IOD) was assessed using Era interim Reanalysis dataset for 33 years (1981-2013). The assessments of Moisture budget showed the advected moisture to be the dominant source of precipitable moisture. Moisture is mainly advected from the Indian Ocean through low-level convergences. Although most positive and negative IOD corresponds with ENSO, DMI was the main dominant forcing for moisture influx. However, the early onset on southwest monsoon was observed to be associated with ENSO and corresponds with dry conditions during positive IOD. However, the relationship between ENSO and DMI was only limited to moisture advection, and it is recommended to further research to know what triggers the early onset of the southwest monsoon. This study is a basis for further study.

The impact of the MJO circulations on air-sea interactions is assessed to improve the understanding and predictability of seasonal rainfall variability 


\section{Synthesis}

over East Africa based on ERA-Interim reanalysis data at different timescales. SST forcing on 2-m surface temperature was utilized to test the predictability of the March-April-May (MAM) rainfall season, covering a period of 33 years (1981-2013). MJO has a major impact on the MAM rainfall dynamics, and inclusion of MAM MJO1 and 8 magnitudes improve its prediction. The study observed that MAM MJO early (March-April) peak and late (April-May) is associated with JJA and OND rainfall variability. The early or late MJO peak seems to suggest a linkage to Southwest monsoon. Further research to establish these links is recommended. 


\section{Bibliography}

Abera, W., Brocca, L., \& Rigon, R. (2016). Comparative evaluation of different satellite rainfall estimation products and bias correction in the Upper Blue Nile (UBN) basin. Atmospheric Research, 178, 471-483. doi:10.1016/j.atmosres.2016.04.017

Adler, R. F., Huffman, G. J., Chang, A., Ferraro, R., Xie, P., Janowiak, J., \& Arkin, P. (2003). The Version 2 Global Precipitation Climatology Project (GPCP) Monthly Precipitation Analysis. J. Hydrometeor, 4, 1147-1167.

AghaKouchak, A., Mehran, A., Norouzi, H., \& Behrangi, A. (2012). Systematic and random error components in satellite precipitation data sets. Geophysical Research Letters, 39. doi: $10.1029 / 2012 \mathrm{gl} 051592$

Arkin, P. A., \& Xie, P. P. (1994). THE GLOBAL PRECIPITATION CLIMATOLOGY PROJECT - 1ST ALGORITHM INTERCOMPARISON PROJECT. Bulletin of the American Meteorological Society, 75(3), 401-419. doi:10.1175/15200477(1994)075<0401:tgpcpf > 2.0.co;2

Behera, S. K., Luo, J. J., Masson, S., Delecluse, P., Gualdi, S., Navarra, A., \& Yamagata, T. (2005). Paramount impact of the Indian Ocean dipole on the East African short rains: A CGCM study. Journal of Climate, 18(21), 4514-4530. doi:10.1175/jcli3541.1

Berhane, F., \& Zaitchik, B. (2014). Modulation of Daily Precipitation over East Africa by the Madden-Julian Oscillation. Journal of Climate, 27(15), 6016-6034. doi:10.1175/jcli-d-13-00693.1

Bharti, V., \& Singh, C. (2015). Evaluation of error in TRMM 3B42V7 precipitation estimates over the Himalayan region. Journal of Geophysical Research-Atmospheres, 120(24), 12458-12473. doi:10.1002/2015jd023779

Bjerknes, J. (1969). ATMOSPHERIC TELECONNECTIONS FROM THE EQUATORIAL PACIFIC. Monthly Weather Review, 97(3), 163172. doi: $10.1175 / 1520-$ 0493(1969)097<0163:atftep>2.3.co;2

Camberlin, P., Fontaine, B., Louvet, S., Oettli, P., \& Valimba, P. (2010). Climate Adjustments over Africa Accompanying the Indian Monsoon Onset. Journal of Climate, 23(8), 2047-2064. doi:10.1175/2009jcli3302.1

Camberlin, P., \& Okoola, R. E. (2003). The onset and cessation of the "long rains" in eastern Africa and their interannual variability. Theoretical and Applied Climatology, 75(1-2), 43-54. doi: $10.1007 / \mathrm{s} 00704-002-0721-5$

Camberlin, P., \& Philippon, N. (2002). The East African March-May rainy season: Associated atmospheric dynamics and 
predictability over the $1968-97$ period. Journal of Climate, 15(9), 1002-1019. doi:10.1175/15200442(2002)015<1002:teammr>2.0.co;2

Carlin, B. P., \& Louis, T. A. (1996). Bayes and empirical Bayes methods for data analysis, Chapman and Hall, London, UK (pp. 399 pp.).

Clark-Carter, D. (2014). z Scores Wiley StatsRef: Statistics Reference Online.

Cook, K. H., \& Vizy, E. K. (2016). The Congo Basin Walker circulation: dynamics and connections to precipitation. Climate Dynamics, 47(3-4), 697-717. doi:10.1007/s00382-015-2864-y

Davies, L., Jakob, C., May, P., Kumar, V. V., \& Xie, S. (2013). Relationships between the large-scale atmosphere and the small-scale convective state for Darwin, Australia. Journal of Geophysical Research-Atmospheres, 118(20), 11534-11545. doi: $10.1002 /$ jgrd. 50645

Davies, T. D., Vincent, C. E., \& Beresford, A. K. C. (1985). JULY AUGUST RAINFALL IN WEST-CENTRAL KENYA. Journal of Climatology, 5(1), 17-33. doi:10.1002/joc.3370050103

Dee, D. P., Uppala, S. M., Simmons, A. J., Berrisford, P., Poli, P., Kobayashi, S., . . . Vitart, F. (2011). The ERA-Interim reanalysis: configuration and performance of the data assimilation system. Quarterly Journal of the Royal Meteorological Society, 137(656), 553-597. doi:10.1002/qj.828

Dibike, Y. B., \& Coulibaly, P. (2007). Validation of hydrological models for climate scenario simulation: the case of Saguenay watershed in Quebec. Hydrological Processes, 21(23), 31233135. doi:10.1002/hyp.6534

Diem, J. E., Hartter, J., Ryan, S. J., \& Palace, M. W. (2014). Validation of Satellite Rainfall Products for Western Uganda. Journal of Hydrometeorology, 15(5), 2030-2038. doi:10.1175/jhm-d-130193.1

Dinku, T., Ceccato, P., Grover-Kopec, E., Lemma, M., Connor, S. J., \& Ropelewski, C. F. (2007). Validation of satellite rainfall products over East Africa's complex topography. International Journal of Remote Sensing, 28(7-8), 1503-1526. doi:10.1080/01431160600954688

Donald, A., Meinke, H., Power, B., Wheeler, M., \& Ribbe, J. (2004). Forecasting with the Madden-Julian Oscillation and the applications for risk management.

Duan, Z., Liu, J. Z., Tuo, Y., Chiogna, G., \& Disse, M. (2016). Evaluation of eight high spatial resolution gridded precipitation products in Adige Basin (Italy) at multiple temporal and spatial scales. Science of the Total Environment, 573, 1536-1553. doi: 10.1016/j.scitotenv.2016.08.213 
Emanuel, K. A., Neelin, J. D., \& Bretherton, C. S. (1994). ON LARGESCALE CIRCULATIONS IN CONVECTING ATMOSPHERES. Quarterly Journal of the Royal Meteorological Society, 120(519), 1111-1143. doi:10.1002/qj.49712051902

Farahmand, A., \& AghaKouchak, A. (2015). A generalized framework for deriving nonparametric standardized drought indicators. Advances in Water Resources, 76, 140-145. doi:https://doi.org/10.1016/j.advwatres.2014.11.012

Feidas, H., Lagouvardos, K., Kotroni, V., \& Cartalis, C. (2005). Application of three satellite techniques in support of precipitation forecasts of a NWP model. International Journal of Remote Sensing, 26(24), 5393-5417. doi:Doi $10.1080 / 01431160500273551$

Frauen, C., \& Dommenget, D. (2012). Influences of the tropical Indian and Atlantic Oceans on the predictability of ENSO. Geophysical Research Letters, 39. doi:10.1029/2011gl050520

Funk, C., Dettinger, M. D., Michaelsen, J. C., Verdin, J. P., Brown, M. E., Barlow, M., \& Hoell, A. (2008). Warming of the Indian Ocean threatens eastern and southern African food security but could be mitigated by agricultural development. Proceedings of the National Academy of Sciences of the United States of America, 105(32), 11081-11086. doi:10.1073/pnas.0708196105

Funk, C., Hoell, A., Shukla, S., Blade, I., Liebmann, B., Roberts, J. B., ... Husak, G. (2014). Predicting East African spring droughts using Pacific and Indian Ocean sea surface temperature indices. Hydrology and Earth System Sciences, 18(12), 4965-4978. doi:10.5194/hess-18-4965-2014

Funk, C., Nicholson, S. E., Landsfeld, M., Klotter, D., Peterson, P., \& Harrison, L. (2015). The Centennial Trends Greater Horn of Africa precipitation dataset. Scientific Data, 2. doi:10.1038/sdata.2015.50

Funk, C. C., Peterson, P. J., Landsfeld, M. F., Pedreros, D. H., Verdin, J. P., Rowland, J. D., . . . Verdin, A. P. (2014). A quasi-global precipitation time series for drought monitoring: U.S. Geological Survey Data Series 832, 4 p. doi:http://dx.doi.org/10.3133/ds832.

Gadgil, S., Vinayachandran, P. N., Francis, P. A., \& Gadgil, S. (2004). Extremes of the Indian summer monsoon rainfall, ENSO and equatorial Indian Ocean oscillation. Geophysical Research Letters, 31(12). doi:10.1029/2004gl019733

Gamoyo, M., Reason, C., \& Obura, D. (2015). Rainfall variability over the East African coast. Theoretical and Applied Climatology, 120(1-2), 311-322. doi:10.1007/s00704-014-1171-6

Gebremichael, M., Krajewski, W. F., Morrissey, M., Langerud, D., Huffman, G. J., \& Adler, R. (2003). Error uncertainty analysis of 
GPCP monthly rainfall products: A data-based simulation study. Journal of Applied Meteorology, 42(12), 1837-1848. doi: 10.1175/1520-0450(2003)042<1837: euaogm >2.0.co;2

GeoCLIM. Retrieved from http://chgwiki.geog.ucsb.edu/wiki/GeoCLIM

Goessling, H. F., \& Reick, C. H. (2011). What do moisture recycling estimates tell us? Exploring the extreme case of nonevaporating continents. Hydrology and Earth System Sciences, 15(10), 3217-3235. doi:10.5194/hess-15-3217-2011

Guo, F. Y., Liu, Q. Y., Sun, S., \& Yang, J. L. (2015). Three Types of Indian Ocean Dipoles. Journal of Climate, 28(8), 3073-3092. doi: $10.1175 /$ jcli-d-14-00507.1

Gupta, H. V., Kling, H., Yilmaz, K. K., \& Martinez, G. F. (2009). Decomposition of the mean squared error and NSE performance criteria: Implications for improving hydrological modelling. Journal of Hydrology, 377(1-2), 80-91. doi:http://dx.doi.org/10.1016/j.jhydrol.2009.08.003

Holley, D. M., Dorling, S. R., Steele, C. J., \& Earl, N. (2014). A climatology of convective available potential energy in Great Britain. International Journal of Climatology, 34(14), 38113824. doi:10.1002/joc.3976

Huang, B. Y., Thorne, P. W., Banzon, V. F., Boyer, T., Chepurin, G., Lawrimore, J. H., . . . Zhang, H. M. (2017). Extended Reconstructed Sea Surface Temperature, Version 5 (ERSSTV5): Upgrades, Validations, and Intercomparisons. Journal of Climate, 30(20), 8179-8205. doi:10.1175/jcli-d-16-0836.1

Indeje, M., Semazzi, F. H. M., \& Ogallo, L. J. (2000). ENSO signals in East African rainfall seasons. International Journal of Climatology, 20(1), 19-46. doi:10.1002/(sici)10970088(200001)20:1<19: : aid-joc449>3.0.co;2-0

Jin, F. J., Kitoh, A., \& Alpert, P. (2011). Climatological relationships among the moisture budget components and rainfall amounts over the Mediterranean based on a super-high-resolution climate model. Journal of Geophysical Research-Atmospheres, 116. doi: $10.1029 / 2010 j d 014021$

Kidd, C., Bauer, P., Turk, J., Huffman, G. J., Joyce, R., Hsu, K. L., \& Braithwaite, D. (2012). Intercomparison of High-Resolution Precipitation Products over Northwest Europe. Journal of Hydrometeorology, 13(1), 67-83. doi:10.1175/jhm-d-11-042.1

Kimani, M. W., Hoedjes, J. C. B., \& Su, Z. B. (2017). An Assessment of Satellite-Derived Rainfall Products Relative to Ground Observations over East Africa. Remote Sensing, 9(5). doi: $10.3390 /$ rs9050430 
Kimani, M. W., Hoedjes, J. C. B., \& Su, Z. B. (2018). Bayesian Bias Correction of Satellite Rainfall Estimates for Climate Studies. Remote Sensing, 10(7). doi:10.3390/rs10071074

Kinuthia, J. H. (1992). HORIZONTAL AND VERTICAL STRUCTURE OF THE LAKE TURKANA JET. Journal of Applied Meteorology, 31(11), 1248-1274. doi:10.1175/15200450(1992)031<1248: havsot>2.0.co;2

Kinuthia, J. H., \& Asnani, G. C. (1982). A NEWLY FOUND JET IN NORTH KENYA (TURKANA CHANNEL). Monthly Weather Review, 110(11), 1722-1728. doi:10.1175/15200493(1982) $110<1722$ :anfjin>2.0.co;2

Krajewski, W. F., Ciach, G. J., McCollum, J. R., \& Bacotiu, C. (2000). Initial validation of the global precipitation climatology project monthly rainfall over the United States. Journal of Applied Meteorology, 39(7), 1071-1086. doi:10.1175/15200450(2000)039<1071:ivotgp >2.0.co;2

Laing, A. G., Carbone, R. E., \& Levizzani, V. (2011). Cycles and Propagation of Deep Convection over Equatorial Africa. Monthly Weather Review, 139(9), 2832-2853. doi: $10.1175 / 2011 \mathrm{mwr} 3500.1$

Levin, N. E., Zipser, E. J., \& Cerling, T. E. (2009). Isotopic composition of waters from Ethiopia and Kenya: Insights into moisture sources for eastern Africa. Journal of Geophysical ResearchAtmospheres, 114. doi:10.1029/2009jd012166

Li, R., \& Fu, Y. F. (2005). Tropical precipitation estimated by GPCP and TRMM PR observations. Advances in Atmospheric Sciences, 22(6), 852-864.

Loriaux, J., Lenderink, G., \& Siebesma, A. P. (2016). Peak precipitation intensity in relation to atmospheric conditions and large-scale forcing at midlatitudes. Journal of Geophysical ResearchAtmospheres, 121(10),

5471-5487. doi: $10.1002 / 2015 j d 024274$

Lyon, B., \& DeWitt, D. G. (2012). A recent and abrupt decline in the East African long rains. Geophysical Research Letters, 39. doi:10.1029/2011gl050337

Madden, R. A., \& Julian, P. R. (1994). OBSERVATIONS OF THE 40-50DAY TROPICAL OSCILLATION - A REVIEW. Monthly Weather Review, 122(5), 814-837. doi:10.1175/15200493(1994) $122<0814$ : ootdto>2.0.co;2

Maggioni, V., Sapiano, M. R. P., \& Adler, R. F. (2016). Estimating Uncertainties in High-Resolution Satellite Precipitation Products: Systematic or Random Error? Journal of Hydrometeorology, 17(4), 1119-1129. doi:10.1175/jhm-d-150094.1 
Maidment, R. I., Grimes, D., Allan, R. P., Tarnavsky, E., Stringer, M., Hewison, T., . . Black, E. (2014). The 30 year TAMSAT African Rainfall Climatology And Time series (TARCAT) data set. Journal of Geophysical Research-Atmospheres, 119(18), 10619-10644. doi:10.1002/2014jd021927

Maidment, R. I., Grimes, D. I. F., Allan, R. P., Greatrex, H., Rojas, O., \& Leo, O. (2013). Evaluation of satellite-based and model reanalysis rainfall estimates for Uganda. Meteorological Applications, 20(3), 308-317. doi:10.1002/met.1283

Manatsa, D., Morioka, Y., Behera, S. K., Matarira, C. H., \& Yamagata, T. (2014). Impact of Mascarene High variability on the East African 'short rains'. Climate Dynamics, 42(5-6), 1259-1274. doi: $10.1007 / \mathrm{s} 00382-013-1848-z$

Mapande, A. T., \& Reason, C. J. C. (2005). Interannual rainfall variability over western Tanzania. International Journal of Climatology, 25(10), 1355-1368. doi:10.1002/joc.1193

Mateus, P., Borma, L. S., da Silva, R. D., Nico, G., \& Catalao, J. (2016). Assessment of two techniques to merge ground-based and TRMM rainfall measurements: a case study about Brazilian Amazon Rainforest. Giscience \& Remote Sensing, 53(6), 689706. doi:10.1080/15481603.2016.1228161

Matthews, A. J. (2004). Intraseasonal variability over tropical Africa during northern summer. Journal of Climate, 17(12), 24272440.

doi: $10.1175 / 1520$ 0442(2004)017<2427:ivotad >2.0.co;2

Matthews, A. J. (2008). Primary and successive events in the MaddenJulian Oscillation. Quarterly Journal of the Royal Meteorological Society, 134(631), 439-453. doi:10.1002/qj.224

Maurer, E. P., \& Pierce, D. W. (2014). Bias correction can modify climate model simulated precipitation changes without adverse effect on the ensemble mean. Hydrology and Earth System Sciences, 18(3), 915-925. doi:10.5194/hess-18-915-2014

McKee, T. B., Doesken, N. J., \& Kleist, J. (1993). The relationship of drought frequency and duration to time scales. The Relationship of Drought Frequency and Duration to Time Scales, 179-184.

Meteorology, A. B. o. Real time Multivariate MJO indices.

Meukaleuni, C., Lenouo, A., \& Monkam, D. (2016). Climatology of convective available potential energy (CAPE) in ERA-Interim reanalysis over West Africa. Atmospheric Science Letters, 17(1), 65-70. doi:10.1002/asl.601

Miao, C. Y., Ashouri, H., Hsu, K. L., Sorooshian, S., \& Duan, Q. Y. (2015). Evaluation of the PERSIANN-CDR Daily Rainfall Estimates in Capturing the Behavior of Extreme Precipitation Events over China. Journal of Hydrometeorology, 16(3), 13871396. doi: $10.1175 / \mathrm{jhm}-\mathrm{d}-14-0174.1$ 
Muller, C. J., Back, L. E., O'Gorman, P. A., \& Emanuel, K. A. (2009a). A model for the relationship between tropical precipitation and column water vapor. Geophysical Research Letters, 36, 5. doi: $10.1029 / 2009 \mathrm{gl} 039667$

Muller, C. J., Back, L. E., O'Gorman, P. A., \& Emanuel, K. A. (2009b). A model for the relationship between tropical precipitation and column water vapor. Geophysical Research Letters, 36. doi:10.1029/2009gl039667

Nagarajan, B., Yau, M. K., \& Schuepp, P. H. (2004). The effects of small water bodies on the atmospheric heat and water budgets over the MacKenzie River Basin. Hydrological Processes, 18(5), 913938. doi:10.1002/hyp.1339

Neelin, J. D., Peters, O., \& Hales, K. (2009). The Transition to Strong Convection. Journal of the Atmospheric Sciences, 66(8), 23672384. doi:10.1175/2009jas2962.1

Neupane, N. (2016). The Congo basin zonal overturning circulation. Advances in Atmospheric Sciences, 33(6), 767-782. doi: $10.1007 / \mathrm{s} 00376-015-5190-8$

Nicholson, S. E. (1996). A review of climate dynamics and climate variability in Eastern Africa Limnology, Climatology and Paleoclimatology of the East African Lakes ed $\mathrm{T}$ Johnson and EOdada

Nicholson, S. E. (2016). An analysis of recent rainfall conditions in eastern Africa. International Journal of Climatology, 36(1), 526532. doi:10.1002/joc. 4358

Nicholson, S. E. (2016). The Turkana low-level jet: mean climatology and association with regional aridity. International Journal of Climatology, 36(6), 2598-2614. doi:10.1002/joc.4515

Nicholson, S. E. (2017). Climate and climatic variability of rainfall over eastern Africa. Reviews of Geophysics, 55(3), 590-635. doi:10.1002/2016rg000544

Nicholson, S. E., \& Dezfuli, A. K. (2013). The Relationship of Rainfall Variability in Western Equatorial Africa to the Tropical Oceans and Atmospheric Circulation. Part I: The Boreal Spring. Journal of Climate, 26(1), 45-65. doi:10.1175/jcli-d-11-00653.1

Nicholson, S. E., \& Selato, J. C. (2000). The influence of La Nina on African rainfall. International Journal of Climatology, 20(14), 1761-1776. doi: $10.1002 / 1097-$ 0088(20001130)20:14<1761: :aid-joc580>3.0.co;2-w

Ogallo, L. J. (1988). Relationships Between Seasonal Rainfall In EastAfrica And The Southern Oscillation. Journal Of Climatology, 8, 31-43.

Paredes-Trejo, F. J., Barbosa, H. A., \& Kumar, T. V. L. (2017). Validating CHIRPS-based satellite precipitation estimates in 
Northeast Brazil. Journal of Arid Environments, 139, 26-40. doi: 10.1016/j.jaridenv.2016.12.009

Philander, S. G. H., Lau, N. C., Pacanowski, R. C., \& Nath, M. J. (1989). 2 DIFFERENT SIMULATIONS OF THE SOUTHERN OSCILLATION AND ELNINO WITH COUPLED OCEAN-ATMOSPHERE GENERALCIRCULATION MODELS. Philosophical Transactions of the Royal Society a-Mathematical Physical and Engineering Sciences, 329(1604), 167-178. doi:10.1098/rsta.1989.0068

Pohl, B., \& Camberlin, P. (2006a). Influence of the Madden-Julian Oscillation on East African rainfall. I: Intraseasonal variability and regional dependency. Quarterly Journal of the Royal Meteorological Society, 132(621), 2521-2539. doi: $10.1256 / q j .05 .104$

Pohl, B., \& Camberlin, P. (2006b). Influence of the Madden-Julian Oscillation on East African rainfall: II. March-May season extremes and interannual variability. Quarterly Journal of the Royal Meteorological Society, 132(621), 2541-2558. doi:10.1256/qj.05.223

Rayner, N. A., Parker, D. E., Horton, E. B., Folland, C. K., Alexander, L. V., Rowell, D. P., . . . Kaplan, A. (2003). Global analyses of sea surface temperature, sea ice, and night marine air temperature since the late nineteenth century. Journal of Geophysical Research-Atmospheres, 108(D14). doi:10.1029/2002jd002670

Reuter, H. I., Nelson, A., \& Jarvis, A. (2007). An evaluation of voidfilling interpolation methods for SRTM data. International Journal of Geographical Information Science, 21(9), 983-1008. doi:10.1080/13658810601169899

Roulston, M. S. (2007). Performance targets and the Brier score. Meteorological Applications, 14(2), 185-194. doi: $10.1002 /$ met. 21

Rowell, D. P. (1998). Assessing potential seasonal predictability with an ensemble of multidecadal GCM simulations. Journal of Climate, 11(2), 109-120. doi:10.1175/15200442(1998)011<0109:apspwa>2.0.co;2

Saji, N. H., Goswami, B. N., Vinayachandran, P. N., \& Yamagata, T. (1999). A dipole mode in the tropical Indian Ocean. Nature, 401(6751), 360-363. doi:10.1038/43855

Saji, N. H., \& Yamagata, T. (2003). Possible impacts of Indian Ocean Dipole mode events on global climate. Climate Research, 25(2), 151-169. doi:10.3354/cr025151

Sassen, K., Wang, Z., \& Liu, D. (2009). Cirrus clouds and deep convection in the tropics: Insights from CALIPSO and CloudSat. Journal of Geophysical Research-Atmospheres, 114. doi:10.1029/2009jd011916 
Segele, Z. T., Lamb, P. J., \& Leslie, L. A. (2009). Large-scale atmospheric circulation and global sea surface temperature associations with Horn of Africa June-September rainfall. International Journal of Climatology, 29(8), 1075-1100. doi: $10.1002 /$ joc. 1751

Seiz, G., \& Foppa, N. (2011). National Climate Observing System of Switzerland (GCOS Switzerland). Advances in Science and Research, 6, 95-102. doi:10.5194/asr-6-95-2011

Shi, F. X., Hao, Z. C., \& Shao, Q. X. (2014). The analysis of water vapor budget and its future change in the Yellow-Huai-Hai region of China. Journal of Geophysical Research-Atmospheres, 119(18), 10702-10719. doi:10.1002/2013jd021431

Sorooshian, S., Hsu, K. L., Gao, X., Gupta, H. V., Imam, B., \& Braithwaite, D. (2000). Evaluation of PERSIANN system satellite-based estimates of tropical rainfall. Bulletin of the American Meteorological Society, 81(9), 2035-2046. doi:10.1175/1520-0477(2000)081<2035: eopsse >2.3.co;2

Souverijns, N., Thiery, W., Demuzere, M., \& Van Lipzig, N. P. M. (2016). Drivers of future changes in East African precipitation. Environmental Research Letters, 11(11). doi:10.1088/17489326/11/11/114011

Stockdale, T. N., Alves, O., Boer, G., Deque, M., Ding, Y., Kumar, A., . .. Yun, W. T. (2010). Understanding and Predicting Seasonalto-Interannual Climate Variability - The Producer Perspective. In M. V. K. Sivakumar, B. S. Nyenzi, \& A. Tyagi (Eds.), World Climate Conference - 3 (Vol. 1, pp. 55-80).

Stokstad, E. (1999). Hydrology - Scarcity of rain, stream gages threatens forecasts. Science, 285(5431), 1199-1200. doi:10.1126/science.285.5431.1199

Sun, X., Xie, L., Semazzi, F., \& Liu, B. (2015). Effect of Lake Surface Temperature on the Spatial Distribution and Intensity of the Precipitation over the Lake Victoria Basin. Monthly Weather Review, 143(4), 1179-1192. doi:10.1175/mwr-d-14-00049.1

Suwendi, A., \& Allebach, J. P. (2008). Nearest-neighbor and bilinear resampling factor estimation to detect blockiness or blurriness of an image. Journal of Electronic Imaging, 17(2). doi: $10.1117 / 1.2912053$

Talagrand, O. (1997). Assimilation of observations, an introduction. Journal of the Meteorological Society of Japan, 75(1B), 191209. doi:10.2151/jmsj1965.75.1B_191

Talagrand, O. (1997). Assimilation of Observations, an Introduction (gtSpecial IssueltData Assimilation in Meteology and Oceanography: Theory and Practice). Journal of the Meteorological Society of Japan. Ser. II, 75(1B), 191-209. doi:10.2151/jmsj1965.75.1B_191 
Tan, M. L., Ficklin, D. L., Dixon, B., Ibrahim, A. L., Yusop, Z., \& Chaplot, $V$. (2015). Impacts of DEM resolution, source, and resampling technique on SWAT-simulated streamflow. Applied Geography, 63, 357-368. doi:10.1016/j.apgeog.2015.07.014

Taylor, K. E. (2001). Summarizing multiple aspects of model performance in a single diagram. Journal of Geophysical Research-Atmospheres, 106, 7183-7192.

Tian, Y. D., Peters-Lidard, C. D., \& Eylander, J. B. (2010). Real-Time Bias Reduction for Satellite-Based Precipitation Estimates. Journal of Hydrometeorology, 11(6), 1275-1285. doi:10.1175/2010jhm1246.1

Tote, C., Patricio, D., Boogaard, H., van der Wijngaart, R., Tarnavsky, E., \& Funk, C. (2015). Evaluation of Satellite Rainfall Estimates for Drought and Flood Monitoring in Mozambique. REMOTE SENSING, 7(2), 1758-1776. doi:10.3390/rs70201758

Trejo, F. J. P., Barbosa, H. A., Penaloza-Murillo, M. A., Moreno, M. A., \& Farias, A. (2016). Intercomparison of improved satellite rainfall estimation with CHIRPS gridded product and rain gauge data over Venezuela. Atmosfera, 29(4), 323-342. doi:10.20937/atm.2016.29.04.04

Trenberth, K. E. (1999). Atmospheric moisture recycling: Role of advection and local evaporation. Journal of Climate, 12(5), 1368-1381. doi: $10.1175 / 1520-$ 0442(1999)012<1368:amrroa>2.0.co;2

Vigaud, N., Lyon, B., \& Giannini, A. (2017). Sub-seasonal teleconnections between convection over the Indian Ocean, the East African long rains and tropical Pacific surface temperatures. International Journal of Climatology, 37(3), 1167-1180. doi:10.1002/joc.4765

Vila, D. A., de Goncalves, L. G. G., Toll, D. L., \& Rozante, J. R. (2009). Statistical Evaluation of Combined Daily Gauge Observations and Rainfall Satellite Estimates over Continental South America. Journal of Hydrometeorology, 10(2), 533-543. doi: $10.1175 / 2008$ jhm1048.1

Villarini, G., \& Krajewski, W. F. (2008). Empirically-based modeling of spatial sampling uncertainties associated with rainfall measurements by rain gauges. Advances in Water Resources, 31(7), 1015-1023. doi:10.1016/j.advwatres.2008.04.007

Wang, H., Murtugudde, R., \& Kumar, A. (2016). Evolution of Indian Ocean dipole and its forcing mechanisms in the absence of ENSO. Climate Dynamics, 47(7-8), 2481-2500. doi: 10.1007/s00382-016-2977-y

Wang, X., \& Wang, C. Z. (2014). Different impacts of various El Nino events on the Indian Ocean Dipole. Climate Dynamics, 42(3-4), 991-1005. doi:10.1007/s00382-013-1711-2 
Webster, P. J., Moore, A. M., Loschnigg, J. P., \& Leben, R. R. (1999). Coupled ocean-atmosphere dynamics in the Indian Ocean during 1997-98. Nature, 401(6751), 356-360. doi: $10.1038 / 43848$

Wei, H. H., \& Bordoni, S. (2016). On the Role of the African Topography in the South Asian Monsoon. Journal of the Atmospheric Sciences, 73(8), 3197-3212. doi:10.1175/jas-d-15-0182.1

Wheeler, M. C., \& Hendon, H. H. (2004). An all-season real-time multivariate MJO index: Development of an index for monitoring and prediction. Monthly Weather Review, 132(8), 1917-1932. doi:10.1175/1520-0493(2004)132<1917:aarmmi>2.0.co;2

Wilks, D. S. (2011). Chapter 8 - Forecast Verification. In D. S. Wilks (Ed.), International Geophysics (Vol. 100, pp. 301-394): Academic Press.

Williams, A. P., Funk, C., Michaelsen, J., Rauscher, S. A., Robertson, I., Wils, T. H. G., . . . Loader, N. J. (2012). Recent summer precipitation trends in the Greater Horn of Africa and the emerging role of Indian Ocean sea surface temperature. Climate Dynamics, 39(9-10), 2307-2328. doi:10.1007/s00382011-1222-y

Williams, K., Chamberlain, J., Buontempo, C., \& Bain, C. (2015). Regional climate model performance in the Lake Victoria basin. Climate Dynamics, 44(5-6), 1699-1713. doi:10.1007/s00382014-2201-x

Wilson, E. A., Gordon, A. L., \& Kim, D. (2013). Observations of the Madden Julian Oscillation during Indian Ocean Dipole events. Journal of Geophysical Research-Atmospheres, 118(6), 25882599. doi: $10.1002 /$ jgrd.50241

Xie, S. C., Zhang, Y. Y., Giangrande, S. E., Jensen, M. P., McCoy, R., \& Zhang, M. H. (2014). Interactions between cumulus convection and its environment as revealed by the MC3E sounding array. Journal of Geophysical Research-Atmospheres, 119(20), 11784-11808. doi:10.1002/2014jd022011

Yang, W. C., Seager, R., Cane, M. A., \& Lyon, B. (2015). The Annual Cycle of East African Precipitation. Journal of Climate, 28(6), 2385-2404. doi:10.1175/jcli-d-14-00484.1

Young, M. P., Williams, C. J. R., Chiu, J. C., Maidment, R. I., \& Chen, S. H. (2014). Investigation of Discrepancies in Satellite Rainfall Estimates over Ethiopia. Journal of Hydrometeorology, 15(6), 2347-2369. doi:10.1175/jhm-d-13-0111.1

Zaitchik, B. F. (2017). Madden-Julian Oscillation impacts on tropical African precipitation. Atmospheric Research, 184, 88-102. doi:10.1016/j.atmosres.2016.10.002 
Zavala-Garay, J., Zhang, C., Moore, A. M., \& Kleeman, R. (2005). The linear response of ENSO to the Madden-Julian oscillation. Journal of Climate, 18(13), 2441-2459. doi:10.1175/jcli3408.1

Zhang, J., Qi, Y. C., Langston, C., Kaney, B., \& Howard, K. (2014). A Real-Time Algorithm for Merging Radar QPEs with Rain Gauge Observations and Orographic Precipitation Climatology. Journal of Hydrometeorology, 15(5), 1794-1809. doi:10.1175/jhm-d13-0163.1

Zhang, Q., Xu, C. Y., Chen, X. H., \& Zhang, Z. X. (2011). Statistical behaviours of precipitation regimes in China and their links with atmospheric circulation 1960-2005. International Journal of Climatology, 31(11), 1665-1678. doi:10.1002/joc.2193 


\section{Author's Biography}

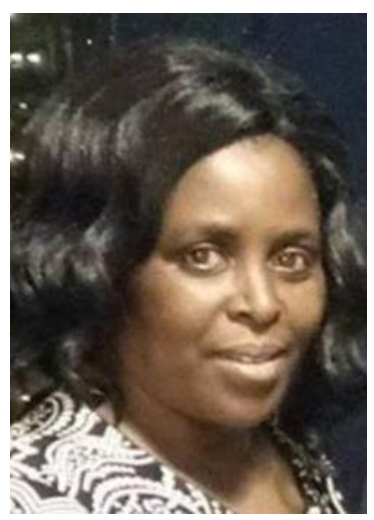

Margaret Wambui Kimani was born on 9th September 1968 in Murangá Kenya. She finished the advanced high school in 1989 where she specialized in Maths, Physics and Chemistry. In 1991 March she joined Kenya Meteorological services as a civil servant for Kenya Government. She enrolled for World Meteorological Organization (WMO) Class IV Meteorologist course in Institute of Meteorological Training and Research (IMTR) Nairobi, Kenya and excelled with a distinction after which she was deployed to Jomo Kenyatta International Airport (JKIA) as a weather observer. In 1996 she was enrolled in IMTR for World Meteorological Organization (WMO) Class III Meteorologist course and graduated with a distinction. In 2004-2008 she was admitted to the University of Nairobi where she did Bachelor of Science in Meteorology and graduated with a first class honour. Between 2007-2008 she worked at JKIA as a supervisor for meteorological observers and later worked as a weather forecaster. As a weather forecaster in JKIA, her duty included making route forecast for pilots nationally and internationally.

Margaret Joined the International Institute for Geo-information Science and Earth Observation (ITC), Enschede, The Netherlands in 2009 and graduated with an MSc degree in water resource and Environmental management in 2011. She was enrolled in IMTR in 2011 after her MSc to undertake Operational Training Course in 2011. In 2012 she did senior management course after which she was deployed to Laikipia county as County director for Meteorological services in 2013. She has attended Drought Forecasting and its use in informed decision making course-2013 (Spain).

Since September 2014, Margaret has been a PhD, candidate at University of Twente faculty Of Geo -information and earth observation (ITC). Her research is within water cycle and climate and deals with seasonal rainfall prediction over East Africa using remote sensing data. While undertaking her Phd research she was nominated as a student assessor in 2018. 


\section{Author's Publications}

Kimani, M. W., et al. (2017). "An Assessment of Satellite-Derived Rainfall Products Relative to Ground Observations over East Africa." Remote Sensing 9(5).

Kimani, M. W., et al. (2018). "Bayesian Bias Correction of Satellite Rainfall Estimates for Climate Studies." Remote Sensing 10(7).

Kimani, M. W., Hoedjes, J. C. B., \& Su, Z. (2016). Improving satellite Derived raingauge Products : Bayesian Approach : powerpoint. 1s-15s. 21st Conference on Satellite Meteorology/20th Conference on Air-Sea Interaction, Madison, United States.

Kimani, M. W., Hoedjes, J. C. B., \& Su, Z. (2016). The Uncertainities Assessments of the Satellite Derived Rainfall Products : powerpoint. 1s-15s. 16th EMS Annual Meeting \& 11th European Conference on Applied Climatology (ECAC), Trieste, Italy.

Kimani, M.W. (2011) Rain rate estimation of northwest Europe and Kenya from seviri sensor retrievals : comparison of precipitation properties visible and near infrared and hydro - estimator algorithms. MSc thesis: Enschede, University of Twente Faculty of Geo-Information and Earth Observation (ITC), 2011. Full text

Kimani, M. W., Hoedjes, J. C. B., \& Su, Z. (2016). The Uncertainities Assessments of the Satellite Derived Rainfall Products : powerpoint.. 1s-15s. 16th EMS Annual Meeting \& 11th European Conference on Applied Climatology (ECAC), Trieste, Italy. 